Portland State University

PDXScholar

The Role of Tourism in Development: A Case Study of Turkey

Habib Alipouraghtapeh

Portland State University

Follow this and additional works at: https://pdxscholar.library.pdx.edu/open_access_etds Let us know how access to this document benefits you.

Recommended Citation

Alipouraghtapeh, Habib, "The Role of Tourism in Development: A Case Study of Turkey" (1991).

Dissertations and Theses. Paper 1184.

https://doi.org/10.15760/etd.1183

This Dissertation is brought to you for free and open access. It has been accepted for inclusion in Dissertations and Theses by an authorized administrator of PDXScholar. Please contact us if we can make this document more accessible: pdxscholar@pdx.edu. 


\section{INFORMATION TO USERS}

This manuscript has been reproduced from the microfilm master. UMI films the text directly from the original or copy submitted. Thus, some thesis and dissertation copies are in typewriter face, while others may be from any type of computer printer.

The quality of this reproduction is dependent upon the quality of the copy submitted. Broken or indistinct print, colored or poor quality illustrations and photographs, print bleedthrough, substandard margins, and improper alignment can adversely affect reproduction.

In the unlikely event that the author did not send UMI a complete manuscript and there are missing pages, these will be noted. Also, if unauthorized copyright material had to be removed, a note will indicate the deletion.

Oversize materials (e.g., maps, drawings, charts) are reproduced by sectioning the original, beginning at the upper left-hand corner and continuing from left to right in equal sections with small overlaps. Each original is also photographed in one exposure and is included in reduced form at the back of the book.

Photographs included in the original manuscript have been reproduced xerographically in this copy. Higher quality 6" x 9" black and white photographic prints are available for any photographs or illustrations appearing in this copy for an additional charge. Contact UMI directly to order.

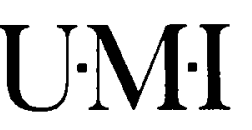

University Microfıms internatıonal

A Bell \& Howell Information Company

300 North Zeeb Road. Ann Arbor. MI 48106-1346 USA

$313 / 761-4700 \quad 800 / 521-0600$ 

Order Number 9204369

The role of tourism in development: A case study of Turkey

Alipouraghtapeh, Habib, Ph.D.

Portland State University, 1991 

THE ROLE OF TOURISM IN DEVELOPMENT:

A CASE STUDY OF TURKEY

by

HABIB ALIPOURAGHTAPEH

A dissertation submitted in partial fulfillment of the requirements for the degree of

DOCTOR OF PHILOSOPHY in

URBAN STUDIES

Fortland State University 1991 
TO THE OFFICE OF GRADUATE STUDIES:

The members of the Cominittee approve the dissertation of Habib Alipouraghtapeh presented May 30, 1991
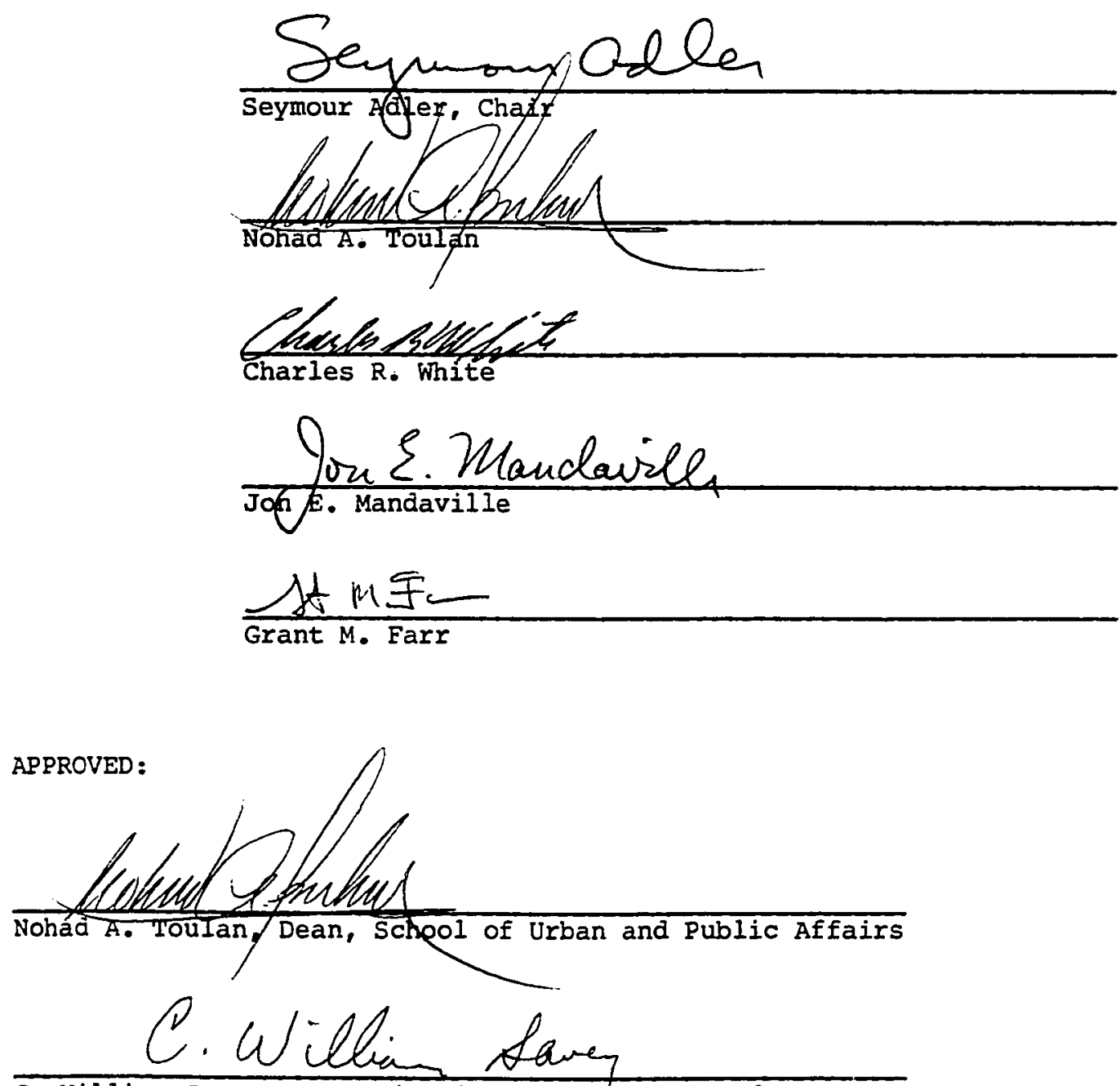

C. pilliam Savery, Interim Vice Provogt for Graduate Studies and Research 
AN ABSTRACT OF THE DISSERTATION OF Habib Alipouraghtapeh for the Doctor of Philosophy in Urban Studies Presented May 30, 1991.

Title: The Role of Tourism in Development: A Case Study of Turkey. APPROVED BY MEMBERS OF THE DISSERTATION COMMITTEE:

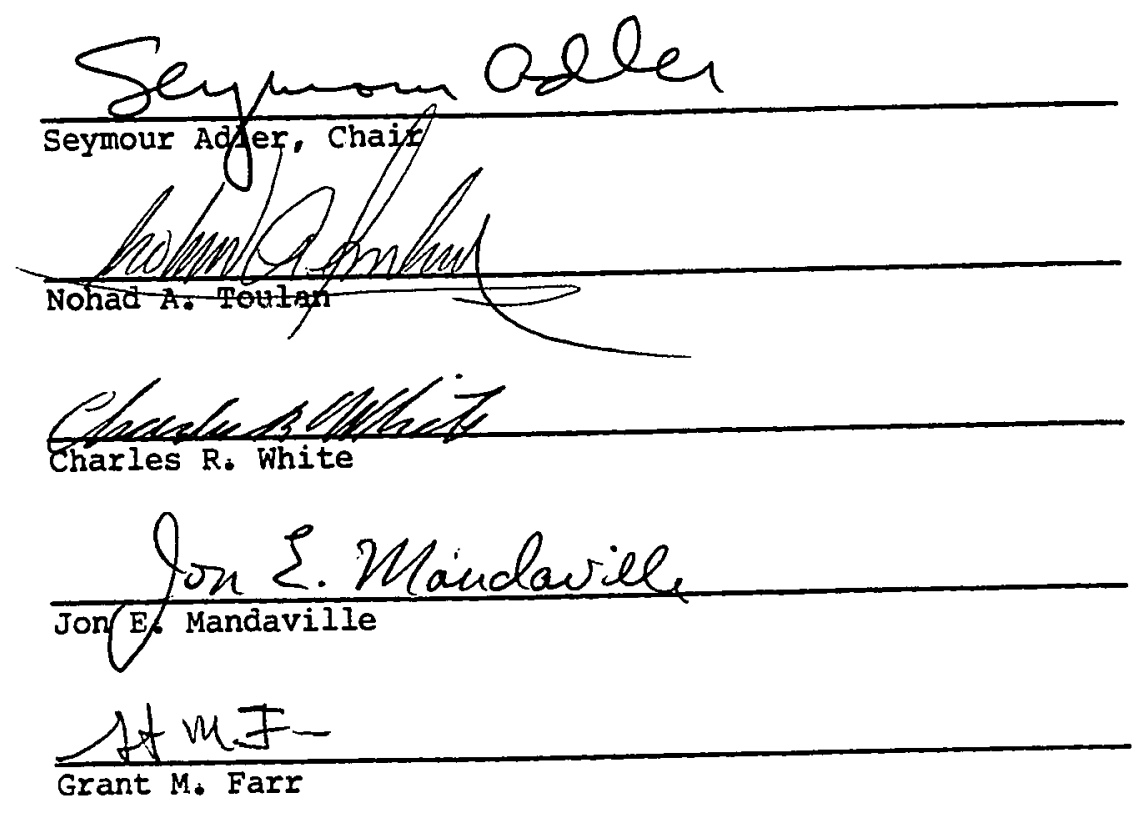

Until quite recently "tourism" was principally a feature of, and was largely confined to, the developed countries. During the past two decades, however, tourism has become an income earning alternative to the many Third forld countries, and many have capitalized on the industry which has become known as a "passport to development." In recent years the situation has worsened for these former exporters of primary agricultural products. These products are suffering from the general fall in world commodity prices and 
competition from larger and more efficient agricultural producers. In addition, the world economic impact has been translated to everburgeoning foreign debt crisis and the further deterioration of balance of payments. The need for foreign currency has been intensified by the new export promotion policies which are replacing import substitution as the dominart development policy in Third World manufacturing.

Tourism under these circumstances is a mixed blessing, and until very recently economists have pondered tourism's contribution carefully and have applied a wide range of theories to a description of the benefits of extended tourism business. In addition, with the new surge in tourism literature not only have the economic benefits of tourism been questioned, but tourism's social, cultural, and environmental impacts have become major issues of contention. The complex matrix of advantages and disadvantages ensures that governments must face an unenviable task of trying to weigh gains from new income and employment against certain less direct and long-term losses. While tourism on the one hand is blessed as the "passport to development," on the other hand it has been characterized as a force which destroys uncomprehendingly and unintentionally cultural values and social customs. In ordex to enhance and secure the positive influences of tourism in the long run and ensure its sustainability as an alternative means of income, an elaborated national tourism policy is required. An effective policy would guide the industry through certain development plans in accordance with the overall national development policies.

The current study suggests that Turkey's tourism development was subject to various deliberate influences and spontaneous dynamics 
without a prior policy formulation in the form of a national tourism policy. This study further suggests that the tourist boom of 1980 s caught the government and private sector by surprise because of the lack of pre-planning or policy research. This is obvious when one examines the tourism organization and administration which is centrally controlled and implemented. The interaction between various levels of government is a critical point.

This study also suggests that Turkey's position as a new tourist destination related positively to its new export promotion policies or the shift from an import substitution industrialization (ISI) economy to an export-oriented growth (XOG) economy, To note, motivations to develop tourism in Turkey are first, to gain foreign exchange, and second, to establish that Turkey represents a politically stable environment for foreign investment.

However, the lack of a national tourism policy has confined the industry to only a "short term economic gain" objective which has ruled out any effort to measure its net economic value instead of gross economic revenue. Furthermore the "planning" process has remained limited to physical planning to the detriment of social, environmental, and territorial planning.

The lack of regional planning with goals to reduce disparities are obvious signs of the failure of planning in the tourism sector. Therefore, this study suggests that tourism has not been employed in a fashion to alleviate or minimize spatial inequalities, but rather the trend has been to its intensification. "Domestic tourism" has been neglected in terms of policy and planning, and social tourism, will 
likely disappear because many will not be able to afford the uncontrolled tourist prices in the new crowded tourist centers.

The result of the study, suggests that tourism development cannot be separated from the "development" ideologies and theories which are translated to policies in the national level. In order to achieve a better understanding of tourism's role within the national development policy, one needs to examine the extension of analysis beyond the coreperiphery relation which is manifested in "dependency theory." The new international division of labor will most likely devise a new pattern for capital accumulation. This new process has been manifested in "dependent development" which produced new formations (i.e., NICs) or "semiperipheral" economies. In order for tourism to be a viable economic and social sector, it must overcome the disadvantages of "dependent development."

The prime task of this study was to examine the complex nature of the tourism industry in Turkey as it relates to the government's effort to tourism development. The study reveals that the government's involvement in the tourism industry was hampered by an impasse in development strategies and ideologies due to the retreatment from the etatist philosophy to the export oriented/privatization scenario. This resulted in a distortion characterized by inactivity in tourism (i.e., the absence of a national tourism policy)。 Tourism was perceived as a short-term remedy to the lack of foreign capital as an invisible sector (replacing worker's remittances from abroad).

All told, the tourism industry, regardless of its myriad potentials, was confined to a few enclave developments as directed by 
market forces rather than as a derivative of formal planning decisions. The government's role remains passive at this point despite a requirement for active intervention in tourism activity. 


\section{ACKNOWLEDGEMENTS}

I wish to express my appreciation to the Ministry of culture and Tourism of Turkish Republic for granting me the permission to conduct this research. My sincere thanks also goes to Mr. Mustafa Turkmen, who allowed this process to become possible.

Similarly, my special gratitude goes to my dissertation chair and advisor, Dr. Seymour Adler, to whom I feel deeply indebted not only for his guidance and patience, but also for his intellectual support and inspiration during this process since the beginning of my work in the graduate program.

I am also thankful to Dr. Nohad Toulan for keeping my hopes alive to endure this program. His advice and mentorship have always assisted me during the times when making a decision was crucial.

I would like to extend my acknowledgements to other committee members, namely Dr. Jon Mandaville and Dr. Charles White, for their encouraging efforts and for not losing their hopes of finishing this task.

I wish to acknowledge the vital contribution by Dr. Grant Farr in supporting and providing partial financial expenses for my research in Turkey. I also thank the Middle East Studies program in supporting this study.

Finally, this dissertation is dedicated to my father, who introduced me to the world of education. I also dedicate this dissertation to Reza Alipour who has played a significant role in my achievement. 
TABLE OF CONTENTS

PAGE

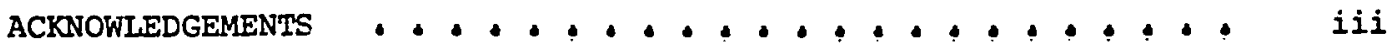

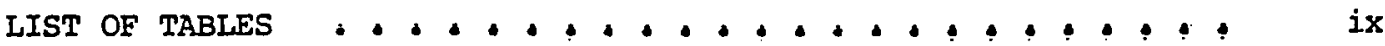

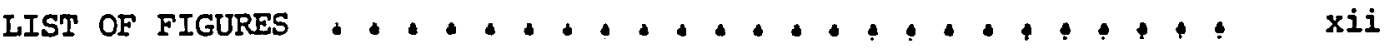

CHAPTER

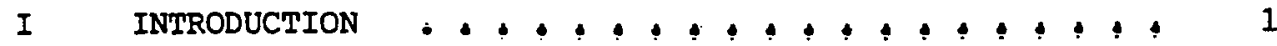

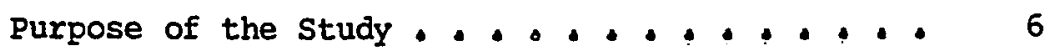

Research Method and Data Collection $4: 4$

Iiterature Review +. . . . . . . . +. + 11

Defining Tourism: Its Nature +. , +, , ., 16

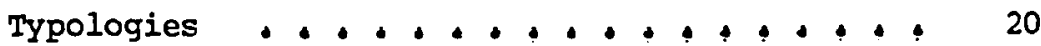

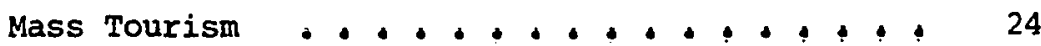

Structures of Tourism - . . . . . . . . . 25

Elements of Supply

Attractions

Transport

Accommodation

Supporting Facilities

Infrastructure

Tourism Demand ............. .... 32

Transnational Corporations and Tourism : 36

Main Hotels

Airline sector

Tiur Operators

Impacts of TNCs 
II POLITICAL ECONOMY OF TURKEY'S DEVELOPMENT:

POST-WAR PERIOD

Multiparty Rule ................. 55

Turkey's New Role............ .... 55

Policies and Problems .... . . . . . . 58

Commercialization and Mechanization of Agriculture 60

Rural-Urban Migration ... . . . . . . . 62

Deve lopment in Crisis .............. 65

New Policies and Prospects: 1960s and 1970s . 68

Policy Implications

Debt and Aid

Balance of Payment Crisis and Workers'

Remittances ... . . . . . . . . . 79

Prelude to Policy Shift and IMF Stablization

Measure +. +. +. . . . . . . . . 81

Development Policies at a Crossroad: Towards

The New Strategy +. . . . . . . . . . 86

Export Oriented Growth and Controversies . . . 89

Constraints and Problems . . . . . . . 95

Internal Constraints

External Constraints

Implications of the Model .. . . . . . . 100

Regional Disparity/Spatial Inequality

Regional Disparity: Policy Issues

Regional Issues and Implications

Regional Implications of Nonregional Policies

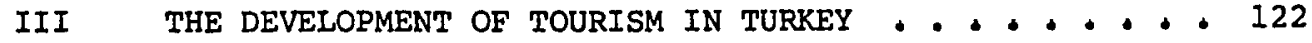

Background ... . . . . . . . . . . 122

Tourism Potential ... ................ 126 
Climatic Potentials .... . . . . . . 131

Seasonal patterns ................ 132

Mode of Arrivals .................... 134

Length of Visit +. +. +. +. +. +. +... 134

Tourist Regions ... . . . . . . . . . 136

Institutional Elements of Turkey's Tourism . . 142

State Planning Organization

Ministry of Culture and Tourism

Tourism Bank

An Analysis of the Institutions . $^{+}++^{+}+.160$

Tourism's Role in Turkey's Economy . . . . . . 167

Tourism Revenue

Tourism Employment

Tourism Market

Tourism Planning: A General Approach . . . 182

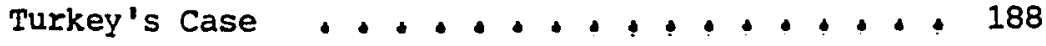

Tourism at the National Level ..... . . , 192

Planning Approach

Purpose and process

Nature of the plans

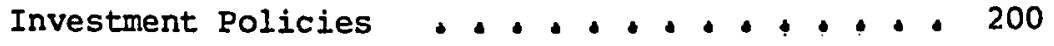

Bodrum's Case Examined: Planning at the Local

Level ..... ................, 204

An Overview

History

Geography

Tourism Boom

Development Model

Development Policy

Planning Approach: Local Level 
Bodrum's Land Use Plan

Pitfalls in Iocal Planning

Implementation

Local Government and Administration

CONCEPTUALIZING TOURISM'S ROLE IN DEVELOPMENT . . . 223

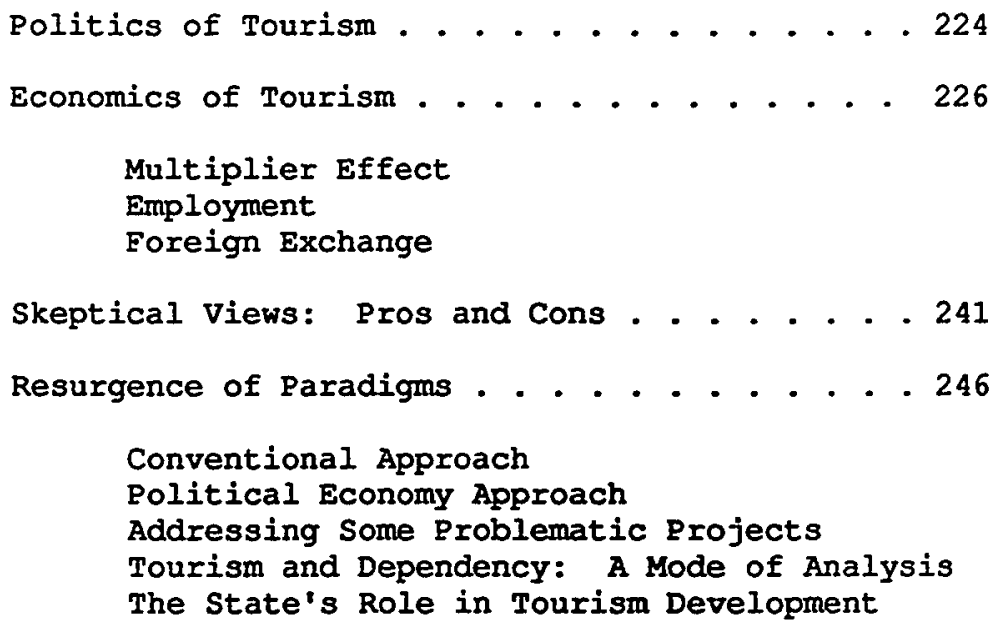


viii

PAGE

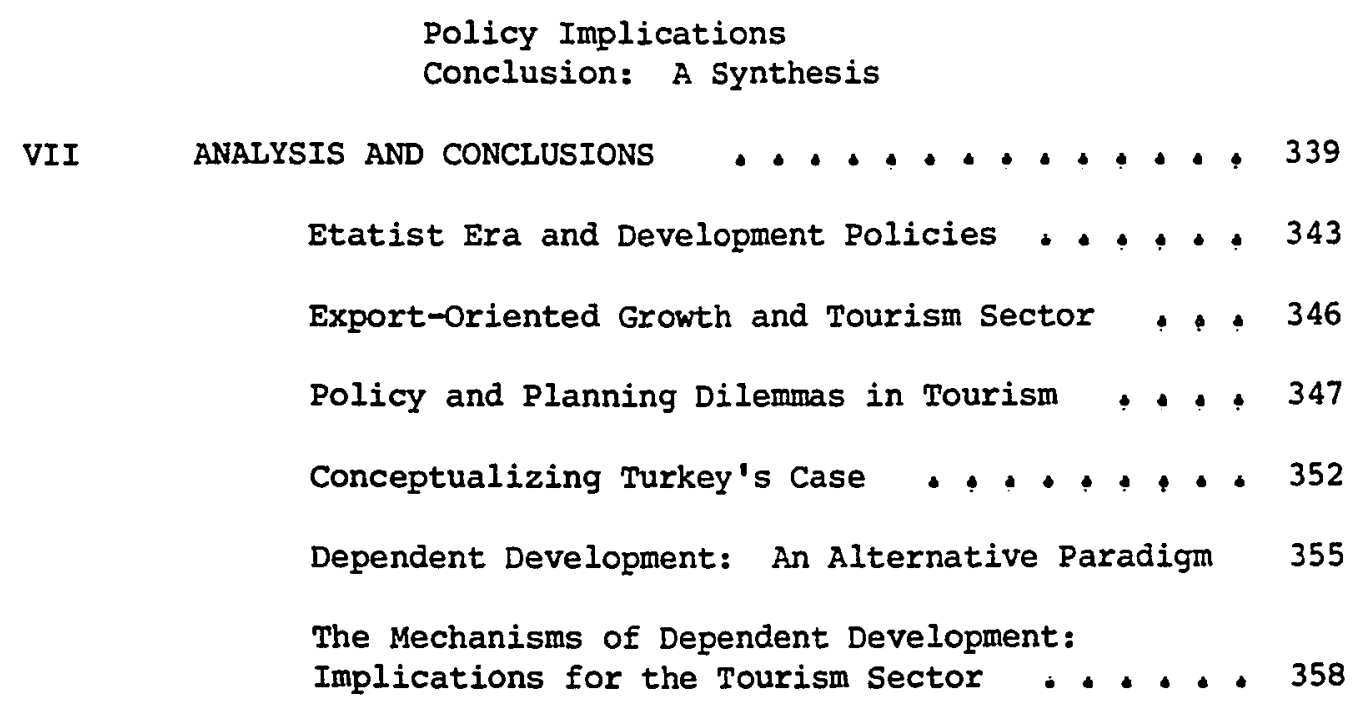

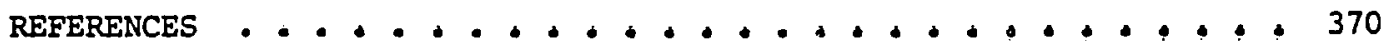




\section{LIST OF TABLES}

TABLE

PAGE

I

II

III

IV

V

VI

VII

VIII

IX

$x$

$X I$

XII

XIII

XIV

XV

XVI
International Tourist Arrivals by Region (x 10 $)$ Number of Units and Rooms in TransnationalAssociated Hotels Abroad, by Country of Origin World Shares of the World's Largest Airlines Military Budget Allotted by Each Country . . 57 Gecekondu Population in 13 Turkish Cities . . 64 Urban and Rural Population .. . . . . . . 66 Top Five U.S. Military Aid Recipients, 1984-1990 74 Sharing the Burden .............. 76 Turkey's Military Debt ............ 76 Foreign Debt, Debt Servicing, and Foreign Credit: 1966-1980 (Million \$) ........ 78 Foreign Trade and Workers' Remittances: 1950-1980 (Million \$) ............. 80 United States Dollar Exchange Rate of the Turkish Lira: 1923-1980 . . . . . . . 83 Balance of Payments (in Million \$) . . . . 89 Percentage Ratio Indicators in External Debts 102 Foreign Capital Investments Approvals (US \$ Millions) .................. 103 Distribution of Land by Land Size: 1973 . . 110 
1986 GDP by Provinces at Current Purchaser's

Prices (Million TL) .........., ..., ,

XVIII

XIX

GDP by Provinces between 1980 and 1986 Relative

Shares of Current Purchase Prices ( 8$),+!$

$\mathbf{x X}$

Tractors by Regions, 1980 . . . . . . , !

Ioan/Deposit Ratios, TCBZ, by Regions, 1981 • 119

XXI

Central and Iocal Government Accounts, 1986 .

Tourist Arrivals and the Bed Capacity Between

the Selected Countries, 1981 . . . . . + 124

Foreigners Arriving in Turkey + . . . . . . . 132

XXIV

Seasonality in Tourism ... . +. + . . . . 133

XXV

Distribution of Foreigners Arriving in Turkey

by Months and Means of Transport, 1987 . * . 135

XXVI

Distribution of the Tourist Establishments

and the Number of Beds in Each Region (Standardized

Establishments only) ..... ..... . . 139

XXVII

Five-Year Development Plan Goals for Foreign

Tourists and Percentage of Achievements $\quad . \quad 146$

XXVIII Tourism Sector's Share of Total Investment * 153

XXIX

Tourism Movements ............... 168

$\mathrm{XXX}$

Share of Tourism Receipts in the Export Earnings and the Balance of Payments (Million \$) . . 171

$\mathrm{XXXI}$

Share of International Tourist Receipts in Gross

National Product (1960-1986 Selected Years) : 172 
XXXII

Share of Tourism Revenues in the Gross National

Product (by Current Consumer Prices) 1963-1987

173

XXXIII

Turkey's Market Share in Northeast Mediterranean

176

XXXIV

$\mathrm{XXXV}$

XXXVI

XXXVII

XXXIX

XI
Percentage Change of Tourist Arrivals to

Turkey from Main Tourist Generating Countries

Tourist Arrivals from Islamic Tourist Generating

Countries and Percentage of Change over the

Years $, \ldots, \ldots, \ldots, \ldots, \ldots, \ldots, \ldots, \ldots$,

Trend in Fixed Capital Investment (Billion TL) :

202

Share of Foreign Capital in the Accommodation

Sector in Turkey

Tourist Income Multipliers for Selected

Countries, Cities, and Regions $, ., \ldots, 4$

235

Growing Importance of Foreign Exchange

Earnings from Tourism $, \ldots, \ldots, \ldots, \ldots$

Tourism Commitments of the World Bank Group

Through 1977 by Region (\$ Millions) . . . . . 251 
IIST OF FIGURES

FIGURE

PAGE

1 International tourism receipts and tourist arrivals * 1.4

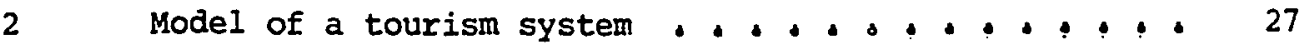

$3 \quad$ Fluctuating demand levels and supply + . . . . . . . 35

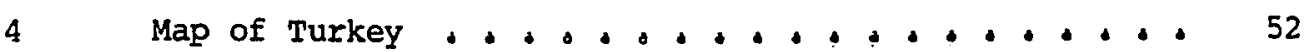

5 Regions in Turkey ... . . . . . . . . . 107

6 Turkey's tourism trend . . . . . . . . . . . . . 125

7 Delineation of Turkey's coastal areas . . . . . . 127

8 Number of foreign arrivals and citizens traveling

abroad ......................... 130

9 Major tourism development projects on the

Mediterranean Sea

10 Ministry of Culture and Tourism central organization 155

11 Room and bed sales in Turban establishments

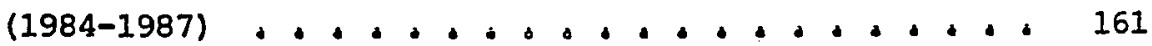

12 Tourism revenue and expenditure (US \$ Million) : : 169

13 International tourism trend in Eastern Mediterranean 182

14 Strategic planning vs. conventional planning . . . 185

15 Basic stages in tourism planning . . . . . . . 187

16 Tourist areas and centers declared according to

the tourism encouragement law . . . . . . . . . 194 
19 A schematic outline of the pros and cons of international tourism in the Third World $, 4,4, !$

20 Tourism process according to functional perspective 253

21 A hypothetical evolution of a tourist area ! . • 255

22 An enclave model of Third World tourism + . . . + 267

23 A structural model of Third World tourism,,,+++ 268

24 A hypothetical model for an alternative tourism

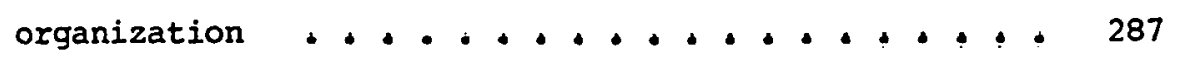

25 Mutual impacts of tourism development and

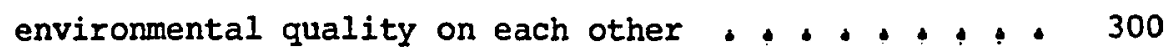

26 Assessing capacity in tourism planning , ! ! ! + 304 


\section{CHAPTER I}

\section{INTRODUCTION}

The aim of this study is to investigate and analyze the development of tourism in Turkey: Such development is a complex and ambiguous phenomenon, and to achieve its goals the adoption of certain policy and planning processes is necessary. This dissertation research was undertaken to examine both policy formulation and implementation as well as the planning process adopted by the Turkish government for the development of its tourism. There is a real need for such a study in order to understand the complexities and the implications generated by the tourism industry, which is widely regarded as an economic, social, political and geographical panacea.

Conceptually, tourism is defined as the sum of the phenomena and relationships arising from the travel and stay of non-residents, insofar as they do not lead to permanent residence and are not connected with any earning activity. "Tourism is, in short, an important human activity not only of economic significance, but also of social, political, cultural and educational significance" (Burkart and Medlik, $1981: 41)$

The growth of mass tourism is a fairly recent phenomenon. In the case of the developed countries (DCs), high growth rates have been registered since the late 1950s, but only in the mid-1960s did tourism 
to less developed countries (LDCs) begin to expand rapidly. ${ }^{1}$ During the period of 1965 to 1976 , tourist arrivals in DCs increased by an average of 58 per annum, while arrivals in LDCs increased by a yearly average of 128. As a result the IDCs' share of world tourism, as measured by tourist arrivals, rose from 68 in 1965 to 108 in 1976. In 1976 gross receipts from foreign tourism represented between 128 and 198 of the total export earnings of Jamaica, Malta, Mexico and Panama, and more than 198 of the total export earnings of Fiji, Jordan, Morocco and Tunisia (United Nations [UN], 1982): The World Tourism Organization (WTO) reported that the total tourist receipts in 1987 amounted to US $\$ 150 \times 10^{(9)}$ which represents about 58 of total world trade, but less than a quarter of this market accrues to LDCs, which have three-quarters of the world population (Go, 1989).

While this industry has become the world's largest single industry, professional standards for "tourism" industry operations, the responsiveness of governmental policy initiatives, the level of

$1_{\text {The terms less developed countries, Third World, and Developing }}$ Nations are used interchangeably through this text. Reference to Third World countries will mean those whose populations have per capita income below $\$ 3,000$ in 1978 or a life expectancy of less than seventy years (Gilbert and Gugler, 1982). This arbitrary dividing line means that all the nations of Asia, Africa, Latin America, and the Caribbean are included, with the exception of Israel, Japan, Hong Kong and Singapore. A comprehensive definition of an LDC suggested by Samuelson (1976:75) is as follows:

A less developed country is simply one with real per capita income that is low relative to the present-day per capita income of such nations as Canada, the United States, Great Britain, and Western Europe generally. Optimistically, a less developed country is one regarded as being capable of substantial improvement in its income leve]. 
industry planning, and the opportunities for university-level education in tourism fall far short of those appropriate for such a large industry (Smith, 1989:1). Nevertheless, tourism occupied the first rank as the world's largest service sector activity (Fletcher and Lathem, 1989). These figures do not take into account the effects of domestic tourism (Fletcher, 1989:514).

Tourism activity in Turkey, as in many other developing countries, has become an important sector to alleviate economic problems. In fact most of the developing countries share the notion that tourism in comparison to other economic activities is an attractive alternative for generating a rapid improvement in the standard of living.

Yet it is obvious that it cannot be considered merely as an economic agent for development. Tourism has positive and negative social, political, economic, and environmental impacts. Tourism, and its role in the socio-economic development of Third World nations, has brought forward heavy criticism and opposing views (Brydon, 1973; Turner and Ash, 1975; Dekadt, 1979).

But tourism remains a panacea for economic development within the governments of the Third World, which are desperatel.y seeking hard currency for their balance of payments, and also to relieve the burden of international debts and devastating capital outflow. For example, Mexico, with $\$ 108$ billion in foreign debt and $\$ 15$ billion in capital flow for the past year, sees tourism as the main solution to economic problems. Thus the Mexican government builds its economic future on sand--the sand of hundreds of miles of sun-soaked beaches that the government hopes to convert into a vacation playground for its rich 
northern neighbors: It is estimated that government officials convinced business leaders to invest as much as $\$ 10$ billion in tourism over the next six years--the world's largest tourism investment ever (The Oregonian, 1989:9A).

This is the common attitude in most of the developing countries worldwide! Turkey is no exception, especially with its vast potential for tourism and its geographical location, which attracts Western Europeans as well as people from the Eastern countries. Moreover, what encourages Turkey to tap its tourism potential is the fact that it has no mineral wealth, such as oil, which most of the Middle Eastern countries have enjoyed; Thus in 1982, Turkey's determination to become a tourist destination manifested in its law for the encouragement of Tourism No. 2634 (EI Kitabi, 1988:30). The stated purpose of the law is to ensure that necessary arrangements are made and necessary measures are taken in order to regulate, develop, and provide for a dynamic structure and operation of the tourism sector: "This determination has culminated in the Ministry of Culture and Tourism (MCT) identifying fourteen areas for tourism development with an estimated 600,000 bed capacity when completed" (Gunn, 1988:44).

The questions confronting the Turkish government and policy makers are not unique nor unfamiliar: First, what should be the nature of policy formulation, and second, how do planning processes translate to mechanisms for tourism development in order to establish a sector with sustainable productivity? or is tourism policy and planning actually what Cheema and Roninelli described: 
Policy makers, planners-ministries, and agencies in most developing countries continue setting and following their own priorities and pursuing their own interests, or at least pursuing their own interpretation of the national interest. The plans were produced usually only for international consumption-ato satisfy the requirements of international leaders.,obut, the plans were often useless in guiding internal decisions; their goals were stated in vague and amorphous terms; the objectives were grandiose; they failed to disaggregate goals into programs and projects that could be carried out; they often lacked cost estimates, ignored limits on resources, and failed to consider the differing needs and conditions of various regions of the country or groups within society. The methods of macro-economic analysis that were adopted from industrialized countries by national planners were difficult or impossible to apply without more accurate and abundant data than were available in poor countries $(1983: 12)$.

Regarding the above statement, the dilemma is obvious but the solution poses an incomprehensible threat to the future of development. The most rapid growth in the tourism industry in recent years has been in the Third World and one is obliged to assess and examine the any negative outcomes due to the economic, environmental, and social impacts of tourism. Even though the examination of all the costs and benefits of the tourism industry in Turkey and most of the Third world countries is complicated by difficulties in measurement and the lack of a policy model, a primary objective has been to introduce the extent and characteristics of the issues involved to enable a better understanding and critical appraisal of the existing situation (Lea, 1988:9). Therefore the focus of this dissertation is an examination of the government's policy and planning process that was either directly or indirectly involved in tourism development. The major aim of this study is to identify the variables that are at work within the tourism organizations and administrative system. These variables involve 
government policies which can have an impact on the outcome of certain programs, whether they be at the national or local level. On a more general level, this study examines how the analysis of the policy and planning process for the development of such a specific industry in a developing country like Turkey, provides additional insights into the complex nature of development relationships and the potential for policy to influence changes in their relationships.

This study of tourism and its role within the overall development context requires an elaborate multidisciplinary analysis. In the past two decades major approaches representing different schools of thought have evolved within the literature (Lea, 1988). Consequently, literature on tourism is far from being monolithic. The controversy about the organization of tourism and its role in development poses a real need for policy formulation towards utilization of the sector (Gunn, 1988; Dekadt, 1979).

PURPOSE OF THE STUDY

The main objectives of this case study can be summarized as follows:

1. To examine the multifaceted policy-making process and planning methods for tourism development by the Turkish government.

2. To assess the implications of these policies in regards to the involvement of both the public and private sector. 3. To evaluate the implementation process of those policies 
through plans and programs taking place in a top-down planning system.

4. To assess the decision-making process in a centralized political and administrative sector including the role of public participation pertaining to this unique industry.

5. To assess any administrative shortcomings in the implementation of the policy and planning of Turkey's tourism projects

6. To build a model for tourism development in Turkey and in Third World environments in general,

7. Finally, and most significantly, to characterize the role of tourism in the development of a so-called nation-state characterized as Third World.

As outlined, what makes the policy analysis approach a significant investigative method for the study of the development of tourism lies with the complexity of the industry itself. Tourism has been described as "the most promising, complex and understudied industry impinging on the Third World" (Turner, 1976:253). It is only recently, however, that this picture has changed somewhat and academic observers often take a much more negative view of tourism's consequences, to the point of forthright criticism of the industry as an effective contributor towards development (Lea, 1988:1).

RESEARCH METHOD AND DATA COLLECTION

Tourism as a field of study has quite a recent beginning. For being such a multifaceted sector, the approach to tourism research has 
attracted various disciplines from different perspectives. In fact, a strong justification for this particular study is the unexplored areas within this body of science, This development may indicate that tourism as a field of investigation is finally coming of age (Jafari and Aaser, 1988):

Despite growing interest, tourism research still remains small when compared, for example, to social science disciplines with long traditions of research and scholarship (Dann, Nash and Pearce, 1988). While the methods of research in tourism vary, there has been one major trend in studying the fields of tourism and leisure which are categorically different but not mutually exclusive. In their analysis, Dann, Nash and Pearce (1988) have revealed the dominant role of a "descriptive" type of analysis with the preferred "data gathering mode" of interviews, observations and content analysis in a field research context.

In carrying out this particular study, two major methods were employed. First, library research was conducted, which consisted mainly of content analysis of reports and available materials of any related literature on tourism development, inciuding the policy and planning process, project development, the administrative organization of tourism, and the policy analysis approach to project development (i.e., formulation of policies, objectives, implementation, evaluation, monitoring and feedback). Close attention was paid to issues of centralized decision making versus the decentralized approach. The second major method was a field study undertaken at two locations, Ankara and the Bodrum Tourist Center, during the months of 
June through December 1988, The studies in Ankara were concentrated mainly on the MCT, State Planning Organization (SPO), Tourism Bank (TB), -TURSAB (Turkish Travel Agents Association), and State Institute of Statistics. This study consisted of extensive interviews with the planners, architects, managers, coordinators and administrators of each applicable agency within those organizations. The interviews included officials at various levels and with different responsibilities and backgrounds. Also interviewed were former officials and experts who had served in the MCT but were no longer active in the government for personal reasons or because they had moved to the private sector. Interviews and discussions were also conducted with university professors who had written or been concerned with tourism at some time. The Bodrum Tourist Center provides an excellent example of the study conducted on implementation and organizational coordination between the Center and its locale. Field study at the local level consisted of discussions and interviews with members of the municipality--the sole representative of MCT, hoteliers, holiday village owners and managers and yachting companies, as well as businesses and the tourists themselves.

Data collection in this field research was supported during the prior field stays, during the summer of 1986, which generated the community profile contained herein. I.iving on site in Bodrum (i.e., Tourist Project Center) as a participant-observer for several weeks facilitated, through observation and personal experience, gathering a great deal of informal information. As Salmen noted, "understanding conditions in an area where a development project is underway requires 
close personal contact and open conversational interviews in an atmosphere of mutual confidence" (1989:108). Finally, during the field stays, key informants were interviewed to gain an overall understanding of the situation. Open-ended interviews were conducted to get the range of local attitudinal concepts regarding the tourism development project. The questionnaire was administered orally, with the responses both written and recorded with a portable tape recorder. Interviews lasted at least one hour, sometimes two hours, with informal conversation afterwards: Great effort was taken to seem casual with those who might be intimidated by formal written materials.

The basic design of this research is based on a policy analysis framework, which is a powerful tool in examining and exploring the interaction among the social, political, and economic organization of a development enterprise, Planning and policy analysis is also aimed at reducing uncertainties regarding insights into or choices about future developments: Policy analysis as an investigative tool becomes attractive when the highly developed quantitative techniques and models are not perfectly tractable and realistically descriptive. To this extent it becomes conceivable to move away from assumptions of a linear process of development and incorporate some key political and organizational variables, hitherto commonly overlooked in standard modeling (Chatterjee and Nijkamp, 1983).

The policy analysis approach is also a powerful tool in providing answers to questions that are critical for the choice of appropriate policy decisions. Moreover, the problems of development are too immense 
and the resources too limited for the process of "muddling through" to continue in developing countries that are plagued with problems of unemployment, hunger and underdevelopment:

There are various factors which influence the policy formulation process, namely investment policy and the type of investment (i,e!, capital intensive by transnationals versus medium and local-oriented enterprises), national objectives of policy makers, interpretation of development in the national context, and the nature of the organizational as well as administrative system involved in the sector: Each of these aspects can influence the outcome of the policy formulation and implementation of policies, The analysis of the extent to which policy-outcome will affect beneficiaries and the environment when certain administrative action is pursued is approached through application of a policy analysis framework: This approach is elaborated by Grindle (1980) in the forms of "content" and "context" analyses, which are mainstays in the process of policy making and implementation, This form of analysis combines the interrelated nature of "development," which is central to understanding the process of policy formulation, and the implementation of it in the Third world.

\section{LITERATURE REVIEW}

International tourism has evolved into such a money-making activity, and it is so demanding in its involvement and planning, that neither governments nor scholars can ignore it: Its complex structure has attracted various schools of thought, thus bringing about an array of surveys and definitions for better understanding, as well as an 
understanding of its long-term effects, The magnitude of such a mass phenomenon is depicted here in Table I and Figure 1.

When one examines the rapidly growing literature on tourism and its role in LDCs, some interesting trends and divisions emerge, First, it was not until 1963 that tourism to developing countries demonstrated a mass character (Theuns, 1987:33) ; In Theuns's terms, mass tourism originating from Europe reached the southern shores of the Mediterranean only in 1963, and it took five more years to reach East Africa. This late development is reflected in the size of the early scientific output on Third World tourism. And again, in his words, "in the sixties research on Third world tourism is still in its infancy. It is only in the 70 s that Third World tourism as a subject for research gained some recognition."

Tourism as an activity involving movement of millions of people worldwide has become of tremendous concern and enthusiasm as a contributing agent to economic development and employment opportunities. Atac-Rosch (1984:1) described it as follows.

It is an industry which transports people rather than goods and services, and draws attention to a country's resources. It depends on the availability, quality and quantity of these resources just as other industries such as agriculture and mining depend on their respective resources.

Literature on the tourism industry has been far from unitary. Notwithstanding its role as an economic agent, tourism along with its obvious international economic impact, transcends governmental boundaries by bringing peoples of the world closer together through the understanding of different cultures, environments and heritages. It is potentially one of the most important vehicles for promoting 


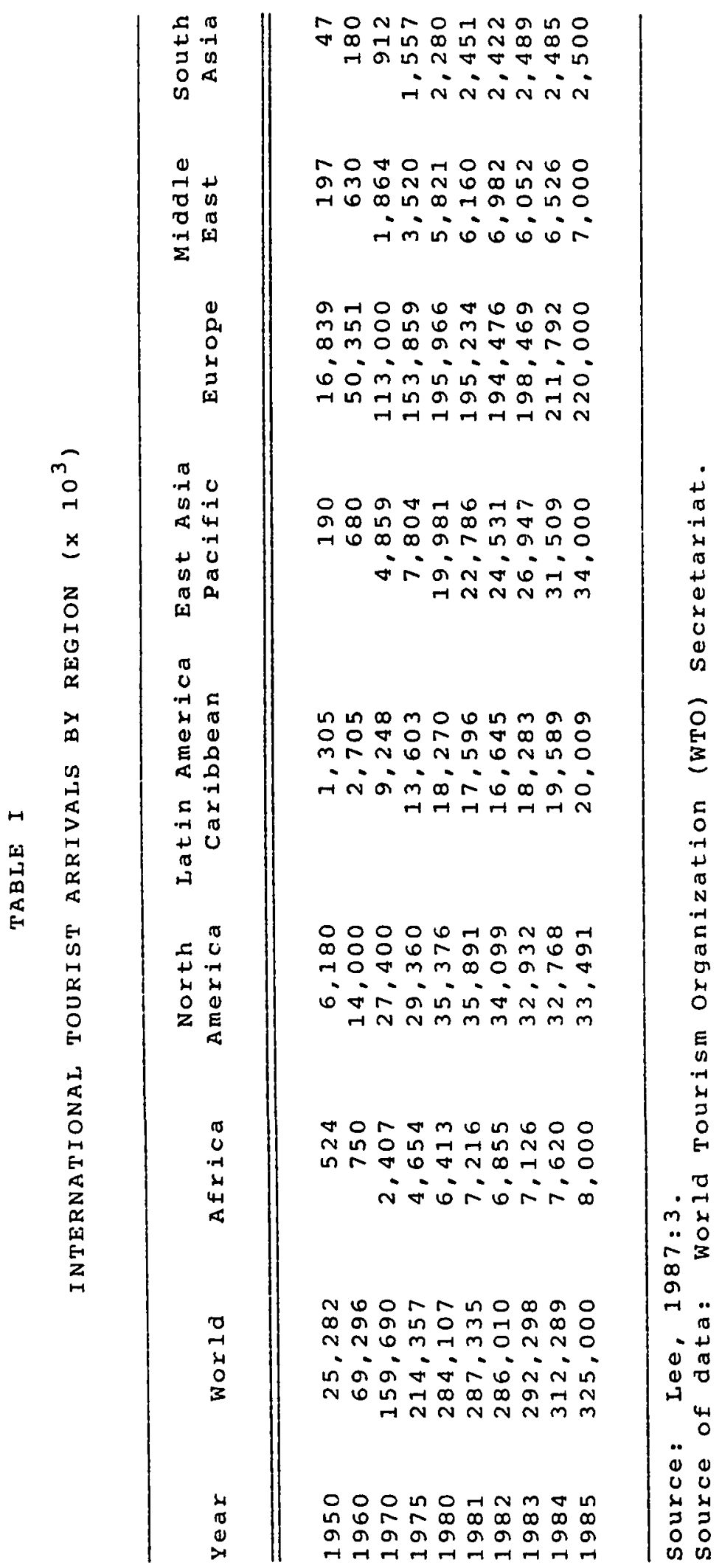




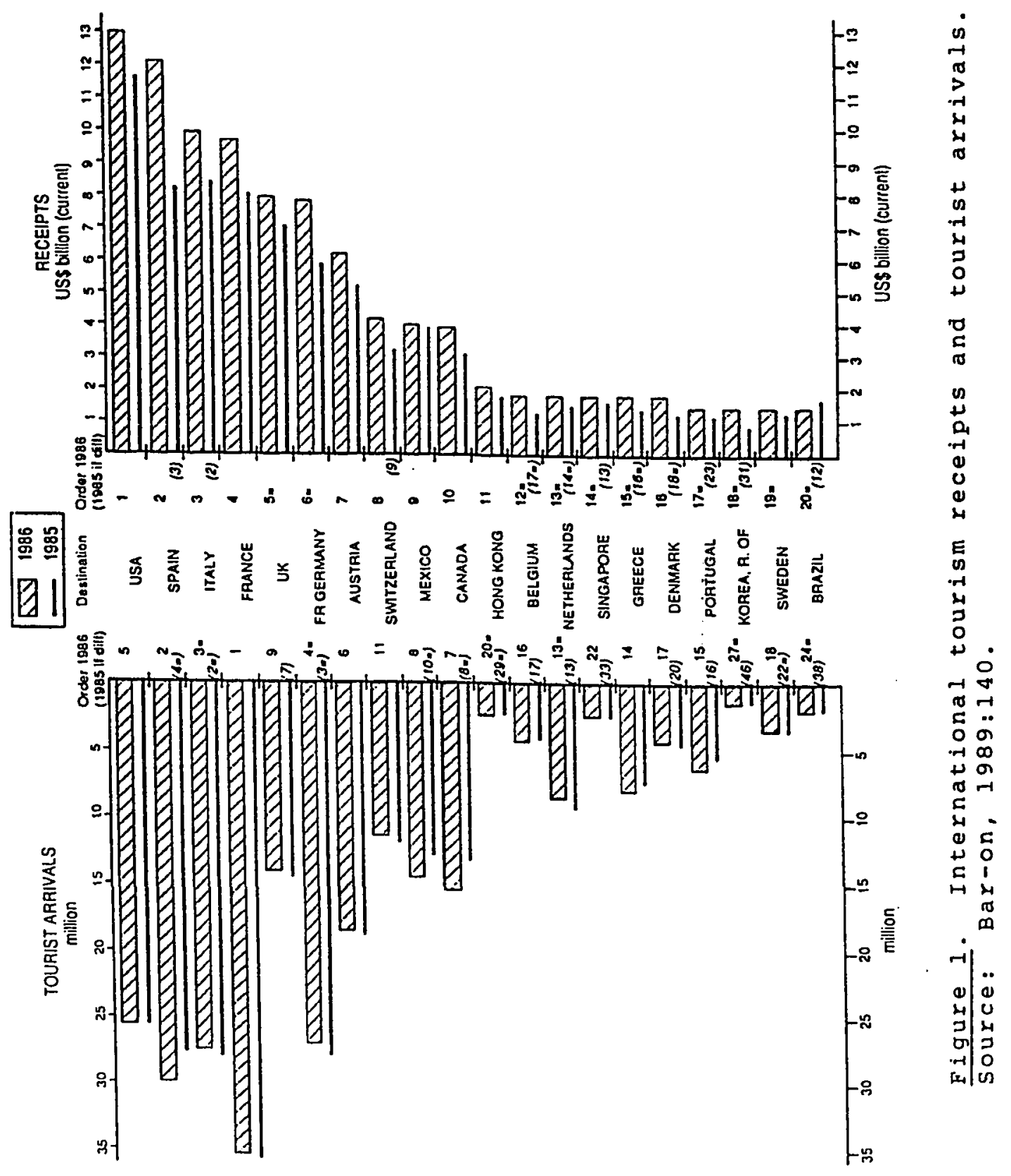


understanding, trust, and good will among peoples of the world (D'Amore,

1988). This is also stated in the WTO's charter as an explicit purpose:

To promote and develop tourism with a view to contributing to economic development, to international understanding, to peace, prosperity, and universal respect for and observance of human rights and fundamental freedoms for all without distinction as to race, sex, language or religion (Gunn and Jafari, $1980: 480$ ) .

To conceptualize tourism's place in development, one needs to delve into the general explanations of "rules" about the way the international tourism industry works in practice. In fact, it is the nature of the tourism industry's involvement in the critical interplay among economic, political, environmental and social elements, which has resulted in the large and rapidly growing literature in the past decade. Kaspar (1987:275) chronicles the growth of tourism literature: 1.The majority of literature on tourism came from Germany, Italy, France, Switzerland, and the United Kingdom, in that order: Despite the limitations of the research, it was nevertheless possible to identify six periods in the evolution of tourism as a science; For example, up until 1918, there was an initial descriptive period, Tourism was still considered a new phenomenon, and its various impacts had only begun to be recognized. From 1918 to 1945 the foundations for a systematic approach to the study of tourism were laid in works such as Hunziker and Krapf (1942). The period 1942-1952 saw the emergence of tourism as a scientific discipline. Between 1952 and 1960 the main directions of research were traced in a number of basic studies (e.g., Clement, 1961). The years 1960 to 1970 could well be called the sociological decade under the influence of marketing studies in the USA and motivational research. Since 1970, mathematical models and scientific critiques have been introduced in the study of tourism in Europe in large scale prognostical research and in works highlighting the negative impacts of tourism on the natural and human environment.

In general terms, research on tourism has been highly fragmented, which simply means that researchers are following separate and often 
divergent paths. For instance, there have been studies of the history of tourism (Sigaux, 1966; White, 1967; Feifer, 1986), as well as impactoriented research. Topics include two perspectives, environmental/ cultural/social and political/economic! Both are critical as well as supportive of tourism impact, For instance, Doxey (1976) and Smith (1989) examined the resentments which may result from tourist-host interactions, Later there followed studies of socio-cultural dimensions of tourism in the Third World by Fraser (1973), Cohen (1971, 1972 and 1973), Jafari (1974), Theuns (1987), Dekadt (1979), and Holden (1984), DEFINING TOURISM: ITS NATURE

Tourism is a peculiar product, a luxury export consumed by noncitizens in the exporting not the importing country, Many of the social, cultural, and political consequences of tourism stem from its being an internally consumed export. Also the same argument can be made for its economic potentials, such as earning foreign exchange, and its problems pertaining to participation of an external investor (Murphy, 1985)。

The main element of the industry is the "tourist;" therefore all development and planning procedures must be on the understanding of who this person is if it is going to succeed (Murphy, 1985). The term "tourist" is derived from the word "tour," meaning, according to Webster's dictionary:

A journey at which one returns to the starting point; a circular trip usually for business, pleasure or education during which variable places are visited and for which an itinerary is usually planned (Murphy, 1985:5), 
Jafari and Ritchie (1981:16) characterized tourism as follows:

The tourism business is often referred to as the travel industry. Some of the typically recognizable "goods and services" of the travel industry are accommodations, restaurants, transportation, travel agencies, recreation, and the like. Most of these products are usually produced with the needs of tourists in mind. Meanwhile, most countries have resorted to the more general term "visitor," and for measurement purposes of this activity a definition adopted by the United Nations Conference on Travel and Tourism in 1963 is as follows: "...any person visiting a country other than that in which he has his usual place of residence, for any reason other than following an occupation remunerated from within the country visited,"

Visitors have been subdivided further into two categories to

assist the measurement of tourist traffic and the assessment of its

economic impact (Murphy, 1985; Pye and Lin, 1983).

1. Tourists--who are visitors making at least an overnight stop in a country or region and staying for at least 24 hours;

2. Excursionists--who are visitors that do not make an overnight stop, but pass through the country or region, An excursionist stays for less than 24 hours

Pye and Lin (1983) called tourism largely a service industry, and by its nature, labor intensive. According to the definition currently accepted by the Wro and the Organization for Economic Cooperation and Development (OECD), tourism includes all journeys of more than 24 hours for recreation, business, study or health purposes (Lee, 1987:2)

Tourism today has become a surprisingly large-scale phenomenon representing one of the largest peacetime movements of people, goods, services, and money in human history (Greenwood, 1976:130). As Singh et al. (1989) addressed: "Developing countries would like a bigger share of the 355 million international tourist arrivals and $\$ 150,000$ million 
worth of international tourist receipts recently recorded." It is the nature and characteristics of the industry that require careful policy formulation and planning organization, Policy planning issues are likely to take a different modeling procedure in comparison to conventional and traditional industries. This notion was elaborated by Christie Mill and Morrison (1985), who indicated that tourism supply and demand, as a service and an intangible experience, were being sold rather than any physical commodity production, and consumption of this commodity takes place at the same time rather than to be shipped elsewhere. One loss at a sale, for example in a restaurant, will be forever. They maintain that tourism supply is relatively fixed, The resources and infrastructure of a destination cannot change as quickly as can tourist demand. The service provided is an amalgamation of several services and products.

Another characteristic of the tourist industry, which differs from traditional industries, is that tourism demand is highly elastic, seasonal in nature, and subject to factors such as taste and fashion as well as the more objective factors of demand (i,e,., price) (Pye and Iin, 1983; Mathieson and Wall, 1982; Young, 1973; Bryden, 1973).

Some scholars of tourism considered it as a modern and rather complex system. As Krippendorf (1986:518) noted:

Modern tourism has become one of the strongest and most remarkable phenomena of the time, To discover its true nature, one must attempt to understand how the various components are connected to each other, and what are the causes and effects, the conjectures and realities.

Krippendorf maintains that one must first grasp the workings of the 
mechanism before he/she can determine the means of controlling,

changing, and improving it.

To understand the functions and the mechanisms of the industry

Baron (1989:3-5) says the following:

1. The large numbers of market segments with differing characteristics which will each be affected in different ways by changes in the overall tourism environment: these include international and domestic tourists and other travelers, from different socio-economic backgrounds and on journeys of different purpose and type,

2. A variety of types of accommodation and of transport, whose supply is relatively ineiastic in the short run (through some substitution is possible when demand exceeds supply for a particular type of service) and whose long-term profitability is essential to maintain and improve standards of service,

3. Strong changes throughout the year and between years, due to the high seasonality of demand in many destinations, to changes in underlying tastes and to interruptions due to unusual events (such as an exhibition, the Olympic Games or a terrorist outrage). There are peak days around holidays and weekends, on which excess demand, congestion and overbooking may be major problems.

4. The transient character of tourism and the "perishability" of unused supply (rooms, aircraft seats, etc.) which cannot be "stored" for later demand.

5. The sale of individual products or services at a variety of different prices. For example, a hotel room will be sold at different rates depending on the season (and even on the day of the week), or whether the guest books as an individual or in a group: An airline seat will be sold at different prices depending on the time of year and the booking restrictions imposed.

There are a number of other features of the tourism industry, which while by no means unique to it, are perhaps more pronounced than in many other industries.

6. Demand is affected by a very wide range of influences including events, habits, promotion and publicity, as well as by economic variables such as prices, exchange rates, incomes and the socio-demographic and "Psychographic" characteristics of the tourists themselves. 
7. Control of the industry is defused, with many different national, regional and local government and public and private enterprises responsible for developing tourism and supply the appropriate transport and other services: Their activities may not be well coordinated.

8. The provision of new tourism facilities and the promotion to develop new markets require a relatively long lead-in time, whereas the factors affecting demand for a specific product may change very rapidly and at short notice.

9. Large investments in tourist facilities are often required, including allocation of land and the training of human resources who may not be employed continuously, with the attendant risks of over- or under-supply.

10. The sheer size of the industry, with the strong competition from tens of other countries, hundreds of resorts and thousands of programmes for international and domestic tourists, is itself a challenge.

\section{TYPOIOGIES}

The tourism industry, like other areas of inquiry, has been subject to classification for appropriate scientific investigations. There are as many types of tourists as there are motives for travel. Each type makes different demands of a destination and has its own particular impact.

Tourist typologies can be grouped into two general categories (Murphy, 1985; Lea, 1988):

1. International types emphasize the manner of interaction between visitors and destination areas, and/or "interactive" kind, stressing great variety of travelers and their behavior at a destination,

2. Cognitive-normative models stress the motivations behind travel and focus on the causes of travel. 
An example of the first type was devised by Smith (1989), who separates tourists into seven demand categories:

$1_{q}$ Explorers: very limited numbers looking for discovery and involvement with local people;

2. Elite: special, individually tailored visits to exotic places.

3. off-beat: the desire to get away from the crowds .

4. Unusual: the visit with peculiar objectives, such as physical danger or isolation.

5. Incipient Mass: a steady flow traveling alone or in small organized groups using some shared services:

6. Mass: The general packaged tour market leading to tourist enclaves overseas:

7. Charter: Mass travel to relaxation destinations which incorporate as many standardized Western facilities as possible.

Each of these categories has a corresponding range of impacts on the host society and destination, with progressively more intensive effects being felt in each category down the list (Lea, 1988:26).

A cognitive-normal typology suggested by Cohen (1979) seeks to distinguish visits in terms of what they mean for the traveler as follows:

1. Recreational: One of the commonest forms of tourism where the trip is designed to relieve the strains and tensions of work with no deeper significance involved. 
2. Diversionary: When the visit is a pure escape from the boredom and routine of home life:

3. Experiential: Describes tourists as the modern pilgrims looking for authenticity in the lives of other societies because they have seemingly lost their own:

4. Experimental: When travelers begin to experiment with lifestyles other than their own:

5. Existential: Lescribes tourists who actually acquire a new spiritual center as a result of the travel experience. The implications of such generalizations, Lea (1988) suggested, can be helpful in designing alternative tourist policies in the Third World: As he noted, some governments wish to maximize income from the industry by encouraging mass tourism with a minimum of local contact $\left(e_{!} g_{!}\right.$, Mexico), whereas others may encourage the tourist trade from a small number of top spending visitors ( $e_{i} g_{i}$, Bali),

Cohen (1979) classified tourists according to the degree to which they seek familiar or strange settings and whether or not they were willing to be institutionalized (organized) in their travel the creation of resort tourism or "ghetto tourism" would be an example of the organized tourism for those seeking familiar settings: Smith's (1977) more detailed breakdown incorporates recent market developments such as the unorganized "hippie treks" to Nepal and the social implications of a highly structured charter business, Cohen's (1972:167-8) typology developed a fourfold classification of tourists' experiences based on their means of travel and purpose of travel: 
1. The organized mass tourist: This is typified by the package tour in which journeys are fixed, stops are planned, and all major decisions are left to the organizer. Familiarity is at maximum and novelty at minimum;

2. The individual mass tourist: In this case the tour is not entirely planned by others, and the tourist has some control over his/her itinerary and time allocations: Familiarity is still dominant.

3. The explorer: They plan their own trips and try to avoid developed tourist attractions as much as possible. Novelty now dominates, but the tourists do not become fully integrated with the host society:

4. The drifter: Drifters plan their trips alone, avoid tourist attractions and live with the members of the host society? Novelty is dominant and familiarity minimal.

A number of tourism taxonomies have been suggested. Some are based on tourist interest (ethnic, cultural, historical, environmental, recreational); yet others have tried to separate tourist types according to a blend of their socioeconomic backgrounds and holiday preferences (Edwards and Cleverdon, 1982):

Two other classifications developed by Gray (1970) as "sunlust" and "wanderlust," which further related to Cohen's (1972) typology of tourists as sunlust (organized and individual mass tourism) and wanderlust (explorers and drifters)! The drifters and explorers are likely to look for and appreciate the lifestyle of the countries they visit and to actively seek to mix with the local populations. On the 
other hand, the institutionalized tourist neither wants nor is able (because of the structure of the pre-arranged package) to mingle with the resident community (Cohen, 1972; Edwards and Cleverdon, 1982) :

\section{MASS TOURISM}

For the purpose of this study a particular categorization has been given weight, This categorization was developed and outlined by Valene Smith: Smith's (1989) categorization has a corresponding range of impacts on the host society and destination, with each category perhaps posing different types of planning strategies. The typology she devised breaks into seven demand categories, as mentioned earlier--explorers, elite, off-beat, unusual, incipient mass, mass, and charter. The last two, mass and charter, are the major concern for Third world development issues as they are more likely to intensively affect the socio-economic structures of the host country.

It was not until post-World War II that the tourist explosion manifested in the form of mass tourism: Movements of large numbers of travelers from one country to another by means of mass transport involves mass hotel accommodations and, above all, mass selling. It is precisely this quality of modern tourism that makes the industry so complex and so highly political (Matthews, 1978). Post-war development in the industrialized countries resulted in prosperity, optimism and a mobile middle-class.

The institutionalization of tourism as a global phenomenon induced the formation of the International Union of official Travel Organizations (IUOTO) in 1946, which was the continuation of the earlier 
organized International Union of Official Tourist Publicity Organization (IUOTPO) of Hague in 1925, Finally on November 1, 1974, the WTO was established as the newest intergovernmental tourism agency on a global level (Matthews, 1978; Cohen, 1973):

Where the aviation industry has become a thriving force in mass movement of people in search of new places, the modern Western urban society has made traveling possible for everyone from the super rich to the working class, from the very old to the infant, from the conservative to the bohemian all over the globe (Feifer, 1986; MacCannell, 1976):

with the invention of mass tourism, the industry could no longer be confined to a few nations as it had been in the era of "grand tour" or romanticism (Feifer, 1986; McIntosh and Goeldner, 1986) \&ather, the internationalization of tourism and its "mass" character encompassed the Third World and resulted in a new phase of literature on "Third World Development and Tourism."

\section{STRUCTURES OF TOURISM}

In order to analyze tourism development, it is necessary to examine its structure, which by no means is an exhaustive description: It is also equally important to learn that tourism development is dependent upon the numerous elements within the rathex complex and broad structure of the industry: Among the many elements of tourism, the elements of demand and supply are considered to be the foundations of a sustainable dynamic tourism sector: As Lea (1988:22) noted, 
Supplying tourist facilities at Third world destinations is a dynamic process of growth and change, as well as the static provision of a range of buildings, services and attractions.

In fact, the elements of supply and demand that industry is so dependent upon can be affected by both international and national events, whether they be political, social, cultural or natural, There exist various examples of such unpredictable events and their disastrous outcomes, namely the Fijian military coup of 1987, which altered the prospects for a successful tourism industry overnight and damaged the economy, thus further weakening the position of the very poor: Perhaps the most notorious example in recent times comes from the central African country of Uganda, where tourism was the third most important source of foreign exchange before the beginning of the Amin regime in 1972. Just six years later, visitor numbers had dropped from 85,000 to only 6,000 , and most of the country's hotels were destroyed or vandalized (Lea, 1988:22-23):

\section{ELEMENTS OF SUPPLY}

Various authors have categorized the supply side of tourism which generally makes up the components of a functioning tourism system. Gunn (1988:69) introduced four components of the supply or "plant" side: transportation, attractions, services, and informational promotion (model of a tourism system depicted in Figure 2). Jafari (1982:2) refers to these as the "market basket of goods and services, including accommodations, food services, transportation, travel agencies, 


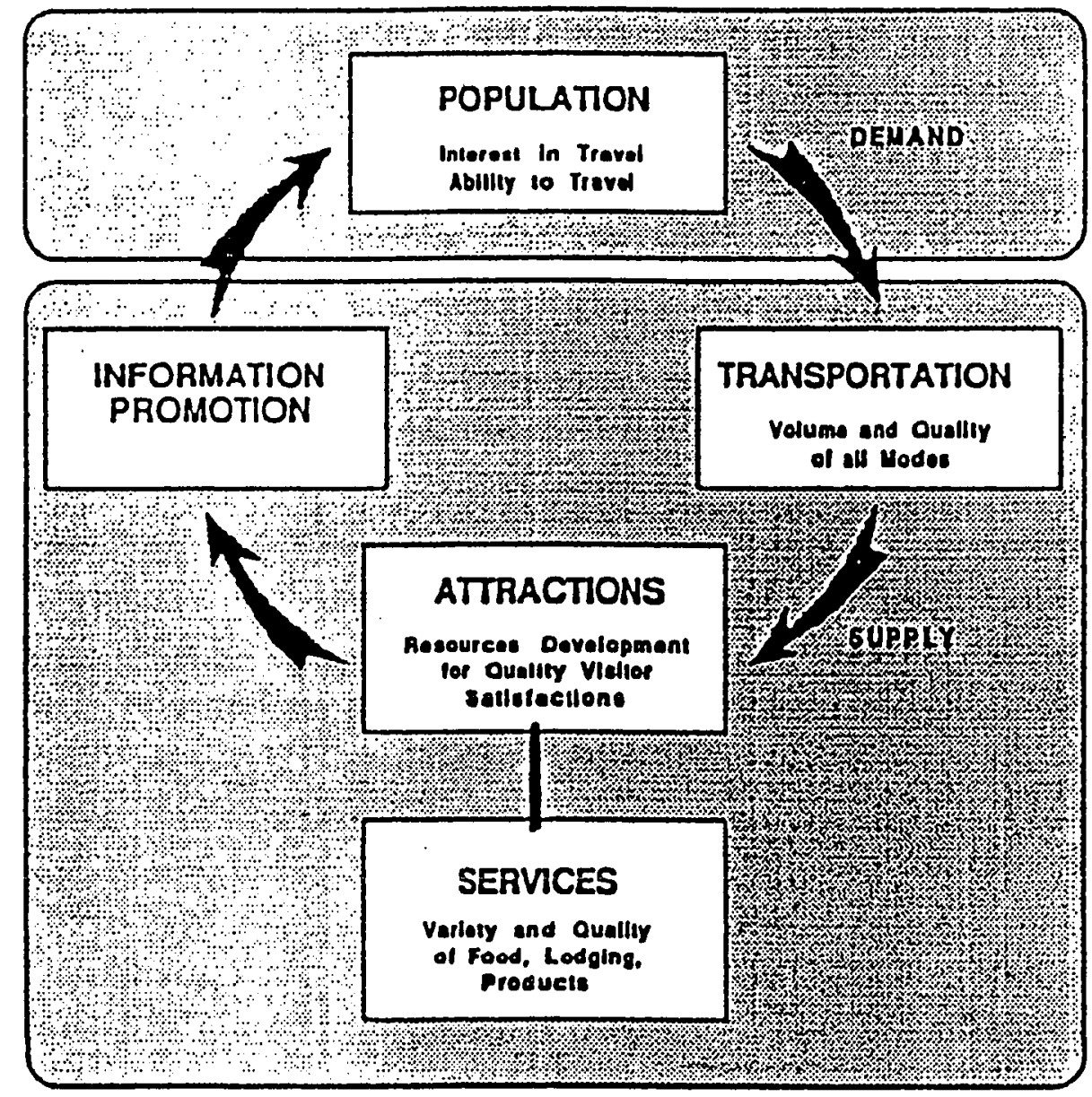

Figure 2! Model of a tourism system, Source: Gunn, 1988:68; 
recreation and entertainment, and other travel trade services" "To these he adds resident-oriented products and market differentiation, Thus elements of supply have been categorized into five broad sections: 1) attractions; 2) transport; 3) accommodation; 4) supporting facilities; and 5) infrastructure:

\section{Attractions}

These may be classified into natural features (land forms, flora and fauna) and historic or modern manmade objects (cathedrals, casinos, monuments, buildings or amusement parks)! A third set of attractions has been categorized into culture, language, music, folklore, dances, cuisine and so forth (Lea, 1988; Pearce, 1981): Attractions have been subject to further classifications on the basis of two very important types of tourism: touring circuit and longer stay (focused) (Gunn, 1988), which require different types of planning and marketing processes.

\section{Transport}

There is an historical association between tourism development and transportation. Patterns of transportation and land use become critical not only to tourism planning but also in the overall national transportation system, Gunn (1988:163) outlined five categories: Tourists, transportation needs and desires (users); tourism and the transportation industry; tourism, government and transportation; tourism environmental considerations of transportation; and tourism transportation as related to overall transportation systems: The implication of transportation system influences the perspectives on the 
development discussion because the modern airbased travel system is nodal in nature and the high levels of technology and capital required favor a metropolitan-based dominance of the system (Pearce, 1981),

Accommodation

Even though there are various types of accommodations, they are basically subdivided into the commercial sector (hotels, motels, boardinghouses, holiday camps, etç) and the private sector (private, permanent residences used for hosting friends and relatives, and second homes--property owned or rented on a long lease as the occasional residence of a household that usually lives elsewhere) (Coppock, 1977:3), Camping and caravanning may constitute an intermediate category: There has been a trend to move away from the traditional serviced type of accommodation to the more flexible and functional forms of self-contained modes of accommodation. In the case of LDCs the provision of self-contained accommodation is less attractive due to the relatively low labor cost (Lea, 1988; Pearce, 1981).

With the increase in "social tourism," public support to stimulate travel by lower income populations, and greater involvement by nonprofit organizations, many collective types of accommodations have emerged, especially in Europe where the need for policies concerning social tourism are more realized;

The latest categorization of the accommodation sector and the changes in the structure of the hotel industry signal an alarming trend which could have critical implications for the indigenous accommodation sector: This category, which is classified as "supplementary accommodation" includes all forms of privately owned and operated 
accommodation, such as youth hostels, private rooms, rental apartments and houses, holiday villages, sanatoriums and recreation camps (Go, 1989:195), According to the WTO, the statistical survey on supplementary accommodation worldwide represents two-thirds of the potential of hotels and similar establishments in terms of room-night availability, For example, Spain's accommodation capacity exceeded 1.2 million places in 1981, while hotels in that nation accounted for slightly more than 478 of that total accommodation inventory, or 595,847 bed spaces, with the balance divided among bed spaces in pensions, guest houses, and campsites (Barke and France, 1986:190):

The home-based structure of the accommodation sector can be effected if there is not a national policy to support it. As Go (1989:195) noted, "Globally, there are roughly 11 million rooms distributed over hotels and similar establishments The top 200 hotel corporations hold about 2,7 million of these rooms" It is on such premises that the role of transnational corporations (TNCs) ( $i_{q} e_{q}$, via the hotel industry) becomes a serious issue within the development paradigms :

The accommodation sector requires particular attention since it interacts with various other aspects within the industry to stimulate higher occupancy, Gunn (1988:216) called for integrated planning pertaining to accommodation development. He wrote the following:

Because accommodation can be affected by the policies and decisions of the other sectors, the leaders would open up communications with them. It would seem that the greater each sector increases its own sophistication regarding tourism integration, the more it will contribute to overall integrated planning for tourism! 
Supporting Facilities

These consist of a range of facilities and services which become indispensable wherever a travel industry paflourishes! Gunn (1988:253) elaborated that

for many small and medium-size cities, the established service businesses are likely to be oriented to a previous economy of forestry, agriculture, or mining, and only to residential needs.

He continues, saying that visitors may be of a dramatically different socioeconomic status requiring new and different services. Thus various supporting facilities in a hierarchical fashion are needed, which may be provided from the outset;

\section{Infrastructure}

An adequate infrastructure is needed to support various forms of physical development which make an area accessible to tourists, as well as particular installations which provide for the requirements of tourists in the area. There are two basic categories of such physical developments--the infrastructure and the superstructure:

The infrastructure includes all forms of construction on and below ground required by any inhabited area in intensive communication with the outside world and as a basis of intensive human activity within! It includes roads, parking areas, railway lines, harbors, and airport runways, as well as utility services of water supply, drainage and sewage disposal, electricity and power supply. The superstructure consists of passenger traffic terminals, hotels, restaurants, entertainment and shopping facilities, and the like (Burkart and Medlik, $1981: 232)$ 
Both categories of facilities are fundamental for tourism expansion and are often forgotten in any evaluation prior to development (Gunn, 1988): Since infrastructure is needed by residents themselves, it requires careful planning to prevent potential friction and resentment between the hosts and guests! Furthermore, they are public sector items and commonly provided by the government or other public authorities out of public funds. It is likely that a new infrastructure will not be paid for by the private sector despite their high profit from the tourism. Because of the intensity of its requirements, noted Burkart and Medlik (1981), and because it is often highly concentrated in particular places and at particular times, tourism creates special problems for the infrastructure,

\section{TOURISM DEMAND}

Three main aspects constitute tourism demand; The first two are international demand from tourist originating countries and regional tourists who are considered international but who originated from a different country in the same region. The third part of the demand comes from domestic tourism within the destination itself. Tourism demand poses a crucial perspective since the international share of the demand flow is not controlled or operated by the host country. This aspect is elaborated by Christie Mill and Morrison $(1985: 358)$ in the following terms:

[The] factor that makes tourism different from other industries concerns the role of travel intermediaries.t.? Specialized intermediaries-- organizations that operate between the producer and the tourist--are often necessary to bridge the gap.... Thus, while in most industries, the 
producer exerts much control over every stage in the development and delivery of the product, in tourism the travel intermediaries can influence, if not determine which services should be offered, to whom, when and at what price;

The vulnerability of the "demand" side of tourism for the LDCs is manifold. The most obvious ones are those related to the nature of the industry as "seasonal," not to mention that tourism is subject to changes in taste or fashion, fears of political instabjility, and allegations of health hazards, One of the intrinsic features of tourism is its seasonality: The word "season" has become the common term to mark the annual period of time when tourists are most noticeable in resort towns (Hartmann, 1986). In general, the annual patterns of tourist activity are differentiated and divided into a peak season, a low season, and an off season, Highly seasonal tourism does not render as much revenue as more evenly spread tourism would, It is this overall economic rationale that generally governs the development of tourist regions (Fartmann, 1986) ì high degree of seasonality not only causes large fluctuations in earnings from tourism, but also exemplifies considerable social costs in terms of under-utilization of productive capacity, and in particular, high levels of seasonal unemployment. The demand aspect of tourism becomes even more critical when there is no pre-planned tourism activity and the spontaneity of the sector is more dominant. This condition tends to overlook the procedures needed for demand analysis, which is usually instituted through forecasting--trend analysis, simple regression, multiple regression and/or Delphi method--and also matching supply with anticipated demand. Further constraints that make the demand aspect cumbersome are the 
inability to pursue a market research analysis--determination of market characteristics, development of market potentiais, market share analysis, sales analysis, competitive destination studies, potentials of the existing and possibly new markets, short-range forecasting, and studies of travel business trends; overall the task of demand analysis for IDCs, as vital as it is, requires, in McIntosh and Goeldner's terms, "knowledgeable planners since it is a perilous business" (1986:221). The notion of demand analysis has triggered new approaches to consumer research and its application to the tourism sector: Dalen suggested a technique that investigates demand population based on socio-demographic characteristics, He claimed that "it is obvious to us that market segmentation of this kind, based on values, could well be used in this field" (1989:186),

One of the dilemmas confronting new destinations (such as Turkey) is the lack of awareness of the complexity which dominates the industry when it comes to marketing, Matching supply and demand with tourism's unforeseeable fluctuations is elaborated in Figure 3 , where three possible outcomes can be expected if no action (i.e., policy) is taken to "level offn the demand (Figure 3, 1a). First, supply is provided so that demand in the peak season is fully satisfied (Figure 3, 1b). This implies that tourists coming to the destination in the peak season will be accommodated comfortably and without overcrowding, However, during the low season the destination will suffer from extremely low occupancy levels, with obvious implications upon revenue! The second outcome occurs when the supply is set at a low level (Figure 3, 1c). The facilities during the peak season will be overcrowded enough to detract 

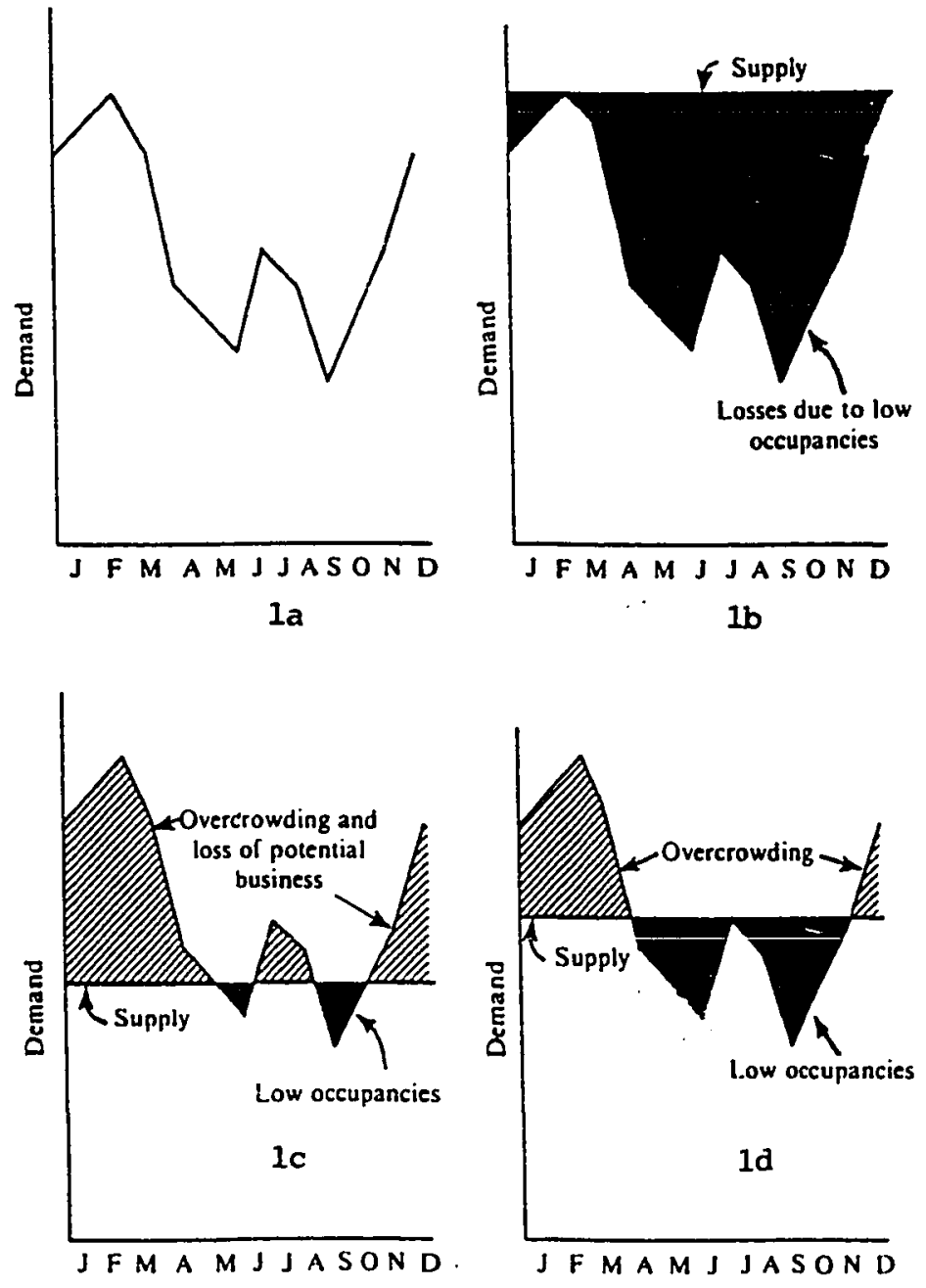

Figure 3. Fluctuating demand levels and supply. Source: McIntosh and Goeldner, 1987:225. 
from the tourist experience, Visitor satisfaction will be at a low level, and the future of such a resort area will be doubtful, Last, if supply is set in between the level of demand during the peak and the off season (Figure 3, 1d), the problems are somewhat mitigated (McIntosh and Goeldner, 1985), Nevertheless the fluctuation will not be a desirable outcome; there are various strategies to overcome this situation, namely: 1) multiple use--supplement peak season attractions of a destination with other attractions that would create demand for travel to that destination during off-season periods, and 2) price differential--create new markets for the off-season periods by employing price differentials as a strong tool to shift demand away from the peak season in favor of the off season (McIntosh and Goeldner, 1985)!

\section{TRANSNATIONAL CORPORATIONS AND TOURISM}

Yet another element of international tourism that inhibits IDCs from controlling the demand side of the industry is the role of transnational corporations (TNCs) $!^{1}$ This is an extension of the traditional concept of a TNC, but in international tourism at least, although there is comparatively little direct foreign investment, there

\footnotetext{
$1_{\text {Transnational corporation, as the term is used here, covers not }}$ only foreign firms with direct investments in a particular host country, but those firms having all major forms of contractual arrangements and enterprises in host countries (UN, 1982:2). In addition, the corporation may, or may not, act as a link between the core and the periphery via a package deal of capital, technology, and management skills, In trying to maximize profits on a global scale, TNCs tend to jeopardize the economic and political sovereignty of Third World countries (Lim, 1985; Vernon, 1977; Hymer, 1974).
} 
is a considerable foreign influence on the extent and pattern of tourism development in many countries (UN, 1982),

Two issues that are important with regard to the potential involvement of TNCs in the tourism industry of a country include: the role, if any, that these corporations can play in the industry and the package of policy instruments needed to ensure that their participation is compatible with overall goals of economic development?

Thus, in tourism as in many industrial sectors, developing countries are confronted in implementing their development policies by large transnational groups whose turnover sometimes approaches their own GDP and whose investment budgets and managerial and skilled staff are generally larger than those of national tourism organizations (Ascher, $1985: 16)$

The form of involvement by TNCs varies, but four types have been classified in their foreign-associated hotels: 1) the TNC has an equity interest sufficient to ensure that it has some de facto if not de jure management control; 2) the TNC operates some kind of leasing arrangement; 3) the TNC's main form of association is management contract; and 4) the TNC's main form of arrangement is a franchise or some form of marketing agreement, over and above that which might normally be involved in a referral or reservation system (UN, 1982): Not to be overlooked is that in several instance particular TNCs have more than one form of association with the same foreign hotel. Nevertheless, the involvement of MNCs is manifested in the perspective based on a desire to enhance a firm's business through the international exploitation of one or more perceived advantages: These 
may include a special technology, a strong trade name, an economy of scale, an efficient distribution system, or the capacity for using lowcost factors of production. The resultant TNC is a set of affiliated firms located in different countries that (1) are linked by common ownership ties, (2) have use of a common resource pool, including managerial services, finance, information, trade names, and patents, and (3) respond to a common strategy normally monitored by a headquarters or home office (Goodman, 1987:7)! In the case of tourism, as documented by Lea (1988:5): "These intermediary companies [tourism transnational corporations--TTC] created and now control a global mass tourism market through their transnational operations in origin and destination countries:" He continues, saying that the largest have expanded vertically to the point where they have interests in all major sections of the industry and are not answerable to politics determined by any single government, As Ascher (1985:16) reiterated, "In present circumstances, developing countries wishing to expand tourism activities are generally obliged to negotiate with TTCs,"

Three major sectors of transnational tourism corporations (TTCs) have been identified for their involvement in international tourism: These include: transport (airlines), accommodation (hotel) and package tour (tour operator) sectors (Ascher, 1985; Christie Mill and Morrison, 1985; Zammit, 1981).

\section{Main Hotels}

As a United Nation's study revealed, there are at least 81 companies owning two or more hotels in most tourist oriented countries, 
of these the United States, France and United Kingdom accounted for 50 percent, 15 and 14 percent respectively (Zammit, 1981:43) : Most problems for the destination countries have resulted when the TNCs have had no financial investment in the hotels, Control is exercised through management contracts or through franchise agreement (Christie Mill and Morrison, 1985), As shown in Table II, hotels associated with United States-based TNCs account for about 50 percent of all the hotels and 56 percent of the rooms, while hotels associated with TNCs based in the United Kingdom, Northern Ireland and France accounted for another 30 percent, encompassing 25 percent of the rooms (UN, 1982): According to the WTO, there are more than 16 million hotel beds in the world, LDC's share of this was approximated to be not more than 10 percent (Ascher, 1985).

The hotel sector is the primary sector for the TNC's involvement in international tourism. One of the characteristics of this sector is that they are linked to various activities pertaining to international tourism including: catering, computerized marketing and reservation networks, car rentals, hotel staff training, design and engineering consultants, the production and sale of hotel equipment, etc. It is this that renders TNCs the power to bargain vis-a-vis LDCs in controlling and affecting indigenous tourist policies

One of the main principles underlying the development of the chains has been their specialization in the sale of luxury services, mainly to "business" travelers--a policy that is associated with large scale, capital intensive enterprise and with high leakage due to 


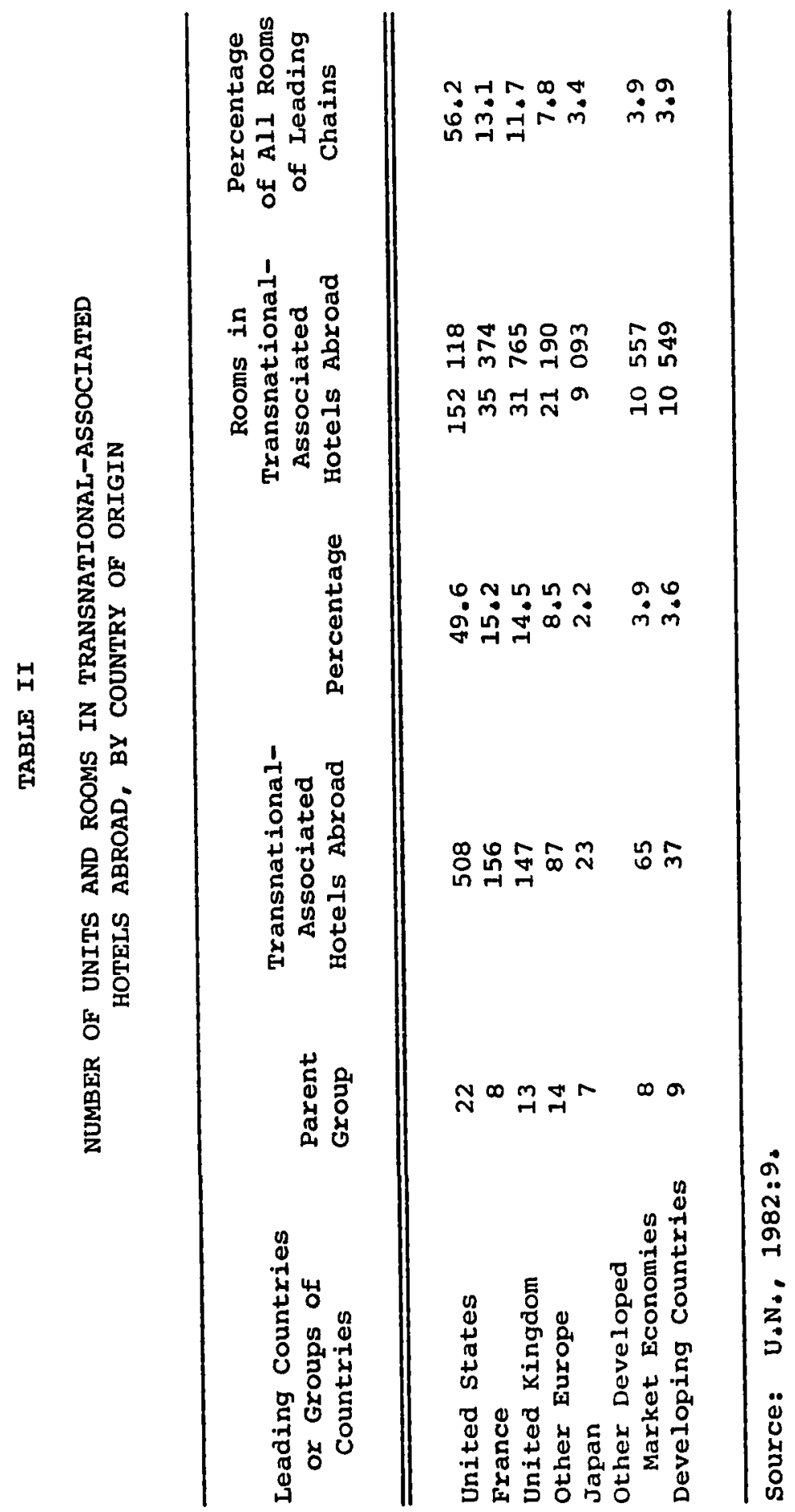


external constraints on the host country (Ascher, 1985); As reported by the United Nations:

In 1978, there were 16 hotel chains linked with international airlines; they accounted for only 58 of the domestic and foreign hotels of all leading hotel or touroperating companies, but for 268 of all foreign hotels and 348 of those in developing countries (UN, 1982:11).

The popular TNCs in the hotel industry are those that are exclusively in hotel enterprises, Fifty-six of the 81 TNCs with overseas hotels have hotels as their main business, Many of the largest also manage or franchise a considerable number of domestic hotels. This is the case, for example, of Holiday Inns (of the United States), Club Miditerranee (of France) and Trust Houses Forte (of the United Kingdom) (Zammit, 1981), Other TNCs in the hotel business are part of a larger enterprise, with a wide range of interests (transport, leisure, entertainment, catering, property), all of which are not necessarily related to tourism,

There are also other policy options that TNCs are adopting to enhance their benefits and to minimize their risks (i.e., lowered occupancy rates) in the future, As Ascher $(1985: 43)$ alluded that

On one hand, they are reducing their assets abroad to a greater extent than ever before and concentrating on management. Thus increasing their potential mobility, But at the same time, they are discarding franchising systems in favor of management contracts, which strengthen the means of control without any increase in risks:

\section{Airline Sector}

Air transport is obviously one of the key operations in international tourism, especially for developing countries, It is estimated that 70 to 90 percent of tourist arrivals are by air (Ascher, 
1985:23). Thus international airline passenger traffic mounted to 200 billion revenue-passenger-miles (RPM) in 1975 (UN, 1982)

What makes the role of international airlines in the Third World tourism more critical is their market share of international RPM (Table III): As Table III demonstrates, the top two airlines accounted for 13 percent of the market share in 1977, the top six for 27 percent, and the top 20 for just over 52 percent of international RPM; Although 42 percent of the international airlines were based in developing countries, they accounted for only 15 percent of international RPM (UN, 1982).

There are considerable ownership and other links among airlines and also between airlines and other related tourist sectors, namely catering, insurance, computer services, technical services and shipping: Additionally, the motives for airline involvement in international hotels may be induced by the need to provide accommodations for airline passengers and to establish links with a destination in order to obtain traffic rights. An example would be Pan Am's net income from its intercontinental hotel operation, which was recorded at $\$ 19.5$ million in 1978 (UN, 1982).

The airline sector is an economic activity that involves very costly investments (in aircraft and infrastructure)! It uses advanced technology and requires sophisticated training, and demands for marketing facilities located in the developed countries, For all these reasons it impedes the intervention by the IDCs in this sector: Moreover, they have adopted a policy of "producing as many trips as possible" to a more commercial practice in the form of "winning, 
TABLE III

WORLD SHARES OF THE WORLD'S LARGEST AIRLINES

\begin{tabular}{|c|c|c|c|}
\hline \multirow[b]{2}{*}{ Rank } & \multirow[b]{2}{*}{ Airline } & \multicolumn{2}{|c|}{$\begin{array}{l}\text { Percentage Share of } \\
\text { International RPM }\end{array}$} \\
\hline & & $\begin{array}{l}\text { Developed } \\
\text { Countries }\end{array}$ & $\begin{array}{l}\text { Developing } \\
\text { Countries }\end{array}$ \\
\hline 1 & $\begin{array}{l}\text { British Airways } \\
\text { (short/long-haul) }\end{array}$ & 6.5 & \\
\hline 2 & Pan Am & 6.5 & \\
\hline 3 & Japan & 3.8 & \\
\hline 4 & Air France & 3.7 & \\
\hline 5 & Trans World & 3.3 & \\
\hline 6 & Lefthansa & 3.2 & \\
\hline 7 & KLM, Royal Dutch & 2.9 & \\
\hline 8 & Qantas & 2.7 & \\
\hline 9 & Alitalia & 2.4 & \\
\hline 10 & Swissair & 2.1 & \\
\hline 11 & Air Canada & 2.1 & \\
\hline 12 & Iberia & 1.9 & \\
\hline 13 & Scandinavian & 1.8 & \\
\hline 14 & Singapore & & 1.8 \\
\hline 15 & Aeroflot & 1.7 & \\
\hline 16 & Condor & 1.3 & \\
\hline 17 & Northwest (US) & 1.3 & \\
\hline 18 & KAL (Republic of Korea & & 1.2 \\
\hline 19 & Air India & & 1.2 \\
\hline \multirow[t]{2}{*}{20} & Canadian Pacific & 1.1 & \\
\hline & Total & 48.1 & 4.2 \\
\hline
\end{tabular}

Source: U.N., 1982:33. 
stabilizing and earning a profit from a share of the market," This resulted in a system of diversified activities which integrates them with numerous global financial strategies,

There are also other transportation companies involved in international tourism including sea cruises, railways and car rental companies which further limits the IDC's position, For example, the car rental sector (i,ẹ, occupied by international corporations) co-exist with small local firms. These TNCs have branches in many countries and are expanding via the interconnection of their networks with those of airlines, hotel chains and travel agencies,

As Ascher (1985:32) elaborated:

One of the problems that rental activities pose for developing countries, apart from the unavoidable imports of automobiles, lies in the growing difficulties of controlling the operations of the major international rental networks. By centralizing payments in issuing countries, the special credit card system these networks have developed leaves little room for foreign exchange commission and facilitates uncontrolled transfers of funds:

\section{Tour Operators}

Tour operators are essentially wholesalers who put together the separate elements that normally make up a tour or a travel package, such as transportation, ground arrangements and accommodations: They are, therefore, in a position to influence the destination and the type and price of services provided to both holiday and business tourists.

The role of the international tour operators in the development of mass market aviation tourism has been significant, As reported by the WTO (1985), they were able to charter planes and guarantee more than 90 percent of capacity by the late 1970s: 
The entry price into different markets is arranged by tour operators regardless of the destination's concession on the package; If the potential market is geographically concentrated, and mass market tourism to a relatively small number of destinations prevails, the entry price could normally be expected to be high. This is because this type of tourism is highly price elastic, so that wholesalers will attempt to reduce the price of an inclusive tour through extensive use of charter flights and block bookings at hotels--the strategy of marketing applied by the British tour operators to Bodrum in 1988, Nonetheless, the competition among the tour operators to book certain destinations can result in low prices for the tourists, but generally at the expense of developing countries (destination), which have been forced to accept relatively low hotel rates (Ascher, 1985), Another feature of the international tour operating sector is its almost total domination by wholesalers in the tourist-generating countries rather than wholesalers in the tourist-receiving country, even though part of the tour package may be put together by or in conjunction with the latter lor travel agents). This can be explained by certain competitive advantages that are enjoyed by tour operators in tourist-generating countries, most of which advantages can be traced to the following: 1) knowledge of the tastes and needs of customers; 2) economies of scale in serving many markets; and 3) connections with airlines and hotel chains domiciled in the same countries (UN, 1982),

At present most tourist-receiving countries are dependent on foreign tour operators for their tourist supply and the arrangements for getting the tourists to their destination (Zamit, 1981), And, although 
tour operators are not direct investors in the host economy, they exercise considerable influence over the tourist sector. The mechanisms and impacts of tour operators upon the host country also can vary depending on what type of tourism is being developed, some tour operators are small, specialized firms, serving a public that has little knowledge of alternative tourist destinations! Other, large tour operators are concerned with mass tourism to places that have usually already begun to establish a reputation as attractive tourist resorts Each of these two types of tour operators has different links with the host country. The small operators dealing with "travelers" or those seeking more distant, exotic locations tend to establish links with local, host country tour operators, relying on the latter's knowledge of the local environment, on the other hand, large tour operators who deal in mass tourism are much more likely to bypass the local operators and establish "arm's length" contracts with hotels in the recipient country--contracts often of two to five years' curation or leases for 15 to 25 years (Zamit, 1981):

\section{Impacts of TNCS}

The TNCs' involvement has been criticized on various grounds, namely their proprietary knowledge and expertise, which result in LDCs' dependence on them; or some believe international hotel chains usurp the sovereignty of LDCs by not integrating their operations with national plans (Edwards and Cleverdon, 1982). This involvement has been pursued via inappropriate technology and excessive reliance on imports, For example, while the import of food and hotel furniture is likely to be 
compatible with the standardization policy of foreign ventures in the tourism sector, it does not have any benefit for the local economy: Another concern among destination countries has been that a foreignowned hotel allows limited opportunity for local employees to reach positions of responsibility (Christie Mill and Morrison, 1985)! Regarding tour operators, who have also been viewed with suspicion, Christie Mill and Morrison (1985:239) elaborated:

Tour operators can wield a great deal of influence over destination, Operators have the ability to direct large numbers of tourists to particular destinations If a country has made a decision to develop tourism to the masses, and if it has consequently built the infrastructure and facilities to service these tourists, it must attract sufficient numbers of visitors to utilize and pay for the facilities. This type of country can become dependent on large tour operators who have the ability to sharply influence where the masses will vacation.

It is not surprising that Pearce cited Spain's policy of "charter inclusive tours," which diverted most of the profit to the operators in the market countries and left relatively little spin-off profit for the tourist industry in the host country (1987:199):

In the case of hotels, domestic enterprises are often more flexible in their operations than the centrally controlled TNCs; therefore, they are potentially more capable of adapting to local conditions! This may result in lower operating costs, greater diversity in the range of services offered by the hotel $\left(e_{9} g_{!}\right.$, in restaurants and/or menus), and greater ability to comply with the economic, social and cultural objectives of the economy, for example, by procuring inputs from local subcontractors, designing the hotel in order to maximize the use of local materials and reflect indigenous architecture, employing 
indigenous management, etc., thereby minimizing the transfer of earnings abroad, Nonetheless, the problem between IDCs and TNCs, which was expressed by the UN (1982:64) in the following terms, will likely create further controversies pertaining to tourism development

There is a strong indication that developing countries often lack full information on the policy alternatives open to them as regards the appropriate form of involvement of transnationals in the light of the policy objectives of the country concerned. Inappropriate involvement by transnationals is probably a major cause of dissatisfaction with their effects, often combined with inadequately formulated policies regarding the size and composition of the tourism sector itself. Improved access to information on the formulation of technical assistance and management contracts could be of value:

The dependence of developing countries on foreign tour operators derives fundamentally from the expertise of these operators as producers and wholesalers of tourism-related services; their krowledge of market, particularly the international market; and their access (in European countries invariably through vertical integration, to the relevant complementary services whereby the total package of tourism-related services can be provided,

International tourism has been integrated into a type of market that has caused a dependent relationship between LDCs and tour operators! It is frequently argued that designing a mass tourism package requires an expert knowledge of the preferences of the market: This is a market which is internal to the transnational tour operators and for which there is no external market. In other words, the knowledge cannot be purchased separately from the other services offered by the tour operators. Governments of LDCs, however, complain that foreign tour operators overlook the existence of their national tourist 
promotion offices and tourist departments, As a result, tour programs are limited in the range of attractions and facilities that they feature, thereby reducing potential sale, Moreover, tour programs may be aimed at attracting a type of tourist not envisaged in the LDC's plans (UN, 1982):

Tourist-receiving countries have voiced concern about the activities of foreign tour operators in three major areas: 1) the bargaining power of tour operators vis-a-vis the local hotels; 2) the dependence of recipient countries on foreign tour operators for their supply of tourists; and 3 ) the fact that what may be profitable to the tour operators in their global strategies may not necessarily be to the best advantage of the host country! This is a common complaint that also applies to TNCs in the manufacturing and resource-based sectors (UN, 1982:77)

Another important issue is that, since the tour operators can use their marketing power to encourage tourists to choose particular destinations and accommodations, they may very well exacerbate the problem of seasonality, which poses a particular problem for tourism in the Mediterranean! Seasonality creates the social and economic costs of under-utilized capacity of hotel, tourist-related industries and services, and seasonal unemployment;

Finally, the structure of peripheral economies in contrast with international tourism system can place any tourist destination into a marginal market position. As Britton (1983:6) elaborated:

A country's tourist product may easily be substituted by both tourists and metropolitan based tourism corporations for an alternative destination. With foreign companies 
largely responsible for advertising, the provision of international transport, the wholesaling of globally spread tours and the provision of international hotel chains, a destination will not have sufficient counter-balancing control over traveler flows to its own tourist plant. The generalization can be made that the structure of the tourist industry ensures that Third World destinations have a largely passive and dependent role in the international system.

However, the following efforts have been recommended to overcome

those strategic advantages of TNCs in international tourism Developing

countries as Ascher (1985:84) advised, need to:

(a) avoid bearing the brunt of the investments (infrastructure, hotels, air transport); (b) secure transfers of strategic "technologies" [management systems and marketing networks] and devise appropriate technologies (a form of tourism that is less expensive in terms of investment and imports, is geared to the countries resources and preserves the national heritage); (c) limit the risks (ineralia, by sharing them with the TNCs, particularly in the hotel and tour-operating sectors), and (d) reduce their dependency and particular country or transnational corporation by evolving a varied and original tourist product, diversifying marketing methods and improving their bargaining position through joint action. 


\section{CHAPTER II}

POLITICAL ECONOMY OF TURKEY'S DEVELOPMENT:

POST-WAR PERIOD

Turkey's unique geographical location has engendered considerable socioeconomic as well as political influences upon her history of development: As the only Middle East state adjoining Europe, contemporary Turkey is also the only Muslim state that openly pursues Europeanization! For example, Turkey uses the European (Roman) alphabet and belongs to the North Atlantic Treaty Organization (NATO) : In the 1980s it was actively seeking full membership in the European common market

The Republic of Turkey encompasses an area of 300,948 miles/779,452 $\mathrm{Km}^{2}$. The population census reported in 1987 was $52,845,000$ (Turk 85.78; Kurd 10.68; Arab 1.68; other 2.18); In 1985 Turkey's GNP reached $\$ 56,06$ billion with per capita GNP of $\$ 1,110$ (also see Figure 4). Turkey's main exports (percentage of total value) include: textiles 17.9, agricultural products 14,7, livestock and animal products 5.1 , chemical products 3.5, The main imports (percentage of total value) are: machinery $14: 1$, fuels 13,3 , chemicals 9.5, iron and steel 6.8 (Held, 1989)! It is significant to note that the inter-war period (1930s) was identified by the birth of "etatism" and "central planning" funded by Ataturk: Ataturk defined etatism as a 


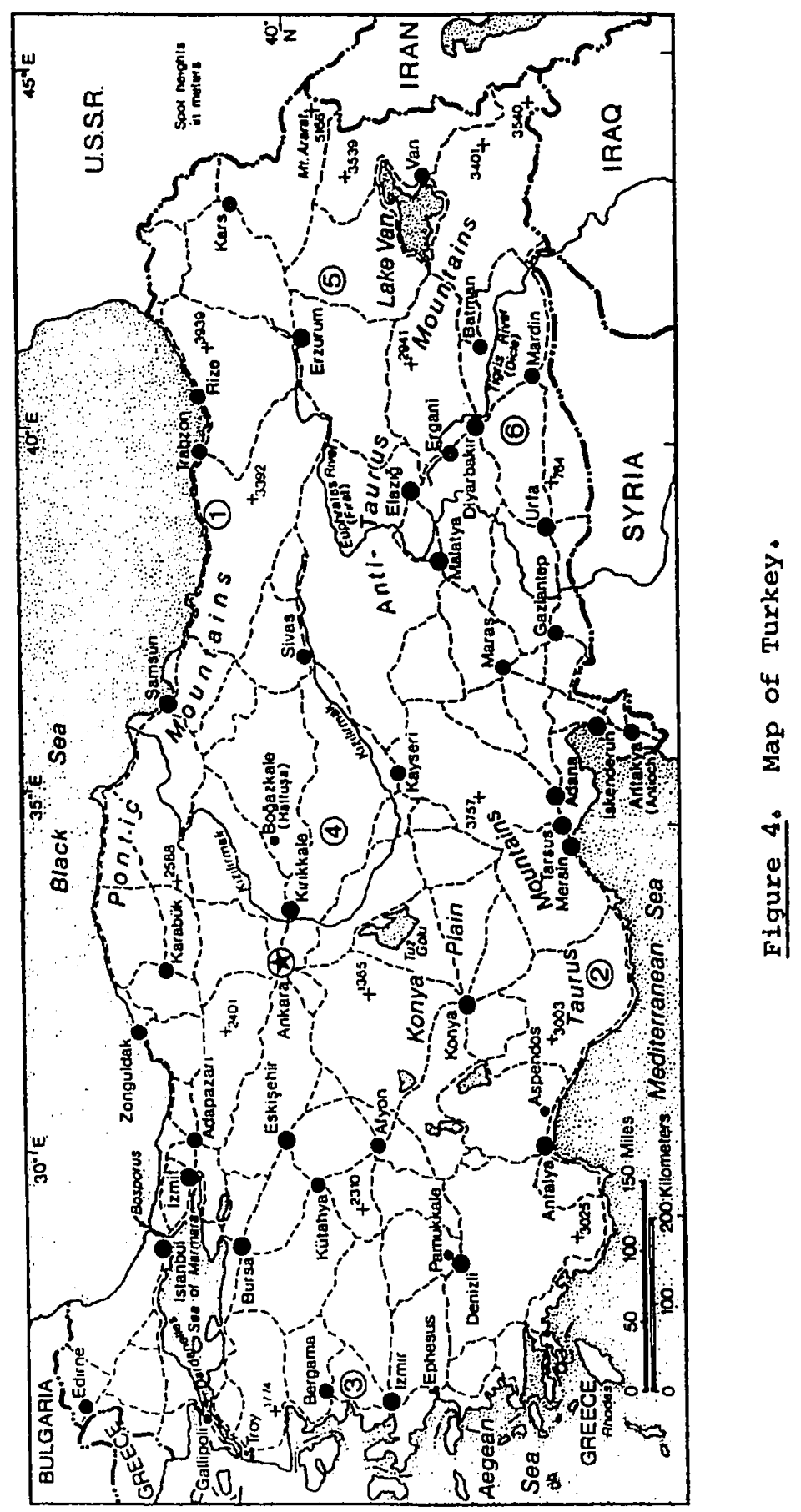


system peculiar to Turkey which has evolved from the principle of the private activity of the individual, but places on the state the responsibility for the national economy, with consideration of the needs of a great nation and a large economy:... He also added that, since things have to be done quickly, it must be a "system different from liberalism (Hershlag, 1988:5):

The period between 1939 and 1950 (iłe!, the war years) became a pivotal point in Turkey's development process: Three major events occurred during this period, first, severe economic dislocation; second, new class alliances; and third, the establishment of a multiparty system (UN, 1979; Ramazanoglu, 1985). Even though Turkey did not take part in the war, the war affected the economic condition and resulted in the implementation of so-called war years policies! The war impacted most severely on the agricultural sector and the different strata of the peasantry! As Pamuk $(1987: 19)$ referred to the situation, The pressure of an emergency situation, however, has a much more severe impact on the agrarian structures in an underdeveloped economy, often leading to decrease in the levels of production.

The government's policy of supplying food to the urban population and the military, first caused severe economic problems for the peasantry (Yerasimos, 1987): During the war years the agricultural production index declined from a base of 100 in 1939 to 70.4 in 1944, while inflation rose from 100 percent in 1939 to 404,6 percent in 1945. The wage index dropped by 31 points, from 100 to 69 , during the same period, and that of per capita GNP declined from 100 to 78 (Yerasimos, 1987:9091; Pamuk, 1988:22):

The war years' policies had a catastrophic effect on Turkey both socially and economically: These policies' adverse effects materialized 
in three ways: First, there was a shortage of labor in the rural areas due to the draft policy of the government which maintained an army of one million while the total population was around 18 million. Most of this burden fell on the rural areas where close to 80 percent of the population lived, second, there was the decline in the amount of acreage under cultivation due to the draft of animals for military purposes! Finally, the government's policy of in-kind taxation and forced purchases from producers at below market price caused farmers to either reduce their acreage or shift to other crops. This condition resulted in the further underdevelopment and polarization between the peasantry and the landed "esraf" (Pamuk, 1988): Moreover the situation was aggravated by failure of policies to deal with land reform and rural issues: In Aydin's (1987:81) terms, "Despite the proliferation of new explanations, the problem is far from being resolved."

Currently, while agricultural credits, post-war mechanization, and commercialization have impacted on the means of agricultural production, the basic rural issues that developed during the war years have not been dealt with, The static situation of the rural system, referred to as the Asiatic Modes of Production (AMP), was not replaced with a dynamic mode of production and an extreme backwardness of agricultural production still exists in the southeastern and eastern regions at the present time: In addition, the post-war development--urbanization/ industrialization--did not reduce the conflict, but rather has shifted the bulk of the population from rural to urban areas thereby creating new conflicts, This in one sense resulted in peasantization of urban 
areas ( $i \_e_{0}$, the proliferation of shanty towns and slums known as "Gecekondus") :

\section{MULTIPARTY RULE}

On May 14, 1950 an election was held and the Democratic Party's (DP) victory put an end to the People's Republican Party's (PRP), single-handed rule since 1923 (Erogul, 1987): A new era of liberal pluralist politics began, which placed Turkey within the new international division of labor: The repercussions of this era culminated in three military coups in 1960, 1971 and 1980. Of these military incursions the ones in 1960 and 1980 were the most serious in scope (Yesilada, 1987):

on the domestic environment, the new government bestowed a new power to the newly allied classes of merchant and agricultural capital These classes rejected Import Substitution as the blueprint for Turkey's economic development and instead favored a liberalized market condition (Ramazanoglu, 1985; Erogul, 1987): Fxternally, the government's most urgent goal was to prevent Soviet domination of the Balkans! Turkey felt threatened, and the only solution was to unconditionally join the West. This move was also conducive to the general policies of Westernization inherited from the etatist era (Erogul, 1987; Ozbudun, 1981).

TURKEY'S NEW ROLE

In a pluralist atmosphere of limited value, the government embarked upon an open/liberal economic policy characteristic of the 
economies on the periphery favored by the metropol. This process would take form by Turkey's wholehearted alliance with the West, and in particularly with the US, who appeared as a hegemonic power after World War II. Turkey qualified for the European Recovery Program, known as the Marshal Plan, which was in some respects an extension of the Truman Doctrine and the precursor to the North Atlantic Treaty Organization (NATO) (Kofas, 1989)。

The political economy of Turkey's new role among the peripheries is more understandable when one analyzes the geopolitical circumstances during the post-war era. The Soviet Union was emerging as a superpower. The Maoist revolution in China, the tide of communist revolutions sweeping across Korea, and Vietnam, and the control of Eastern Europe by the Soviets led to a growing sense of economic instability: Such world developments impacted negatively on American economy, whose continuous expansion depended on securing markets and raw materials overseas.

In an environment such as this, the application of the Marshal Plan to Turkey in 1947 qualified her to become a part of the "free world," eligible for grants and aids in exchange for military dependence and economic liberalization.

To place this issue into a broader perspective, Table IV provides a lucid comparison of the defense allocations of six NATO countries in fiscal year 1952-53. Table IV shows the percentage of the budget allotted by each country; on the ideological ground DP's Foreign policy was instrumental in furthering the socioeconomic ties with the West which eventually engulfed Turkey in crisis after crisis. As Erogul (1987:110) elaborated: 
TABLE IV

MIIITARY BUDGET ALLOTTED BY EACH COUNTRY

\begin{tabular}{lr}
\hline Country & Percentage \\
\hline Turkey & 338 \\
Greece & 42 \\
Italy & 23 \\
France & 32 \\
Holland & 27 \\
Belgium & 23 \\
& \\
\hline
\end{tabular}

Source: Kofas, 1989:116.

Against Jawaharlal Nehru's defense of nonalliance, the Turkish delegate Fatin Rustu zorlu articulated the interests of the West. In short Turkey not only confronted the Soviet union and its allies in order to curry favor with the West, but also took a stance against Third world countries trying to remain outside the competition between the superpowers: Turning its back on the legacy of Mustafa Kamal, a leader in the struggles for national independence, the DP administration led a persistently pro-West policy not only in anticommunism but even colonialism.

During its first period in power, the DP distanced itself from political liberalism while trying its best to achieve economic liberalism, The repercussions of its political ideology on the domestic landscape materialized into a repressive move in May of 1951" This came in the form of strengthening the already repressive articles of the Panel code, which dealt a heavy blow to freedom of the press! This decree gave the government the authority to distribute official notices, thus creating the possibility of withholding them from critical publications and financially smothering them (Erogul, 1987)! Consequently, the political policies of the DP resulted in forthright 
repression, pushing Turkey toward an increasingly unadulterated form of dictatorship (Erogul, 1987),

\section{POLICIES AND PROBLEMS}

DP's economic policy encompassed three phases. The first, from the election until 1954, was a period during which emphasis was placed upon increasing agricultural production, The second, from the massive crop failure of 1954 until August 1958, was characterized by domestic and foreign economic difficulties and economic policy consisted largely of ad hoc measures to counter them (Krueger, 1974). The third phase, finally paved a process for international influence crystallized in application of IMF's austerity package which would embark the Turkish economy on a transformation into an export-oriented (outward-looking) system; As a result this has set out the de facto devaluation process under the monetary policies and stabilization programs:

The DP came to power with an ideology that reconciled the commercial sector and the large landowners, Moreover, the DP made extraordinary efforts to open Turkey to foreign capital. While the government was responding on a case-by-case basis to its economic conditions, there were not any consciously formulated and enunciated policy shifts (Krueger, 1974). Meanwhile, the US aid in various forms was pouring in. The process of Turkey's integration into the world economic system was well underway. Hershlag (1988:12) noted, !.the 1950s brought a clear departure from etatism and central planning. This period was characterized by an encouraging of the influx of foreign capital and foreign interests, invoking too heavy commitments and danger of insolvency, 
Consequently, Turkey became a target for uS foreign policy in the immediate post-war period, which aimed to establish a pro-American regime based on open liberal economics, The class interest of DP in alliance with the US policy began a process of dismantling the national economy built under the Kamalist regime during the 1930s, As Berberoglu (1982:81) indicated,

In the early 1950s, the IBRD (or World Bank) placed two major conditions which had to be met if Turkey expected to draw any funds from the bank: (1) State investments in industry had to be substantially reduced, and (2) Turkey should seek to finance its development largely through external sources ( $i+e_{4}$, through foreign loans and private foreign investments): The Bank also counseled Turkey to expand agricultural productionstsand not make any investments in heavy industry:

These measures were taken in the form of price restructuring to favor agricultural products

Internationally, the pressures upon the Turkish state arose from the US foreign policy which carried specific instructions extolling the virtues of a market-based world division of labor. Turkey's part in such a market was to be a supplier of agriculture commodities, particularly cereals, which were to initially feed Europe in the postwar reconstruction, and more generally to develop as a market for manufactured exports from the West (Margulies and Yildizoglu, 1987; Keyder, 1987):

This policy had other purposes as well, namely to increase rural development, and thereby to prevent extreme impoverishment which might lead to political upheavals in rural area! This had also been a concern of international agencies like the IBRD, USAID, ILO, International Fund 
for Agricultural Development (Aydin, 1987): Aydin further elaborated

that

\begin{abstract}
4.this is one of the reasons that these agencies have been pumping capital into the rural areas in the Third world. The aim of keeping political stability in the rural areas of underdeveloped countries does not necessarily contradict economic interests. In the short run investments made for political considerations might look uneconomical, but in the long run, since it enables the interest of dominant classes to be consolidated, it is not irrational (1987:101):
\end{abstract}

Therefore, the agricultural policies favored domestic interest groups (landed classes) to call for a liberal foreign trade regime based on agricultural production and exports! One should bear in mind that the discontent of large landowners with the urban-based industrialization policies of the etatist period, and the land reform bill of the 1930 s which repressed the small and middle peasants, were a contributing factor in the victory of the DP, As Pamuk (1988:33) noted,

The examination of the government policies during the war years suggests that the vote of the peasantry was, at least in part, a vote of protest against the wartime policies of the single party regime.

\title{
COMMERCIAIIZATION AND MECHANIZATION
}

OF AGRICULTURE

Internally, the class structure of Turkey necessitated the resumption of her pre-depression role within the new post-war international division of labor: Turkey willingly accepted the role of food supplier to the Hest (Aydin, 1986) Externally, the US and international institutions directed and encouraged the new agricultural policies: As Aydin (1986:40) pictured: 
Thornburg's 1950 report is an example of American intervention in Turkish policy making: In this report, entitled "A Criticism of Today's Economic Situation in Turkey," Thornburg noted that Turkey was an agricultural country and should be content with simple agricultural equipment and that Turkey did not need artificial fertiliser, so that the establishment of a fertiliser factory would be unnecessary. The Karabuk Iron and Steel plant should be liquidated, and the government should take measures to encourage foreign capital to invest in Turkey:

Such policy advocacy and imposition was not meant to be a long-term development strategy, but rather it was a short-lived policy necessitated by the international interests of the post-war period, Commercialization of agriculture facilitated by mechanization which became possible due to the us aid, culminated in mass purchase of tractors from abroad which accounted for about 75 percent of all investment in machinery in the 1950s, Aydin (1986:41) reports, "The number of tractors also rose, from 1,750 in 1948 to 16,585 in 1950 , 37,743 in 1954 and 40,000 in 1955:" This, along with provision of cheap credit to the landowners, intensified the area under cultivation which, between 1950 and 1960, increased from 9,868,000 hectares to 15,305,000 hectares: In the same period agricultural credits rose from iL 780 million in 1950 to TL 2,602 million in 1955 (Aydin, 1986:41), The impressive development of agriculture throughout the post-war period presents, at first sight, a deceptive picture of continuity: The more or less steady rise in most variables tends to conceal important shifts midway through the period, both in the role of agriculture within the economy as a whole, and in the place of Turkey within the international division of labor (Margulies and Yildizoglu, 1987) With the end of the Korean War, the US and Canada had begun to market their 
grain. As a result, the decreasing exports and increasing imports created a foreign currency problem which signaled the end of import liberalization, However, the 1950 s were a period of expansion of world capitalism as well. Foreign capital came to Turkey to invest, in cooperation with Turkish capital, in the manufacture of luxury consumption goods! The highly profitable and protected domestic market contributed to the development of an assembly industry in Turkey: International organizations like the IMF, OECD, and IBRD gave their approval and support to Turkey's import substitution industrialization during the 1960s which was aimed at the internal market (Aydin, 1986; Berberoglu, 1982):

Post-war development strategies facilitated the addition of multinationals and foreign capital to Turkey's social, political and economic structure: These events placed hex on the road to "Dependent Development (Berberoglu, 1982): This formation became possible by a triple alliance of the state, local capitalists, and multinationals, which produced various long-term national crises (Aydin, 1982):

RURAL-URBAN MIGRATION

Rural-urban migration has transformed Turkey's landscape by resulting in the phenomena of "Gecekondus," or squatter settlements creating one of the gravest problems in the recent history of Turkey: As Karpat (1976:56) elaborated:

Partly in order to increase the agricultural production and partly to comply with the demands of the upper agrarian groups, the incoming Democratic Party government of Adnan Menderes engaged in a massive mechanization of agriculture. About one million farmers were dislocated by some 40,000 
tractors introduced in this perioda coupled with the adjustment of the village economy to regional and national markets resulted in cost accounting, efficiency, and increase in production. This development eliminated the marginal farms and left no justification for surplus manpower to stay in the village.

Table $\mathrm{V}$ demonstrates the Gecekondu population in 13 Turkish cities: Rural-urban migration has become a process of structural anomalies not only in Turkey but also in most of the Third World countries. The "fast depeasantization" and urbanization without a corresponding increase in industrialization can lead to many problems, including eroding labor conditions and decreased wages, While the "push" factors of migration--economic hardship, poverty in the village, and the lack of land not only reveals the policy consequences of pseudourbanization, they also enforce the creation of an "informal econony" (Portes et al , 1989). The whole process can reduce or eliminate incentive for technological progress, innovation, and investment (Ybarra, 1989:224-5) * These processes are not random but reflect the character of the specific social and economic order in which they occur: As portes et al: (1989:298) addressed, The changing geometry of the formal-informal relationship follows the contours delineated by economic history as well as the character of state authority and its interaction with private interest [and multinationals]. The development of the unregulated sector depends very much on the form adopted by the regulated one, for each, mirrorlike, reflects the other, or, to suggest an alternative analogy, both fit as parts of the same puzzle:

The processes of rural-urban migration, the radical transformation of the agrarian system, transition from a pre-capitalist economic system to capitalist development, and nonindustrialization can be explained and 
TABLE V

GECEKONDU POPULATION IN 13 TURKISH CITIES

\begin{tabular}{lrrrr}
\hline & $\begin{array}{c}\text { Number of } \\
\text { Gecekondu } \\
\text { (units) }\end{array}$ & $\begin{array}{c}\text { Total } \\
\text { Gecekondu } \\
\text { (population) }\end{array}$ & $\begin{array}{c}\text { Total City } \\
\text { Population }\end{array}$ & $\begin{array}{r}\text { Percentage of } \\
\text { City Population }\end{array}$ \\
\hline & & & & \\
Adana & 18,925 & 104,088 & 231,548 & 44,95 \\
Ankara & 70,000 & 385,000 & 650,067 & 59,22 \\
Antakya & 2,635 & 14,493 & 45,674 & 31,73 \\
Bursa & 8,713 & 47,493 & 153,886 & 31,14 \\
Diyarbakir & 1,400 & 7,700 & 79,888 & 9,64 \\
Erzincan & 3,500 & 19,250 & 36,420 & 52,86 \\
Erzurum & 5,750 & 31,625 & 90,069 & 35,11 \\
Iskenderun & 4,275 & 23,513 & 62,061 & 37,89 \\
Istanbul & 120,000 & 660,000 & $1,466,535$ & 45,00 \\
Izmir & 18,025 & 99,138 & 296,635 & 33,42 \\
Mersin & 896 & 4,928 & 68,485 & 7,19 \\
Samsun & 5,700 & 31,350 & 87,688 & 35,75 \\
Zonguldak & 14,000 & 77,000 & 54,010 & \\
& & & & \\
\hline
\end{tabular}

Source: Karpat, 1976:59,

investigated by either dependency or modernization theories there are both specific and universal definitions and characteristics for the phenomenon of "migration," especially labor migration! In Turkey's case the policies of the state in its quest for development within the context of uneven capitalist development has played a detrimental role by not addressing or considering what Ramazanoglu (1985:162) pointed out: "a major disruption in the way in which agricultural production is organized and related to the economy as a whole! That is, changes occur in who produces what for whom, and how," The result was the growth of Gecekondu as an alternative for villagers 
and to agrarian poverty: Hence the urban population jumps from 25 percent in 1950 to $43: 9$ percent in 1980 (Table VI) Failure of the urban economy to grow as fast as the labor force also resulted in substantial underemployment and unemployment in Turkish cities. The Ministry of Reconstruction and Settlement has estimated that the proportion of underemployment among the squatter dwellers in Ankara and Izmir ranged as high as 70 percent in the mid-1960s (Danielson and Keles, 1985):

\section{DEVELOPMENT IN CRISIS}

Agricultural policies, economic liberalization, and ISI fulfilled the market expectations for a short while; The agricultural boost became a classic case of "unbalanced growth" under "administrative and economistic" development ideology (Sachs, 1989) : Krueger (1974:30) noted that "from 1952 until 1958 the debt hung over the entire exchange regime and affected everything: even export data and export prices are incomprehensible, except in that light:" He noted that this condition was exacerbated by the lack of coordination in economic policy during the Menderes (DP Prime Minister) years! Thus by the end of the 1950s, the economy was devoid of both planning and laissez-faire; This strategic disorientation was reflected in the economic parameters of the country, with the second half of the 1950 s erasing many of the achievements of the first half (Hershlag, 1988:19).

By 1958 Turkish importers often were unable to buy foreign exchange from the central bank to pay their commercial debts. Krueger noted, "Turkey was the first country to overdraw her IMF quota, and the first to request an extension of time when payment came duen (1974:30) ? 
TABLE VI

URBAN AND RURAL POPULATION

\begin{tabular}{|c|c|c|c|c|c|}
\hline & \multicolumn{2}{|c|}{$\begin{array}{l}\text { Province and District } \\
\text { Centers }\end{array}$} & \multicolumn{2}{|c|}{$\begin{array}{c}\text { Sub-districts and } \\
\text { Villages }\end{array}$} & \multirow[b]{2}{*}{ Total } \\
\hline & Population & 8 & Population & 8 & \\
\hline 1950 & $5,244,337$ & 25.0 & $15,702,851$ & $75 ٪ 0$ & $20,947,188$ \\
\hline 1955 & $6,927,343$ & $28 \div 8$ & $17,137,420$ & $71: 2$ & $24,064,793$ \\
\hline 1960 & $8,859,731$ & $31 \cdot 9$ & $18,895,089$ & 68,1 & $27,754,820$ \\
\hline 1965 & $10,805,817$ & 34.4 & $20,585,604$ & 65.6 & $31,391,421$ \\
\hline 1970 & $13,391,101$ & 38.5 & $21,914,075$ & $61 ! 5$ & $35,605,176$ \\
\hline 1975 & $16,869,068$ & 41.8 & $23,478,651$ & $58 \div 2$ & $40,347,719$ \\
\hline 1980 & $10,645,007$ & 43.9 & $25,091,950$ & 56,1 & $44,736,957$ \\
\hline
\end{tabular}

Source: Keyder, 1987:297:

Source of data: Devlet Istatistik Enstitusu, Istatistic Yilligi (various years).

Meanwhile, the total foreign debt rose to $\$ 1,5$ billion by 1957 ; In early 1958, total indebtedness exceeded 10 percent of the GNR, while arrears alone accounted for over two percent of the Give and almost equaled exports (Krueger, 1974:31): Schick and Tonak (1987:342) noted, "By the summer, foreign exchange reserves were nonexistent and import licensing was suspended,.. Foreign aid was reduced to a trickle, as all sources tied their aid to the approval of the IMF:" Finally, OECD also decided to suspend all aid unless the Turkish authorities agreed to a package of drastic stabilization measures required by the IMF.

The total consolidated debt amounted to $\$ 422$ million; payments were to start with $\$ 14$ million in 1959 , and rise by $\$ 5$ million each year until 1963; the balance would be paid in equal installments until 1970 (Schick and Tonak, 1987). 
Meanwhile the hyperurbanization was taking its toll " During the first 15 years of explosive growth, more than 90 percent of all migration was to cities with 100,000 or more inhabitants, The most dynamic cities were the three largest, Together, Istanbul, Ankara and Izmir added over one million residents during the 1950s, with Ankara more than doubling over the decade (Danielson and Keles, 1985) Interestingly enough, most of the spatial growth of the main cities was taking place in the form of their squatter housing (Gecekondu) : Gecekondu also reflected the growing, politically oriented and class-conscious force which began to have a long-term impact on the political economy of Turkey in upcoming years. Thus a rise in informal economic activity began to appear on the urban landscape in the form of child scavengers, an indication of a radical breakdown in agrarian structures which left many women unable to feed their children (Ramazanoglu, C., 1985)! In the 1950s there was also a spurt in the growth of the ever-increasing working class, from 643,000 industrial workers in 1951 to 975,509 in 1960 (a 528 increase over the ten-year period) (Berberoglu, 1982) A new militancy of industrial workers was on the rise--a familiar consequence of dependent development (Lim, 1985; Berberoglu, 1982). While the number of workers as a whole increased by 113 percent between 1948 and 1958, the increase in the number of unionized workers during the same period was 405 percent, Accordingly, noted Berberoglu (1982:74), "The percentage of unionized workers in Turkey increased from 15.8 percent in 1948 to $37: 4$ percent in 1958 " Finally, with the general stagnation of the economy, the enormous military expenditure, the burden of debt, the continuous trade deficit, 
and the resultant balance of payments crisis, as well as, the forced adoption of "austerity measures" the country entered into a state of political and economic crisis! The years from 1959 to 1961 witnessed very slow growth, with the average annual increase of the real GNP barely reaching two percent, less than the rate of population growth. Eventually, a bloodless military takeover brought down the government on May 27, 1960,

NEW POLICIES AND PROSPECTS:

1960S AND 1970S

The coup of May 27, 1960 reaffirmed a new phase in the process of Turkey's development, First, the new constitution was written which democratized Turkish politics, which soon came to be described by the right as a luxury for Turkey (Ahmad, 1981): Second, for the Army, the coup of 1960 marked a beginning of the process of its establishment in the political environment, which reaffirmed itself in three interventions (directly in 1960 and 1980, and indirectly in 1971) as a privileged entity (Vaner, 1987),

Nonetheless, 1960 became identified as the year which necessitated the regulation of the process of accumulation by the state, a task which the DP administration severely politicized in its last years, but was not capable of fulfilling (Walstedt, 1980; Keyder, 1987) From these perspectives the 1960 coup is considered to be restorationist rather than transformatory! As Hershlag (1988:21) noted, The strategies of the 1960 s and partly also those of the 1970s restored the fundamental concept of planning of the 1930s, Still based mainly on the industrialization drive 
and inward-oriented $[i, e$, , import-substitution industrialization], supported by a high degree of protectionism.

Therefore, the restrationist nature spurred the formation of the SPO and the promulgation of a series of post-war Five-Year Development Plans (FYDPs)! As Milor (1990:2) noted,

Indeed, the founders of the Turkish Planning Agency, the State Planning Organization (SPO), were driven by the desire to initiate major structural reforms not only in order to free the markets from the stranglehold of merchant and agrarian interests, but also to bypass the markets, when these fail to concentrate scarce capital resources in high value-added and capital fields.

Meanwhile, the ratified constitution of May 1961 accomodated the various demands of the masses including the right to collective bargaining and the right to strike, the right to form new political parties, press freedoms, university autonomy and freedom of speech and assembly (Berberoglu, 1982) The inception of the Turkish New Deal targeted two new clients, industrialists and organized labor (Keyder, 1986). Keyder elaborated that there was a difference between Turkey's case (a peripheral country) in comparison to the similar transformations in the advanced nations, First, the close dependence of the policy alternative on the particular context of inter-state relation, and second, the relatively small weight of the two client groups: ISI, which applied to Turkey's political economy, was borne within the developmentalist perspective under the "structuralist" approach to industrialization in developing countries during the 1950 s and 1960s: It is characterized by the following notions:

* A belief that development is a process of major structural transformation with industry, and manufacturing in 
particular having a major role (i,e , Turkey's role from being an agricultural production unit changed to an industrial one);

* A skepticism regarding the role of the price mechanism as a means of allocating resources in developing countries, due primarily to the assumed low price elasticity of both supply and demand;

* Following from this a belief in the importance of government planning ( $i e_{4}$, establishment of the SPO in Turkey) controls of various types as a means of allocating resources and achieving the structural shifts necessary for development; and

* An emphasis on the need to change the pattern of trade, and in particular to reduce the importance of primary exports (Weiss, 1988)

It has been obvious that the liberalized economy and dependence on the agricultural sector was not solving the difficulties of balance of payments and the debt crisis; Therefore, adoption of policy of planning, coordination, and import substitution brought relative success in various areas! Industrial output increased at an average rate of 10 percent per year; construction registered approximately seven percent annual growth: During this period industrial employment grew at an average annual rate of four percent, far from the rapid pace of urbanization:

Nevertheless, in accordance with the rise in the importance of the internal market, the private sector moved into the industrial sector, 
while the state sector was concentrated in the production of intermediate commodities as inputs for the private sector (Aydin, 1986; Gulalp, 1983): International organizations such as IMF, OECD and IBRD approved and supported the ISI during the 1960s (Dogan, 1980): In addition, the new policy of ISI also aimed to boost the domestic manufacturing sector: In this case, a policy was formulated to protect the domestic manufacturing from international competition: in this regard Keyder $(1987 \mathrm{~b}: 151)$ elaborated that

the formula of Import Substitution Industrialization (ISI) is an appropriate label for this economic regulation aimed at altering the location of the economy in the world division of labor: The defining feature of ISI is precisely the protection of domestic industry, which develops to produce the very manufacturers hitherto imported.

Aydin (1986:43) explained

that the import substitution industry, from the 1930s to 1950 s concentrated on consumption goods like textile and food processing, while the trend from the late 1950s onwards has been one of concentration on durable consumer goods like cars, refrigerators, etc.

However ISI, while encouraging market protection from international competition, did not exclude foreign capital from penetration whether it was via foreign borrowing or in the forms of transfer of technology, intermediate goods and investments goods:

This period of ISI in Turkey produced certain political actions which were manifest in the form of an alliance between periphery and the center. Accordingly, one can make an analcgy between these circumstances and certain strategies that characterize Third world societies in terms of their relation to center. Therefore, the strategy that Turkey can be identified with is one of alignment of local ruling 
class with international capital to increase the extraction of surplus through unequal exchange and direct appropriation from production (Armstrong and McGee, 1985): Given the post-war structural transformation of advanced industrial countries, it is likely that the ISI strategy was conducive to international capital's pursuing a worldwide strategy (Keyder, 1987b)

\section{Policy Implications}

Turkey's economy under the ISI recorded an industrial growth of 78 percent for the domestic market during the 1960s--one of the highest among the newly industrialized countries (NIC) in the world, But such development benefited primarily the large monopolies and holding companies, while smaller firms either couldn't survive or grew at a much slower rate than before,

The state also became an important player in this period of accumulation process! As Keyder noted (1987b:299):

Not only did the state emerge as the natural transmission belt between the international and the domestic economies, but the bureaucrats were also called upon to organize and administer an internal economic policy consistent with the requirements of the new industrialization model.

Therefore, planning through the establishment of the SPO was introduced to work within the framework of a dependent capitalist economy rather than against it (Berberoglu, 1982; Aydin, 1986; Dogan, 1980) ? Nonetheless, the five-year plans of the 1960 s and 1970 s were aimed at the integration of all sectors of the economy as well as that of industrialization and self-suffiency: The developmental philosophy/ ideology that was emphasized on quantitative growth was the notion of 
the "trickling-down" theory (Hershlag, 1988): In addition, the SPO became a mechanism for state alliance with major economic classes of the society (Keyder, 1986b): As Krueger (1974:120) realized,

development plans became central to government economic policy in the 1960s, Through the plans and their implementation, the foreign trade regime was much more closely related to other economic policies than it had been in the 1950s.

The early foreign involvement in economic activities began when 80 percent of the rubber industry fell under the control of three foreign firms--Goodyear, Pirelli, and Royal Tire, In oil, despite the challenge posed by the state-owned Turkish Petroleum Corporation (TPAO), three oil companies--Mobil Oil, Shell, and British Petroleum--gained the monopoly rights, In other sectors of the economy, transnational conglomerates such as Unilever, Philips, Squibbs, Abbot and Pfizer made large profits during the 1960s and 1970s (Berberoglu, 1982):

Debt and Aid

An analysis of Turkey's political economy would not be complete without consideration of her role as a military power in the region. This aspect manifested in her membership in NATO as having the second largest army after the US within the organizationa Military aid to Turkey began during the Marshal Plan years of 1949-1952, when the US gave Turkey $\$ 500$ million to modernize its military, and Turkey allowed the US to build 26 military installations on its soil (Wenger, 1989): The high degree of aid dependence is a characteristic of dependent development. Turkey is ranked third, behind Israel and Egypt, among US military aid recipients worldwide! Table VII illustrates such dependent 


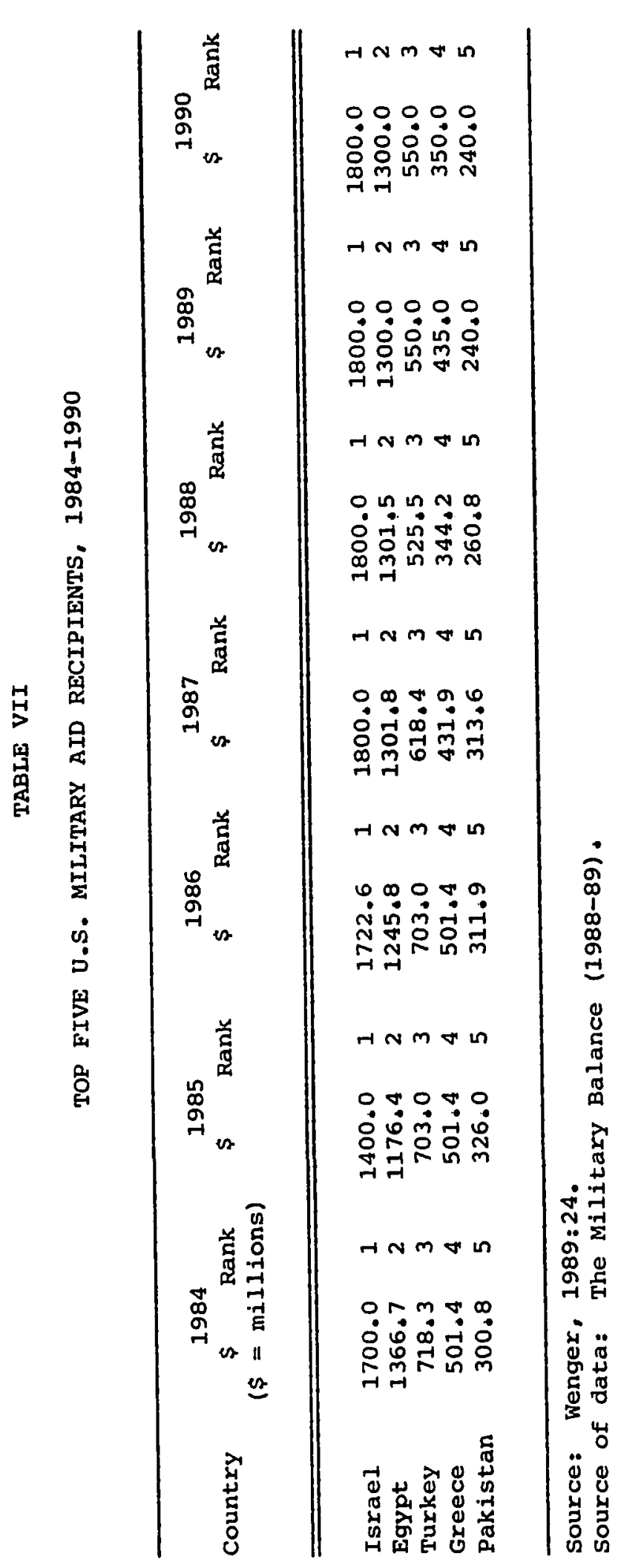


relations: Turkey's membership in NATO costs a defense expenditure of 22,4 percent of her total spending, This is in a country with GNP per capita of $\$ 1,110$ in comparison to 22,9 percent of the Federal Republic of Germany with $\$ 12,080$ GNP per capita or 28,7 percent of defense spending in the US with GNP per capita of $\$ 17,500$ (Wenger, 1989:26) (see Table VIII): As forecasted by International Advisors, Inc., Turkey's military debt will amount to $\$ 446,3$ million by 1995 (see Table IX). However, in Turkey's case a unique courtship has been developed between the military and capital on the road to its political and economic as well as social evolution. This courtship of convenience, combined with Turkey's geopolitical importance, has been faithfully subservient to the international division of labor, whether it be in the form of import substitution or export promotion, which in both cases fits into the world system perspective. As Kemal (1984:13) eloquently described,

There is a predictable parallelism between the general policies adopted by the army and the various measures which certain segments of the capitalist class considered to be in their interest--"predictable" because both are opposed not only to the establishment of a socialist regime, but even to a significant degree of popular control over the state apparatus $4:$ Especially after the 1960 coup, measures were taken to integrate the army further into the developing capitalist structure. It has by now become almost a tradition to offer positions on the executive boards of corporations to high officers, especially generals :

Military aid remains as a strong link factor between Turkey and the US for the last five decades, A second link factor that binds Turkey to international capital is her debts to financial giants, What is their impact on the lives of common citizens is a research question, but the adverse impact can be traced through comparison of the salary of 
TABLE VIII

SHARING THE BURDEN

\begin{tabular}{lrr}
\hline & $\begin{array}{c}\text { Defense Expend. } \\
\text { as of Total } \\
\text { Spending }\end{array}$ & $\begin{array}{c}\text { GNP } \\
\text { per capita } \\
(1986)\end{array}$ \\
\hline \hline & & \\
1. USA & 28.7 & 17,500 \\
2. FRG & 22.9 & 12,080 \\
3. Turkey & 22.4 & 1,110 \\
4. Greece & 21.9 & 3,680 \\
5. UR & 11.2 & 8,920 \\
6. Spain & 11.2 & 4,840 \\
& & \\
\hline
\end{tabular}

Source: Wenger, $1989: 26$.

Source of data: International Institute for

Strategic studies. The Military Balance (1988-89), World Resources (1988-89).

TABLE IX

TURKEY'S MILITARY DEBT

\begin{tabular}{lrrr}
\hline & Principal & Interest \\
& & $\begin{array}{c}\text { Total } \\
(\$=\text { millions })\end{array}$ \\
\hline & & & \\
1989 & 97.8 & 162.2 & 260.0 \\
1990 & 137.1 & 235.5 & 372.6 \\
1992 & 181.3 & 273.2 & 454.5 \\
1993 & 156.1 & 268.2 & 424.3 \\
1994 & 117.5 & 246.4 & 363.9 \\
1995 & 200.0 & 248.7 & 448.7 \\
& 211.1 & 235.2 & 446.3 \\
\hline
\end{tabular}

Source: Wenger, 1989:25.

Source of data: International Advisors, Inc. 
a Turkish conscript to a US private which is less than a dollar a month for the former and $\$ 646$ for the latter. In terms of debt linkage Turkey's debt service as percent of exports of goods and services remained \$11,0 million as of 1978 (Lim, 1985; Kenna and Stork, 1989) However, the debt crisis of developing countries not only has not bypassed Turkey but rather Turkey has been the first major LDC debtor to face a payment crisis after 1973, This was exacerbated by the global oil crisis of 1973-4, As Hershlag (1988:22) reported, ", „.in 1974, while imports of oil increased quantitatively by only 30 percent, their cost rose by 350 percent." Indeed, Turkey's debt reschedulings prior to 1982 were the largest ever undertaken and accounted for nearly 70 percent of the total volume of debt renegotiated by all LDCs in the 1978-1980 period (Celasun and Rodrik, 1989:193). Table X indicates the debt and debt servicing which even after the rescheduling, amortization plus interest totaled almost a third of export earnings during 19671970, New loans were thus increasingly used to finance the repayment of old debts, illustrating the heavy burden borne by Turkey (Schick and Tonak, 1987): As Krueger (1974:132) noted, "Rescheduling provided debt relief of more than $\$ 100$ million in 1965 , and $\$ 115$ million during the following two years."

Against the backdrop of such anomalous characteristics, Turkey has been informally referred to as "the Baker Plan country before the Baker plan" (Celasun and Rodrik, 1989): The Baker Plan (in October 1985) called for intensive market-based micro-level domestic adjustments in return for expanded international lending to the problem debtors. 


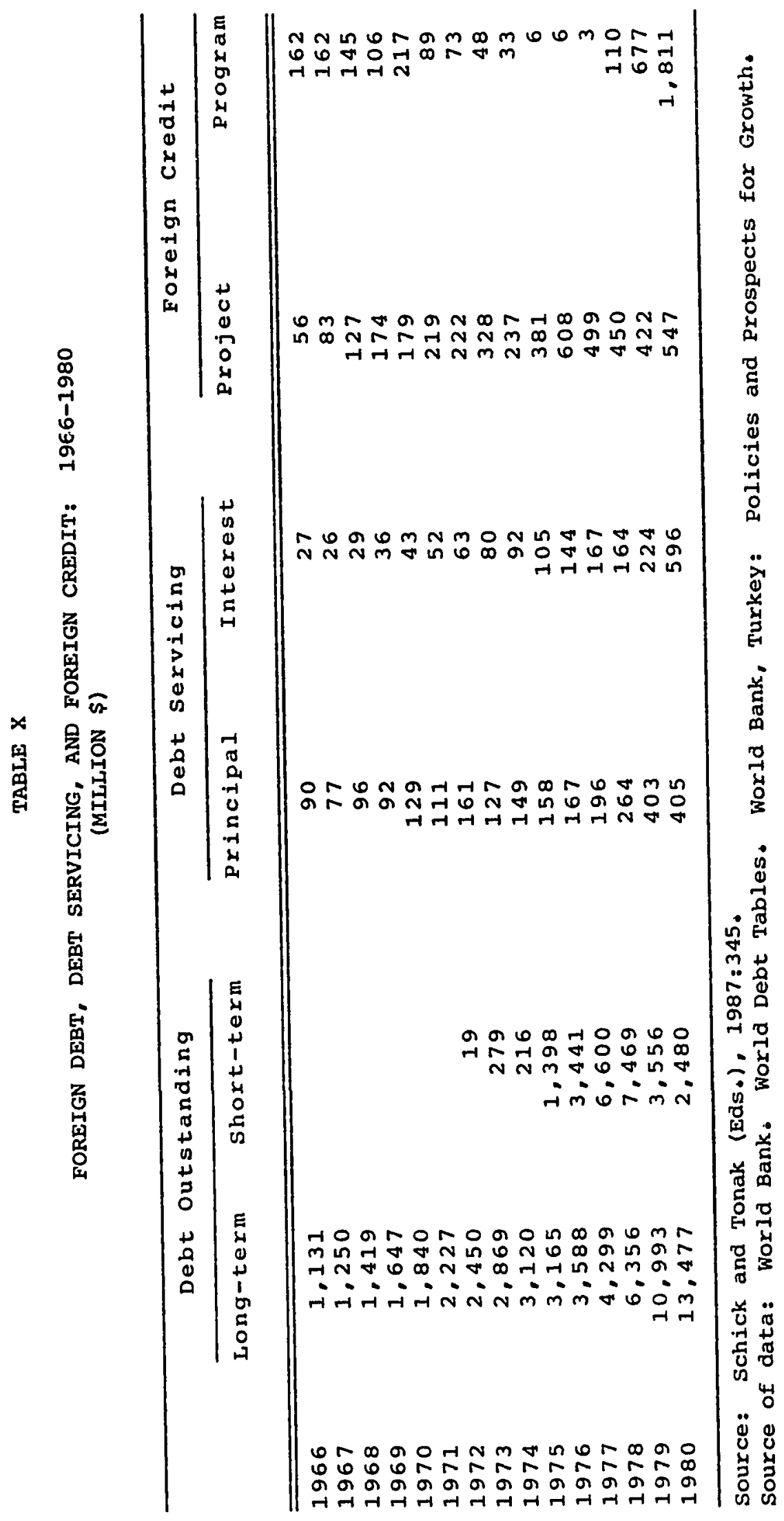


BAIANCE OF PAYMENT CRISIS AND

WORKERS' REMITTANCES

Dependent development did not lead to the avoidance of further crisis in the socioeconomic and political structure: The "crisis" can be characterized as a process of constant economic and political distress with short-term solutions: The case in point was the balance of payment crisis of the late 1960s and early 1970s (Table XI): Between 1963 and 1969 the deficit fluctuated between 1.0 and 2.5 billion TL, rising to $3: 2$ billion TL in 1970 . Right before the second military intervention of March 12, 1971, Turkey registered a huge $7: 3$ billion TL deficit in foreign trade: During this period Turkey's laborers moved abroad, particularly to Germany: This process was encouraged by statesponsored emigration (Ramazanoglu, 1985) a By 1981 the number of Turkish workers in Germany reached 1,546,3000 (Basgoz and Furniss, 1985), Remittances flowed to Turkey on a massive scale which offset the trade deficit to a large extent. During 1971-1972, foreign exchange flows from remittances exceeded those from exports by 50 percent (Pamuk, 1981). Between 1969 and 1982 a sum equivalent to $\$ 14+3$ billion was injected into the Turkish economy by Turks working abroad and for a short period before the recession deepened, Turkish workers financed a widening and ultimately disastrous trade gap (Ramazanoglu, 1985; Berberoglu, 1982; Tusiad, 1982):

The crisis of the pre-military intervention of 1971 was rather a complex one. The average annual deficit for the years from 1961 to 1970 came to US $\$ 180$ million and with amortization of public debt the total 
TABLE XI

FOREIGN TRADE AND WORKERS' REMITTANCES: 1950-1980

(MILLION \$)

\begin{tabular}{|c|c|c|c|c|}
\hline Year & Exports & Imports & $\begin{array}{c}\text { Trade } \\
\text { Balance }\end{array}$ & $\begin{array}{c}\text { Workers' } \\
\text { Remittances }\end{array}$ \\
\hline 1950 & 262 & 252 & 11 & \\
\hline 1951 & 314 & 354 & 40 & \\
\hline 1952 & 363 & 489 & 126 & \\
\hline 1953 & 396 & 468 & 72 & \\
\hline 1954 & 335 & 421 & 86 & \\
\hline 1955 & 313 & 438 & 125 & \\
\hline 1956 & 305 & 358 & 53 & \\
\hline 1957 & 331 & 346 & 15 & \\
\hline 1958 & 247 & 284 & 37 & \\
\hline 1959 & 363 & 433 & 70 & \\
\hline 1960 & 321 & 468 & 147 & \\
\hline 1961 & 347 & 509 & 162 & \\
\hline 1962 & 381 & 622 & 241 & \\
\hline 1963 & 368 & 688 & 320 & \\
\hline 1964 & 411 & 537 & 126 & 9 \\
\hline 1965 & 464 & 572 & 108 & 70 \\
\hline 1966 & 491 & 719 & 228 & 115 \\
\hline 1967 & 523 & 685 & 162 & 93 \\
\hline 1968 & 496 & 764 & 268 & 107 \\
\hline 1969 & 537 & 801 & 264 & 141 \\
\hline 1970 & 588 & 948 & 360 & 273 \\
\hline 1971 & 677 & 1,171 & 494 & 471 \\
\hline 1972 & 885 & 1,563 & 678 & 740 \\
\hline 1973 & 1,317 & 2,086 & $-\quad 769$ & 1,183 \\
\hline 1974 & 1,532 & 3,777 & $-2,245$ & 1,426 \\
\hline 1975 & 1,401 & 4,738 & $-3,337$ & 1,312 \\
\hline 1976 & 1,960 & 5,129 & $-3,169$ & 982 \\
\hline 1977 & 1,753 & 5.797 & $-4,044$ & 982 \\
\hline 1978 & 2,288 & 4,599 & $-2,311$ & 983 \\
\hline 1979 & 2,261 & 5,069 & $-2,808$ & 1,694 \\
\hline 1980 & 2,910 & 7,909 & $-4,999$ & 2,071 \\
\hline
\end{tabular}

Source: Schick and Tonak (Eds.), 1987:343.

Source of data: Krueger, Foreign Trade Regimes (1950-59), p. 22; OECD, Turkey (various years). 
average annual deficit reached us $\$ 300$ million during this period (World Bank, 1975:129). One of the major reasons for the steadily worsening deficit in the balance of payments was the drain on the budget caused by increased military spending (Berberoglu, 1982). Allocations for defense expenditures, which totaled 1.9 billion TL in 1960 rose to 2.6 billion TL in 1962, 3.2 billion TL in 1964, 3.8 billion in 1966 and 4.4 billion TL in 1968--an average of 24.4 percent of the budget during this period (Berberoglu, 1982).

In the interest of triple alliance Turkey was forced to appeal to the international financial institutions as is typical of dependent development (Aydin, 1986; Lim, 1985; Evans, 1979), By 1970, the foreign aid arrival amounted to $\$ 950$ million (Dogan, 1980). The price of the assistance, however, was again the promulgation by the usual set of stabilization measures in cooperation with the IMF.

PRELUDE TO POLICY SHIFT AND IMF STABILIZATION MEASURE

Turkey's international debts were engulfing the economy and qualified Turkey to transform itself from the problem country of the 1970s to the model debtor of the 1980s: In Celasun and Rodrik's (1989:209) terms this was attributed to the role of both the domestic policy changes and of the external environment; As they reiterated "ever since the mid-1970s, the debt accumulation process has been marked by recourse to rather exotic arrangements (i.e., due to Turkey's geopolitical position as the member of NATO) whose long-term stability is problematic." 
Turkey's total foreign debt increased from $\$ 2.2$ billion in 1970 to $\$ 15$ billion in 1979. The crisis intensified towards the end of the period, and required remedies from international financial agencies More than 250 private Western banks applied a "rescue operation" to Turkey, cultivated by the IMF--who was disappointed by the political instability and the government's inability to secure aid, as well as its fruitless concessions which undermined the establishment of social democracy in Turkey (Schick and Tonak, 1987).

Therefore, a prescription was unfolded for economic crisis known as "mini-devaluation" by the IMF (see Table XII): This included, declaration of economic growth (which had already fallen from $7 \%$ per year prior to 1976 to about 28 in 1978); a wage freeze; a 20-30 percent devaluation of the Turkish Lira (already devalued on 15 occasions between 1972 and 1977). This situation was aggravated by implementation of a policy called Deposits Convertible to Foreign Exchange (DCFE) which was first initiated by the right-wing (JP) party in 1967, and later interrupted by the Social Democrats (RPP) led coalition in 1973 (Hale, 1981). This policy was aimed at using state guarantees to rapidly obtain large amounts of foreign exchange! While it had been intended to attract the savings of migrant workers, the main depositors, however, turned out to be foreign commercial banks. Nonetheless, the DCFE became an Achilles' heel when its debt reached $\$ 2.97$ billion by 1978 with interest reaching $\$ 90$ million per annum, In short, the DCFE provided an exceptionally short-sighted method of getting short-term, high-interest loans for a foreign exchange-starved Central Bank. As Schick and Tonak noted (1987:351), 
TABLE XII

UNITED STATES DOLLAR EXCHANGE RATE OF THE TURKISH I,TRA : 1923-1980

\begin{tabular}{cccc}
\hline Starting & TL per $\$$ & Starting & TL per $\$$ \\
\hline & & & \\
\hline & 1.68 & $07 / 08 / 75$ & 14.25 \\
1923 & 1.88 & $08 / 08 / 75$ & 14.50 \\
1925 & 1.83 & $08 / 28 / 75$ & 14.75 \\
1926 & 1.91 & $10 / 28 / 75$ & 15.00 \\
1927 & 1.94 & $03 / 15 / 76$ & 15.50 \\
1928 & 1.95 & $04 / 04 / 76$ & 16.00 \\
1929 & 2.07 & $10 / 27 / 76$ & 16.50 \\
1930 & 2.12 & $03 / 01 / 77$ & 17.50 \\
1931 & 2.11 & $10 / 21 / 77$ & 19.25 \\
1933 & 1.66 & $03 / 01 / 78$ & 25.00 \\
1934 & 1.26 & $04 / 10 / 79$ & 26.50 \\
1940 & 1.38 & $05 / 10 / 79$ & 26.50 \\
$09 / 07 / 46$ & 2.80 & $06 / 10 / 79$ & 47.10 \\
$08 / 23 / 60$ & 9.00 & $01 / 25 / 80$ & 70.00 \\
$08 / 10 / 70$ & 14.85 & $04 / 02 / 80$ & 73.70 \\
$1228 / 71$ & 14.00 & $06 / 09 / 80$ & 78.00 \\
$02 / 16 / 73$ & 13.85 & $08 / 04 / 80$ & 80.00 \\
$08 / 15 / 73$ & 14.00 & $10 / 11 / 80$ & 82.70 \\
$05 / 14 / 74$ & 13.50 & $10 / 26 / 80$ & 84.80 \\
$10 / 20 / 74$ & 13.85 & $11 / 09 / 80$ & 87.95 \\
$05 / 17 / 75$ & 14.00 & $12 / 10 / 80$ & 89.25 \\
& & & \\
\hline 19698 & & & \\
\hline
\end{tabular}

Source: Schick and Tonak (Eds.), 1987:350.

Source of data: Hale, Development of Modern Turkey, p. 26263; OECD Economic Surveys, Turkey, 1985, p. 65. 
"By February 1977, foreign exchange transfers for imports were suspended as the government found itself unable to pay even the salaries of its diplomatic personnel abroad،" The "Austerity package" introduced was in many ways similar to those applied in 1958 and 1970, except that now the role of the state was reduced further than ever before. The goal of industrialization and development was shifted from ISI to an outward-looking strategy based on export promotion (as applied in NICs known as Gang of Four--South Korea, Taiwan, Singapore and long Kong). More emphasis was placed on "the forces of the market," Overall, as noted by Schick and Tonak (1987:351):

The 24 January measures were the quintessential IMF plan and were greeted favorably in the west, as "bold" and "courageous." The OECD meeting on 16 April resulted in a pledge of $\$ 1.6$ billion in aid. On 18 June, a three year IMF standby credit totaling $\$ 1,650$ million was announced, an amount approximately six times Turkey's quota and the largest such proportion in standby assistance ever granted. OECD countries also agreed to reschedule for a second time $\$ 2.9$ billion in debt, which had been already rescheduled in 1978 and 1979.

The IMF stabilization measure include the following proposals:

a) To put greater emphasis on supporting the export sector.

b) To devalue the Turkish Lira. The Turkish Lira had previously been kept at unrealistically high levels in order to facilitate the relatively cheap import of manufactured goods in line with import-substitution policies.

c) To open the economy to international competition and to encourage foreign capital.

d) To introduce policies which would lead to the transformation of the agricultural sector. 
e) To change the taxation system in order to encourage the further accumulation of capital.

f) To establish and maintain political stability (Ramazanoglu, $1985: 93-94$ ).

On January 25, 1980, Demirel (the Prime Minister of the new government) announced a comprehensive economic stabilization program, drafted "in consultation" with the IMF by his economic advisor Turgut Ozal. Yalpat reported (1984:19),

This third and heaviest dose of "IMF medicine" in two years included a 33 percent devaluation, devotion to restrained money growth, abolishments of price controls and subsidies to state economic enterprises, and cessation of deficit spending--all to be monitored by the IMF.

The ideological force within the IMF was based on a monetarist economic and political strategy which no longer corresponded to the world capitalist system based on the maintenance of individual national economies. The new vision of the world was one in which existing economies would be rationalized and remodeled into a world economy; a single economic system with its various national economies serving this global economy as if they were its sectors, all operating to satisfy the demands generated within the world system rather than within the national economy (Brett, 1983; Wallerstein, 1982; Cho, 1985). Moreover, the implementation of the new strategy of "out-ward looking" economy and the rest of the proposals to support it needed a politically stable environment which was a far-fetched desire on Turkey's part. However, to create and sustain such an environment, the military embarked upon its third intervention on September 12, 1980 to oversee the implementation of the 1980 IMF Stabilization Program (Schick and Tonak, 1987; Keyder, 1987c; Ahmad, 1984). 
Nonetheless, socioeconomic pressure along with political upheavals created a panorama of failure best described as: uneven and discontinuous growth (for the most part falling behind targets); a so far backward agricultural/rural system; surplus of labor in both rural and urban areas; deficits and inflation, One can add to this the resurfacing of neo-fundamentalist trends derived from deeper social, economic and political malaise (Hershlag, 1988).

DEVELOPMENT POLICIES AT A CROSSROAD:

TOWARDS THE NEW STRATEGY

With the beginning of the 1980s, Turkey's strategy of inwardoriented economy based on ISI came to an end, As Demirgil (1987:1) described,

During the second half of the 1970s the principle problems facing Turkey included a severe shortage of foreign exchange, a large balance of payments deficit, a heavy burden of short term external debt, a large public sector deficit, a slowdown in growth and increasing unemployment.

In January 1980, a new set of economic policies was introduced with stepped-up reliance on market forces rather than direct government intervention. These measures included a flexible foreign exchange rate policy, price decontrols, a restrictive monetary policy, liberalization of foreign trade and payments regulations, an interest rate policy designed to encourage domestic savings, and the introduction of a new foreign investment policy (under the Free Production Zones).

The new strategy for development which was prescribed for Turkey identifies the export sector of the economy as the "leading sector" 
which is known as export-oriented growth (XOG); Over the last decade this growth strategy has been effectively "recommended" to a large number of LDCs facing debt servicing difficulties (Kazgan, 1989:59). The XOG model is popular with Far East economies such as South Korea, Taiwan, Hong Kong and Singapore known as the gang of four (Cho, 1985; Frank, 1981; Kazgan, 1989). Today several other economies have adopted this model including People's Republic of China, India, Yugoslavia, Mexico, Brazil, and Malaysia.

Economic success of some of these countries, namely the members of "gang of four," has led to a certain amount of capital accumulation and the high volume of export and GDP growth. Therefore, these countries can collectively be referred to as the NICs, or semiperipheries (Lim, 1985; Evans, 1979). Thus Turkey qualified as a NIC with the adoption of XOG initiated with IMF's stabilization measures and the military's intervention. If the strategy was going to be successful, the following policy recommendations (i.e., by IMF) had to be adopted.

1. Abolition or liberalization of foreign exchange and trade restrictions and controls.

2. Devaluation of the exchange rate.

3. Control of bank credits, higher interest rate and reserve requirements.

4. Control of government deficits by reducing spending, especially on social welfare, increasing taxes, and decreasing subsidies to state economic enterprises and consumers.

5. Control of wages.

6. Dismantling of price controls:

7. Curbing monetary expansion。 
8. Boosting business confidence.

9. Greater hospitality to foreign investment (Schick and Tonak, 1987:353)

The policy shift of the 1980s also took place within an environment of burgeoning population growth, labor force unrest, and unemployment. Turkey's population was forecasted to reach 55.54 million by 1989, and 73 million by the year 2000. In terms of "labor force," by the mid 1980s it numbered 19:6 million, According to the OECO's estimate the unemployment for 1985 was 2,380,000 without including rural disguised unemployment (Hershlag, 1988)

A major relief to the unemployment problem has been the migration of Turkish labor abroad, and the transfer of remittances back to Turkey (reaching $\$ 2.5$ billion a year). Such a prelude along with the shift to an open economy were conducive to tourism activity, albeit the government's unintentional passive role in its planning: It was after the adoption of XOG and policy shift from ISI that the tourism sector began to become a significant sector within the economy. The foreign exchange earning capacity of tourism combined with the declining workers' remittances from abroad made the development of tourism attractive: As Demirgil (1987:2) reported:

Foreign exchange remittances of Turkish workers have stagnated under the impact of world economic conditions but also because of alternative opportunities offered to the Turkish workers abroad. „workers' remittances have decreased from $\$ 2071$ million in 1980 to 1714 million in 1985 ,

The net income from tourism has increased considerably from $\$ 212$ million in 1980 to $\$ 770$ million in 1985. See Table XIII for balance of payments condition and the role of invisible items including tourism. 
TABLE XIII

BALANCE OF PAYMENTS

(IN MILIION \$)

\begin{tabular}{lrr}
\hline & 1980 & 1985 \\
\hline & & \\
\hline & 4999 & 3385 \\
Foreign Trade Deficit & 2910 & 7958 \\
Exports & 7909 & 11343 \\
Imports & -668 & -36 \\
Invisible Items & 212 & 770 \\
$\quad$ Tourism (net) & -668 & -1753 \\
Interest Payments on & & \\
$\quad$ Foreign Debt & 2071 & 1714 \\
Workers' Remittances & 3210 & 1013 \\
Current Account Deficit & & \\
& & \\
\hline
\end{tabular}

Source: Demirgil, 1987:1-7,

EXPORT ORIENTED GROWTH AND CONTROVERSIES

The new economic model of XOG has spurred controversies among developmentalists in the case of Turkey in particular and among the Third worldists in general. Whether this strategy with the known deficiencies of the market system, and LDCs dependence on external variables will succeed as a push factor has been questioned and is subject to skepticism.

As Kazgan (1989:59) noted:

The XOG (export oriented growth) model as well as the assumptions on which it is based contrast sharply with theories of economic development formulated in the $1930 \mathrm{~s}$ and elaborated over the quarter of a century following the Second World War.... Economic development calls for institutional changes as well as changes in attitudes. Free 
play of maxket forces is not a panacea for the socioeconomic ills of LDCs. Renefits of integration with the world market are dubious (Myrdal, 1957). Development theorists who adhere to these views ridicule the proponents of the XOG strategy for failing to see how all LDCs--or those which are identified as exporters of manufacturers--could possibly expand exports at a rate equal to that of Far East economies. They further criticise the XOG model for failing to specify (i) the conditions under which the presumed positive effects of the expansion in exports can be transmitted to the rest of the economy, and (ii) the necessary conditions for eliciting an accommodating response to export expansion from domestic economic agents.

Turkey's entrance into the ranks of NICs with XOG model came much later in comparison to, for example, South Korea, who adopted XOG model in 1960s. Empirical analysis of a few LDCs' XOG have raised alarming skepticism whether this model will be able to cure Third World's development problems in the given world economic system, In Turkey's case, proponents of XOG model argue that all the sources of external financing were exhausted and the proportions of the trade gap were impossible to adjust or remedy by 1977 (Ebiri, 1985). Ebiri noted, Dimensions of the problem were far from the reach of marginal adjustment in export incentives and/or import restrictions, bringing a major overhaul and a very radical transformation of the development strategy was needed.

And/or in other terms the ISI was at a deadlock; it had already sung its swan song during the 1974-1977 period and all that was needed was to open the economy to an outward-looking path of development.

At the other end of the spectrum were the opponents who argued that the development problems were not attributed to the ISI per se, but rather to a sexies of external factors and to the "mismanagement" and "mistakes" in the implementation of the ISI (Ebiri, 1985). 
In fact, the existing conflict among so-called Turkish

"developmentalists" stems from the uniqueness of historical process that Turkey has undergone since the establishment of the republic in 1923, This was reflected in the theoretical differences among Turkish "dependencia" in contrast to, for example, the Latin American case, which experienced colonial subjugation, whereas Turkey was never colonized, Turkey's ISI policies based on etatist platform is similar to the "closed economy" policies experienced in Japan with strong nationalist sentiments in Turkey's Kamalist period.

Three key issues were important for the XOG's implementation in the long term and to its success and failure, Both proponents of XOG and its critics dwell on these key dimensions for they establish the main links to the external factors in the world system economy and international market! These are (1) trade, (2) finance, and (3) technology. The trade dimension was essential to determine whether a country wants to join the international market as a producer and exporter vis-a-vis the domestic market. The financial aspect was to allow foreign capital and investment in key export activities, rising exports generally creates better conditions to borrow: And technology was expected to be transferred, adopted, assimilated and finally to become technologically advanced. However, the shift from ISI to XOG has been explained by three different perspectives. The first perspective uses the "capitalist dependence" theories of underdevelopment which fit into "dependencia" paradigm in regard to Turkey's development. All those who adhere to 
this paradigm conclude that present difficulties emanate from the crisis that world capitalism is experiencing, Therefore, a periphery (ite., Turkey) is a part of this crisis and cannot expect to solve her own problems without severing her links with the world capitalist system (Altintas, 1978; Berberoglu, 1982; Sonmez, 1980). The second view raises the issue of "international conspiracy," which interrelates with "dependencia," albeit certain notions of its own. This perspective believes Turkey was on her way to economic development and industrialization via the import substitution model, but such progress was not welcomed by the industrial world and became a disturbing element, Therefore, they acted against her via IMF to block the progress, They assert that IMF, in fact, has been trying to hinder Turkish development efforts since the beginning of the 1950s: Devaluations were forced upon the Turkish governments in order to serve the interests of the Western countries (Dogan, 1980; Boratav, 1979). Some even accused the World Bank of deliberately reducing the growth rate of the Turkish economy Ebiri (1985:103) argued that

both "capitalist dependence" and "international conspiracy" explanations are widely accepted.... And both explanations are used, although somewhat naively, to form the arguments against export oriented growth.

The third explanation of the recent crisis attributes the problem to the policy implementation of ISI. Adherents to this perspective argue this in two different versions: The first version believes that ISI started with the wrong production policy, namely consumer goods, contrary to the objectives of the five-year plans. This version is more compatible with noncapitalist way of development (NCWD): 
This view also criticizes the government for not having a conscious program, which led to the application of resources too thinly and on a small scale (Exdem, 1980; Boratav, 1979): The second version of the third perspective concludes that ISI with the problems mentioned above prolonged its survival until 1974 by two ways: First, the traditional central control of the economy created an environment where most of the distortions escaped public attention or were accepted as "facts of life," and second, large sums of migrant workers' remittances enabled the Turkish economy to survive the large and widening trade gap (Ebiri, 1985).

Opposing the aforementioned perspectives is the view that XOG is the only alternative to further economic growth and halt stagnation. This position accused the proponents of ISI of being "philosophical dogmatists" of the post-war developmental thinking in Turkey. ISI proponents were criticized for not realizing the ubiquitous trade gap and disproportionate $r$ ise in the numbers of unemployed and underemployed. Turkey's trade gap reached $\$ 21.6$ billion under the ISI. Additional problems with ISI could be witnessed in terms of efficiency, economies of scale, capacity utilization, job creation, income inequality, and political structure (Ebiri, 1985)

In explaining Turkey's political economy, "dependencia" itself comes under criticism for its "universality" approach and for its shortcoming in emphasizing each individual country's peculiar dynamics (e.g., Turkey), In fact, the criticism of dependency theory and its application gradually matured to a full force debate among various 
developmentalists either it be Marxists or Neo-classical reaction

(Blomstrom and Hettne, 1984).

Thus Turkey's "dependencia" criticized as Ramazanoglu (1985:17)

addressed,

Although dependency theory has been valuable in emphasizing that all "traditional" societies have histories, its theorists have failed to look at the different ways in which the capitalist mode of production has transformed precapitalist social formations. By having to classify all cases as either typical or atypical of peripheral capitalism, they have had to overlook historically critical differences in the way in which pre-capitalist formations have been incorporated into the world capitalist system.

Ramazanoglu further argues that such universalism has its roots in Lenin's pamphlet on imperialism which underestimated the diversity of possible paths of development which could result from differences in pre-capitalist productive systems and the variable ways in which they could be incorporated into the world capitalist system. And/or the universalism of the theory is justified by the additional assumption that capitalism on a world scale is a system of exchange rather than interrelated systems of production, circulation, distribution and exchange. In the dependency view, it is the inequality and the exploitativeness of exchange relations dominated by the centers of capitalism which prevents the Third Woria irom developing.

It is on such a premise that the internal dynamics of the Turkish development process became subject to a new theoretical analysis which perceived the crisis of Turkish economy as a part of the world economic crisis, Contrary to what "dependencia" portrays one should not overlook the tremendous struggle within the Turkish upper strata to gain control 
of the state: This manifested itself in the coups of the 1960s, 1970s and 1980s (Keyder, 1979, 1987; Ramazanoglu, 1985).

CONSTRAINTS AND PROBLEMS

The increase in economic growth, industrialization, and urbanization for a handful of NICs who adopted XOG strategy is undeniable: Particularly, growth has been concentrated in favor of some Pacific Basin and Southeast Asian countries, namely the west coast of the USA, Japan, the gang of four, People's Republic of China, India, Malaysia and Thailand.

One of the problems exposed by critics is the concept of "trade dependence" and its dangers for several reasons: 1) export demand is sluggish; 2) terms of trade are against LDCs; 3) the raw material exporting countries do not have the flexibility to adjust themselves to changing market conditions; 4) export-oriented economies do not contribute to the technical knowledge, or to the training of skilled administrators, managers, technicians and workers; 5) export sectors fail to provide a focus around which an integrated national economy can develop; 6) export-oriented economies have developed patterns of distribution and economic-political power that thwart modern industrial and agricultural growth (Frank, 1981; Cho, 1985; Kazgan, 1989). Many countries have expressed disappointment with the "second industrialization" phase which was supposed to emphasize capital intensive and high technology products, but failed due to capital shortages and technological backwardness. Cho identified some structural characteristics that take the following forms: 
1. Technological innovation and automation in the core countries, which exodes the competitiveness of the semiperiphery's cheap labor force;

2. The diminished strength of labor in the core which encourages a flow of investment back toward the core;

3. The emergence of widespread offshore production sites in other, poorer Third World countries (the periphery proper), has squeezed the semiperiphery's competitiveness from the other side; and

4. The rise of internal resistance by industrial workers and farmers in the semi-periphery, due to emergent contradictions in the export-led industrialization strategy as it confronts these world system constraints (Evans, 1975, Kazgan, 1989; Cho, 1985).

Kazgan's (1989) analysis of export-oriented industrialization has raised various issues which are essential conditions for the strategy's success, These conditions, if not achieved, will doom the strategy to failure. Kazgan formulated two categories of constraints of the exportoriented model, and warned against forced measures for export expansion. Furthermore, it is questionable whether all the iDCs should adopt this strategy since its temporary success has been concentrated in only certain geographical centers.

\section{Internal Constraints}

The first set of constraints are internal. If the export sector is going to play a "leading role" certain conditions should be fulfilled: First, the export receipt should grow steadily over time at a "very high" rate (say, not less than 108 per annum) without strong fluctuations from year to year! second, the terms of trade should at least remain stable and should definitely not deteriorate seriously in the course of export expansion, Third, the export manufactures should 
have strong forward and backward linkages with the rest of the domestic economy. If the export sector is an enclave dependent on some foreign country rather than the domestic economy, exports can grow without creating substantial beneficial effects within the latter; This was the case in the export sectors of colonies (Kazgan, 1989:61-62).

Kazgan's analysis also pointed to the spread effects of the export sector. This notion captures a significant topic within the development process which "dependent development" tends to result in exclusion (Evans, 1975). However, the crux of the matter is "an even expansion in the export sector without creating external diseconomies for other productive sectors" (Kazgan, 1985:62). Again, the following conditions are enumerated by Kazgan: First, the exportable manufactures must be internationally competitive at an effective exchange rate that is the same for exports and for imports and must display a high elasticity of supply. If this condition does not hold, then the export sector will have to be supported by high rates of real devaluation--in fact this has been just the result in Turkey's case and most of the Third World who adopted XOG (Schick and Tonak, 1987; Berberoglu, 1982; Kazgan, 1989; Cho, 1985). Second, for the benefits to spread throughout the whole economy, exported manufactures should display diversity in their factor content. They should have both technology and skill intensive components so that the learning effects created in export industries may spill over to other sectors (Kazgan, 1989:62) . Contrary to this condition, there are created "employment illusion" and technologies that permitted a substantial amount of "deskilling" (Cho, 1985:68; Frank, 1981). Deskilling is also implicit in the production process itself, 
which is broken down into partially mechanized operations and partially simple, repetitive manual operations, Moreover, some export production is divided so that one operation is performed in one part of the world, while others are undertaken elsewhere, and the final product is assembled in still another part of the world (Frank, 1981:104-5). The third condition requires the marginal propensity to import by the social classes to which the increased export income accrues should not be higher than the national average; This condition ensures that the expansion in export income does not flow to foreign countries in the form of increased imports (Kazgan, 1989:63). To this Kazgan adds the "demonstration effect" or "conspicuous consumption." such pattern will result in the wealthy social classes emulation of industrialized countries consumption behaviors, "The outcome would be a shift upward of the consumption function, inducing a decline in the domestic savings ratio and a rise in the current account deficit" (Kazgan, $1989: 63)$.

\section{External Constraints}

External constraints to XOG's success are as significant as the internal ones, Besides the protectionism on the rise, there are different kinds of tariff systems on the commodities that are exported from the Third World countries. For instance, production networks involving the export of components to Third world countries, that are processed and assembled there, and then reexported to industrialized countries, have been favored by "offshore assembly provision" (OAP) : This is accepted by many industrialized countries, and no customs duty 
is charged on the re-imported components, For example, United States Tariff code 807-00 passed in 1963 reduced duties on any product whose parts originate in the US and which is sent abroad for assembly (Cho, 1985:68) : Whereas US International Trade Commission (USITC) has a different standard of tariff for non-OAP imports from Third world countries, Interestingly, the US non-OAP imports grew at a compound rate of 12 percent annum between 1966-1972, while OAP imports from Third World countries grew at 60 percent per annum (CHO, 1985:69),

An important external constraint is the automation versus cheap labor which resulted in the eroding of the comparative advantage of the Third World's cheap labor, In Rada's (1981) report some key industries, such as electronics and textiles are returning to the core countries: Not to mention the impact of the declining strength of labor in the core, and growing resistance of the labor in the semiperiphery as well as the emergence of new cheap-labor sites in the periphery. As Cho (1985:77) reports:

By the early seventies, !exports of manufactures from Third World countries were concentrated in a few countries. In 1973, the eight largest exporters accounted for 74.6 percent of the manufactured exports by all Third world countries, and South Xorea was the second largest, accounting for about 16 percent of the 1973 total. In 1975, the share of the eight largest exporting countries declined to 62,7 percent from 74.6 percent in 1973 ;

Perhaps the triple alliance between state, local capitalists, and multinationals is turning into an Achilles' heel, since such an uncelebrated stability of the "menage a trois" has the genius of contradiction embedded in it, obviously the state as an actor in the process of capital accumulation carries a load of nationalism which may 
contradict the objectives of multinationals, on the other hand it is essential for the elite alliance to remain concentrated in order to succeed, Evans's (1975) analysis of the Brazilian case exposes a contradiction in terms of development which manifested in exclusion of masses, He reiterated:

Concentration is the consequence of maintaining the elite alliance intact, Any attempt to redistribute income from elite to mass would threaten the stability of the "menage a trois"... success at working out the contradictions within the elite has created a structure which precludes dealing with the problem of exclusion.

Nonetheless, the solution to the exclusion may result in the breakdown of alliance and ultimately in stagnation, Again Evans

(1975:142) anticipates that

pressure toward redistribution is still a future possibility, in which the multinationals are the most likely to be squeezed (i,e, within the nationalist elements of the elite, populism is not entirely dead). If they respond with reluctance to take new risks or make greater commitments to industrialization, then both the rate of accumulation and the future participation of the multinationals will become problematic. Without the enthusiastic participation of the multinationals, the alliance may degenerate, producing stagnation and creating the conditions for either fascism without popular mobilization or state socialism with the preservation of class privileges.

IMPLICATIONS OF THE MODEL

The hopes of the 1960 s and 1970 s for the majority of the exportoriented IDCs are turning to skepticism according to the evaluations by Helleiner (1976) and Nayyar (1975, 1976), as well as of Sabalo and Trajtenberg (1976), Michalet (1976), Vaitsos (1976), Frank (1981). Turkey's case as a newcomer to the ranks of outward-looking economies shows the signs of mixed feelings, For instance, TUSIAD's report of per 
capita income is a sign of success of XOG regardless of the redistribution issue, Per capita income materialized at $\$ 1,254,8$ in 1987 representing an increase of 5.5 percent in 1986 and 4.7 percent in 1987 (TUSIAD, 1988:4)。

However, TUSIAD's report on Turkey's economic performance, not to mention the political and social issues, was not able to draw a rosy picture as intended, In 1987, debt servicing to non-banking private lenders amounted to $\$ 866$ million (TUSIAD, 1988:102), As Table XIV illustrates, the debt ratio to GNP has grown steadily (TUSIAD, 1988:102). Turkey's struggle to become a competitive producer in the world market is not a harmonious "miracle" as was planned, Borrowing by the public sector of 5,5 percent of GNP in 1986, was planned to fall to 4.1 percent in 1987, When it rose to 8,7 percent, the state industries took 4,7 points of that and invested high while delaying price rises. The government's interest payments, equivalent to 2.4 percent of GNP in 1985 rose to 3.4 percent in 1986, and hit 4.1 percent in 1987. The Economist (1988:11) reports:

Least of all in a poor country does lunch come free, Borrow and print money as if there were no tomorrow, and your consumers and industrialists will soon find that, when tomorrow obstinately turns up, lunch--and bank loans--cost twice what they did yesterday:

Thus far the achievement of a healthy balance of payments; advancement of technical training, technological development; increased employment; promotion of "self-reliance," "independence" and economic development, are far-fetched goals, Any sporadic signs of economic growth, can be attributed to workers' remittances, small revenues from tourism, and more importantly to the war between Iran and Iraq which 
TABLE XIV

PERCENTAGE RATIO INDICATORS

IN EXTERNAI DEBTS

\begin{tabular}{lrrrrrr}
\hline & 1982 & 1983 & 1984 & 1985 & 1986 & 1987 \\
\hline \hline & & & & & & \\
\end{tabular}

Source: TUSIAD, 1988:102。

supported Turkey's export items. The fall in economic growth to 3,4 percent in 1988 from eight percent in 1986 demonstrates the external constraints of XOG in the form of the cyclical features of the strategy (Kazgan, 1989): The fall in economic growth was complemented by Turkey's external debt of $\$ 39$ billion and the expected payment service of $\$ 7$ billion in 1989, For the same year inflation stood as high as 64.5 percent, with the devalued Turkish currency at \$1 equal to 2000 TL (Wenger, 1989:25). However, Turkey's venture into XOG put into test in the real life of citizens reflected in Yalpat's (1984:21) report:

The four percent average growth in GNP/GDP since the generals took over has been way below what is deemed necessary to keep unemployment in check-- OECD estimates this figure at 7 percent. In 1982, the highly dubious official unemployment figure stood at 18,2 percent of an 18 million strong labor force, up from 15.4 percent in 1980. The share of wages and salaries in national income fell substantially--a 1980 study shows that the poorest 20 percent of families in Istanbul earned only 2.4 percent of the total income, while the richest 20 percent earned 69 percent of the total. 
The process of XOG would not be complete unless mNCs participated in it: During the 1980s, 800 foreign firms began their activities with $\$ 3,16$ billion in the various lines of production, including tourism, Table XV illustrates foreign capital investment. TUSIAD reported "the biggest investment amount of $\$ 132.7$ million is directed at tourism, followed by the chemicals industry with $\$ 84.0$ million, trade with $\$ 46.1$ million, and the textiles industry with $\$ 34.2$ million" (1988:91).

TABLE XV

FOREIGN CAPITAL INVESTMENTS APPROVALS

(US \$ MILLIONS)

\begin{tabular}{lrrr}
\hline Years & $\begin{array}{c}\text { Number of } \\
\text { Firms }\end{array}$ & Amounts & Cumulative \\
\hline \hline & & & \\
1979 & 91 & 228.1 & 228.1 \\
1980 & 100 & 97.0 & 325.1 \\
1981 & 127 & 337.5 & 662.6 \\
1982 & 170 & 167.0 & 829.6 \\
1983 & 185 & 102.7 & 932.3 \\
1984 & 267 & 271.0 & 1203.3 \\
1985 & 421 & 234.5 & 1437.8 \\
1986 & 610 & 364.0 & 1801.8 \\
1987 & 839 & 536.0 & 2337.8 \\
& & & \\
\hline SOurce: & TUSIAD, 1988:91. &
\end{tabular}

While under the new strategy foreign investments were welcomed, the trend towards big business and monopolization has grown steadily. As Yalpat (1984:21) reports, "The economic darwinism supervised by the government took its toll in the form of record bankruptcies, especially in the small business sector." 
The pressure on small businesses was felt deeper when the famous collapse known as "Kastelli collapse" took place, Kastelli, Turkey's largest finance house, went under with liabilities valued at $\$ 780$ million--equivalent to eight percent of total bank deposits. To prevent panic, the government announced that all Kastelli debts were under "state guarantee:"

The Kastelli collapse was explosive testimony to the uneven nature of the new economic regime with respect to different segments of monopoly capital. The Bank Kastelli was the only major finance house that remained outside the control of a major corporation or bank: Kastelli's plea for a $\$ 250$ million rescue package was denied primarily because their provincial style contrasted sharply with the magnates dominating the financial and industrial scene (Yalpat, 1984) ? Turkey's experience with XOG strategy has not reached its postgrowth period yet. with the evidence from other comparative economies, the initial euphoria has been replaced with skepticism and disillusionment. Political freedom, social justice, democracy and redistribution of income have not become the end product of "development strategy:" Turkish development is reflected by the run of events in the wake of its adoption of the XOG (i.e., borrowing jumped from $\$ 13$ to 39 billion in 1980s, inflation of $70 \%$, GDP growth hardly exceeded the population growth, and the spurt during the second period was due to deficit spending). The distribution of income has also become increasingly more skewed in the last decade (Kazgan, 1989; Schick and Tonak, 1987; Yalpat, 1984; Berberoglu, 1982). Turkey's process of 
capital accumulation is only one indication of the dilemmas of development in the Third World as Amirahmadi (1989:181) elaborated:

Middle-class movements generates enormous potential for revolutionary changes in the direction of realizing democracy, social justice, and national independence! Their realization, however, remains constrained by powerful domestic and international forces:

In reference to early adopters of the XOG strategy he reiterated:

Transition to a post-growth society where these democratic goals are the prime movers of development also remains constrained by the present deadlock in development thinking and the inability of the middle class to break through the deadlock.

Regional Disparity/Spatial Inequality

Three decades of intensive ISI has left the country in crisis:

Its magnitude is promulgated by two military coups to restore the order and stability, a necessary precondition for dependent development The subject of regional underdevelopment not only remains a central concern of much of the literature, but also it becomes more attractive since the reqional differences between Eastern/Southeastern and Western Turkey have been increased. As Aydin (1986:57) noted,

Inter-regional inequalities have been recognized as a problem since the first five-year development plan (1963-1967), and various policies have been adopted in the hope of getting rid of these inter-regional inequalities, Nevertheless, according to the Fourth Five-Year Development Plan (1979-1983), despite all envisaged policies and efforts, inter-regional imbalance has gradually increased.

Regional underdevelopment has been subject to various analytical and theoretical discourses which are pertinent to Turkey's domestic policies as well as her position within the international division of labor. 
Regional underdevelopment, particularly of Eastern and Southeastern Turkey with a dominant Kurdish population (Figure 5), has been approached in the context of the "Turkish agrarian debate." These debates have formed numerous theses among Turkish scholars who have dealt with the political economy of development, namely Boratav and Erdost thesis: "cumulative causation" applied by Keles; and an ethnic/ nationalistic approach by Besikci (Aydin, 1989).

The intellectual debate on regional disparities or regional underdevelopment, not only manifests the realities of the existing situation, but also elaborates the structural analysis as an objective to find mechanisms for transformation and remedy: Moreover, these debates are sometimes dangerous in their implications as policy platforms for various parties and organizations who are active in altering the social structures:

In Turkey's case, for instance, Boratav and Erdost's thesis notwithstanding their inspiration from Marx's writing becomes problematic for not being able to articulate the rural underdevelopment within the new international structure and relations after world war II, which in Bernstein's (1977:60-61) words is not a "superimposition model" as Boratav and Erdost make us to believe, rather it is a "penetration model" where capital controls the conditions of production without taking over the organization of production. Regarding Keles's "cumulative causation"--inspired by Myrdal, although they show ever-increasing regional inequalities empirically, they fail to position them in the very process of capital accumulation which is affected by state and international players directly. It is 


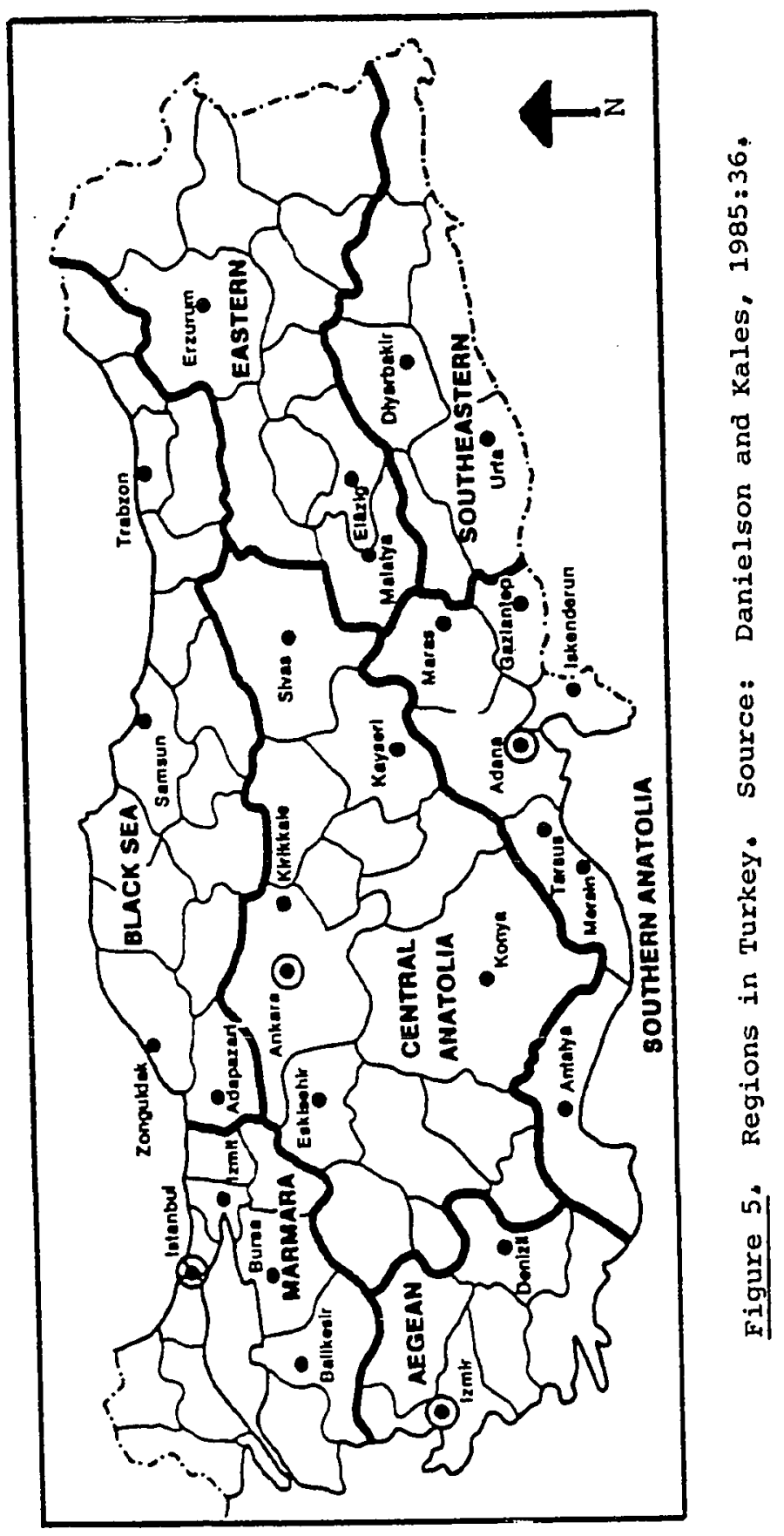


this failure which leads to an ahistorical analysis that cannot account for exploitation, domination, or unequal and dependent development (Aydin, 1986; Berberoglu, 1982; Mandel, 1974),

The nationalistic analysis is concerned with the domination of the Kurdish nationality in the Eastern and Southeastern regions by the Turkish nationality of the western regions. The question of development then is explained in terms of ethnicity rather than economics (Aydin, 1986).

What Aydin $(1986,1987)$ has argued in the specific case of Turkey is Turkey's position in the world-system which can be articulated through state, local capitalist, and international interests in their quest for capitalist development. Thus it is such conditioning that resulted in regional inequalities which was also elaborated by Mandel (1974) as an inevitable outcome of a capitalist economy, the aim of which is to grow continually through investments in the areas where the highest rate of profit is possible, Mandel continues that investments are unequally distributed because the factors determining the rate of profit are unequally distributed within the country and therefore the growth of the economy will be uneven, This situation favored the various investors--local or international--by creating the national market which produced the flow of labor from underdeveloped regions to developed regions. This flow of labor, as noted by Aydin (1986:264),

is a concrete manifestation of Turkey's underdevelopment: an underdevelopment which is itself conditioned by Turkey's position within the capitalist world economy, in which countries such as Germany--with one million Turkish migrant workers--occupy hegemonic positions. 
According to Aydin's analysis, the state's policy began during the etatist era which aimed to create a Turkish capitalism, giving priority to the areas where the existing infrastructure rendered possible the most rapid and profitable returns on investments. During the etatist policies, the infrastructural extension to Eastern Anatolia with the Haydar Pasa (Istanbul) to Kurtalan (Siirt) railway line, which cut across Turkey from northwest to southeast and facilitated the labor flow, opened new markets.

Finally, Turkey's regional underdevelopment can only be understood treating her regions as a part of Turkey's industrialization process via ISI. The state's policies, promulgated by support for continuous transfer of resources from the agricultural to the industrial sector, ensured the terms of trade which were used against the agricultural sector: The industrial sector, however, was protected through the terms of trade, tariff walls, arbitrary import quotas and low foreign exchange rates. Further mechanisms were developed to lower wage levels, and exclude land reform policies in order to sustain existing land ownership. This situation was reinforced by the introduction of the Green Revolution which contributed to the inequalities in income distribution in rural areas, mostly benefiting large private farms (Aydin, 1986). This policy was subject to severe criticism by the World Bank itself, which stated that the Green Revolution policies were intensifying inequalities in underdeveloped countries.

Regional underdevelopment and spatial disparities are manifested through various constructs, For instance, the rural-urban dichotomy by itself demonstrates that the income distribution was favoring urban 
areas (Danielson and Keles, 1980), Such a dichotomized condition was intensified in the intra-rural level by the land distribution system which can be seen in Table XVI. As can be seen, two percent of rural households in Turkey are landless, As for those who own land smaller than 10 decares (10 decares $=1$ hectare $=2.471$ acres), the percentage is 20. Thus, about 42 percent of all rural households own very little or no land at all, and the land owned by this 42 percent makes up less than three percent of total privately owned land (Ulusan, 1980:140-1).

TABLE XVI

DISTRIBUTION OF LAND BY LAND SIZE: 1973

\begin{tabular}{|c|c|c|c|c|}
\hline \multirow[b]{2}{*}{$\begin{array}{l}\text { Land Size } \\
\text { (decares) }\end{array}$} & \multicolumn{2}{|c|}{ Households } & \multirow{2}{*}{$\frac{\text { Total Privately }}{\text { Simple }}$} & \multirow{2}{*}{$\begin{array}{l}\text { Owned Land } \\
\text { Cumulative } \\
\text { Percentage }\end{array}$} \\
\hline & $\begin{array}{c}\text { Simple } \\
\text { Percentage }\end{array}$ & $\begin{array}{l}\text { Cumulative } \\
\text { Percentage }\end{array}$ & & \\
\hline Landless & 22.37 & 22.37 & --- & -- \\
\hline $1-5$ & 10.13 & 32.50 & 0.81 & 0.81 \\
\hline $6-10$ & 9,61 & 42.11 & 1.91 & 2,72 \\
\hline $11-20$ & 14.88 & 56.99 & 5.71 & 8.43 \\
\hline $21-30$ & 9,35 & 66,34 & 5.91 & $14 \div 34$ \\
\hline $31-40$ & 6.93 & 73.27 & 5.94 & 20,28 \\
\hline $41-50$ & 5.71 & 78,98 & 6.35 & 26.63 \\
\hline $51-100$ & 14,97 & 93,95 & 39,51 & 66.14 \\
\hline $101-200$ & 5.43 & 99,38 & 19.83 & 85.97 \\
\hline $201-500$ & 0,00 & 99,38 & 0.00 & 85.97 \\
\hline $501-1000$ & 0.50 & 99,88 & 8,76 & 94.73 \\
\hline Over 1000 & 0.12 & 100,00 & 5,27 & 100,00 \\
\hline
\end{tabular}

Source: Ulusan, 1980:140, Source of data: State Planning Organization (SPO): 
According to surveys conducted by the Ministry of Village Affairs, the inequitable distribution of land is most pronounced in the east and southeast regions (SPO, 1972). In terms of the distribution of industrial activities, the disparity between the eastern and southeastern regions and the rest of the country is also evident in the degree of industrial development, of Turkey's 6,317 public and private industrial establishments in manufacturing only 2,4 percent are located in the east which absorbs only 1.5 percent of the work force (Aydin, 1986)

Turkey's tourism policy will in all likelihood intensify the regional disparities, since it is concentrated in the west and southwest regions. This can be attributed first to the lack of a national tourism policy to develop an integrated tourism project. Second, the comparative advantages of Western and Southwestern Turkey--in terms of the available infrastructure and natural resources make them more profitable targets or as Mandel (1974) and Aydin (1987) articulated, any investment in the backward regions will be contradictory to the investment objectives of profit making, Therefore, state policies, multinationals, and local capitalists are reluctant to leave the available infrastructure in the West for underdeveloped East albeit its latent potentials:

\section{Regional Disparity: Policy Issues}

Regardless of geographical and natural comparative advantages between regions, governmental policies play a decisive role in lessening or increasing the balance between regions, For instance, a national 
tourism development policy can play an effective role based on its policy goals, whether the policy is a deliberate act to decentralize activities for long-term community benefit, or to alleviate the state's short-term needs in general. As noted by Gore (1984:236),

regional planning is what governments define it to be..this means that a theory of the practice of regional planning must be located within some theorization of the state.4:4 This is what understanding regional planning in political terms entails, And only through a political analysis is it possible to understand what the activity actually is:

In Turkey's case the process of regional inequalities are not discrete, but rather have been in a continuous decline in the economic production and as a result of distorted social mobility. Table XVII demonstrates the differences in the GDP between selected western and eastern provinces:

The gradual decline in GDP of selected Eastern provinces between 1980 and 1986 can be noted from Table XVIII The role of "state" and "sector" have a determining impact upon regional planning activities via what Gore (1984:242) noted,

In general, regional planning involves interventions which are "explicitly" directed to change the spatial distribution of physical infrastructure, population and human activities within the territory of a state. "Spatial organization," that is, the way in which phenomena are distributed in geographic space to achieve some objectives is the central focus of regional planning;

Thus, the lack of a national tourism policy may not be seen as an "explicit" policy within the larger context of national development, but it has implicit spatial effects. The regions, therefore, are not arbitrarily defined, but are the material expression of the ends to which the state's power is applied (Gore, 1984). The concentration of 
TABLE XVII

1986 GDP BY PROVINCES AT CURRENT

PURCHASER'S PRICES

(MIILION TL)

\begin{tabular}{lrr}
\hline Provinces & 1986 & $\begin{array}{c}\text { Percentage } \\
\text { (milion TL) }\end{array}$ \\
\hline & & \\
Western & & 8,13 \\
Izmir & $3,182,107,1$ & 1,20 \\
Mugla & $470,017,9$ & 2,33 \\
Manisa & $910,869,3$ & 23,30 \\
Istanbul & $9,124,332,5$ & 0,50 \\
Eastern/Southeastern & $195,397,3$ & 0,06 \\
Mardin & $25,221,5$ & 0,27 \\
Hakkari & $106,147,4$ & 0,68 \\
Van & $265,536,9$ & \\
Erzram & & \\
\end{tabular}

Source: Istanbul Chamber of Industry (1988)

TABLE XVIII

GDP BY PROVINCES BETWEEN 1980 AND 1986

REIATIVE SHARES OF CURRENT PURCHASE PRICES

(s)

\begin{tabular}{|c|c|c|c|c|c|c|c|}
\hline & 1980 & 1981 & 1982 & 1983 & 1984 & 1985 & 1986 \\
\hline Mardin & 0,56 & 0,58 & 0,57 & 0.49 & 0,45 & 0.51 & 0.50 \\
\hline Hakkari & 0.11 & 0.10 & 0.10 & 0.09 & 0.07 & 0.07 & 0,06 \\
\hline Van & 0.36 & 0,35 & 0,34 & 0,32 & 0.29 & 0.28 & 0,27 \\
\hline Erzrum & 0,84 & 0.82 & 0.82 & 0,72 & 0.71 & 0.69 & 0.68 \\
\hline Kars & 0,49 & 0,53 & 0.49 & 0,50 & 0.45 & 0.45 & 0,43 \\
\hline Diarbakir & 0.85 & 0.84 & 0.77 & 0.81 & 0.82 & 0.83 & 0.81 \\
\hline
\end{tabular}

Source: Istanbul Chamber of Industry, 1988. 
13 touristic centers in two adjacent regions (western and southwestern) for the purpose of tourist investment has certain developmental implications which can be understood as an integral aspect of state policy for regional planning. In Gore's terms "and in developing countries, this means studying it as an integral part of state development policy "

To note, development of tourism as it appears now, will result in the furthering of unequal development which has already produced the following picture as Danielson and Keles (1980:282-283) described.

Because of these regional disparities, urban development has been heaviest in Western Turkey, and urban migrants tend to flow westward from the impoverished eastern provinces: Most of the major urban centers are located in the west of a line drawn between Samsun and Adana.t! As reiterated by Danielson and Keles, in 1975, urban centers in the west accounted for 92.7 percent of the 10.3 million Turks who lived in cities with more than 100,000 inhabitants:

The situation in the eastern provinces has not been encouraging in the 1980's in the labor force and the falling GDP of eastern provinces: In fact, the regions with less per capita GDP are those that remained neglected in terms of utilizing their tourism potentials. Therefore, tourism has not been realized as a deliberate policy to achieve longterm regional policies. It also has not been defined by national plans nor by an overall regional strategy:

Regional Issues and Implications

In Turkey as in most of the IDCs, population and activities are unevenly distributed over the space, Therefore, disparities are acute in various areas, namely, industrial disparities, service disparities, 
income disparities, and migration disparities, As pertaining to industrial disparities, the share of employment is close to ten percent in the western regions and even reaches 20 percent in Izmir and Istanbul; whereas, it is below six percent in the Black sea and central provinces, and as low as one or two percent in most eastern provinces close to the Iranian borders: In terms of service disparities, differences are obvious in relation to public services and rate of urbanization, For instance, rates of schooling in secondary education was 60 percent or more for western provinces and less than 20 percent in the eastern provinces: The rate of urbanization was recorded as 55 percent for the western part versus 30 percent for the eastern regions: Income and migration disparities are augmented by the economic stagnation and lack of an industrial basis in the eastern provinces (OECD, 1988)

Regional Implications of Nonregional Policies One key to understanding regional disparities is to look at the regional implications of the government's nonregional policies: Foreign trade policies: Prior to 1980, Turkey adopted an importsubstitution policy. Local industries were heavily protected from foreign competition by quotas or high tariffs. This policy alone contributed primarily to the richer regions in the western provinces which were manufacturing areas, Poorer regions, as agricultural areas, did not benefit from such protections, of course, one can argue that agriculture price subsidies counterbalanced this situation, but surprisingly it is the western regions again with the fertile 
agricultural lands that benefited from these subsidies, For the same reasons, it is likely that the shift from ISI to export-oriented strategy will benefit western regions only for they are the exporters of goods:

Public versus private sector policies: Policies, until 1980, have favored public enterprise as opposed to private businesses! The public sector's policy of investment (under the State Economic Enterprises (SEE)) has been more sensitive to the dispersion of investment overall, As OECD (1988:25) reported:

Public enterprises were not constrained. بby cost considerations. They could more easily be located in high cost areas and it seems that the share of public investments, or of employment in public enterprises, is higher in lagging regions.

Conversely, the shift to privatization in post 1980 will be more favorable to the western regions for the reasons of low cost, better infrastructure, and overall comparable advantages.

Agricultural policies: Until 1980, the government was actively involved in helping the agricultural sector by policies of 1) production price supports, 2) irrigation investments, 3) agricultural input--fertilizers, seeds, tractors--subsidization. However, these subsidies (through the budgetary transfers) also benefited the most developed regions, since they were also important agricultural producers

For example, tractors were produced at a cost significantly higher than international prices, and sold to peasants at a price lower than production cost due to government subsidies, Table XIX demonstrates 
TABLE XIX

TRACTORS BY REGIONS, 1980

\begin{tabular}{lll}
\hline Number of & Hectars Sown \\
Regions & Tractors $(000)$ & Tractor \\
\hline
\end{tabular}

\begin{tabular}{ll} 
Northeast & 12 \\
Southeast & 16 \\
Central East & 30 \\
Central North & 69 \\
Central South & 52 \\
Aegean & 96 \\
Marmara & 74 \\
Mediterranean & 56 \\
Black Sea & 31 \\
Turkey & 435 \\
& \\
\hline Source: oEcD, 1988:26, \\
Source of data: World Bank, 1983b,
\end{tabular}

that the western developed regions were the highest beneficiaries of tractor subsidies notwithstanding the lower acreage of cultivatable land.

In terms of irrigation policies, the construction of dams and reservoirs and the distribution of water is controlled by the General Directorate of State Hydraulic Works (DSI):

Credit policies: "Credit" is one of those areas that has been under strict governmental control, Many of the specialized banks, at least until 1980, were state owned (i,e., Agricultural Bank, The People's Bank, The Housing Bank, The Provincial Bank)! Interest rates on deposits were limited to levels much below the rate of inflation, thereby discouraging savings! Iending was allocated for designated 
purposes or sectors, that is, agriculture, exports, state economic enterprises, housing, small artisan and traders, regional development, local authorities, tourism, maritime navigation.

Credit policies, in general, have benefited the most prosperous regions. This was certainly the case for exports, maritime navigation, tourism--because these activities are centered in the developed regions. For example, Agriculture Bank loaned less money to the eastern regions than it was getting from them; As Table $\mathrm{XX}$ indicates, investment opportunities in agriculture were more promising in the west than in the east. Therefore, credit policies did not work favorably for the less developed regions of the country,

Centralization policies: In Turkey's highly centralized system of government, only two levels of government are realized for planning and implementation--the national and the local levels, Most of the power, and money, and expertise is at the national level. This can be seen in Table XXI which shows revenues and expenditures.

Although the share to local governments has recently been increased, in practice, municipalities, not to mention provinces, are heavily dependent on central government decisions. Most public services, such as education, transportation, health, sanitation, water, electricity, are directly provided by the central government or by nationwide agencies.

Centralization has had a mixed effect on regional development. As OECD (1988:30) reported, "All this considered, it seems likely that the centralization that prevails in Turkey has operated in favor of the less developed regions of the east." 
TABLE XX

LOAN/DEPOSIT RATIOS, TCBZ, BY REGIONS, 1981

\begin{tabular}{lc}
\hline Regions & Ratios \\
\hline & \\
\hline & \\
Northeast & 0.73 \\
Southeast & $0: 56$ \\
Central East & $0: 68$ \\
Central North & $1: 73$ \\
Central South & $0: 96$ \\
Aegean & $1: 59$ \\
Marmara & 0.68 \\
Mediterranean & $3: 75$ \\
Black Sea & $1: 81$ \\
Turkey & 1.44 \\
\hline
\end{tabular}

Source: OECD, 1988:28,

Source of data: World Bank, 1983b,

TABLE XXI

CENTRAL AND LOCAL GOVERNMENT ACCOUNTS, 1986

\begin{tabular}{lcc}
\hline & $\begin{array}{c}\text { Central } \\
\text { (in bilion } T L)\end{array}$ & $\begin{array}{c}\text { Local/Central } \\
\text { Percentage }\end{array}$ \\
\hline \hline Total Revenues & 4,476 & 15 \\
Taxes & 3,829 & 4 \\
Shared Taxes & --- & - \\
Transfers from Central Gov: & -647 & 29 \\
Other & 647 & 12 \\
Total Expenditures & 5,263 & 12 \\
Current Expenditures & 2,086 & 30 \\
Investments & 989 & 3 \\
Othex & 2,188 & \\
\hline
\end{tabular}

Source: OECD, 1988:29, 
Equally important to note, the government has committed to the development of eastern regions by the establishment of the Department of Less Developed Regions and "Priority Development Areas!" As OECD (1988:34) reported, "The foundations on which the regional policy objectives are based, therefore, appear to be more social or political than economic: "

However, the policies of the "etatist" era under state's involvement in reducing regional disparities-- notwithstanding their minimal success--likely will be abandoned by shift to export orientation which encourages state's minimal intervention in the process of development (iıę, privatization of public enterprises)! As Danielson and Keles (1985:209) reiterated:

While government policies through the 1950 s played a significant role in spreading urbanization and industrialization, these efforts had relatively little impact on the eastern and southeastern regions, which continued to lag far behind the urbanized western provinces in industrialization, income, and public services,

Moreover, implementation of regional development plans became a conflicting area among planners in terms of priorities and goals! As Danielson and Keles (1985:210) noted:

Industrialization remained the prime development goal, and dispensing investment to enhance territorial social justice has not been viewed by most economic planners as an efficient way to industrialize;

Thus, "tourism" as a means to development under the same "traditional" planning system in the context of XOG, not only will intensify regional disparities, but also the sector itself will have an uncertain future, This is for two clear reasons: First, the planners assume the problem of less developed regions would be spontaneously 
solved as the rate of economic growth increases (an economistic approach). Second, tourism as regional planning itself, has been handicapped by the absence of policy/planning which is reinforced by shortcomings of government agencies as is needed to be organized on a regional basis:

The major planning problem is lack of regional policies due to the Turkish administrative system, Major subdivisions is Turkey's provinces, and none is large enough to encompass an entire region, As Danielson and Keles (1985:212) described,

Regional planning and administration, in the sense of a systematic, integrated, cross-sectoral approach to a geographic area, either gets done at the provincial level, „or at the center. The provinces are poor, understaffed and geographically too small for sensible planning of some functions, while the central government is distant and remote from the problem.

Furthermore, tourism likely will suffer due to lack of legal authority of regional plans and lack of active constituency pressing for their execution, Even SPO, the most important central agency for regional development, has been unwilling to use its power in favor of the investment proposals made by the regional plans (Danielson and Keles, 1985)。 
CHAPTER III

THE DEVELOPMENT OF TOURISM IN TURKEY

BACKGROUND

The recognition of tourism and its subsequent history began after the establishment of the Turkish Republic in 1923: This does not mean that tourism did not exist before the Republican era, but if it did, there is no indication of its recognition as an economic activity. My examination of the development of tourism is directed to the postRepublic era, and it was not until the 1960 s that the literature began discussing this sector and its development.

Historically the first tourism movement was the Turk Seyyahin Cemiyti, or the "Turkish Association of Travelers," in September 1923. The aim of the Association was to organize trips in order to make Turkey's important cities and works of art known, as well as to instill pride in the Turk about his heritage. Meanwhile, the Association, in cooperation with the municipality, the inter-city boat service company, and the Navigation Administration, transported tourists by small boats and had the authorities prepare a list of taxi and boat fares and porter fees.

The name of the Association changed to "The Touring and Automobile Club of Turkey" (T.T.O.K॰) in 1930. Important steps were taken in 1934 when for the first time this sector attracted the government's attention, and tourism was joined with the Foreign Trade Department and 
Turkish office until 1937. In 1939 it was upgraded to the "Directorate of Tourism."

In 1940, another tourism office was established in the administrative body of the "Directorate General of Publication." The tasks of the Department of Tourism were defined in 1943 by the law regulating the "Directorate of Press and Information." The name of this Directorate General was changed to "The Directorate General of Press, Information and Tourism" on June 30, 1949, by Law No. 5392. According to Article 17 of the same law it was decided that a "Tourism Consultative committee be established to discuss tourism affairs and necessary measures in this connection."

The first meeting of this committee was held on December 19, 1949. Draft Law No. 6086, entitled "Encouragement of the Tourism Industry," which was prepared by the Tourism Consultative Committee, was put into effect on May 22, 1953.

The Directorate General of Press, Information and Tourism became the Ministry of Press, Information and Tourism on November 25, 1957, and continued its functioning under the name of the Ministry of Tourism and Information by Organization Law No, 265 on July 2, 1963.

The administrative evolution of this sector went on to yet another change in 1968 when the "Affairs of Tourism and Information" became an independent ministry which finally entered its present phase on March 16, 1982, as "The Ministry of Culture and Tourism" (MCT) (Hamitogullari, 1968, 1970; Turkey, Tourism, 1986). Table XXII demonstrates the gap between Turkey and other Mediterranean destinations in terms of tourist 
TABLE XXII

TOURIST ARRIVALS AND THE BED CAPACITY

BETWEEN THE SELECTED COUNTRIES, 1981

\begin{tabular}{lrr}
\hline Country & Tourist Arrivais & Bed Capacity \\
\hline \hline Turkey & $1,405,311$ & 58,200 \\
Portugal & $2,566,000$ & 98,800 \\
Greece & $5,094,349$ & 295,704 \\
Spain & $40,129,323$ & 981,600 \\
Italy & $43,506,114$ & $1,576,871$ \\
France & $30,572,000$ & $1,578,000$ \\
\hline
\end{tabular}

Source: ATA, 1986:32.

Source of data: Tourism Policy and International Tourism in OECD Member Countries.

arrivals and bed capacity. See also Figure 6 , as it illustrates

Turkey's tourist trend between 1974-1985.

One of the reasons for the numerous changes in the organizational responsibilities of the tourism sector was the insignificancy of the sector itself prior to 1980 s (i.e., its share in GDP and export). For instance, the establishment of the SEE in the 1930s, as the main policy instrument for industrialization, did not consider the importance of the service sector in general and therefore tourism in particular. This trend continued until the 1980s. It was then that tourism was recognized as a promising sector to earn foreign exchange. Therefore, tourism as an independent sector and as an exclusive ministry became indispensable

Secondly, the lack of overall cohesiveness in the state structure in terms of the consolidation of various groups and party governments led to much of the disorganization of the tourism sector. 


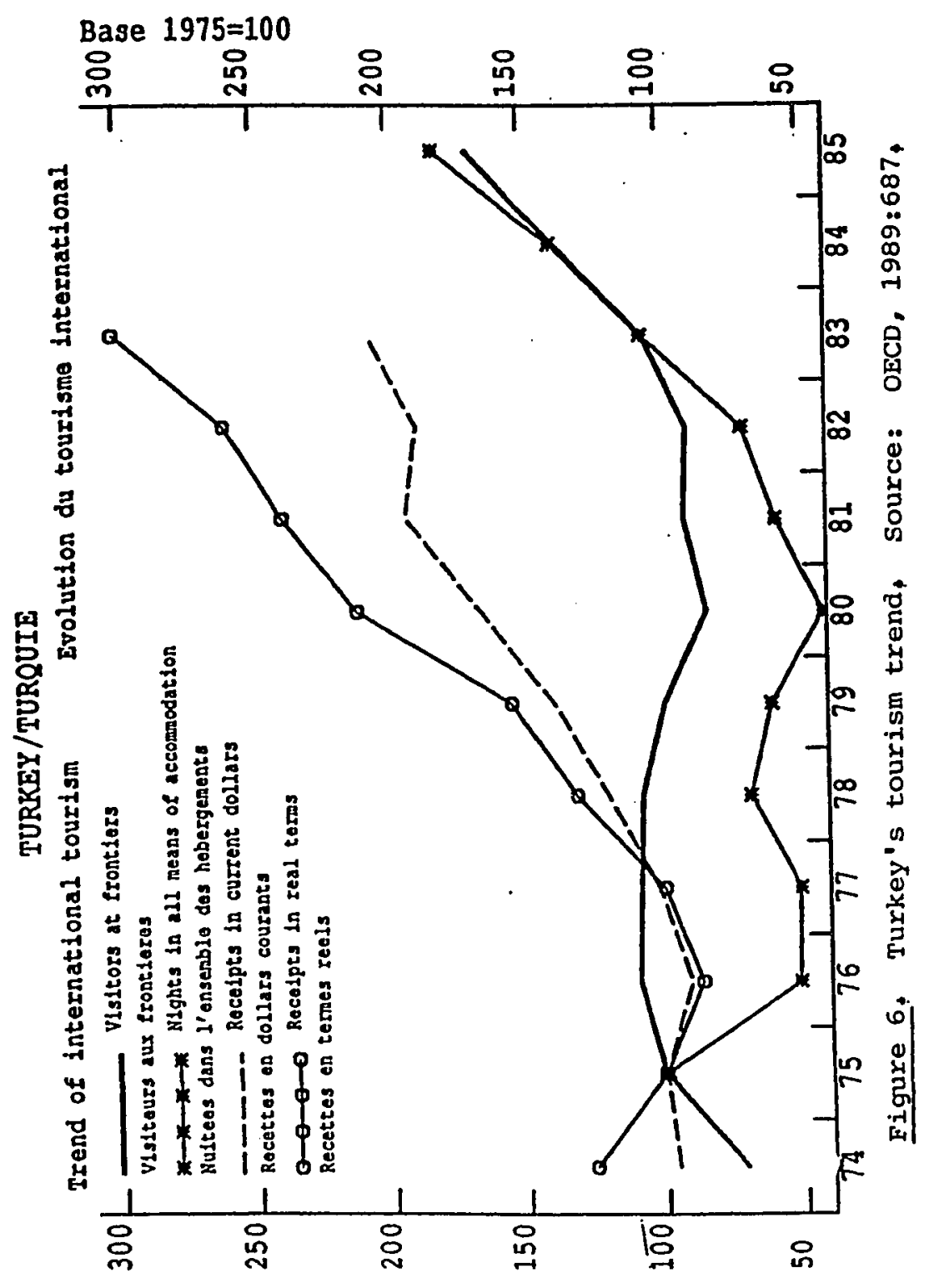


The instability of the government became apparent between the 1950 s and 1980 s as manifested in the three successful military interventions. The organizational changes may very well be explained by the governmental instability. Moreover, the instability also reflects the deficiencies of legitimacy, capacity to make policy, participation in policy process, and information, as well as being open to foreign models (Horowitz, 1989).

TOURISM POTENTIAL

Turkey has an exceptional wealth of tourism assets which compare favorably with those of competing countries in the Mediterranean region and elsewhere (Diamond, 1979; Firat, 1989). Its natural attractions include a vast, varied and unspoiled landscape with forests, rivers and mountains as well as an extensive selection of beaches along its 8,333 kilometers of coastline (vs $2,753 \mathrm{~km}$ of landline) extending on three sides (Figure 7) (Turizm el Kitabi, 1988)。 Turkey's geographical location forms a bridge between Europe and Asia, giving it the role of a transition culture between East and west. Turkey, due to her position as a Mediterranean, Middle Eastern and Balkan country, is situated on the most important main development axis of international tourism activities. Turkey is on the juncture of the Asia, Europe and Africa continents: Because of this geographical position, she is accessible to great development with regard to international tourism (Akoglu, 1970). The country's potentials and richness are termed "touxism patrimony." The factors which constitute tourism patrimony are

* Natural beauty 


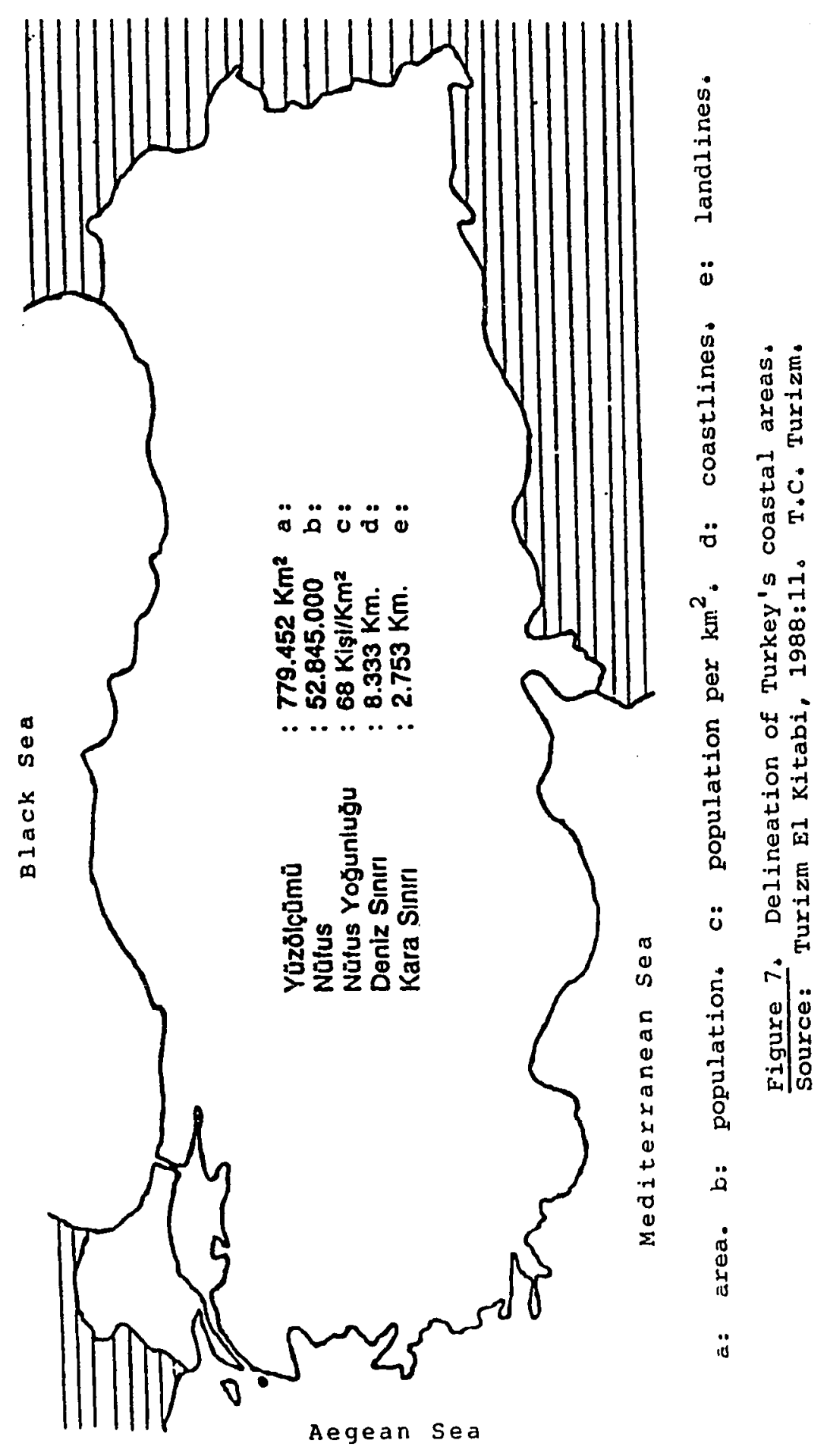


* Archeological and historical works

* Customs and traditions, that is, culture

* Folklore and hospitality

Turkey is a country which bears the signs and possesses the works of 14 civilizations (Akoglu, 1967:31-32).

1. The most ancient works belong to the civilizations of the Stone Age and are found in Asia Minor. The remnants of a neolithic city belonging to 8500 B.C. were found in "Catalhoyuk" (Konya) in excavations made in 1962-63. Archeologists once thought that the most ancient civilizations were to be found in 6500 B.C. Mesopotamia, but now accept that the most ancient are to found in Asia Minor (now Turkey).

2. Tell Halef civilization belonging to a period between $3800-$ 3500 B.C.

3. Works of the Uruk civilization, 3400-3100 B.C.

4. Artifacts belonging to the third century B.C.

5. Hatit civilization, 2500-1900 B.C.

6. Hiti-Hurit civilization, 2200-700 B.C.

7. Frichian civilization, 1180-seventh century B.C.

8. Ionian, Eolian, Dorian, Lydian civilizations, 1100-sixth century B.C.

9. Macedonian civilization, Alexander the Great, 334 B.C.

10. Roman civilization, 129 B.C. --450 A.D.

11. Byzantium civilization, 475-1453

12. Seljuk-Turkish civilization, 1071-1300 
13. Ottoman-Turkish civilization, 1300-1923

14. Turkish Republic, 1923-present

The recent boom in Turkish tourism (758 increase in 1987) (see

Figure 8) can be explained by Turkey's role as a newcomer in tourism fashion in the Mediterranean region: This process can be explained through the Product Life Cycle (PLC) theory: PLC is a generalization of a product's evolution as it passes through the stages of introduction, growth, maturity, and decline (Cooper and Jackson, 1989:379): Accordingly, the region's traditional tourist destinations have already entered their maturity. Therefore, a new product, Turkish tourism, is in its introduction stage, While the tourism sector was overlooked under the ISI strategy, its conduciveness to exploitation under XOG can be elaborated from various angles.

Tourism potentials can be reflected in the sector's activity by comparing the year 1987 with the year 1983, as follows:

* 758 increase in foreign arrivals $(2.7$ million $)$

* 1008 increase in the number of licensed beds $(118,000)$

* 3008 increase in foreign exchange receipts from tourism (US $\$ I_{0} 8$ billion)

* 508 increase in tourism investments

* 6008 increase in the tourism investments with foreign capital

Tourist potentials and attractions are one part of the tourism system which needs to be coordinated along with other elements in the tourism system. As Gunn (1979) noted, tourist attractions are only part of the total tourism system and should not be viewed as isolated 


\section{(1,000 persons)}

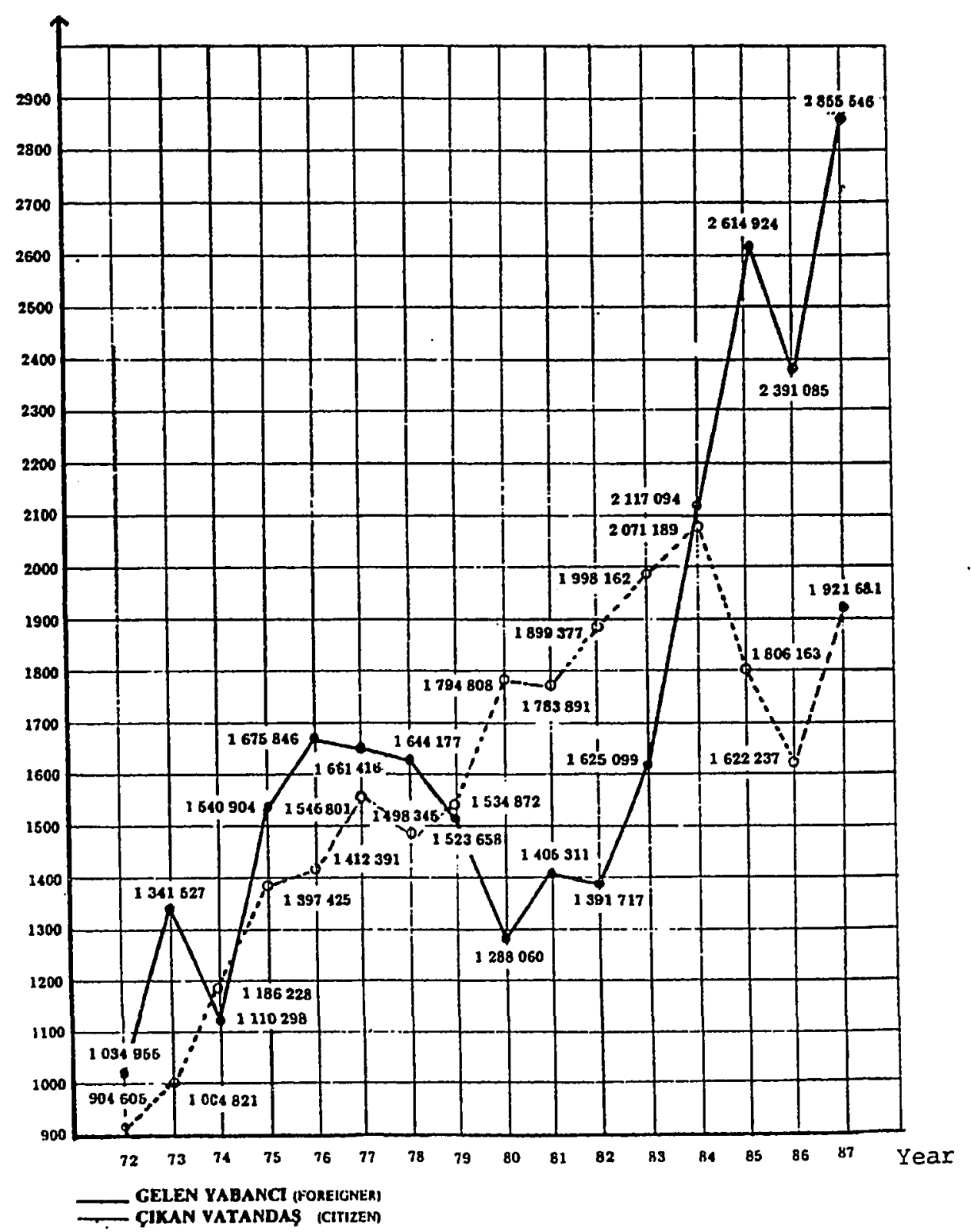

Figure 8. Number of foreign arrivals and citizens traveling abroad: Source: MCT, 1988:72. 
elements; Gunn (1979:21) suggests that, although all five elements, e.gi, tourist characteristics, transportation, attractions, service facilities, and information/direction, are necessary to a viable tourism system, the real energizer is the integration of attractions (Uysal, 1983:13)

CLIMATIC POTENTIALS

As might be expected in a country the size of Turkey, which comprises some 781,000 square kilometers, the climatic conditions vary considerably from region to region. The annual average amount of sunshine ranges from 150 days in the north to 300 days in the south. In the tourism development areas along the coasts of the South Aegean and Mediterranean, the tourism season lasts from April to October

Turkey's geographical location has made it very suitable for attracting tourists from the tourism-generating countries of Europe and from the growing Midale East tourism market, as it lies within the preferred non-stop flight range of up to four hours. As Turkmen

(1988:1) noted,

Turkey has all the ingredients necessary for a perfect tourism destination; she possesses a diversity of scenery and climate, an unpolluted coastline of more than 8,000 kilometers; a rich cultural heritage with more than two million historical treasures in her museums; a wealth of layer after layer of archaeological sites dating as far back in time as the earliest known human settlements; a rich variety of flora and fauna; one of the world's most famous cuisines and the well known warmth and hospitality of its people who regard a tourist not as a "customer" but a "visitor:"

There is a famous saying along the coastal areas of the South Aegean and the Mediterranean which goes: The whole year is called "the season." 
SEASONAL PATTERNS

One of the characteristics of the tourism sector in Turkey is its seasonality, Table XXIII depicts the tourist arrivals by months, the heaviest being from April to October. It is estimated that about 80 percent of the visitors come to Turkey between April and October: The number of months in the year when foreign tourist hotel occupancy falls below 50 percent of peak month occupancy is six months, as compared to Greece and Spain, which reported eight and seven months, respectively (Zammit, 1981:42): (Also see Table XXIV!̣) This situation requires that consideration be made of potential uses for tourism facilities during the off-season period, perhaps for domestic tourism or alternative programs:

TABLE XXIII

FOREIGNERS ARRIVING IN TURKEY

\begin{tabular}{lrrrr}
\hline Months/Years & 1984 & 1985 & 1986 & 1987 \\
\hline \hline January & 65,864 & 102,277 & 79,502 & 77,471 \\
February & 62,574 & 108,110 & 77,964 & 90,336 \\
March & 90,783 & 156,620 & 138,794 & 104,774 \\
April & 150,301 & 199,962 & 183,026 & 230,324 \\
May & 181,844 & 234,629 & 232,468 & 286,026 \\
June & 197,145 & 255,155 & 234,671 & 321,604 \\
July & 302,720 & 368,155 & 316,749 & 393,697 \\
August & 319,910 & 369,285 & 338,922 & 456,854 \\
September & 266,925 & 300,206 & 277,927 & 341,125 \\
October & 211,228 & 242,288 & 231,265 & 265,351 \\
November & 142,843 & 153,709 & 151,276 & 152,242 \\
December & 124,957 & 124,568 & 128,521 & 135,742 \\
Total & $2,117,094$ & $2,614,924$ & $2,391,085$ & $2,855,546$ \\
\hline
\end{tabular}

Source: TUSIAD, 1988:86: 
TABIE XXIV

SEASONALITY IN TOURISM

\begin{tabular}{ccc}
\hline & Foreign Tourist Hotel & Number of Months in \\
(or Accommocation) & Year When Foreign \\
Nights in Lowest Month & Tourist Hotel Nights \\
or & As Percentage of Peak Month & Less than 508 \\
of Peak Month & (average 1975-1976) & of \\
\hline
\end{tabular}

Bermuda

18

Eqypt

Greece

61

Hong Kong

India

Israel

Italy

Ivory coast

Jamaica

Kenya

Malta

Mexico

Morocco

Pakistan

Philippines

Portugal

Republic of Korea

Senegal

Singapore

Spain

Sri Lanka

Thailand

Tunisia

Turkey

Yugoslavia

$\begin{array}{rr}18 & 3 \\ 61 & 0 \\ 7 & 8 \\ 71 & 0 \\ 49 & 2 \\ 42 & 2 \\ 11 & 2 \\ 37 & 8 \\ 49 & 4 \\ 55 & 3 \\ 15 & 0 \\ 48 & 7 \\ 10 & 1 \\ 48 & 9 \\ 57 & 1 \\ 34 & 0 \\ 51 & 6 \\ 40 & 3 \\ 73 & 3 \\ 24 & 0 \\ 26 & 7 \\ 54 & 6 \\ 17 & 0 \\ 24 & 7 \\ 2 & 6 \\ & 10\end{array}$

Source: UN, 1982:90.

The issue of seasonality manifests a crucial problem because of its effect on "tourist hotel-nights": Tourist hotel-nights in the "trough" month are only between two and 24 percent of hotel-nights in the peak months, in the case of Turkey, Tourist seasonality appears to 
be problematic for the regional tourist service system. In Robinson's (1976) terms, it represents a multi-problem for tourist planners, since it touches upon questions of employment and is a detracting factor to capital investment for "uneconomic" tourist service business.

MODE OF ARRIVALS

The means of transportation for visitors until recently was dominated by the land, particularly for the visitors from neighboring countries. Today the bulk of Turkey's visitors arrive by air (49.548). Traditionally, Istanbul was the dominant gateway, but after the opening of airports in Anatalya and Dalaman, air travel become the dominant mode. Table XXV indicates the distribution of foreigners arriving in Turkey by month and means of transport. As Table XXV indicates, train travel still has the lowest share of use by visitors to Turkey (Uysal, 1983; International Tourism Reports, 1989).

The Istanbul Chamber of Commerce reported that out of a total of $2,855,546$ foreigners visiting Turkey in $1987,1,414,710$ tourists preferred airways, 814,055 preferred road, 62,417 preferred railway, while 564,364 preferred sea transportation. This means that out of the tourists visiting Turkey in 1987, 49.5 percent traveled by air, 28.5 percent by road, 2.2 percent by train, and 19.8 percent by sea (Economic Report, $1988: 72)$.

LENGTH OF VISIT

Even though the average length of stay has increased over the past decade, there is still a need to increase the average length in 
TABLE XXV

DISTRIBUTION OF FOREIGNERS ARRIVING IN TURKEY BY MONTHS AND MEANS OF TRANSPORT, 1987

\begin{tabular}{|c|c|c|c|c|c|c|c|}
\hline & \multicolumn{5}{|c|}{ Means of Transport } & \multirow[b]{2}{*}{ Total } & \multirow{2}{*}{$\stackrel{8}{\text { Share }}$} \\
\hline & & Air & Land & Train & Sea & & \\
\hline January & & 39504 & 31270 & 2717 & 3980 & 77471 & 2.71 \\
\hline February & & 40504 & 40812 & 3308 & 5397 & 90336 & 3.16 \\
\hline March & & $\begin{array}{ll}55 & 081\end{array}$ & 38046 & 3101 & 8546 & 140774 & 3.67 \\
\hline April & & 126474 & 63537 & 4480 & 35833 & $230 \quad 324$ & 8.07 \\
\hline May & & 167833 & 59576 & 2892 & 55675 & 286026 & 10,02 \\
\hline June & & 183029 & 68099 & 4199 & 66357 & 321604 & 11.26 \\
\hline July & & 196365 & 103886 & 9159 & 84287 & 393697 & 13.79 \\
\hline August & & 211971 & 133661 & 11466 & 99756 & 456854 & 16.00 \\
\hline September & & 159913 & 78425 & 7164 & 95623 & $341 \quad 125$ & 11.95 \\
\hline October & & 114723 & 68759 & 5961 & 75908 & 265351 & 9.29 \\
\hline Novemiber & & 64740 & 63860 & 4685 & 18957 & 152242 & 5.33 \\
\hline December & & 54208 & 64124 & 3365 & 14045 & 135742 & 4.75 \\
\hline Total & 1 & 414710 & 814055 & 62417 & 564364 & 2855546 & 100.00 \\
\hline \& Share & & 49.54 & 28.51 & 2.9 & 19.76 & 100.00 & \\
\hline
\end{tabular}

Source: MCT, 1988:34.

Source of data: General Directorate of Security.

comparison to other tourist attracting countries in the region. This

can be achieved by planning and marketing strategies that offer $a$

variety of sightseeing or in-bound touring to different regions.

Unfortunately, the dominant role of foreign tours can disturb such

marketing tactics. For example, a set contract between a package tour and the tour company will be an obstacle to flexibility of the tourists in terms of time. However, it has been documented that for all foreign visitors, the average stay in Turkey was 5.2 days between 1969 and 1972 . 
This increased to 8.5 days between 1977 and 1981 (Uysal, 1983:20). This was reported to have increased to 9.5 by 1985 (Bar-on, 1989).

A recent development in the tourism industry reported by OECD (1987:118) is that the total nights spent by foreign visitors in all forms of registered accommodations rose from 1.1 million in 1980 to 8.3 million in 1987. No data are yet available for 1988, but as International Tourism Reports $(1989: 46)$ estimated, it might reach 11 million. This would suggest at first sight that the volume of foreign tourism has expanded tenfold during the cecade.

Data on the length of stay needs to be organized and analyzed to report the correct number, both for registered and non-registered accommodations. There have been indications that an increasing proportion of foreign visitors arriving at Turkey's frontiers could be staying in hotels and other registered accommodations; again, this is in part due to the increasing numbers of holiday makers from Europe staying for one or two weeks in a hotel, pension or holiday camp. At the same time, a decreasing proportion are the Muslim tourists who tend to avoid registered accommodations, usually staying privately, often in an unregistered apartment (International Tourism Reports, 1989).

TOURIST REGIONS

Traditionally, the spatial distribution of tourist activities in Turkey has been concentrated in the western regions. Even though, comparatively, the western and southwestern regions are tourist demand areas (e.g., for sun, sand and sea), the tourism potentials of other regions should not be ignored. Actually, the bulk of antiquities, 
historical and archeological attractions are located in the eastern regions with their unique culture; However, as of today 80 percent of tourist establishments are in the three western and southwestern regions of Marmara, Ege (Aegean Coast) and Akdeniz (Mediterranean Coast), while the rest are distributed in the remaining regions of the country which encompass four more regions of Icanadolu (Central Anatolia), Karadeniz (Black Sea Coast), Dogu Anadoldu (East Anatolia), and Guney Dogu Anadolu (Southeast Anatolia) (see Figure 9):

The Black Sea Coast, which is a potential region for expanded tourism, particularly domestic tourism, has not attracted any attention for tourism development one of the reasons for this under-utilization of the region is the lack of policy for future planning, This is reflected in the policy crisis in tourism for domestic tourism. Secondly, the private sector is unwilling to participate in a region that may not be as lucrative as other regions, Table XXVI indicates the distribution of the tourist establishments and the number of beds in each region for the years 1983-1987, where there are 285 establishments in the Marmara region; the southeast region had only 21 tourist establishments for the year 1987 .

The reasons for underutilization of various potential tourist regions (e.g., Black Sea) is because of the absence of "national tourism planning" as a part of broader development policies. As Pearce (1989:250) noted,

As Acerenza and others have argued, planning for tourism at the national level, as at other scales, should be undertaken in the light of broader national development goals and objectives: 


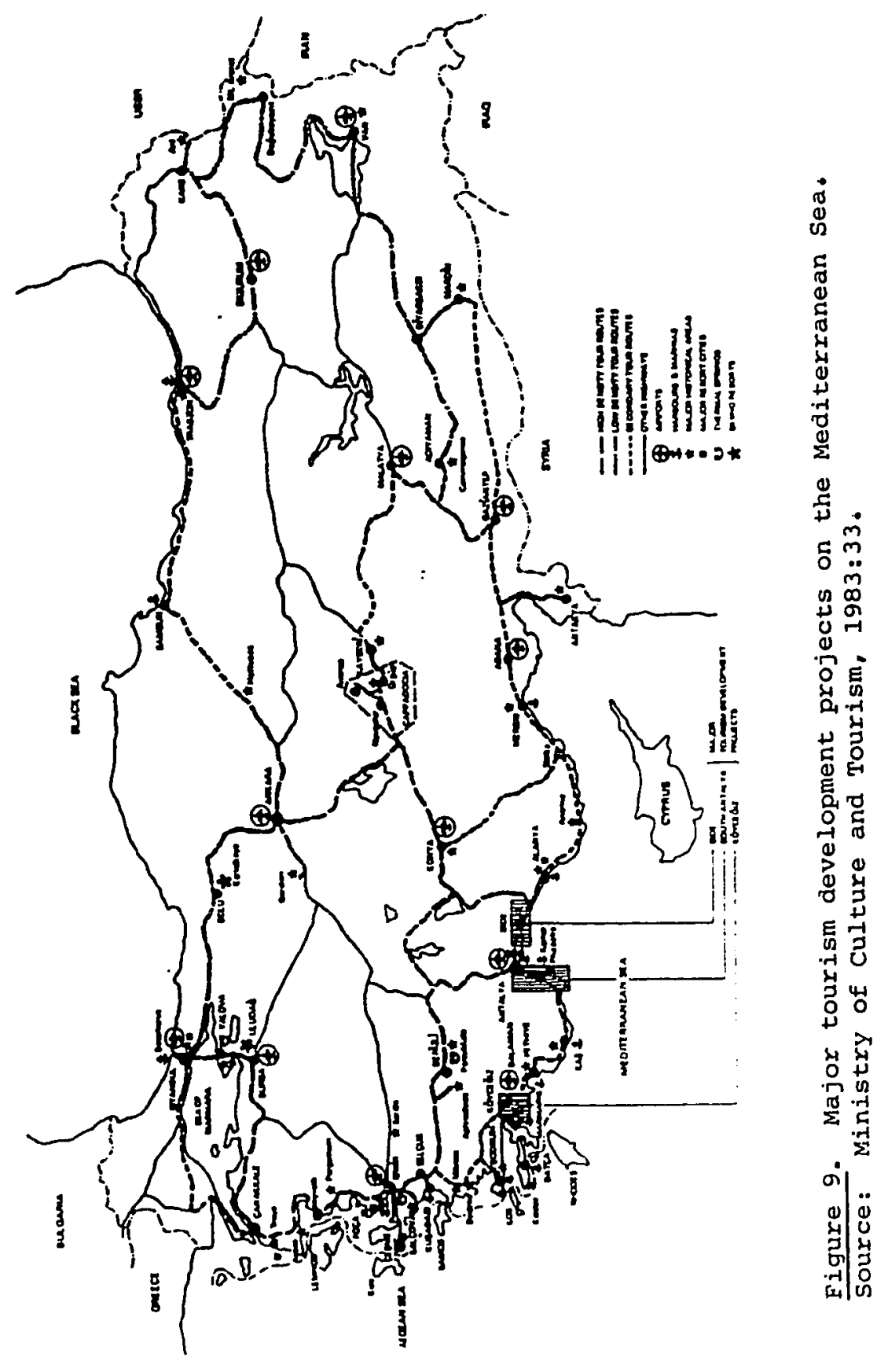




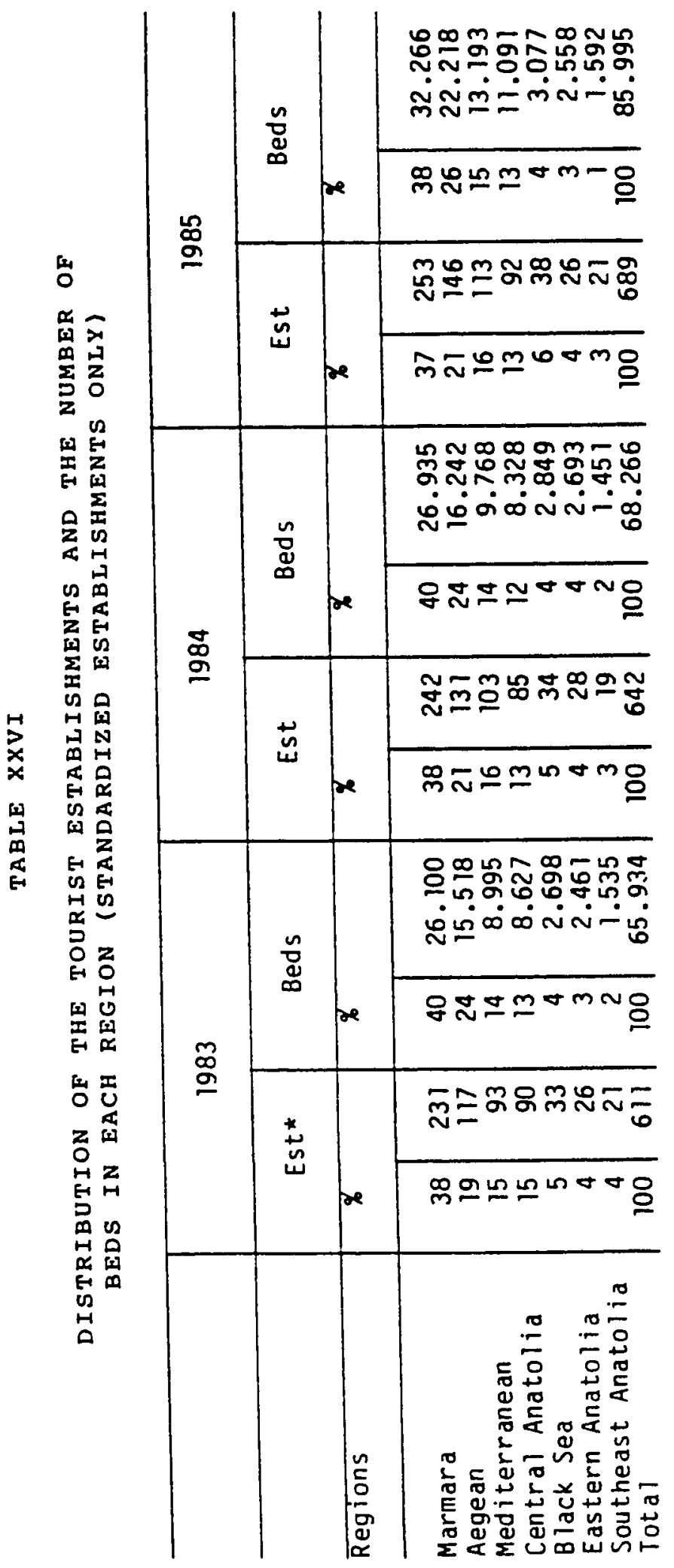




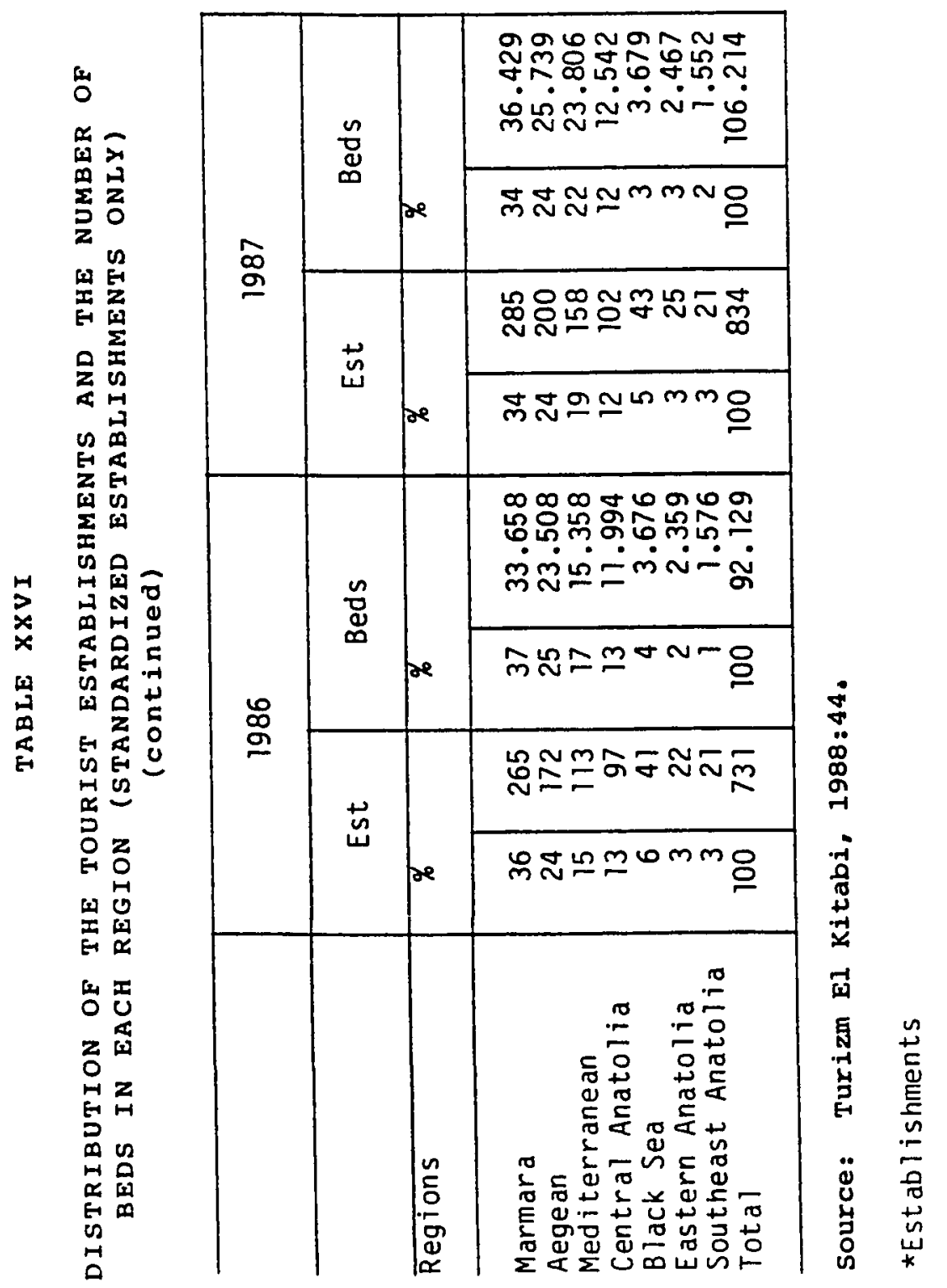


Tourism planning usually falls into one of three categories: First it can be encouraged explicitly by firm government direction that plans for future development in terms of the country's long term goals. Second, it can be loosely or vaguely articulated by the government and the tourism planner has little guidance as to what overall goals should be pursued through the development of tourism. Thirdly, it can be expressed in terms of overall tourism goals with no reference to broader issues (Pearce, 1989). Turkey's case clearly fits into the latter two categories, first for the lack of planning for certain regions that have clear potentials as tourist regions. Therefore, the Black Sea region as well as southeastern regions have yet to have any planning process applied.

It is obvious that present tourist investment policies are in favor of those regions that are already developed, regardless of the comparative advantages between regions. Even though tourism revenue rose at levels beyond expectations, particularly after the introduction of the Law Encouraging Tourism and the "tourism development fund," still the utilization of tourism resources are far from being satisfactory. While tourism attractions are many in number, not all of them are known or presented properly. Tourism demand and supply are both geared toward the western provinces of Turkey. The regionalization of tourism is as old as the planning experience itself. The ideal of channeling limited resources of supply toward those areas which are defined as having a priority in tourism development has resulted in a handicap to the eastern, less developed provinces. These areas are ineligible for attracting public and private investments. The SPO in a report for OECD 
member countries elaborated that the tourism profile of the East is not encouraging although the potential for the area is very rich in terms of tourism resources! The limited overnight capacity and the lack of presentation investments are the main tourism-related problems of the less developed regions (SPO, 1987);

Consequently, the tourism sector has become one more means to intensify an already established regional planning which has come under attack for being a functional approach rather than a territorial approach; As Gore (1984:159) described,

Functional approach is concerned with the location of economic activities.... It is concerned as a purely technical exercise which relies heavily on mathematical models, such as input-output analysis--it emphasizes efficiency and policy decisions are usually made outside the regions which are affected by them, in a few centers of power, ,as Friedmann and Weaver boldly put it, "growth center doctrine is quite useless as a tool of regional development:"

The terxitorial regional planning approach to remedy the regional disparities, advocates an integrated mobilization of the human and natural resources of specific historically defined regions, It is an "endogenous activity" conducted within the regions where its decision takes effect. It engages the people of that region within the planning process, which necessarily becomes a political process, and it emphasizes equity through seeking a general improvement of the quality of living for all the people in the area (Gore, 1984:160),

INSTITUTIONAL ELEMENTS OF TURKEY'S TOURISM

Turkey's tourism is organized and administered by the following three institutional elements: the State Planning Organization (SPO), 
the Ministry of Culture and Tourism (MCT), and the Tourism Bank (TB): These institutional elements are responsible for marketing programs, education and training, legislation and regulations, public and private sector investment policies, public and private organizational structures, policies and planning, and environmental and socioeconomic program.

\section{State Planning Organization}

It was not until the formation of the SPO after World war II that tourism became recognized as a sector to be included in the National Development Plans, Central planning was introduced on May 27, 1960, as a guiding principle of economic policies, and with the Republican party back in power in the coalition government after the election of october 1961, the concept of central planning gained strength,

On September 30, 1960, Law No, 91 concerning the establishment of the SPO was issued. The SPO was to undertake the task of the implementation of the plan through its three departments: 1) the Economic Planning Department; 2) the Social Planning Department; and 3) the Coordination Department (SPO, 1964; Hershlag, 1968): The SPO oversees the National Development Plan and it performs the following functions:

a) To assist the Turkish government in determining economic and social objectives and policies through full-scale collection and evaluation of data on all types of natural and economic resources:

b) To make recommendations and to act in an advisory capacity for the government in order to secure coordination of the activities 
relating to the economic policy of the Ministries,

c) To prepare long and short term plans for the realization of objectives adopted by the government:

d) To advise on the improvement of the organization and the functioning of the government offices, agencies, and local administration's concerns, in order to assure the successful implementation of plans and programs.

e) To follow up the implementation and evaluation plans, as well as revisions where necessary.

f) To propose measures which will further the activities of the private sector and bring it more in line with the goals and objectives of the plan (Guneysu, 1983). The centralized top-down nature of the SPO is crystallized into "the high planning council" that acts as the supreme body of the SPO, It is composed of the prime minister or deputy prime minister who acts as the chairman, the ministers appointed by the cabinet, the undersecretary, and the presidents of social and economic planning and coordination.

In the meetings of the "high planning council" the draft of the five-year plans and annual programs/proposals for investment projects are discussed in order to reconcile the political, financial and technical aspects of these documents.

The high planning council is also responsible for determining the social and economic objectives as well as the strategies for planning. When the council begins to discuss the strategy of a plan, the planners set forth the alternatives which are taken into consideration by the 
council before arriving at the final decision,

The main objectives of the plan and its strategy as determined by the council are transmitted as guiding principles to the authorities of the SPO. The council also reviews the draft plans and programs to secure their conformities with the perceived objectives:

Finally, the plan/program and investment proposals are submitted to the Grand National Assembly for approval: The approval by the GNA implies legislative power, imperative to be observed by all government organizations and ministries as well as the Ministry of culture and Tourism (MCT) (Guneysu, 1983).

The declaration of the SPO culminated in its Five-Year Development Plans, described in Table XXVII. The SPO also actively monitors foreign investment in the tourism industry via the Foreign Investment Department, which is attached to the Prime Ministry! This Department, which was established in 1980 and granted the necessary authority to speed up and simplify the procedures and formalities for foreign investment, can issue, without delay and on behalf of the government, investment encouragement certificates for tourism projects to the extent authorized under existing legislation and forward other proposals directly to the Council of Ministries for their approval. Its authority relates to hotel or holiday village projects of over 200-bed capacity. The SPO's responsibility and its tourism guidelines can be captured in the five-year development plans, Each plan includes a tourism sector which elaborates basic principles and progress, targets and estimates, investments, implications and political measures. It is 
TABLE XXVII

FIVE-YEAR DEVELOPMENT PLAN GOALS FOR FOREIGN TOURISTS AND PERCENTAGE OF ACHIEVEMENTS

\begin{tabular}{|c|c|c|c|c|}
\hline & Year & $\begin{array}{l}\text { Plan } \\
\text { Goals }\end{array}$ & $\begin{array}{l}\text { Total } \\
\text { Foreigners }\end{array}$ & $\begin{array}{c}\text { Percent of } \\
\text { Achieved Goal } \\
\text { (million person) }\end{array}$ \\
\hline $\begin{array}{c}\text { I } \\
\text { First Five Years }\end{array}$ & $\begin{array}{l}1963 \\
1964 \\
1965 \\
1966 \\
1967\end{array}$ & $\begin{array}{l}200,000 \\
240,000 \\
288,000 \\
345,000 \\
415,000\end{array}$ & $\begin{array}{l}198,841 \\
229,347 \\
361,758 \\
440,534 \\
574,055\end{array}$ & $\begin{array}{r}99.4 \\
95.6 \\
125.6 \\
127.7 \\
138.3\end{array}$ \\
\hline $\begin{array}{l}\text { II } \\
\text { Second Five Years }\end{array}$ & $\begin{array}{l}1968 \\
1969 \\
1970 \\
1971 \\
1972\end{array}$ & $\begin{array}{r}588,000 \\
735,000 \\
920,000 \\
1,150,000 \\
1,435,000\end{array}$ & $\begin{array}{r}602,996 \\
694,229 \\
724,784 \\
926,019 \\
1,034,995\end{array}$ & $\begin{array}{r}102.6 \\
94.5 \\
78.8 \\
80.5 \\
72.1\end{array}$ \\
\hline $\begin{array}{l}\text { III } \\
\text { Third Five Years }\end{array}$ & $\begin{array}{l}1973 \\
1974 \\
1975 \\
1976 \\
1977\end{array}$ & $\begin{array}{l}1,243,000 \\
1,404,000 \\
1,586,000 \\
1,792,000 \\
2,026,000\end{array}$ & $\begin{array}{l}1,341,527 \\
1,110,298 \\
1,540,904 \\
1,675,846 \\
1,661,416\end{array}$ & $\begin{array}{r}107 \div 9 \\
79.1 \\
97 \div 2 \\
93.5 \\
82.0\end{array}$ \\
\hline & 1978 & $1,910,600$ & $1,644,177$ & 86,1 \\
\hline $\begin{array}{ll} & \text { IV } \\
\text { Fourth } & \text { Five Years }\end{array}$ & $\begin{array}{l}1979 \\
1980 \\
1981 \\
1982 \\
1983\end{array}$ & $\begin{array}{l}2,178,100 \\
2,461,300 \\
2,756,600 \\
3,087,700 \\
3,458,300\end{array}$ & $\begin{array}{l}1,523,658 \\
1,288,060 \\
1,405,311 \\
1,391,717 \\
1,625,099\end{array}$ & $\begin{array}{l}70.0 \\
52.3 \\
51.0 \\
45.1 \\
47.0\end{array}$ \\
\hline & 1984 & $1,800,000$ & $2,117,094$ & $117: 6$ \\
\hline$\frac{\mathrm{V}}{\text { Fifth Five Years }}$ & $\begin{array}{l}1985 \\
1986 \\
1987 \\
1988 \\
1989\end{array}$ & $\begin{array}{l}2,000,000 \\
2,200,000 \\
2,400,000 \\
2,700,000 \\
3,000,000\end{array}$ & $\begin{array}{c}2,614,924 \\
2,391,085 \\
2,855,546 \\
\ldots \\
\ldots\end{array}$ & $\begin{array}{c}130.7 \\
108: 7 \\
119.0 \\
\cdots \\
-\cdots\end{array}$ \\
\hline
\end{tabular}

Source: Turizm El Kitabi, 1988:34,

Source of data: Kultur Ve Turizm Bakanligi Turizm Istatistikleri Bulteni, 1987, 
likely that the SPO leaves most of the other responsibilities to the MCT (SPO, 1963, 1969, 1975, 1987)。 First Five-Year Development Plan (1963-1967): This plan outlined its principles and targets with emphasis on the tourism sector and contributions to Turkey's needed balance of payments, This plan included a general description of how to increase the demand and make this sector more productive by increasing the tourist staying days (length of visit) to achieve more revenue, The plan is short of objectives and methodology for development as well as implementation; The plan also openly recommended the concentration to be given to those regions that are already tourist attracting centers, but it came up short in addressing the other regions' potential tourist resources that may be utilized under other programs, It mentions:

As resources will be limited in the next five years it will not be possible to develop more than certain of the various regions suitable for tourism. In order to avoid waste, efforts will be concentrated on regions most likely to attract tourists and where these efforts will yield results in a short time (SPO, 1963:379):

The first five-year plan made a projection on demand and

investments based on the existing situation:

Finally, the plan includes measures to achieve the proposed goals, For example,

An organization will be promptly established and given the necessary authority to deal with all aspects of tourism, the establishment of "Tourism Development Societies" in towns and cities with the participation of the relevant tourist organizations will be encouraged (SPO, 1963:382).

Also, in the case of the $\mathrm{TB}$, it recommends restructuring and modification in dealing with financial support for tourism investment, 
Second Five-Year Development Plan (1968-1972): This plan is differentiated from the first five-year plan in two ways: One was the issues of social and cultural aspects of tourism which were briefly mentioned and also the delineation of new directions and policies, with the public sector playing a strong role in the tourism sector. This plan indicated that

although targets of the first plan were generally realized, during the first three years, measures foreseen for this period could not be taken on time due to deficiencies experienced in the implementation of the plan (SPO, 1969:637):

The plan's shortcomings were a clear indication of a lack of policy objectives and tools for planning and implementation. Short-term goals still were dominant and realized targets were not achieved; The second five-year plan did not make it possible to bring all incomes from foreign tourists into official channels. The additional capacity for meeting demand had not shown the required progress as far as quality and quantity were concerned, For the first time the issue of domestic tourism was mentioned. This plan was not short of criticizing the organization of the tourism industry and the institution in charge of the sector: The plan openly declared:

As of this date, it has not been possible to ensure the coordination which is very much required between the public and private tourist agencies: Tourist information is not of any commercial nature and is not carried out separately of political and cultural information. The organization of the education and training activities in tourism sector required for the tourism credit policy was not fully realized, and also financial and legal measures to promote the tourist industry were not brought up to an efficient level (SPO, 1969:638), 
The second five-year development plan also concentrated its investment targets on the western regions, and it was during this period that the Ministry of Tourism and Information was becoming an institution that should be exclusively for the tourism sector. This plan naturally took a strong stand on political measures toward the development of the tourism sector. Those measures briefly were as follows:

1. Amendments necessary to current "organization law" to reorganize the Ministry of Tourism and Information structure.

2. Tourism information on Turkey will be given only by the Ministry and appeal for multisectional cooperation.

34 The plan realized the importance of services, particularly the food service industry and its hygienic quality

4. The Tourism Installations Association will be organized. This was for clarification of an institution to be authorized for a uniform operational policy.

5. Realization of the needs to apply a policy to encourage investment in deprived regions.

6. The issues of education and training to be coordinated under one institution rather than different public organizations.

7. Physical planning for tourism according to Turkey's genera] physical plan.

8. Cooperation with other countries in the region. During the second five-year development plan an acute shortage of tourism supply and services emerged. 
Third Five-year Development Plan (1973-1977): During this plan period emphasis was again directed towards capturing a larger part of international tourism and previous plans were criticized for not achieving their targets. Principles and measures for duration of this plan can be summarized as follows:

1. Investments, promotion activities and the reorganization of the tourism sector shall be based on the requirements of mass tourisma

2. In principle, investments for tourism superstructure shall be made by the private sector in accordance with the requirements of the international and domestic tourism activities. In cases where the Turkish private sector proves financially inadequate in undertaking joint projects with foreign investors, the public sector shall provide partnership for the foreign investors: The public sector will also intervene when pilot operations are needed to activate the market.

3. Physical planning studies shall continue in regions where there is a high potential for tourism by reorganizing the use of land and infrastructural activities, Physical planning studies shall also be oriented toward preventing the unregulated development of hotels and recreation areas! The plan calls for construction of tourism installations to be made in harmony with the infrastructural investments:

4. Coastal lines, tourism zones and national parks shall be preserved and utilized in the interest of the public. 
5. Financing for tourism superstructure shall be provided mainly through the Tourism Bank.

6. By spreading the holidays in the country during the year, domestic tourism activities shall be regulated in order to prevent domestic demand for accommodations coinciding with foreign use, Resort facilities of public enterprises will be made available for international tourism.

7. Emphasis on training and education.

To summarize, the third five-year plan was also a reflection of a lack of a harmonious planning and policy to conform and parallel the economic and social policy of tourism to national policy in general. It lingered on without a clear policy objective, which the tourism sector requires :

Fourth Five-Year Development Plan (1979-1983). During the fourth five-year plan period Turkey's tourism faced a setback and less than 50 percent of forecasted goals were achieved. This was due to the political upheavals which had affected the tourism industry, Nonetheless, the tourism movement was on its course and, ironically, more people traveled abroad: According to the reports during this period, Turkish tourists' expenditures increased 25 percent. On the other hand, most of the predicted needs of tourism supply were not met; Therefore, needs for services and tourist facilities, including the increase of standardized bed numbers, lagged behind; Investments for tourist facilities were shared between private and public sectors which geared toward the acute need for accommodations. 
During the fourth five-year plan the essentials of a tourism policy and its encompassment within the framework of a plan were missing. Its generalized nature without clarification and separate analysis of economic, social and physical aspects could only be attributed to a lack of an overall policy and the political turmoil in Turkey (SPO, 1981)。

Fifth Five-Year Development Plan (1985-1989). This is a period where new economic policies have been formulated on the national level, as well as the establishment of MCT as an independent institution responsible for tourism development. The plan refers to targets, principles and overall policies as well as indicating protective measures for natural and cultural environmental assets! The plan refers to the notion that "Turkey will develop its tourism relations with the OECD and OPEC countries, including Balkan and Third World countries" (SPO, 1987:134): The question remaining to be answered was how Turkey could intensify her share of the tourism trade based on long-term policies in a planned framework. "The plan lacks in its elaboration of 'domestic tourism' instead it only refers to employees will be made to take rest and holiday on maximum concessional terms" (SPO, 1987:134). In this period the overall economic policy on the national level is based on privatizing and minimizing of public sector and its involvement in tourism investment due to the shift in the national development strategy from import substitution industrialization (ISI) to export oriented growth (XOG) + Regarding this policy, the plan advocated the role of the TB to be one of the major lenders for tourism development rather than making direct investments (SPO, 1987). As Table 
XXVIII indicates, the share of total investment has declined through the plan periods

TABLE XXVIII

TOURISM SECTOR'S SHARE OF TOTAL INVESTMENT

Plan Period Target Achieved

\begin{tabular}{llc}
\hline \hline First Five Year $(1963-67)$ & 1.4 & 1.3 \\
Second Five Year $(1968-72)$ & $2: 3$ & 2.1 \\
Third Five Year $(1973-77)$ & 1.6 & 1.0 \\
Fourth Five Year (1979-1983) & $1: 2$ & 0.6 \\
Fifth Five Year (1985-1989) & 0.9 & - \\
\hline
\end{tabular}

Source: MET, 1988:135,

Source of data: DPT - Kalkinma Planlari, Yillik Planari,

\section{Ministry of Culture and Tourism}

The second institutional element for tourism development lies with the MCT, which was elevated to an independent ministerial level in 1982 ; But it was not until 1980 that the integration of the legislative improvements and the ensuring policies were introduced; Basic responsibilities of the Ministry include:

* Underlying development policy

* Supervision of tourism development

* Promotional activities

* Project evaluation and implementation

* Financial assistance

While the SPO prepares the national development plans and general guidelines for each sector, tourism's development, including the industry's planning process and policy formulations, are mostly handled 
by the MCT: One could claim that the role of the Ministry is the most vital and important to the future of this industry among the three institutions (SPO, TB and MCT):

Organization, The central organization of the Ministry (shown in Figure 10) encompasses four main units and one sub-unit. The four main units are:

1. Minister (Bakan) and his/her counselors who are responsible for the decisions that deal with the issues of national interest and concerns, Various departments are organized around the Ministry, including the research center, law, legislation, and regulations, counselors, fine arts, press and public relations, coordinators, and national issues. These departments are elevated to directorate levels which are assisting the Minister regarding overall policy issues in tourism development nationwide.

2. The second tier in the hierarchy is the number of agencies that are responsible for different functions relating to tourism and culture! This tier is known as "Ana Hizmet Birimleri" or "principal units."

3. The third level in the hierarchy occupies the personnel and education slots as well as administrative financial affairs.

4. The fourth category is filled up by agencies that are related to the MCT in a more sub-organizational level independent of the Ministry.

5. The last section is related to the whole organization 


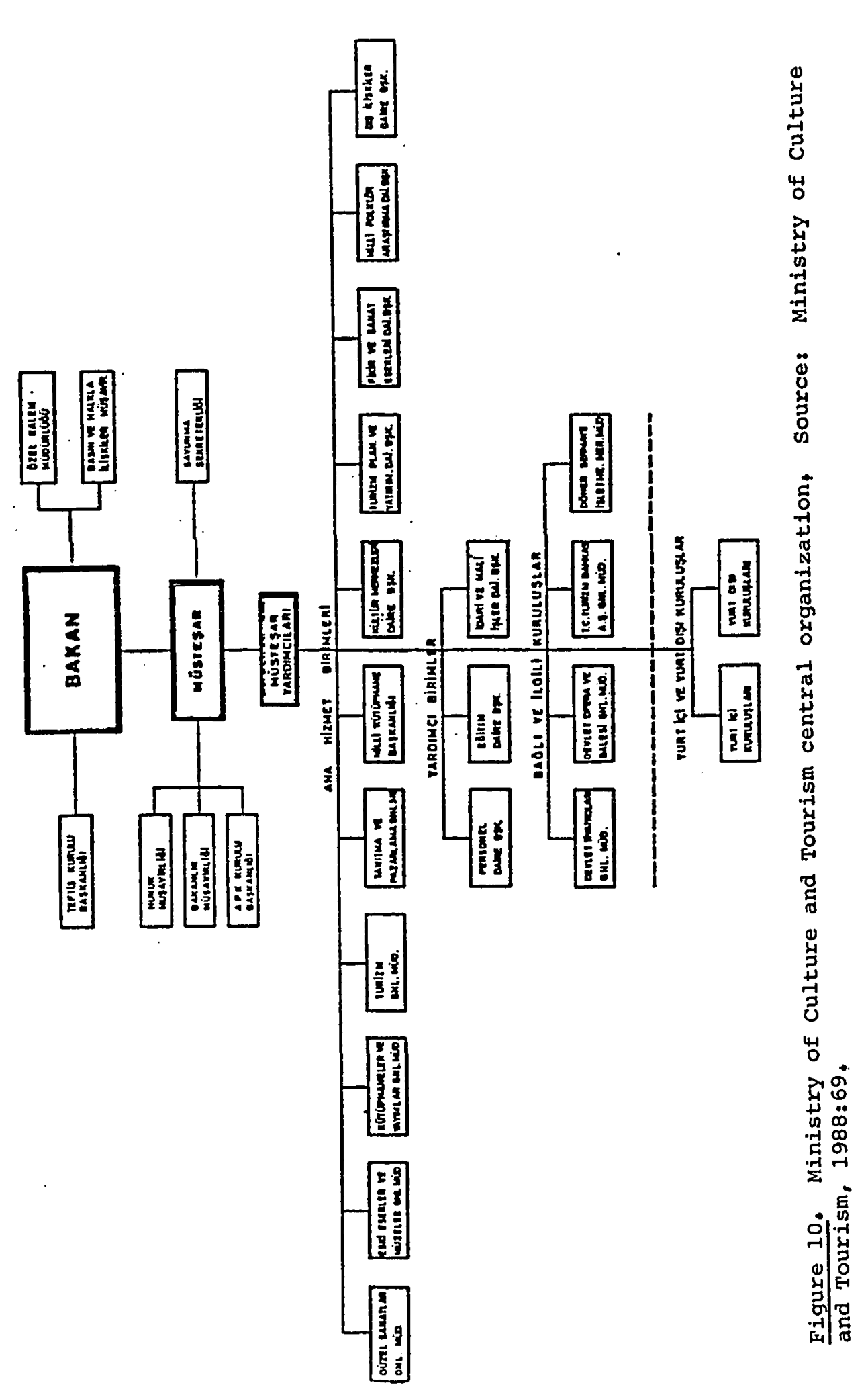


concerns ceremonial issues, but is not an official member of the body of the whole institution.

Functions: As for the other sectors of the Turkish economy, Turkey has adopted the mixed economy principle in the tourism sector (until 1980). In accordance with this policy, the infrastructure for tourism development is provided by the government; superstructural facilities are generally left to private sector investors, even though the government, through the state Pension Fund and the TB, directly owns and operates a number of tourist facilities. Further functions of the Ministry include: assisting, guiding and coordinating public sector investment in Turkey's tourism development which supervises and encourages all business activities in the fields of tourism. The Ministry formulates Turkish tourism development policies and is responsible for coordinating their implementation.

The Ministry reviews feasibility studies submitted in support of proposals with foreign participation and ownership, not only in light of their general economic desirability, but also to ensure that the project will meet the code of standards relating to tourism laid down by the Ministry :

The Ministry is also responsible for assisting potential domestic and foreign investors in the evaluation and implementation of tourism development projects by providing technical know-how, statistical data and information related to potential sites, in order to ensure rapid completion of projects. The Ministry assists investors in obtaining incentives provided by the government for eligible projects and coordinates the infrastructural facilities. In order to facilitate this 
coordination process, a "high coordination council for tourism affairs," comprising the ministers concerned, under the chairmanship of the Prime Minister, has been established. The decisions of this council are implemented by the "tourism implementation council," consisting of the under secretaries of the ministries concerned (MCT, 1983); The MCT undertakes the process of allocation of state lands or appropriation of private land in tourism regions: As documented, Lands owned by the treasury or under the use and control of the state or forest lands located within the boundaries of the Tourist Regions and Tourist Centers, if earmarked for tourism purposes pursuant to land use plans, are allocated to the Ministry of Culture and Tourism following completion of procedures required by Act No, 2634 on the Encouragement of Tourism:

The MCT may expropriate privately owned lands located in tourism zones and tourism centers are earmarked for tourism purposes in accordance with land use plans, Following the expropriation, such real property having gained the status of "Treasury owned land," may be allocated to entrepreneurs under the provisions of the by-law on allocating such lands to tourism investments (TB, 1987:39):

The research, planning and coordination department, within the Ministry's organization, produces the implementation report on an annual basis. The main responsibility of this branch is to identify any other Ministry that will be needed for implementation of a project, and establishment of a time frame for implementation (Kultur ve Turizm Bakanligi, 1985):

The MCT plays the main role in Turkish tourism development, Among the other institutions, the Ministry's role is vital in shaping the future of tourism in Turkey: The Ministry is assigned the duty of investigating, preserving, evaluating the national, moral, historical and cultural values: Evaluating the country's tourism potential to the 
widest extent and making it a prosperous sector of the economy is among the Ministry's duties: The Ministry is also authorized and assigned to direct, to encourage and to cooperate with organizations that are connected with tourism and culture (TB, 1988a):

\section{Tourism Bank}

The third institutional element of the tourism industry in Turkey lies with the $T B$, which is responsible for investment and financial aspects of tourism, It was established in June 1955 originally for the following purposes:

* To develop the tourism sector through direct investment;

* To operate tourism facilities; to provide financial support to tourism enterprises:

The legal status of the Bank was declared as a State Economic Enterprise under the provisions of Decree Law No, 233 incorporated as a development and investment bank for tourism,

According to the Articles of Incorporation of the Bank, published in March 1985, the Bank is identified as a sectoral development and investment bank for tourism whose share capital is owned by the government to engage in tourism industry operations and banking activities but not accepting deposits

To fulfill the objectives of the fifth five-year plan and be in line with the government policy by mid-1985, the Bank made a structural change in its objectives and thus ceased making investments directly. It concentrated on adopting a merchant banking role, In all likelihood, the bank will be diverted from non-banking activities in tourism, such 
as training and planning. In parallel with the change of its policy, it is programmed that the privatization of the tourism operations will be realized by the end of 1988, and in 1989 the Bank is planned only to be engaged in banking operations.

Before the policy restructuring was applied to the Bank, it was active in different aspects such as physical planning, land use investigation, and subdivisions as well as the zoning of tourism amusement areas. It had decided to develop a group of joint venture companies with parties having high expertise in each field to provide professional services to the tourism sector. A recent aim of the Bank is to contribute to the improvement of the attractiveness for foreign and domestic investors, and will focus on enhancing any factors that will further develop the competitive position of Turkey. The Bank is also a contact point for any tourism investors and at the service of the tourism sector for information and data, services procurement, financial matters and general consulting.

The Bank's activities are now concentrated wholly on increasing credit resources, facilities, and services available to the tourism sector. Direct investment and operational activities by the Bank are being phased out. The change of policy from owning and operating tourist projects and establishments, to a creditor and lender for tourism investment is incongruent with new national economic policy which advocates privatization and foreign capital investments. As Altinordu, the chairman who was appointed at the time of this policy change, related, 
The Bank believes that tourism development can and should be achieved by private enterprise, The 23 TURBAN facilities established by the bank, have fully accomplished their leadership mission in investment and management. Privatization of these establishments is expected to be completed by the end of 1988 (TB, 1988a:7).

The change in the policies of the Bank can be explained by the new economic policies which affected the Bank. At the tine of the Bank's establishment, the private sector was unwilling to invest in a sector that hardly even existed, Facilities needed to be developed and the TB began to build up its TURBAN chain of hotels, campsites, marinas, and other facilities, which have established a high reputation in Turkey's tourism market (International Herald Tribune, 1988:11)! Figure 11 presents the TURBAN's activities:

\section{AN ANALYSIS OF THE INSTITUTIONS}

While the SPO, MCT and TB are all three nationally recognized institutions in the policy process of the tourism sector, the spo has had a longer history than the other two institutions in terms of involvement in development activities, Its five-year plans on tourism (prior to 1980) reflect the fact that tourism was not considered to be as important as it is realized now: Thus the scope of the policy process lacked vital elements including, economic, social and environmental considerations in a general national policy context as well as a national tourism development context. The lack of geographical planning levels can be inferred from this, Furthermore, SPO cannot be separated from the overall national 


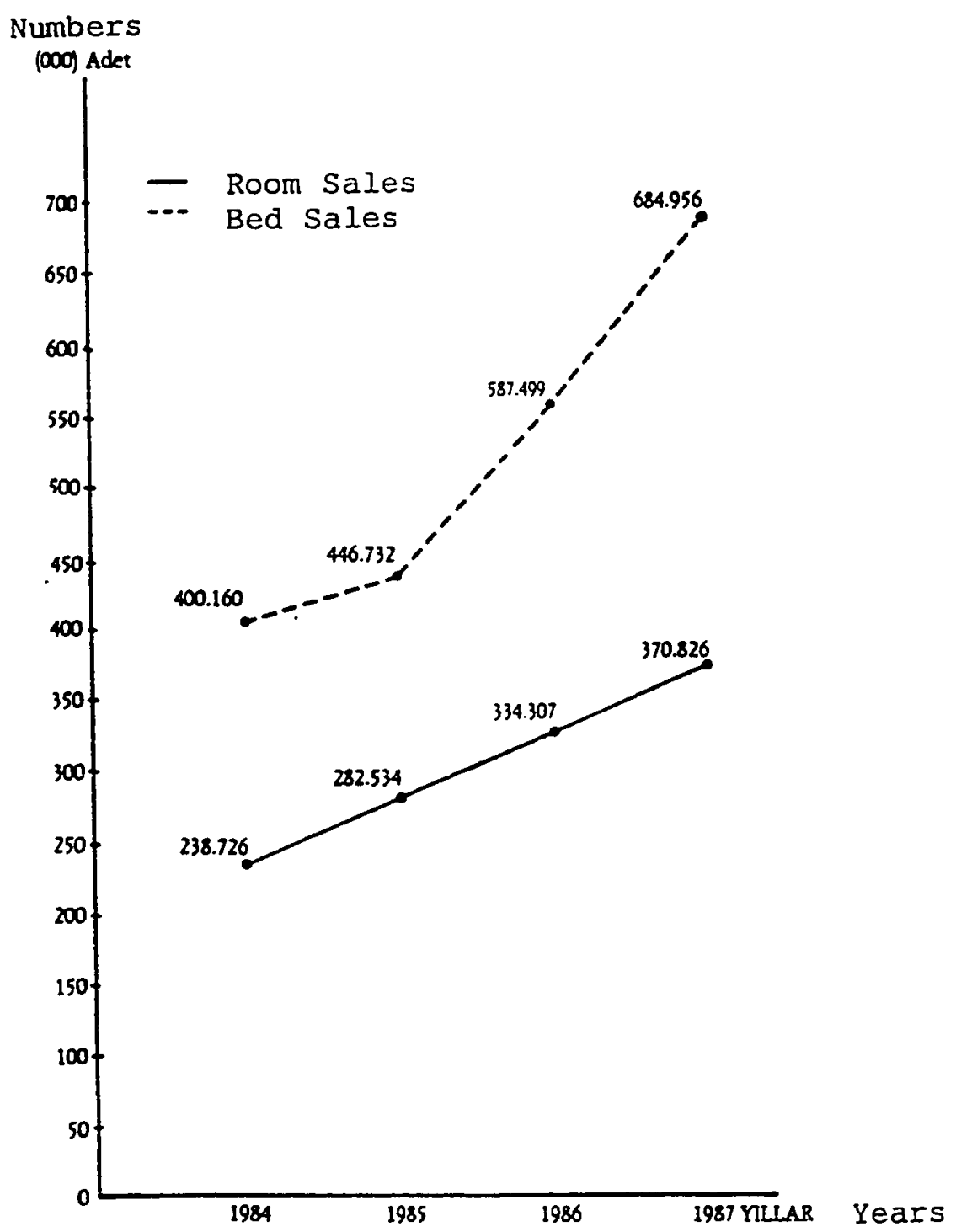

Figure 11. Room and bed sales in Turban establishments (1984-1987) , Source: Tourism Bank, 1988:12, 
development policy which evolved from the "etatism"I of the 1930 s to the disruptions of the 1960s and 1970s and finally to the policy shift of the 1980s, Whereas, for instance, Malaysia's New Economic Policy produced the national tourism master plan, Turkey's policy shift produced rather a dislocation of policy elites without a cohesive policy process (Heper, 1990; Din, 1982)!

Equally important, the TB's role shifted from an arm of state intervention and implementation tool to an economic bureaucracy distancing itself from civil service as well as civil societal elements: The implications of this process crystallized further in the state's relunctancy to be involved in tourism where its intervention was needed the most (Pearce, 1989): Moreover, the policy shift removed the TB from its various planning roles (as a state agency). As Heper (1990:332) noted,

In this period the majority of civil servants had a lesser role to play in the making of economic decisions, At the same time the "techno-cratization" of decision-making made the bureaucracy politically less responsive:

TB's role further withered with the process of privatization which in fact removed TB from being a part of the tourism system to become a private banking institution. The impact of privatization as a policy shift was described by Heper (1990): He noted,

Consequently attention increasingly shifted to the external investors! In the final months of 1988 and in the early 1989 a new wave of privatization occurred, all of which

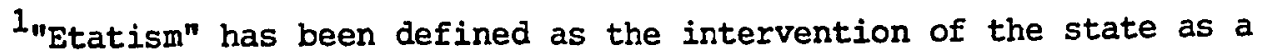
pioneer and director of industrial activity, in the interest of a national development and security, in a country in which private enterprise is either suspect or ineffective (Walstedt, 1980:63) 
involved the sale of the whole or a substantial part of an enterprise to a foreign investor: For example, a major cement company (Citosan) owned by SEE was sold to the French Societe Ciment Francais, 70 percent of the catering services of the Turkish airlines were sold to Scandinavian Airlines, and the Bogazici Airlines were transferred to a consortium which included Aer Lingus (Heper, 1990:327):

The major ramifications of this process is discernible from the

dual system of tourism enterprises in Turkey: MCT is likely to remain as the sole, directly involved institution in tourism development But MCT is active in only one type of tourism enterprise (Belgeli), and this is the type that is associated with the large industrial tourism investment--both domestic and foreign. As Rodenburg (1989:206)

elaborated,

Scale has two meanings here: (1) relative size and capitalization, $i, e_{\uparrow}$, physical plant of an enterprise, and its correlate; (2) the relative bureaucratization, i.e., degree of industrial organization,

He continues,

Size and bureaucracy defines scales of enterprise which, in the case of hotels and pensions, attract different categories of customers:

The second type of tourism that MCT has been reluctant to be involved in and consequently not to guide is the local oriented small scale tourism (Belgesiz) which is known as craft tourism, While the large industrial tourism is a corporate activity, "craft tourism" is homogeneous, tending to be family-owned and operated,

MCT's behavior towards these two kinds of tourism development is detrimental to the following objectives; (1) increased earnings, (2) increased foreign exchange, (3) increased investment, (4) increased job opportunities, (5) increased production, (6) increased entrepreneurship, 
(7) increased infrastructure, and (8) the minimization of adverse social and cultural effects, Consequently, while the shift to the new policies of export orientation and privatization, are congruent with large industrial tourism, the encouragement of local oriented enterprises are unlikely: The SPO has played a significant role formulating the policies of the past as well as of the present. The shortcomings of the SPO during the five-year plan periods can be understood by analyzing the historical evolution of the SPO,

The SPO was established in the 1960s, and while designed to achieve major structural reforms, it failed to institutionalize in accordance with the original technocratic designs, In the early years of the SPO, conflicts between politicians and special interests groups completely undermined the authority of SPO planners and ruined any hopes of making necessary reforms, As Milor (1990:5) explained,

Indeed, when the military support ended following the transition to a multi-party democracy in October 1961, early planners, to their dismay, did not find a receptive audience for their ideas among the ranks of civilian politicians: Consequently, despite the prime minister $I$. Inonu's personal support, the founders of the SPO felt themselves to be in a political vacuum and chose to resign in November, 1962,

This became the pivotal event which impaired the fundamental policy/decision process not only in the tourism sector, but also in other areas of development, Some attributed the formation of the SPO to certain groups who were in opposition to the party in power Because of this lack of consensus on the role of the SPO, the SPO could not perform as an institution based on a common developmental strategy (Milor, 1990; Krueger, 1987): The nature of the problem became apparent when the state failed to keep the SPO as an autonomous agency: Thus conflicts 
developed on various grounds ( $i, e_{i}$, allocation of subsidies to private

sector, evaluating SEE's management system and performance): Again

Milor's analysis revealed,

While in Tinbergen's model, the experts of the SPO emerged as the technocratic formulators of the state's industrial policy, : [in a different, approved draft] they were reduced to their traditional bureaucratic roles [what the Ministry of culture and Tourism represents todayl, merely registering the wishes of private capitalists on what the state should do to help and bolster them, and then a comprehensive list of these wishes would be called a "plan" (Milor, 1990:15),

\section{Therefore,}

had early planners been successful in carving out operational space in the design and implementation of economic policy for the economic technocrats within the state machine, then the Turkish state might have become what political scientists call a "developmental" state, functioning to promote economic growth [as in Taiwan and Korea] and international competitiveness (Milor, 1990:5),

The tourism sector during the 1980 s was a reflection of the past

failure and problems of the SPO, Conflicts between new tourism experts

(technocrats) and politicians were common,

Experts had little authority, and were subject to the whims of politicians and powerful special interest groups. As the institutional framework of the SPO could not insulate its incumbents from the demands of powerful interest groups, planners became overloaded by erratic and tedious demands emanating from the political realm irrespective of the nature of the government (Milor, 1990:26),

The tourism sector suffers from this conflict between the

politician's desire and the planner's rational choices. In this context

I quote a former MCT employee from an interview recorded in the winter

of 1988, in Ankara:

I finally stopped going to office at the MCT and waited to be officially discharged. My concern was that there must be a comprehensive research of our tourism sector and to come up with a model based on Turkish cultural, social and 
economic needs. But my proposal as the economist/planner in the tourism sector not only was ignored, but also angered traditional bureaucrats, or I say they were threatened.

In retrospect, planners in the early years of the SPO had similar

grievances! As Milor $(1990: 26)$ referred to one of them saying

There was no way that we as planners would not trip over our own feet because we could not run so fast as to keep up with politicians' promises and ad hoc impositions on us, with no regards for the plan's overall equilibrium and consistency:

The MCT, which represents Turkey's national tourism organization, has yet to become an organized tourism expert to guide the industry in a rational fashion! For example, as Hershlage (1988) noted,

Turkey still lacks tourism consciousness and the human and organizational capacity to "sell" her own undisputable potentials to the potential visitor throughout the world. Even the quiet optimistic forecasts of tourism earnings by the end of this decade fall far behind those of other comparative economics [Spain and Greece], and Turkey's own potentials:

This was also revealed in my interviews with the director of policy development, and the director general of tourism (regional planner) on October, 1988, As the first interviewee addressed,

At first we thought the best way to accommodate the industry was to increase bed capacity, but now we realize that increased bed capacity is confounded by the lack of infrastructure, human and technical, and the lack of services to tourist establishments; This was our main objective which was a one-dimensional goal for such a multidimensional industry:

When I asked the second interviewee why there was a dual system in tourism that undermines craft tourism, she replied: "This is a question of legal framework that has to be divided in the parliament," In reference to "lack of tourism consciousness," I interviewed the Deputy of General Directorate of Tourism (October 11, 1988): When I asked if 
he could elaborate on the Ministry's developmental ideologies and

objectives, and/or the present policies, he replied that

there are two purposes for our agenda. The first is the economic benefit, and the second is to introduce a new image of Turkey internationally [a political purpose]: Therefore, we will utilize tourism on those two basis:

TOURISM'S ROLE IN TURKEY'S ECONOMY

When Turkey shifted from a mixed economy approach (adopted since 1961) to privatization and liberalized economic policies (adopted since 1980), the tourism sector was subject to intense restructuring in terms of foreign investment and private sector involvement. The fifth fiveyear development plan (1985-1989) addressed its targets as follows:

The objective aimed at is to realize a net foreign currency inflow worth 540 million dollars at the end of the fifth plan period through an average annual 14.28 raise of foreign tourism receipts and of 18,98 of expenditures It is estimated that the number of incoming tourists and visitors will increase by 10.88 per annum and amount to 3 million persons at the end of the period, whereas that of Turkish nationals going abroad will attain about $2,500,000$ (SPO, 1987:134),

Table XXIX indicates the tourism movements including Turkish nationals going abroad:

Tourism was viewed as an economic activity utilizing resources of sun, sea, sand and scenery and requiring only simple technology: Tourism was expected to cure the shortage of foreign exchange earnings and the unemployment problems in the country: since the industrial exports of the country and foreign exchange remittances from workers abroad are limited in nature, tourism seemed like an alternative for earning foreign exchange, 
TABLE XXIX

TOURISM MOVEMENTS

\begin{tabular}{lcrrr}
\hline Year & $\begin{array}{c}\text { Number of } \\
\text { Foreigners } \\
\text { Visiting Turkey }\end{array}$ & $\begin{array}{c}\text { Change } \\
8\end{array}$ & $\begin{array}{c}\text { Number of } \\
\text { Turkish Nationals } \\
\text { Going Abroad }\end{array}$ & $\begin{array}{c}\text { Change } \\
8\end{array}$ \\
\hline \hline & & & & \\
1979 & $1,523,658$ & $-7,3$ & $1,534,872$ & 2.4 \\
1980 & $1,288,060$ & $-15,5$ & $1,794,808$ & 16.9 \\
1981 & $1,405,311$ & 9,1 & $1,783,891$ & -0.6 \\
1982 & $1,391,717$ & $-1,0$ & $1,899,377$ & 6.5 \\
1983 & $1,625,099$ & 16,8 & $1,998,162$ & 5.2 \\
1984 & $2,117,094$ & 30,3 & $2,071,189$ & 3.7 \\
1985 & $2,614,924$ & $23: 5$ & $1,806,163$ & $-12,8$ \\
1986 & $2,391,085$ & $-8,6$ & $1,622,237$ & $-10,2$ \\
1987 & $2,855,546$ & 19,4 & $1,921,681$ & 18,5 \\
& & & & \\
\hline
\end{tabular}

Source: Economic Report, 1988:109,

\section{Tourism Revenue}

Until recently tourism did not play a very significant role in the Turkish economy: All throughout the planned period, the tourism industry received around 9,5 percent of the government budget and one percent of all capital expenditure annually! Promotion campaigns and activities were also limited due to negligible budgets allocated for promotion (Turizm Bankasi, 1987)! Figure 12 presents the tourism revenue and expenditures for years 1975-1987,

Along with the increasing number of foreign visitors, the tourist receipts of Turkey increased as well. The increase in real prices was 17,1 percent in 1983 and 46.1 percent in 1984; the increase in current rates was 9 percent and 35 percent, respectively (Olali, 1986; Manisali and Yarcan, 1987): 


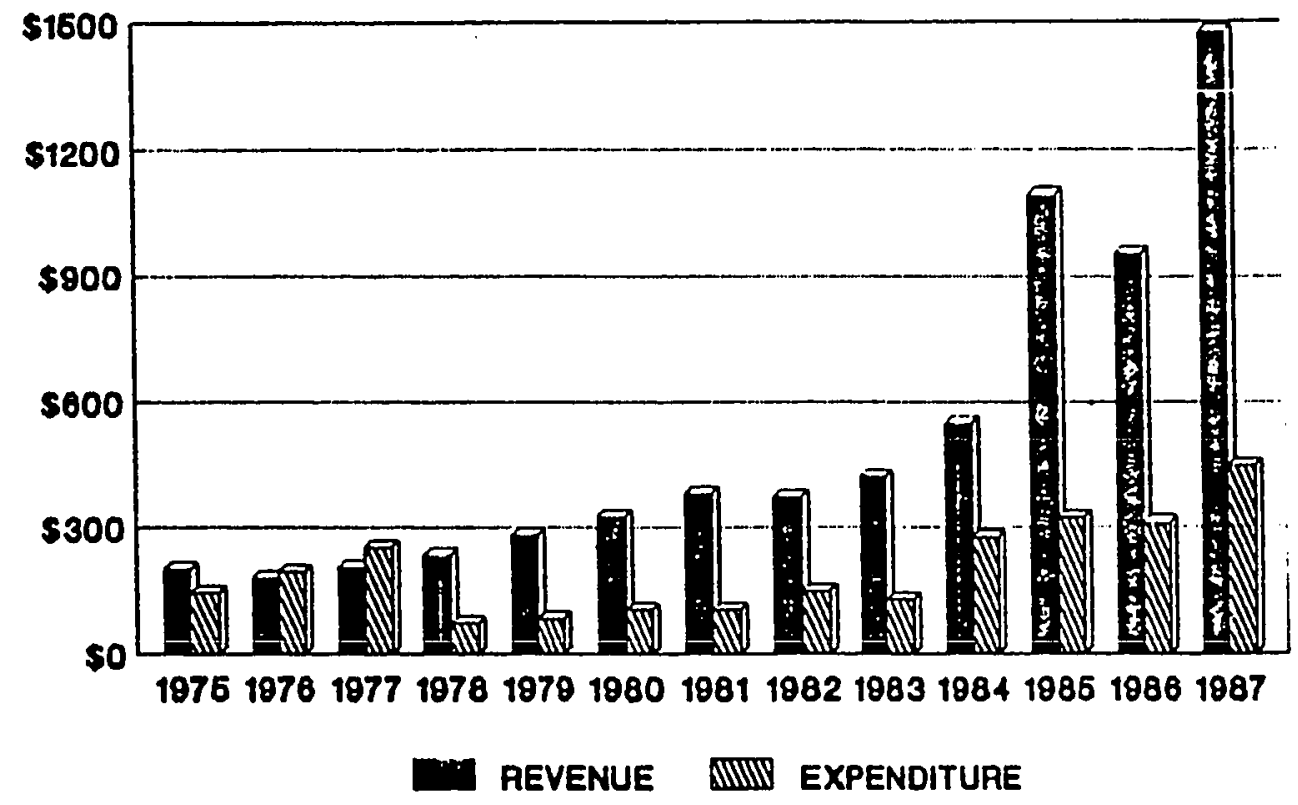

Figure 12. Tourism revenue and expenditure (US $\$$ Million): Source: Tusiad, 1988:87. 
The share of tourism receipts in export earnings on average is eight percent. There was a decline in the share of tourism receipts in export earnings since 1980, This was due to the export boom in Turkey after 1980 which was a direct result of new legislation encouraging exports (TUSIAD, 1986), Within the same period the relative share of tourism receipts in balance of payments account on average was 11 percent: Among the invisibles, tourism, one of the greatest potential earners of foreign exchange, constituted less than three percent of GNP by 1987: Table XXX depicts the share of tourism receipts in the export earnings and the balance of payments! Thus, the relative net contribution share of tourism receipts increased numerically

It is possible that the actual contribution of tourism to export earnings and balance of payments was higher than reported due to the laws that permitted the exchange of foreign currencies to take place without restriction (i.e., to the banks)! This led to the foreign exchange not being channeled to state accounts directly from the tourist; therefore, the actual foreign exchange earnings should be expected to be higher than what is reported from the banking systems The share of tourism to the economy is the ratio of tourism receipts to GNP، Tourism receipts/GNP ratio in Turkey is lower than for most European countries with the exception of Ireland and the Netherlands (Table XXXI).

In 1985 the net revenue from tourism and travel soared by 184 percent from $\$ 271$ million in 1984 to $\$ 770$ million. There was a slight decrease (to $\$ 642$ million) in 1986 , but by 1987 it rose sharply and contributed more than $\$ 1,000$ million for the first time ever. Along 
TABLE XXX

SHARE OF TOURISM RECEIPTS IN THE EXPORT EARNINGS AND THE BALANCE OF PAYMENTS

(MILLION \$)

\begin{tabular}{|c|c|c|c|c|c|c|}
\hline Years & Exports & Receipts & $\begin{array}{l}\text { \& Share } \\
\text { of Tourism } \\
\text { Receipts in } \\
\text { Export } \\
\text { Earnings }\end{array}$ & Imports & Balance & $\begin{array}{c}8 \text { Share } \\
\text { of Tourism } \\
\text { Receipts in } \\
\text { Balance of } \\
\text { Payments }\end{array}$ \\
\hline 1963 & 368,0 & 7,7 & 2,1 & 688,0 & $-320,0$ & 2,4 \\
\hline 1964 & 411,0 & 8,3 & 2,0 & 537,0 & $-126,0$ & 6,6 \\
\hline 1965 & 464,0 & 13,8 & 3,0 & 572,0 & $-108,0$ & 12,8 \\
\hline 1966 & 490,0 & 12,1 & 2,5 & 718,0 & $-288,0$ & 5,3 \\
\hline 1967 & 523,0 & 13,2 & 2,5 & 685,0 & $-162,0$ & 8,1 \\
\hline 1968 & 496,0 & 24,1 & 4,9 & 764,0 & $-268,0$ & 9,0 \\
\hline 1969 & 537,0 & 36,6 & 6,8 & 801,0 & $-264,0$ & 13,9 \\
\hline 1970 & 588,0 & 51,6 & 8,8 & 948,0 & $-360,0$ & 14,3 \\
\hline 1971 & 677,0 & 62,9 & 9,3 & 1171,0 & $-494,0$ & 12,7 \\
\hline 1972 & 835,0 & 103,7 & 12,4 & 1563,0 & $-728,0$ & 14,2 \\
\hline 1973 & 1317,1 & 171,5 & 13,0 & 2099,0 & $-781,9$ & 21,9 \\
\hline 1974 & 1532,2 & 193,7 & 12,6 & 3777,6 & $-2 \quad 245,0$ & 8,6 \\
\hline 1975 & 1400,1 & 200,9 & 14,4 & 4738,7 & $-3 \quad 338,6$ & 6,0 \\
\hline 1976 & 1960,0 & 180,5 & 9,2 & 5128,0 & $-3 \quad 168,0$ & 5,7 \\
\hline 1977 & 1753,0 & 204,9 & 11,7 & 5796,3 & $-4 \quad 042,4$ & 5,1 \\
\hline 1978 & 2288,2 & 230,4 & 10,1 & 4599,0 & $-2310,8$ & 10,0 \\
\hline 1979 & 2261,2 & 280,7 & 12,4 & 5069,4 & $-2808,2$ & 10,0 \\
\hline 1980 & 2910,1 & 326,7 & 11,2 & 7909,4 & $-4999,2$ & 6,5 \\
\hline 1981 & 4702,9 & 381,3 & 8,1 & 8933,4 & $-4230,7$ & 9,0 \\
\hline 1982 & 5746,0 & 370,3 & 6,5 & $8 \quad 842,7$ & $-3096,7$ & 12,0 \\
\hline 1983 & 5727,8 & 411,1 & 7,2 & 9235,0 & $-3507,2$ & 11,7 \\
\hline 1984 & 7133,6 & 840,0 & 11,8 & 10756,9 & $-3623,3$ & 23,2 \\
\hline 1985 & 7958,0 & 1482,0 & 18,6 & 11343,4 & $-3 \quad 385,4$ & 43,8 \\
\hline 1986 & 7456,7 & 1215,0 & 16,3 & 11104,8 & $-3648,1$ & 33,3 \\
\hline 1987 & 10190,0 & 1721,1 & 16,9 & 14163,1 & $-973,1$ & 43,3 \\
\hline
\end{tabular}

Source: MCT, 1988:83.

Source of data: State Institute of Statistics. 
TABIE XXXI

SHARE OF INTERNATIONAL TOURIST RECEIPTS IN GROSS NATIONAL PRODUCT (1960-1986 SELECTED YEARS)

\begin{tabular}{lcccccc}
\hline Year & Portugal & Spain & Italy & Yugoslavia & Greece & Turkey \\
\hline & & & & & & \\
1960 & 1.0 & 2.9 & 1.8 & 0.4 & 1.4 & 0.1 \\
1969 & 5.4 & 4.6 & 2.0 & 2.3 & 1.8 & 0.3 \\
1980 & 4.8 & 3.3 & 2.3 & 1.8 & 4.3 & 0.6 \\
1984 & 5.0 & 5.0 & 2.0 & 2.4 & 3.9 & 1.1 \\
1986 & 5.4 & 5.2 & 1.6 & 2.4 & 4.6 & 1.6 \\
\hline
\end{tabular}

Source: Anastasopoulos, 1989:572

Source of data: OECD (1956-1988), IMF (1988).

with workers' remittances, tourism and travel regularly account for the vast bulk of surplus on the "invisible" account (TUSIAD, 1988:85):

In recent years, efforts toward the improvement of Turkey's share in the world tourism revenues have been expedited, The targets axe being established under the development plans and the legal arrangements have been realized with the enactment of Law No. 2634 as "Tourism Encouragement Law." The positive results of this process were observed in 1984 when both the number of tourists and tourism revenues noted a significant increase.

The share of tourism revenues in the GNP is rather low: The biggest increase in the ratio of tourism revenue/GNP was noted in 1987 with a rate of 2.7 percent (MCT, 1988). Tourism's share in the Growth National Product is shown in Table XXXII. Tourism receipts, expenditures, and net revenues were considered through the invisible balance. Revenues from tourism were established 
TABLE XXXII

SHARE OF TOURISM REVENUES IN

THE GROSS NATIONAL PRODUCT

(BY CURRENT CONSUMER PRICES)

1963-1987

\begin{tabular}{|c|c|c|c|c|c|c|}
\hline Years & & Iillic & on $\mathrm{TL}$ & Million $\$$ & Million \$ & $\begin{array}{l}8 \text { Share of Tourism } \\
\text { Revenues in the } \\
\text { Gross National Product }\end{array}$ \\
\hline 1963 & & 66 & 801.4 & 7422.4 & 7.7 & 0.1 \\
\hline 1964 & & 71 & 312.8 & 7923.6 & 8,3 & 0.1 \\
\hline 1965 & & 76 & 726.3 & 8525.1 & 13.8 & 0.2 \\
\hline 1966 & & 91 & 419.0 & 10157.7 & 12.1 & 0.1 \\
\hline 1967 & & 101 & 480.6 & 11275.6 & 13.2 & 0.1 \\
\hline 1968 & & 112 & 493.4 & 12499.3 & 24.1 & 0.2 \\
\hline 1969 & & 124 & $892 ، 9$ & 13877.0 & 36.6 & 0.3 \\
\hline 1970 & & 147 & 776.1 & 9951.3 & 51.6 & 0.5 \\
\hline 1971 & & 192 & 602.3 & 12969.9 & 62.9 & 0.5 \\
\hline 1972 & & 240 . & 809.2 & 17200.7 & 103.7 & 0.6 \\
\hline 1973 & & 309 & 829.4 & 22130.7 & 171.5 & 0.8 \\
\hline 1974 & & 427 & 097.5 & 30507.0 & 193.7 & 0.6 \\
\hline 1975 & & 535 & 771.0 & 37598.0 & 200.9 & 0.5 \\
\hline 1976 & & 674 & 985.7 & 41283.5 & 180.5 & 0.4 \\
\hline 1977 & & 872 & 893.8 & 49177.1 & 204.9 & 0.4 \\
\hline 1978 & 1 & 290 & 723.4 & $53 \quad 690.7$ & 230.4 & 0.4 \\
\hline 1979 & 2 & 199 & 520.0 & 52962.2 & 280.7 & 0.5 \\
\hline 1980 & 4 & 435 & 153.0 & $58 \quad 480.4$ & 326.7 & 0.6 \\
\hline 1981 & 6 & 553 & 596.2 & 59502.4 & $381 \cdot 3$ & 0.6 \\
\hline 1982 & 8 & 735 & 010.4 & 54308.7 & 370.3 & 0.7 \\
\hline 1983 & 11 & 551 & 860.1 & 51570.8 & 411.1 & 0.8 \\
\hline 1984 & 18 & 374 & 839.9 & $\begin{array}{ll}50 & 362.7\end{array}$ & 840.0 & 1.7 \\
\hline 1985 & 27 & 789 & 414.8 & 53612.3 & 1482.0 & 2.8 \\
\hline 1986 & 39 & 177 & 169.6 & $58 \quad 526.7$ & 1215.0 & 2.1 \\
\hline 1987 & 55 & 757 & 220.2 & $\begin{array}{ll}64 & 428.7\end{array}$ & 1721.1 & 2.7 \\
\hline
\end{tabular}

Source: MCT, 1988:82.

Source of data: State Irstitute of Strategies. 
as $\$ 1,259$ million in 1987 . Net inflows from touxism amounted to $\$ 809$ million in 1987, as compared with a figure of $\$ 637$ million for 1986 , representing a net increase of 27 percent (TUSIAD, 1988:107) However, OECD's (1987:50) report indicated tourism's role in overall economy as following:

For Turkey, tourism, while playing a relatively small part in the overall economy, with its receipts making up only 21 percent of GNP, is of major importance as a source of foreign currency, Six percent of ail foreign currency earnings are attributable to tourism, and receipts from tourism make up one-fifth of the national invisible income, Employment in the tourism sector constitutes 343 percent of all registered workers but, because of the very large agricultural sector, it forms a much greater part of service sector:

In a different report, OECD concluded that earnings from Turkish tourism increased 215 percent between 1981 and 1986 Japan was a distant second, showing a 95 percent growth in tourist earnings over the same period (Time, 1988:67):

\section{Tourism Employment}

Tourism is a manpower intensive activity and increasingly provides direct and indirect employment both in the skilled and unskilled categories. Unfortunately, no detailed studies are available as to the employment statistics of these direct and indirect beneficiaries. This situation is not only attributed to Turkey's case; but also applies to international tourism as well, It is estimated, very roughly, that the accommodation sector absorbs not less than 50 percent of the total employment in tourism industries! The wTO has estimated that in 1980 about eight million persons were employed in the accommodations sector alone (Kaul, 1985:68). 
Another aspect of tourism employment which requires a detailed study and availability of data is the cost of creating a job in this industry! Figures from Israel suggest the volume of fixed capital required per worker in hotels is rather higher than in industry, but lower than in agriculture and transportation. The English Tourist Board has estimated it costs about $L 700$ a year to create a job in tourism and that jobs once created tend to endure (Kaul, 1985:69) :

The available data on employment records was based on the service sector which encompasses the tourism industry as well, The total employment in the service sector for 1987 reported as 2,527,000 persons: This comprises 50,4 percent of the employment sector in comparison to 17.4 percent in agriculture and 32.2 percent in industry (Turizm el Kitabi, 1988:20):

\section{Tourism Market}

Changes in the status of tourist receiving countries and tourist exporting countries since the 1950s, and the diffusion of new tourism countries into the international market, is an important aspect of international tourism activities. Classical tourism countries like Switzerland and Austria are now being replaced by the Mediterranean countries, chiefly Spain, On the other hand, the Federal Republic of Germany has replaced the United States of America (USA) in being first place among tourist exporting countries, Akoglu (1970) made a projection of the international tourism movement to OECD and Mediterranean countries which indicated the highest rates of increase in the flow of tourists will be to the Eastern Mediterranean region and that this heavy 
flow will continue to increase: Table XXXIII presents Turkey's market share.

TABLE XXXIII

TURKEY'S MARKET SHARE IN NORTHEAST MEDITERRANEAN

\begin{tabular}{lrrr}
\hline Destinations & 1980 & 1985 & Inc 8 \\
\hline \hline Turkey & 7.0 & 12.0 & 5 \\
Greece & 36.3 & 35.3 & -1 \\
Malta & 5.5 & 2.9 & -2.6 \\
Cyprus & 2.6 & 4.4 & 1.8 \\
Yugoslavia & 48.6 & 45.4 & -3.2 \\
\hline
\end{tabular}

Source: Turkmen, 1988:11.

Over the last five years, the main market of international tourism for Turkey was the OECD countries. OECD countries have a market share of 55 to 60 percent in Turkish tourism, while the shares of non-OECD European countries vary between 15 and 17 percent and Middle Eastern countries have 11 to 12 percent; other countries have a share of 11 to 19 percent varying according to years. Table XXXIV depicts the percentage of change of tourist arrivals to Turkey from main tourist generating countries.

Among the OECD countries, the Federal Republic of Germany consistently ranks in the first place in terms of visitors to Turkey. The second most important tourist market, the USA, usually consisting of excursionists (visitors or tourists who are staying for less than 24 hours), is recently dropping behind other countries, like Greece: Recently Greece became a prominent tourist generating country for 


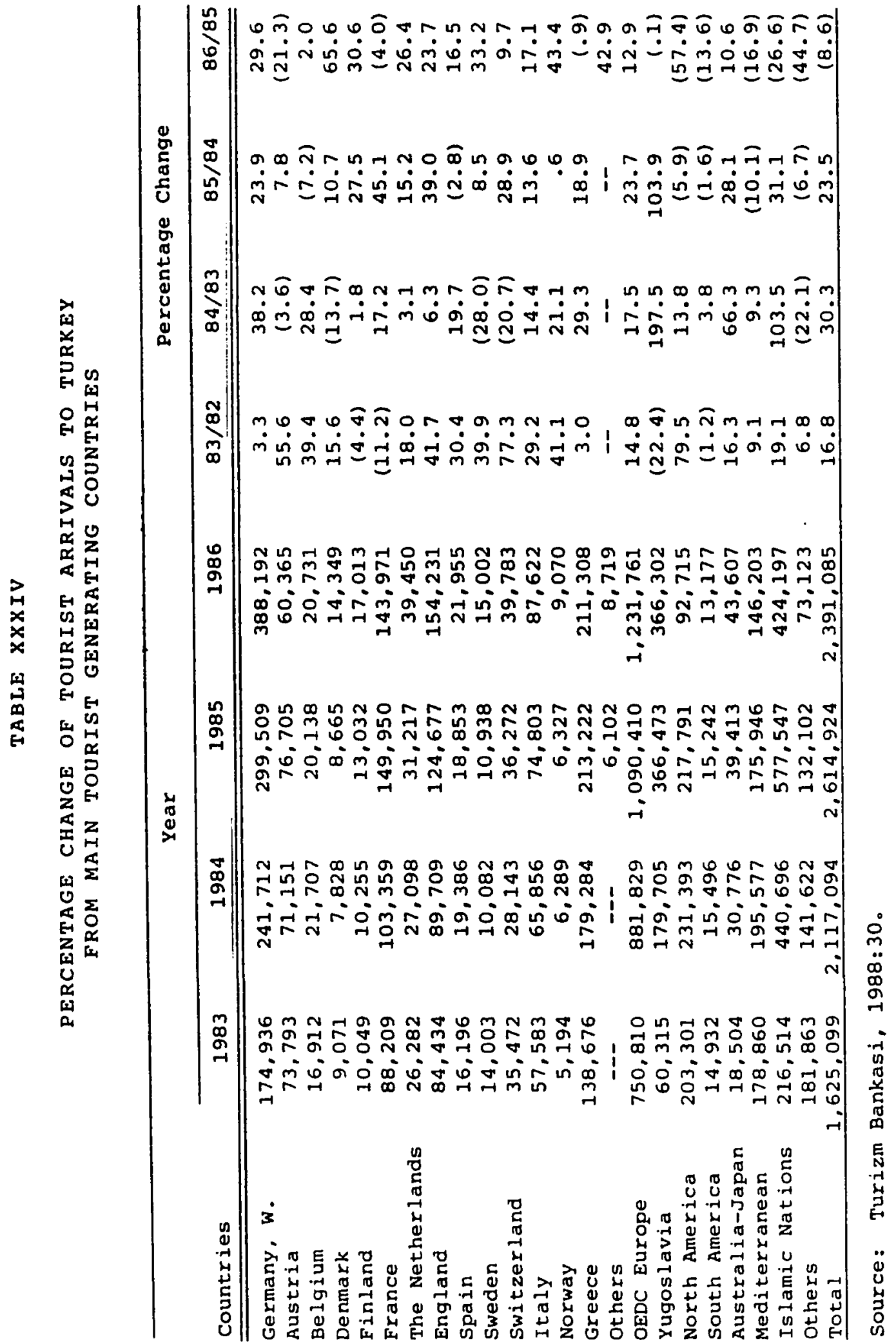


Turkey: The dominant OECD tourist markets comprise about 50 percent of the total tourist market of Turkey (Manisali and Yarcan, 1987:19), The USA market has a special place in the Turkish tourism market: This market is mainly the excursionist cruise market, which does not create a demand for accommodation capacity However, the cruise market, because of the decreasing availability of cruises in the Mediterranean, lost its importance for Turkey in 1985. Subsequently, there was a very drastic decrease in this market in 1986.

In a recent survey of motivation for travel to Turkey in comparison to Greece, 66 percent of the tourists replied that their motivation to come to Turkey was because it was inexpensive (Manisali and Yarcan, 1987). Surveys of these sorts are rarely done in Turkey. But this survey revealed that price policy played a role in attracting tourists.

Islamic nations have patronized Turkish tourism for various conveniences. First, Turkey is a Moslem nation with strong religious foundations. Even though it is a secular state, religious practices and pilgrimage activities have survived intact! second, the convenience of geographic location has made traveling accessible and travel distances are short: The number of arrivals at registered accommodation establishments, for tourists from Islamic countries was 424,197. Table XXXV indicates this movement from Islamic countries and the percentage change over the years, which is an obvious low demand from those countries

As might be expected, Western Europe is the major regional market for Turkey, being the source for two out of every three visitors from 


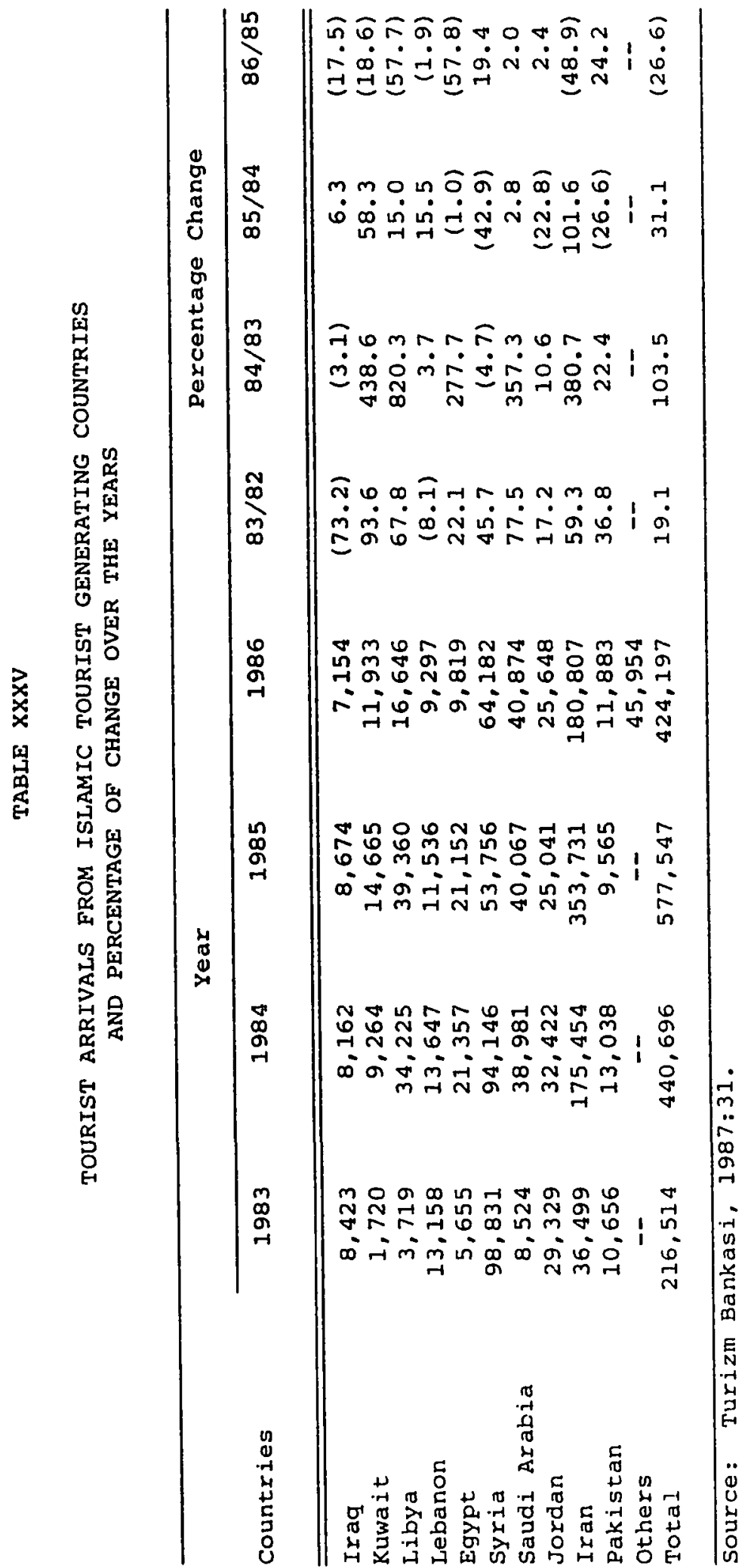


abroad. This proportion has tended to rise since the mid-1970s, One reason for this is the phenomenal increased growth in travel from Yugoslavia and Greece. Another obvious reasons is the stagnation of the Eastern European market, particularly the virtual ending of travel from Bulgaria. Another major aspect has been a significant fall in travelers from Muslim countries which has made more room for European travelers. The significance of this change is evident from the fact that in the mid-1970s the Muslim world was the largest single source of visitors to Turkey, accounting for more visitors than Western Europe; in contrast, by the late 1980s, visitors from Western Europe were outnumbering Muslim visitors by three to one: In essence, the past decade has seen Turkey's market orientation swing from East to West (International Tourism Reports, 1989:44)

The factors behind such a shift can be attributed, first to Turkey's destination fashion in western Europe (i১e., as a new destination to be discovered). Second, to lack of a clear policy of tourism to capitalize on regional markets. The third factor can be derived from the tourism system and the types of tourist industry that is dominant. Turkey's tourist industry--as a latecomer--is geared toward what Rodenburg (1989) called "large industrial tourism" and less on "craft tourism،" For example the Belgesiz, which cater to craft tourism are left on their own and given no government advice or support. As a result craft tourism or even small scale industrial tourism declines. And the regional market (e.g., Muslim countries) which was catered to by craft tourism gradually losses its growth. 
As Uysal (1983:15) examined the trend of international tourism to Turkey, he noted that the main part of the business comes from developed countries whose citizens have higher incomes and more leisure time. However, noted Uysal, the Middle Eastern travel market has great growth potential because of increasing trade volume and cultural agreements between Turkey and the Middle Eastern countries (1983:17): However, with the existing potentials, Turkey has yet to compete for the market share of Mediterranean tourism in comparison to rivals like Greece, Yugoslavia and Spain! (See Figure 13!)

The fluctuation in the Middle Eastern travel market, despite its tremendous potential, can be explained by a deficiency in the overall planning and policy process of the state, For instance, there has been no formulation of a policy on how to best utilize this sector to cater to different markets (i,e!, Muslim vs, European)! The preceding argues for the ability of tourism to become a significant sector, but indicates clearly that the industry has not been deliberately organized in terms of a development strategy:

The goals are expressed, but the methods of achieving them has yet to become a tangible/feasible policy to be implemented, As will be analyzed further, national tourism development is in disarray. This can be attributed to the absence of policy rather than to a fault within the tourism system itself: The state's responsibility in this process is the major issue, As English (1986:80) addressed,

Just as social scientists have tended to overlook the tourist industry in favor of other, more "business-like" activities, so governments may be guilty of ignoring this sector: Yet for a growing number of developing countries it is becoming very big business. 


\section{$(1,000,000)$ \\ Persons}

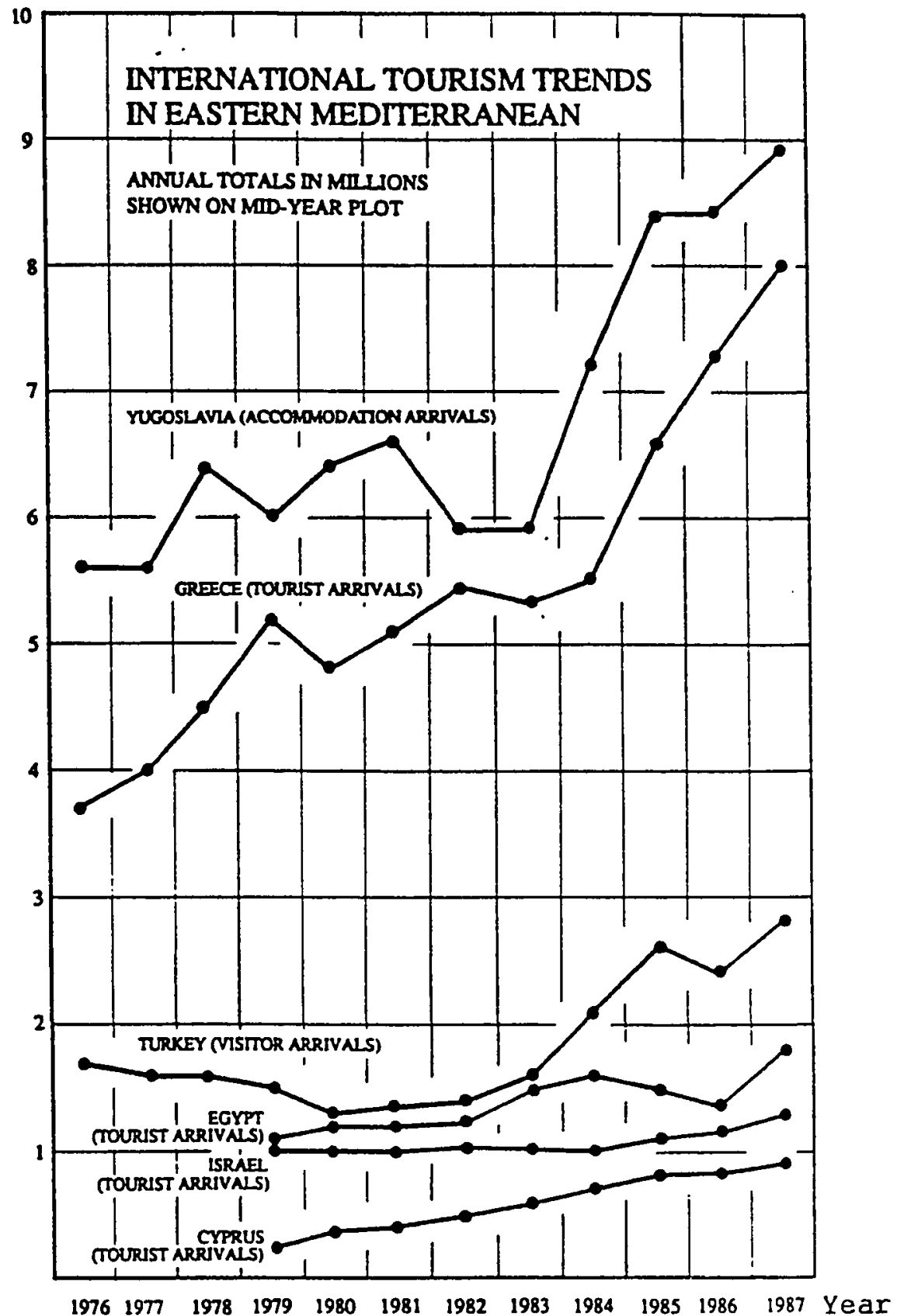

Figure 13. International tourism trend in Eastern Mediterranean. Source: International Tourism Reports, $1989: 37$. 
CHAPTER IV

POLICY AND PLANNING ISSUES

IN TURKEY'S TOURISM

TOURISM PLANNING: A GENERAI APPROACH

Tourism planning has had a rather short history and this general trend is predominant in this field worldwide. As Inskeep (1988:360) noted:

The planning of tourism as a distinct activity requiring a particular body of knowledge and a systematic technical approach is a relatively new specialization in development planning: General planning literature carries little reference to tourism planning, and it is not yet being taught as a separate subject in university planning departments.

Or in Gunn's terms, "Most tourist endeavors are characterized by a lack of planning" (1979:23).

Atac-Rosch (1984:99) in her analysis of 21 tourism plans inferred that "it is not possible to limit tourism planning to physical/ environmental planning. Tourism planning as she noted should be a coordinated effort of many different theories of planning put into practice."

Some definitions and criteria have been conceptualized by various scholars in the field of tourism. For instance, a definition conceptualized by Gunn (1989) defines tourism planning as an inclusive amalgam that goes beyond what is known as design--the physical and esthetic design of land and structures at the site scale usually carried 
out by the profession of architecture, landscape architecture, interior design, and fine art. Gunn reiterates "tourism planning" integrates these professional activities with social, economic, and political action.

Another planning concept that has been integrated into tourism planning is the recognition of the great complexity of planning and the limitations of even the most apt professional planners. This has led to the concept of "planning for integrated development," This has resulted in the development of what Lang (1986) called "planning that is practical and as a process known as strategic planning implying action rather than a static state when a plan has been accomplished" (Gunn, 1988). Figure 14 demonstrates the strategic planning in contrast to conventional planning. In addition, from the general planning concepts, Braddon (1982) has discussed the further specificity of tourism planning, He elaborated a definitional approach to tourism planning which also represent its complex nature as follows:

1. There is no single definition of tourism planning so an analysis of its constituent elements helps an understanding of the termo...

2. Tourism pianning is very closely linked with development planning in most parts of the world, The planning process needs to take account of very many factors ranging from topography to economy and from tourists' needs to residents' needs. It is subject to a great many external influences which both modify the process and the outcome the implementation of the plan. 


\begin{tabular}{|c|c|}
\hline STRATEGIC PLANNING & CONVENTIONAL PLANNING \\
\hline $\begin{array}{l}\text { Acton-oriontad; plaming and } \\
\text { implemontation as a singlo procass }\end{array}$ & $\begin{array}{l}\text { Plan-orionted; planning separatod } \\
\text { from implomentation }\end{array}$ \\
\hline $\begin{array}{l}\text { Orionted to the orgenization's } \\
\text { mandate and is intomaleaternal } \\
\text { emironmont }\end{array}$ & $\begin{array}{l}\text { Orientod b substantive bsuves; } \\
\text { organizational bsues ave } \\
\text { suppressed }\end{array}$ \\
\hline Focused and soloctive & All-noompassing \\
\hline $\begin{array}{l}\text { Siluational analysis inctudes } \\
\text { oxamination of organization's valuee } \\
\text { erilque of its porformance }\end{array}$ & $\begin{array}{l}\text { Organization's values not } \\
\text { considered and ks porformance } \\
\text { nol examined critically }\end{array}$ \\
\hline $\begin{array}{l}\text { Environmental sean considors lactors } \\
\text { in external onvironment affocting } \\
\text { achiovemont of objectives }\end{array}$ & Environmemal sean reroly done \\
\hline $\begin{array}{l}\text { Explicit mission statemont, fully } \\
\text { cognizant of lmplomentation } \\
\text { capability }\end{array}$ & $\begin{array}{l}\text { Vague goabs, not lostod lor } \\
\text { consistoncy or implementabitity } \\
\text { In a shared action space }\end{array}$ \\
\hline Prosetive, whi contingancy planning & $\begin{array}{l}\text { Prosctive and reactivo; no } \\
\text { contingency plansing }\end{array}$ \\
\hline $\begin{array}{l}\text { Strongly oriontod bo albcation of } \\
\text { organizational rosourcos; budgat is } \\
\text { the koy irfogralor }\end{array}$ & $\begin{array}{l}\text { Planning otten soparated from } \\
\text { budgoting; tand bocomes the koy } \\
\text { integrator }\end{array}$ \\
\hline Plansing process is ongoing & Planning procoss is poriodic \\
\hline $\begin{array}{l}\text { Bulds capacity for plansing and } \\
\text { organizational loarning }\end{array}$ & $\begin{array}{l}\text { Capraciy-building not an explicil } \\
\text { objoctivo }\end{array}$ \\
\hline $\begin{array}{l}\text { Values irtution and judgoment } \\
\text { highty }\end{array}$ & Values analysts highly \\
\hline
\end{tabular}

Figure 14. Strategic planning vs. conventional planning. Source: Gunn, 1988:18. 
3. Tourism is a social, economic and environmental activity: Its planning has to operate at various levels; nationally, regionally, locally.

4. Tourism planning must take account of conservation of the physical environment:a. The spatial planning of tourism can be very effective in this regard:

5. Ideally tourism planning should be fully integrated with all socioeconomic activities and at all levels of involvement; This would ensure the optimal use of tourist resources with least social, economic and environmental costs, 6. Tourism planning is not just a formulation of plans for the future. It is also about the implementation of plans, It is therefore important that the right economic conditions exist for development to take place in accordance with the plan: It is also important that tourism planning is marketoriented, providing the right product for the consumer--the tourist.

7. At the outset of planning the aims must be stated (Pearce, 1989:246)

Last but not least is the concept of basic stages in tourism planning (Figure 15) as advocated by Acerenza. For Acerenza, the process begins with an analysis of what has already been achieved, that is with a critical assessment of the various impacts, both positive and negative, of previous tourist development and an analysis of the political significance of tourism. 


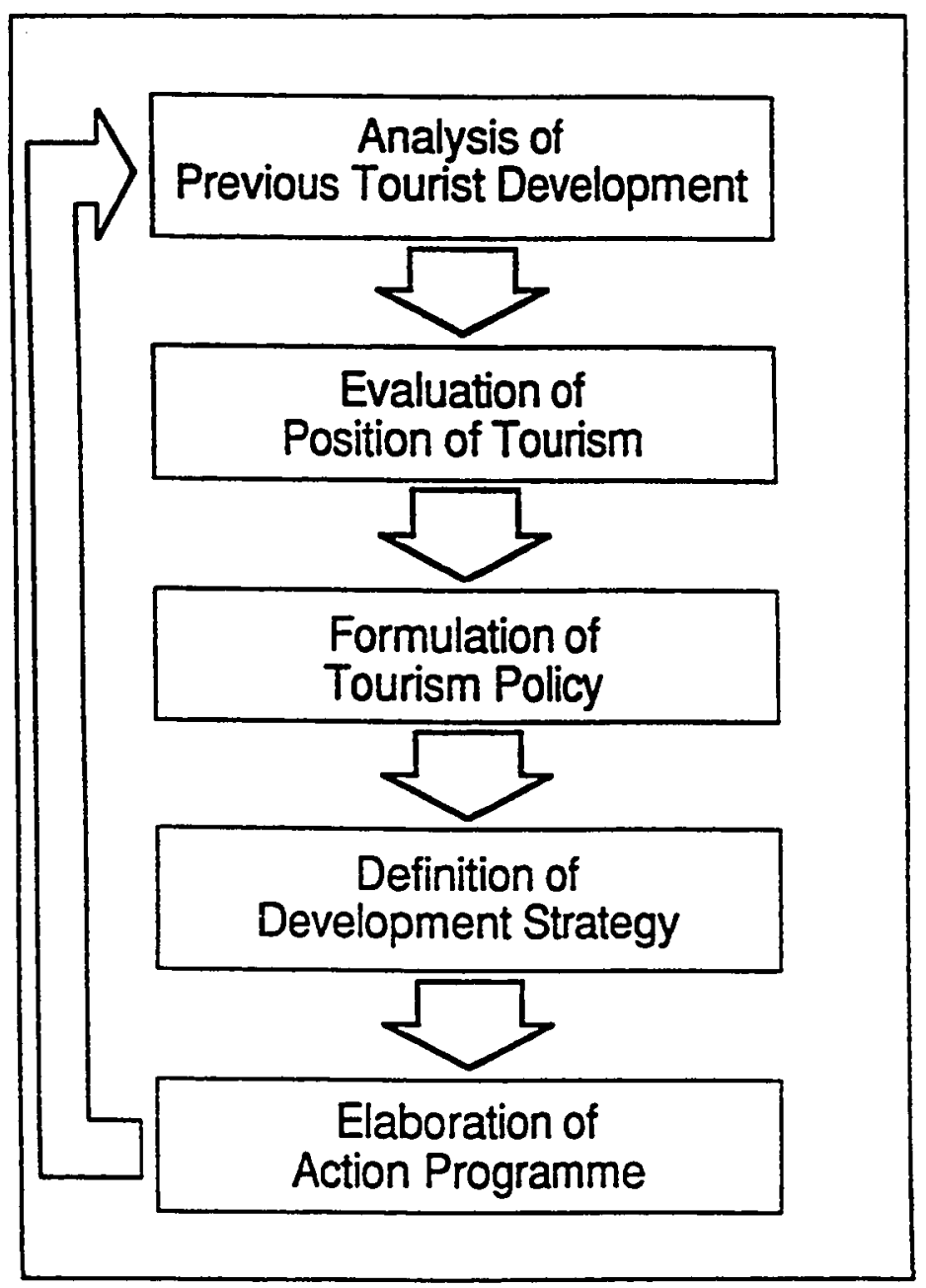

Figure 15. Basic stages in tourism planning. Source: Pearce, 1989:247. 
This information is fed into the second stage, one which Acerenza sees as being fundamental but one which was often omitted or given little weight in earlier plans, that is an evaluation of tourism's position from different perspectives, Therefore, tourism must be seen in terms of national social and economic priorities so that it might contribute more effectively to meeting broader development goals The third step elaborates tourism policy as the complex of tourism related decisions which should integrate harmoniously with the national policy for development; Stage four is the determination of the development strategy, here the emphasis shifts to the means of developing available resources to meet the goals outlined in the tourism policy:

Stage five completes the transition to the operational phase where specific action programs are defined in five main fields: institutional organization, development, marketing and promotion, manpower development and financing, Finally, a feedback loop from this stage to the initial stage occurs, At this point the results of the action programs are fed back into the analysis of the previous tourism planning development, thus creating a long-term continuing process (Pearce, 1989:246-249);

\section{TURKEY'S CASE}

The concept of tourism planning in Turkey has only taken form in recent years, despite the existence of national plans since the 1930s: The form of such "planning" has been realized and confined to "physical plans" and "physical tourism development projects"" Atac-Rosch (1984), analyzing various tourism plans, noted that this is not unusual, 
Confusion over "Planning" as a method for a "systematic" approach to development projects, and the objectives to be achieved through the tourism sector is rampant (Rondinelli, 1983; Sessa, 1988) : Such perplexity in the development process results in a negligence in recognizing the tourism sector as a "system"--a collection of units with reciprocal interrelations or a collection of elements bound together by a network of relationships (Sessa, 1988).

Nonetheless, in the 1960 s there were efforts to theorize tourism and its development (Akoglu, 1967; SPO, 1968; Dalli, 1970; Camlibel, 1970; Olali, 1970; Gulersoy, 1970): Unfortunately, none has been able to produce a model to guide Turkey's tourism based on the Turkish socioeconomic and political environment, As Gulersoy (1970:226) described "the Turkish community is in a process of peculiax transition from a demolished East to an as yet unestablished West." Most of the studies have treated the tourism phenomenon in a reductionist way $\left(i, e_{\text {, }}\right.$ a procedure or theory that reduces complex data or phenomena to simple terms), or as Sessa (1988) noted, many attempt more business oriented than system oriented applications.

Tourism planning has been simplified to an objective of securing all the services required by the national and foreign tourists (Akoglu, 1967). But this is only the demand side. There are various elements that must be harmonized in a systematic tourism model. Most of the tourism-related articles are filled with the position of international tourism and the probability of Turkey's share of the market, In general, tourism has suffered from an inadequacy of appropriate forecasting and carrying capacity analysis as well as in depth 
ecological studies, not to mention its administrative handicaps; The main emphasis of most tourism planning has been directed towards marketing and commercialization,

Tourism planning is obscured by the lack of understanding of the nature of the industry. This is clearly demonstrated in the objectives that are outlined for the tourism policy! In fact, these objectives have become "policy" and "planning" themselves. As Rondinelli (1983:81) noted, "One of the most frequently cited obstacles to the more effective management of development projects is the imprecision of their goals and objectives." He argues that this condition causes constant conflict among government officials, project managers, consultants and participants. There is no separate analysis of how to organize and systematize this sector in order to sustain the resources of tourism, In terms of a systematic approach to tourism planning the criteria laid out by Van Doorn, proposes the study of four components of the phenomenon: the tourist; the intermediary framework (i,e., what is called the tourism industry and all those supporting services which must be used by the tourist); the supply of tourist resources (i,e:, the necessary balance between infrastructure and superstructure, their functions, and the impact on the territory); and the social context of tourism (i.e., the socio-cultural, technological and political changes which are associated with tourist flows) (Sessa, 1987:220). The annual programs take some measures for tourism planning which have resulted in final policy formulation, however, none of these measures actually relate to tourism planning except for some limited marketing procedures. overall, tourism planning in Turkey has not been perceived as what Gunn 
(1988:17) called "strategic planning:" Turkey's case is one of

conventional planning with little or no strategic planning;

The absence of strategic planning is conspicuous in parts of the coastal lines of Turkey (e.g., Gemilik and Kumle in Bursa) in which haphazard building and polluting of resources has endangered the future of tourism, As Young $(1973: 157)$ realized, this situation is a worldwide consequence of the lack of planning system when he stated:

Hundreds of miles of coastline have been ruined irremediably by virtually uncontrolled building of hotels, restaurants, bars and houses. Beaches have been divided into unsightly allotments, and noise from jukeboxes, fumes from traffic and sheer human overpopulation pay witness to the chaos man has made of the organization of his leisure; These evil consequences are not "inherent" in the development of tourism; they just happen when tourism is developed in a thoughtless and casual way:

While tourism requires a strategic planning and an inclusive approach to various aspects, a look at Turkey's five-year development plans, clearly shows that the dominant theme is only economics (Atac-Rosch, 1988); In addition, the development plans and their relationship to the tourism sector have shown various linkage problems (e.gh, the lack of linkage between the first and the fifth five-year plans in terms of environmental protection in the coastal lines) (Atac-Rosch, 1988)! Turkey's tourism remained subject to what Seidman (1979:13) stated:

By and large, not only in Africa but world-wide, planning was notable mainly for its lack of implementation, :;

The core of the problem is that the management of planning never received the attention that the economics of planning attracted; 
He further argues for more attention to the skillful use of legal systems to reinforce or secure development, Again, in Turkey's case, the diversion from a mixed economy to a liberalized policy which unleashed the private sector raised doubts about the role and function of the legal system for the sustainable productivity in the tourism sector:

The dilemma which has occurred historically is that the government has always been directed to act based on short-term needs to solve immediate economic problems, This condition either resulted in or subjected the public sector to a condition of not realizing the importance of the philosophy of planning as Myrdal (1968:251-2) stated:

Planning, is a determined effort, through democratic institutions for collective decisions, to makestintensive, comprehensive, and long range forecasts of future trends, and to formulate and execute a system of coordinated policies framed to have the effect of bending the foreseen trends toward realizing our ideals, spelled out in advance as definite goals:

TOURISM AT THE NATIONAL LEVEL

The MCT, as one of the main institutional elements of tourism acts as Turkey's National Tourism Organization, As will be clarified further along, MCT's performance and know-how has functioned in an environment that can be best described as "leading national tourism development without a national tourism policy:" This is not an unfamiliar paradox in the development process of most developing countries, As Pearce (1989:250) noted, "4:planning for tourism at the national level, as at other scales, should be undertaken in the light of broader national development goals and objectives." In many cases, Pearce reiterated, 
national development goals may not be clearly articulated and the tourism planner has little guidance as to what overall goals should be pursued through the development of tourism. In many instances Pearce continued, "Tourism plans focus specifically on tourism goals with little direct reference to broader issues, thus lessening the likelihood that tourism will contribute effectively to national development" (1989:250): The MCT's programs and their implementation are controlled and organized via investment for tourism facilities, especially accommodations and physical planning for tourist regions, areas and centers, In the planning process for tourism development the terms regions, areas, and centers remain quite ambiguous when it comes to the characteristics and policies which are supposed to identify and distinguish each entity: Therefore, these three notions overlap and almost become a monlitick spatial quantity;

Planning Approach

Despite the lack of a national tourism policy and minimal attention to the tourism sector in the five-year development plans, MCT has taken certain approaches to tourism planning during the 1980s, This particular approach to tourism planning has focused specifically on tourism goals ( $i_{3} e_{;}$, foreign exchange earning) with little direct reference to broader development issues, thus there is no such thing as "planning tourism at the national level,"

Tourism development is divided into seven tourist areas--Istanbul, Izmit, Bursa, Ankara, Izmir, Mugla, and Antalya, Except for Ankara, the rest of the tourist areas are located along the Aegean and the 


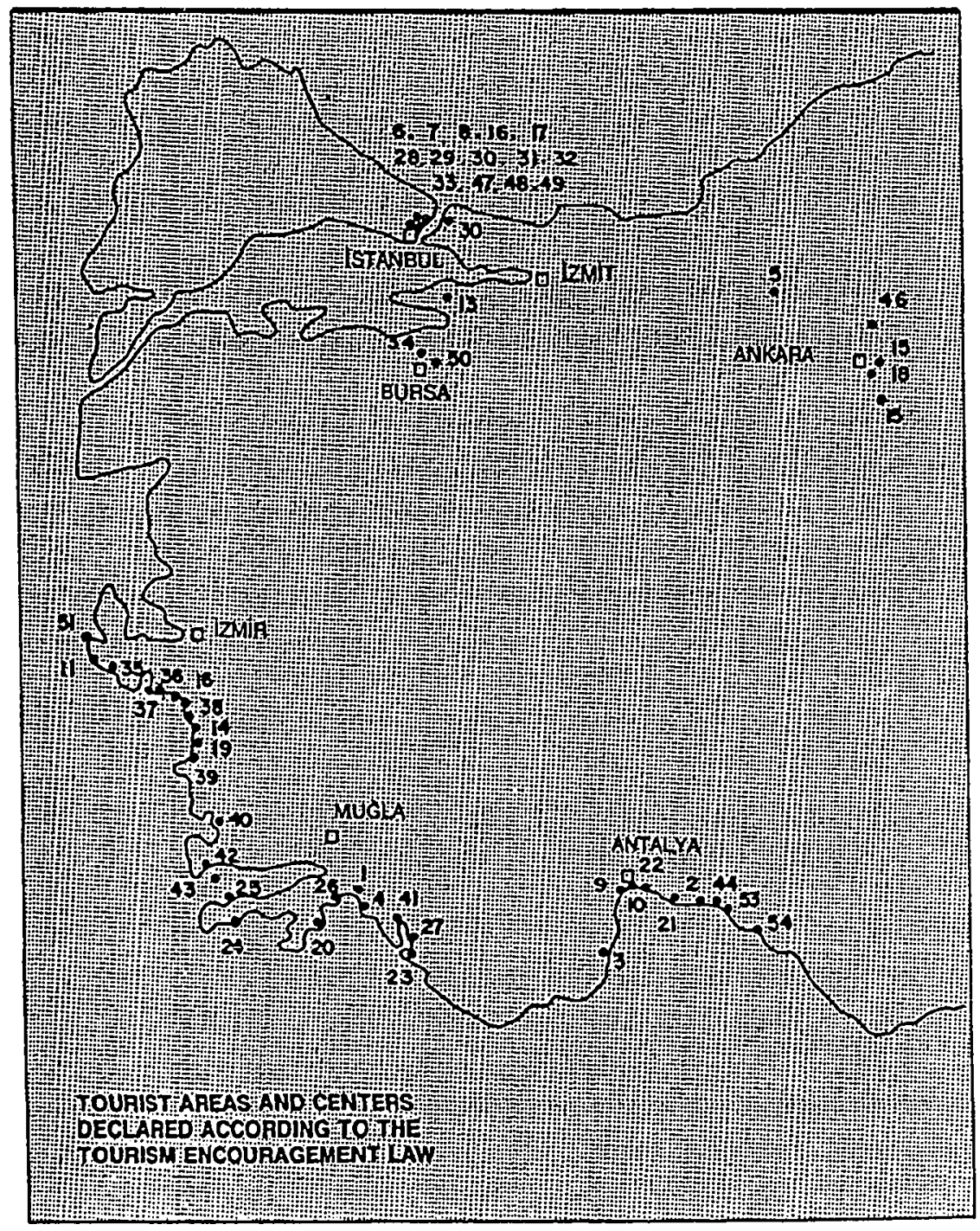

Figure 16. Tourist areas and centers declared according to the tourism encouragement law: Source: Turkey, Tourism, $1987: 38$. 
area has its clusters of tourist centers! Three of these tourist areas--Izmir, Mugla, and Antalya have been subject to planning and development guidelines known as "Southwest Turkey Touristic Investment Areas" (STTIA). To note, these three investment areas located in two regions of Aegean (covering Izmir and Mugla), and part of Southern Anatolia (covering Antalya).

With the tourist boom of the 1980 s MCT began to take a planning approach which concentrated on the two tourist areas of Mugla, and Antalya (with highest potential of tourist attracting resources known as sea, sand and sun). From those two areas they have targeted 13 touristic centers (Southwest Turkey Touristic Investment Areas (STTIA). (See also Figure 17,) As will be discussed later, Bodrum Peninsula is one of those 13 targeted centers for tourism investment or so-called tourism planning. As indicated in Figure 17, the lower section is an enlarged planning center which corresponds to center (1) in the upper part of the figures (Bodrum Yarimadasi). Purpose and Process. Tourism development centers (STTIA) are further delineated into Touristic Installations zones. In order to facilitate tourism investment, MCT has developed a package of planning maps called "Turizm Yatirim Alanlari" or tourism investment areas. This package contains two distinctive but overlapping detailed plans: : implementation (uygulama imar plani) and master (nazim imar plani). These two planning maps are in fact the land use plan of 16 tourist centers encompassing 13 MCT targeted tourist activity centers! Their planning concerns are in the three tourist areas of STTIA. 


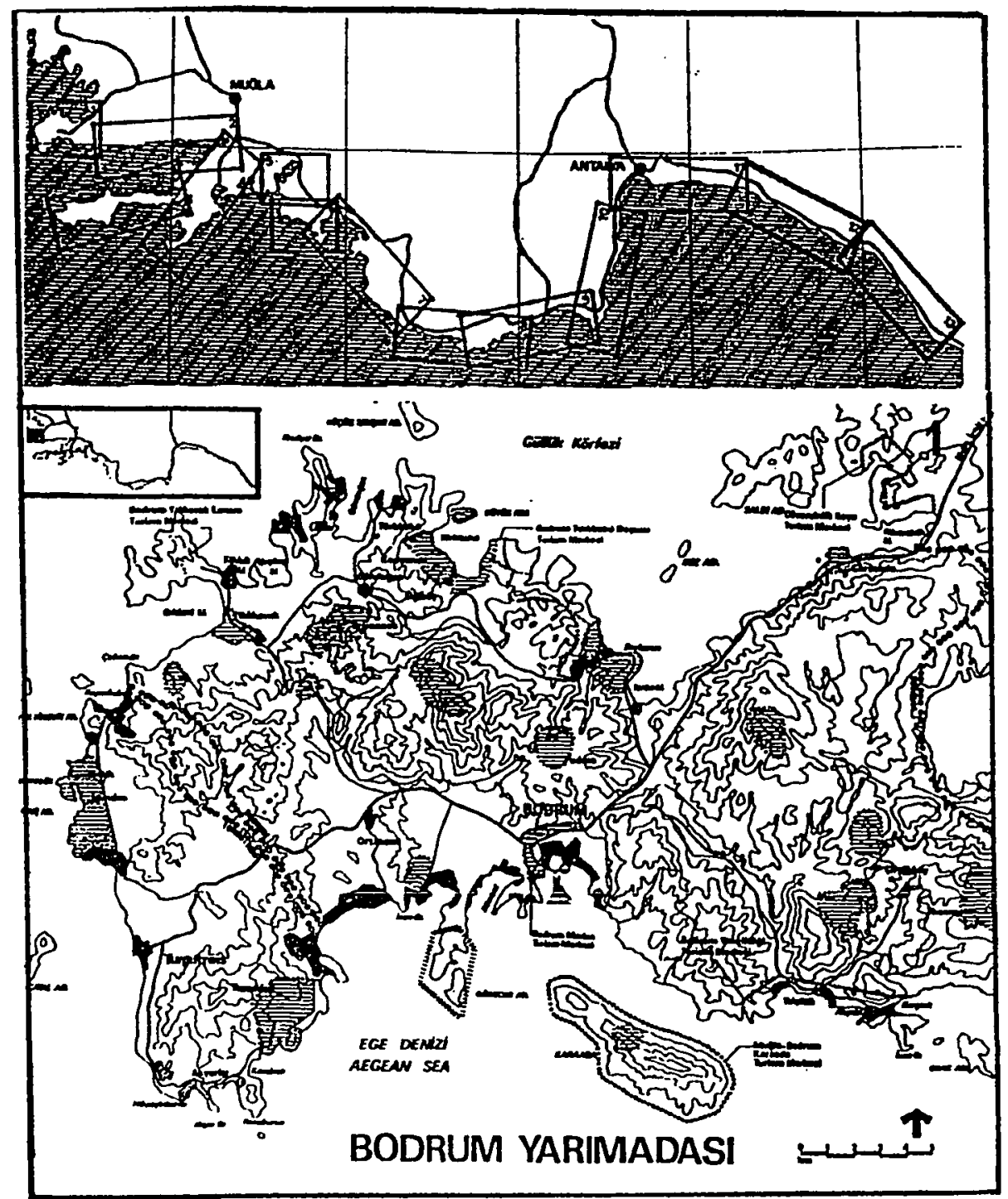

Figure 17. Southwest Turkey touristic investment areas. Source: Tourism Bank, 1987:14-15. 
MCT targeted tourist activity centers, Their planning concerns are in the three tourist areas of STRIA

The main purpose of these so-called master plans are to outline guidelines for land acquisition and construction regulations. This is to encourage and facilitate tourism activities on those lands (mostly state owned) that have been set aside for construction of tourist establishments, Regarding land acquisition, Act No, 2634 on the encouragement of tourism has introduced a number of new facilities with regard to land acquisition for tourism investment purposes applicable in the "touristic regions," "touristic areas" and "touristic centers" as set up and declared upon the recommendation of the Ministry of culture and Tourism and by decision of the council of Ministers pursuant to same Act: Therefore, the possibilities for land acquisition will vary dependent upon whether the land is located in a touristic region, area or center (TB, 1987:38) : To note, significant to this process is the issue of "land" which can be categorized as: a) public lands including: treasury owned land, lands under the use and control of the state, and forest lands; b) privately owned lands, Lands owned by the treasury or under the use and control of the state or forest lands located within the boundaries of the Touristic Regions or Touristic Centers, if earmarked for tourism purposes are allocated to the MCT following completion of procedures required by Act No: 2634 on the encouragement of tourism.

The procedures pertinent to the allocation, leasing of, and establishing such lands for tourism entrepreneurs, are administered by 
the MCT under the provisions of the "By-law on Allocating Publicly-owned Lands to Tourism Investments $"$ "

The MCT may expropriate privately-owned lands located in touristic zones and touristic centers and allocate them for tourism purposes in accordance with land use plans, Following the expropriation, such real property having gained the status of "treasury owned lands" may be allocated to entrepreneurs under the provisions of the "By-law on Allocating public-uwned lands to Tourism Investments" (TB, 1987) The plans also have the same procedures for foreign nationals who are willing to make investments in the tourism field--especially on public-owned lands. Foreign nationals, as indicated by the plan, "are subject to the same restrictions as the country's national and enjoy the same status as the national ventures" (TB, 1987:40):

Nature of the Plans

The three so called planning tools in tourism development--master plan, land use plan, and implementation plar--are strictly physical plans, For instance, the master land use plan (nazim imar plani), in its broader definition, indicates a systematic approach to what uses a land may be allocated for in a specific area, However, in order to proceed with the construction, it is necessary to have implementation plans (uygulama imar plani) which directly restrict and facilitate the architectural project itself:

The "implementation plans" may be a part of a previously endorsed "master plans" or drawn up independently for an area for which no master plan has, previously, been prepared, Furthermore, cadastral divisions 
if available, are also indicated on such maps, which are endorsed by the municipalities if relating to municipal and adjacent areas and by the provincial governments if relating to other areas;

Another task of implementation plans is to delineate the coastal lines or "the coast/bank brinkline?" The coast brinkline is the natural border where the waters of a sea, lake or river touch the land--save for situation of flooding and overflowing, and where sandy, gravel, rocky, marshy and swampy beaches have been formed by water activity, These procedures are established by the provincial government.

Equally important is that these plans represent the environmental arrangements in each tourist center, as well (cevre duzeni plani): Regarding the authorities' relation to these plans, the endorsement of these plans within municipal borders and the adjacent areas is vested with the municipalities, while the provincial governments are authorized to endorse those plans of areas located outside such borders, However, within the touristic zones and centers the competent authority to endorse any of those plans rests with the MCT! This latter part of authorization has resulted in the dichotomized tourist investments-namely, those ventures that MCT directly endorses (Belgeli).

Two more authoritative bodies are involved in the process of these plans, including the Municipal Council and Provincial Administrative Council of the Provincial Government. These councils are expected to review those tourist activities that MCT directly encourages either within the municipality or outside the municipalities!

To note, there are established historical and natural sites which are delineated by the "Supreme Council of Immovable cultural and Natural 
Assets" which may attract tourist investors: It was required that any land use plan or architectural projects should acquire this council's agreement (MCT, 1987; TB, 1987):

\section{INVESTMENT POLICIES}

In the area of investment, basic legislation, Law 2634 of 1982 "for the encouragement of tourism" offers incentives for investors operating in the tourism sector: These include:

* Allocation of public land to investors on long-term lease or

* Credits supplied by the TB

* Considering tourism investors as exporters

* Setting up installments for the forest fund

* Giving facilities to enjoy electric, gas and water charges at reduced prices

* Giving precedence to Turkish Postal and Telecommunication system (PPT)

* The right to employ foreign personnel

* The right to sell liquor

* The right to operate chance games (gambling)

The Ministry also provides incentives designed to encourage the construction of tourism installations (MCT, 1983; Turkmen, 1988; International Tourism Reports, 1989), These include:

* Investment subsidies

* Custor exemption

* Exemption from construction duties 
* An incentive premium

* A premium for supporting usage of resources

* Allocation of foreign exchange exempted from tax and duties

The overall national policy for investment, particularly by

foreigners, has been directed towards tourism as well. As in any other sector, tourism has also offered various incentives to attract foreign capital. As was noted in the International Herald Tribune (1988:8),

once upon a time, foreigners believed that it was usually wisest to come into Turkey on a joint venture. Not anymore. The government no longer insists as it did ten years ago, on a large local stake in a joint venture. It also welcomes 1008 owned foreign investment.

Regarding such enthusiasm, the Ministry provides the following reasons for investing in tourism which again is a proclamation of some implicit policies in the tourism sector:

* Geographical location provides her to capture tourism business from everywhere

* Shortage of beds in cities and resort areas

* Highly attractive incentives for investors

* Low building cost compared to European countries

* Freely appiicable room rates

* Long-term leasing possibilities

* Rapidly growing market

* Benefits of liberal economy on import

* Loans or guarantee for overseas loan financed by TB

* High gross operating profit margins

Table XXXVI depicts the trend in policy changes from public

investment toward private participation in the sector from 1977 to 1988 , 


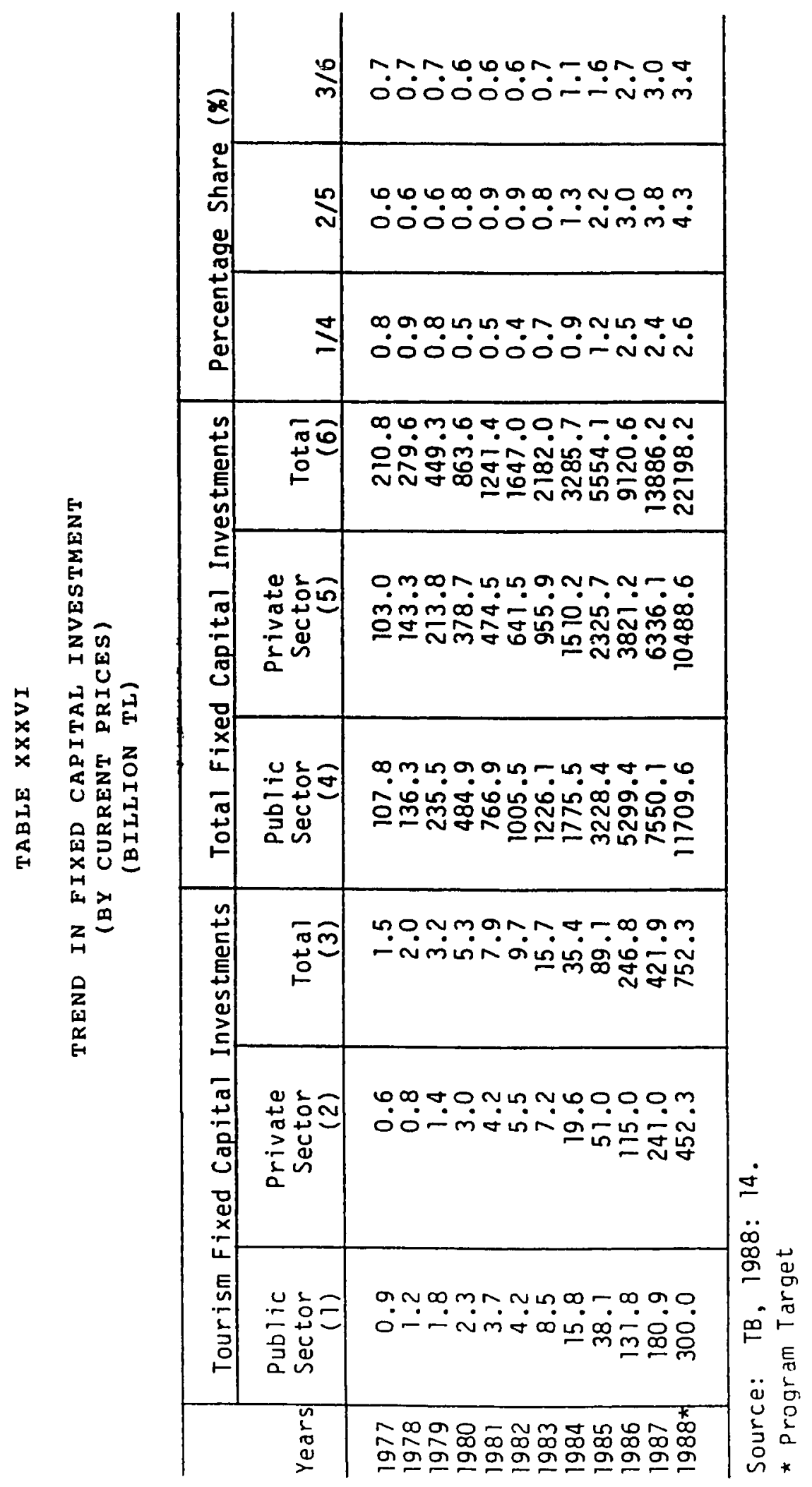


Law No, 6224 provides a comprehensive system of guarantees for foreign capital invested in Turkey: Foreign capital may be imported in the form of cash, equipment, materials, services or technical knowhow: The shift in the government's new economic policies has been in favor of foreign capital and investment which have brought in $\$ 2,3$ billion (US) between 1980 and 1987 (SPO, 1988:2)! Under the new policy for foreign investment, the investment allowance rate in the tourism sector is 100 percent, The resource allocation support premium is indicated as 40 percent for accommodation facilities, services facilities and marina for yachting: Minimum equity requirements for the financing of investments benefiting from the investment incentives were announced as 50 percent (SPO, 1988),

With the new economic policy, the trend in foreign investment has been gradually increased in the sector which is also reflected in the accommodations development for tourism activities: TNCs are actively involved in the investment as well as management of hotel industry in various tourist centers! Table XXXVII indicates TNC by the type of activity and their share in the investment (Hacioglu, 1988:111-3). The number of foreign capital investments permitted in 1987 was 77, reflecting an increase of 92.5 percent compared to the previous year: The amount of foreign capital investments permitted in 1987 increased to $\$ 132,67$ million, which is 2,85 times more compared to the previous years (Economic Report, 1988:72):

New policies to create the alternative financial resources are geared toward the flow of foreign capital and credits which have increased markedly, Financial resources obtained abroad grew from TL 
TABLE XXXVII

THE SHARE OF FOREIGN CAPITAL IN THE ACCOMMODATION SECTOR IN TURKEY

\begin{tabular}{llcr}
\hline Establishment & Managing Firm & $\begin{array}{c}\text { Bed } \\
\text { Capacity }\end{array}$ & $\begin{array}{c}\text { \& Foreign } \\
\text { Capital }\end{array}$ \\
\hline \hline Hilton & Hilton Int & 700 & 100 \\
Sheraton & Sheraton & 855 & 100 \\
Etap Marmara & Wagon List & 704 & 70 \\
Club Med Foca T.K. & Club-Med & 900 & 99 \\
Altin Yunus & Unit Brew Dan & 1030 & 11 \\
Kervansaray Mocamp & British Petrol & Camplinger & 100 \\
Cemyura Tatilkoyu & ICBAG-Invest & 721 & 90 \\
Club Salima & Unit Int & 690 & 96 \\
\hline
\end{tabular}

Source: Hacioglu, 1988:111.

Source of data: Service World International, Vol, 13, No 3 ,

40,0 billion to TL 75,0 billion. Thus during 1987 foreign investment in Turkish tourism grew by an impressive 87 percent in one year (TB, $1988 a: 7)$

\section{BODRUM'S CASE EXAMINED: PLANNING}

AT THE LOCAL LEVEL

An Overview

Illustrative of the implementation of tourism planning and its success or failure is the case of Bodrum Tourism Center. In this case study a functioning tourism system can be seen through various factors of discovery which not only concern Turkey, but also are of concern to planners worldwide, especially where development of tourism threatens to run out of control (International Tourism Reports, 1988), 
The Bodrum Tourist Center is what Time (1988:66) called

unpolluted, unspoiled, unconventional and a genuine bargain. It has grown from a small fishing village to a center of tourism explosion which houses nearly 100,000 tourists even though its population capacity is around 10,000 . This has taken not only Bodrum by surprise, but Turkey itself: Bodrum has become the hottest tourist spot in Europe.

Bodrum's case can be seen as an experiment in the tourism development in the field of implementation. It was here that one could observe the process of implementation and its function in a centralized administrative system. It was on this particular field that the shortcomings of a development project manifested itself in what International Tourism Reports (1989:50) noted as, "construction site syndrome:" Bodrum was most frequently singled out because it appears to have run out of essential services, sewage disposal being a particular problem, Based on observations, critics charge that it is already on its way to becoming a spoiled Eden, As Time (1988:67) noted, "purists are particularly troubled by the burgeoning development of cheap apartment buildings and hotels along the Aegean Sea coast! some people say that Bodrum's attractiveness began to decline long ago:" Bodrum's case represents the much deeper rooted problems that impinge upon the mechanisms of tourism development in Turkey as a whole: The significant shortcomings in Bodrum concern carrying capacity, The case of Bodrum reflects the alien character of this notion to the government as well as to the private sector: Therefore, because of a lack of legislation from MCT to extend control to the local government, Bodrum was left to deal with the strain imposed on its amenities and resources with no legal course to prevent it. These strains include: 
first, environmental stress due to haphazard construction development on a deficient infrastructure, second lack of impact studies or procedures to overcome the stress that results from the generation of new or increased waste residues which are a widespread problem in resort communities, The collapse of the Millstatter Lake in Austria during the 1970s following a tenfold increase in tourist traffic in the preceding two decades and restriction on bathing in certain Mediterranean beaches are cases in point (Pearce, 1981): Regardless of fragility of the environment, which is significant, the problem in Bodrum is basically one of planning and management, and the means to control and regulate the infrastructure malaise that has been created;

This may result from the rapid expansion of tourism wherein construction of accommodation outstrips the provision of treatment facilities. This situation arose simply from a basic inability of local authorities to organize and plan for pitfalls;

Bodrum is also in the process of struggling either to retain a locally oriented scale of tourism or to allow large industrial development; This has manifested itself in resentment between local craftsmen and large scale tourism enterprises, A change in development plans was perceived as a threat to craft tourism, which is an indigenous adaptation to the tourist resources and as such is congruent with traditional social relationships and values, As Rodenburg (1989:223) noted,

Different scales of tourism provide different services but compete directly with one another: The competitive advantage held by large industrial tourism, in attracting package and group tourists, is due to its economic muscle and international connections, not to "economies of scale," 
History

Bodrum is over 35 centuries old, Halicarnassus, as it was called then, was the main port of the kingdom of Caria and lay between the Thalassocracy of the Achaeans and the kingdom of Mira, itself a subject state of the Hittites. It became a part of the Lydian Empire and fell to Cyrus II when Croesus lost the battle of Sardis (Mansur, 1972:3) It became the capital city during the reign of King Mausolus: During this time the city prospered through physical transformation and the establishment of various castles including the well-known mausoleum today:

However, the little port and the bay bordered by small, white homes until recently remained far from the center of things in Turkey: It was too well protected by its mountains and too far from the capital. It took modern administration, modern political organization and some economic development to integrate it to some extent into the rest of the country:

\section{Geography}

Bodrum is located on the southern side of largest peninsula surrounded in the north by the Gulf of Mandalya, the west by the Aegean Sea, and the south by the Gulf of Kerme, the ancient Ceramos! Bodrum is roughly on the same latitude as Syracuse and Granada, on the 37th parallel (Mansur, 1972) (see Figure 18):

\section{Tourism Boom}

Until 1960 tourism in its modern form was something unknown to Bodrum residents: The dominant form of accommodation was "pensions" 


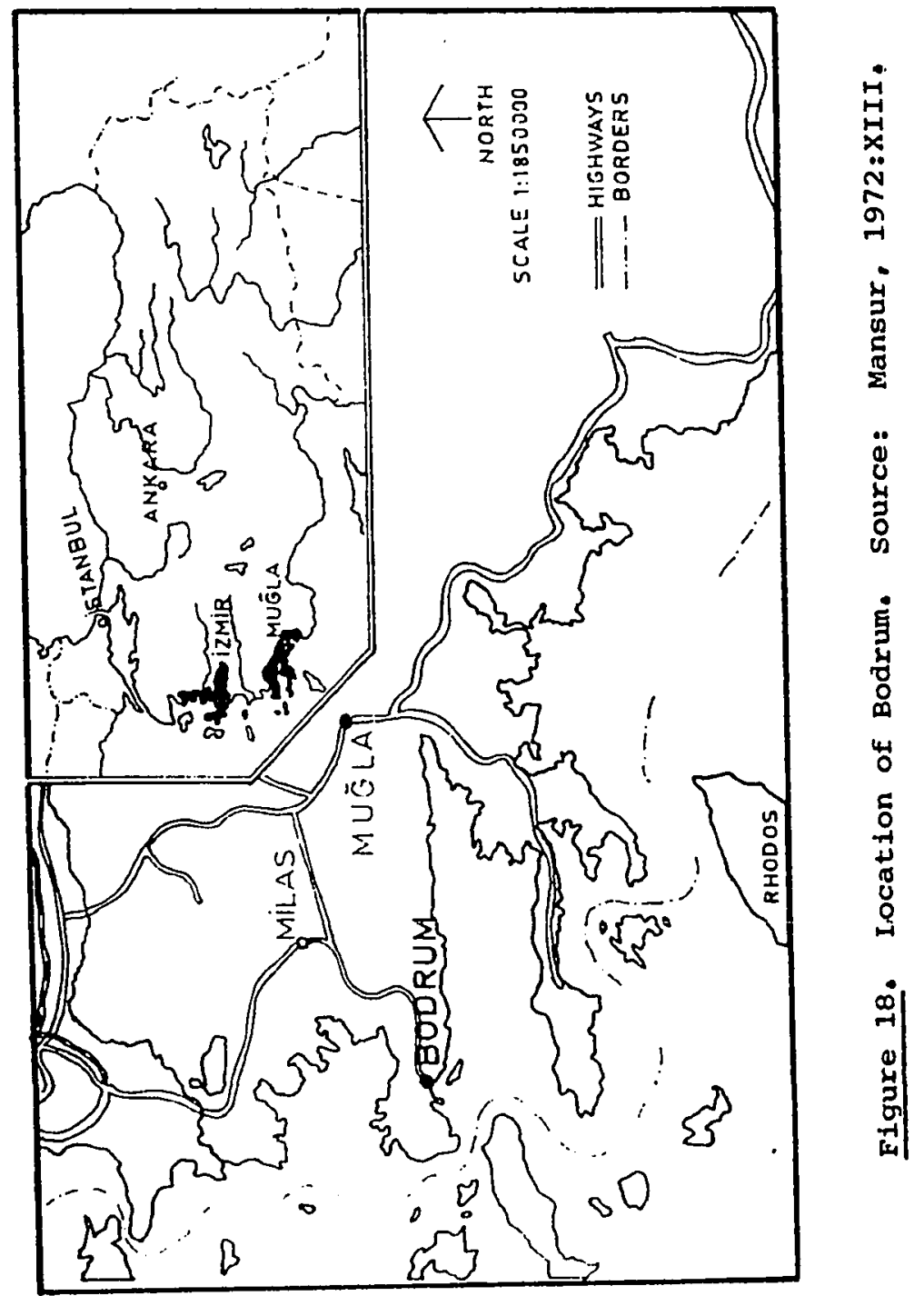


which were hosted by households on a non-commercialized basis: As Mansur (1972:65) noted, "In 1960, the Tourism Association devised a way to save the hosts from embarrassment: they would take the money from the tourists and give it to the hosts afterwards!" Today Bodrum is a dynamic tourist center offering various advantages from a diving school to operating several yachting companies. Existing licensed bed capacity is 2,098 and another 591 beds are under construction (Turkey Tourism, 1987): Bodrum forms a peninsula which comprises the TURBAN Bodrum Marina of hundreds of berths. It has access to various unspoiled beaches and islands which are supplemented by its archeological values, It is also home to the fifteenth century castle of st, Peter which is presently operated as an underwater archeological museum, Underwater excavations are continuing in the Bodrum area, funded and operated by an American-based archeological group: During the peak months (May to October) the museum has about 1,000 visitors a day (Bodrum, 1988) It is predicted that this number will increase in response to other new attractions coming to the castles Another activity, second to tourism in the area's economy, is the boat-building factory which has been operating since the fourth century Bac (Bodrum, 1988)

Development Model

Bodrum is classified as "coastal tourism" in the typologies of tourist development! Pearce (1981:14) originated three distinct classifications for the way "coastal tourism" is dealt with In his elaboration, coastal tourist centers become subject to tourist activity through 
1. spontaneous development;

2. tourist resorts resulting from a planned and localized development; and

3. extensive development Bodrum's case as examined fits into "spontaneous" development, characterized by a winter influx of well-to-do gentry, artists and writers who favored the city prior to the invasion by mass tourism, The aristocratic phase of tourism has been absent in Bodrum: Bodrum traditionally has been a fishing village and a port with some agriculture and industry associated with boat building, The coastline and climate are extremely attractive and this has led to an influx of summer tourists during the 1980s: Demand started to exceed supply, and the city was ill-equipped for such activity: In the race to expand, construction has been anarchic, planning measures have been in short supply and environmental degradation unavoidable:

\section{Development Policy}

Gajraj (1989:202) pointed out that

By the beginning of the 1980s, many governments realized that the development of their tourism industry in the two previous decades had not taken adequate account of the available resource base of the environment (physical, cultural and social), nor had the demand on the countries, infrastructure been properly determined, It was realized that in many cases, the industry was in danger of destroying itself if further growth continued in the same way as before.

Bodrum represents one of those cases that succumbed in a situation of policy absence, The prime indication of such a condition is the lack of integrative planning to incorporate broad goals beyond physical 
development. The absence of policy has resulted not only in a type of physical development that has no balance with the existing infrastructure, but it also led to the pursuit of mere economic benefit in a situation known as the "tourist trap!"

The absence of a policy has translated to a condition which does not adhere to what Pearce (1981) called either an integrated or a catalytic development, which are generally adopted as key criteria to appraise tourism developments and to identify their foreign process: Furthermore, the pursuit of tourism planning goals without considering the social and environmental aspects of tourism remained what Gunn (1988) called "incomplete and at times even damaging:" This has been realized in the context of four fundamental tourism goals that are identified for every tourism enterprise. These goals are: satisfactions to users, rewards to owners, protected utilization of environmental resources, and local adaptation, Bodrum's case manifested the ills that existed in the whole process, namely the lack ci communication and the antagonism between governmental agencies and private enterprise, as illustrated in the case of $\mathrm{M}$ Club. "M Club" began its operation during the summer of 1988 as one of the multimillion dollar investments designed to acquire "5 Star" prestige ir. Bodrum; In Iny interview with the owner-general manager of the club (September 12, 1988), as well as with the mayor of Bodrum (September 15, 1988), it was revealed that the project had generated an uneasy atmosphere on various grounds, For instance, the first objection was inferred from the lack of strong governmental organization to deal with tourism. A Club was built to operate as a casino, but after the project was completed, it 
was not clear which tourists (foreign or domestic) were being catered to: I posed the question, "What is the local government's role?" Mra $\mathrm{X}$ replied,

the municipality lacks personnel, authority, and control, It is a handicapped agency: To my knowledge the tourism bank is the only element that functions well.

As I asked what he thought of the future of tourism in Turkey, the answer was: "If there is not an immediate policy, the future of tourism is in great danger:" Interestingly, in another interview with $T, M, T$, Holliday village in Bodrum (September 17, 1988) the same pessimism was expressed and the role of the municipality indicated the dilemmas of a centralized system. A dual character of tourism activity undermined a collaborative planning which was essential to create a local-oriented commitment to preserve the environment and integrate tourism goals into the total community and the area's social and economic life. Policy absence resulted in a problem of incomplete tourist facilities that remained unsolved for lack of clear regulations on the government's part and skepticism of private developers toward the future of tourism in Bodrum;

Bodrum's case demonstrated how the neglect of "public support" for tourism can result in serious consequences for future growth!

Planning Approach: Local Level

As mentioned earlier, Turkey's tourism has concentrated in the western and southwestern regions, Accordingly, 13 tourism investment centers (Turizm Yatirim Alanlari) have been delineated; Bodrum Peninsula (Bodrum Yarinadasi) is one of the classified touristic centers that was examined closely as a local level planning process, One of the 
specifications of the local level planning process of tourist areas is that each local area basically adapted those plans which were prepared by the MCT for the 13 touristic investment centers! MCT has produced a master plan for each area ( $i, e,$, Bodrum Peninsula Land Use and Master Plan) (see Figure 17), which emphasizes the designated tourist development areas in order to encourage investment; Thus, Bodrum's planning process is based on the same plans produced by the MCT for tourism investment. And this is not by coincidence, since Bodrum is one of those designated touristic centers However, in the context of these plans one aspect has been bestowed to the local authority and that is the "construction regulations," As noted,

Each municipality has regulations on construction, enforceable on areas covered by the land use plan, within the municipal borders a. However, next to the land use plan the architectural project to be drawn up must also comply with the more detailed rules for project preparation, spelled out in the construction regulations (MCT), 1987:42),

Bodrum's Land Use Plan

Bodrum's municipality is the only authority on the local level to represent the political party in power which has an appointed mayor; However, with the burgeoning tourism activity, municipality has also adopted certain codes and regulations in 1985 (Bodrum Imar Yonetmeligi ve Planlari) or Bodrum construction regulation and planning, This plan has nothing new or different from those plans that were produced by the MCT for regulatory procedures for construction, For instance, Bodrum has adopted a building height code that allows no more than two floors 
in each building construction. This way it prevents high rise projects, in order to preserve its historical character, However, the city lacks the authority to control or monitor projects beyond its boundary In addition to the mayoralty, an assembly of councilmen also observes the regulation of the land use plan in situations where there exists any conflict over the land, Because a building code is enforced, all construction activities are required to be reported to the municipality One of the goals of this process has been the protection of areas that are exclusively designated for tourist facility development use, To reinforce these areas protection from non-touristic use, a committee has also been appointed to intervene in cases of conflict

Nevertheless, in the Bodrum case the general concern is with land use planning, with tourism constituting only one form of land use which the municipality must plan for: As Pearce $(1989: 268)$ noted "This is not positive development planning but rather is regulatory in nature and is concerned with reducing conflict over the use of land;"

Pitfalls in Local Planning

The first dilemma at the local level was the lack of autonomy which resulted in the lack of initiative for a locally oriented development plan. First, the local effort was concerned primarily with regulating physical development and has not included marketing and promotional elements nor given much attention to the broader issues of development; Second, there was a lack of statutory authority to prevent certain establishments from bypassing all the municipality's 
regulations. For example, certain tourist establishments in Bodrum were allowed to operate independently from local regulations, under the permission of the MCT.

Bodrum's municipality has a traditional political role (clientalist) rather than an organization with knowledge to develop tourism. A local tourist board was needed along with the municipality that had authority to concentrate on tourism, for example, to impose taxes on tourist establishments.

The lack of autonomy at the local level, coupled with the lack of a local tourism development plan, and conflicts between MCT supported establishments and local institutions were reflected in the locally undesired development of tourism establishments on the coastline. Furthermore, MCT allowed certain establishments to locate beyond Bodrum's city limit. These establishments were responsive only to the MCT, which resides in the capital. Therefore they were on their own because there was no coordination between them and the city of Bodrum. Although decentralization and delegation of authority to the municipalities was defined as a development goal, it has not yet become a reality in the tourism sector. As Hershlage (1988:130) indicated, through decentralization of physical planning and settlement decisions, delegating more powers to the municipalities, assisted by a larger share of the public budget (11 instead of 3 percent), and [this is supplemented by] granting them the authority to collect wealth taxes.

In an interview with the mayor of Bodrum, it was revealed that the municipality still remained understaffed, underfinanced and without any legal authority to collect taxes from numerous high income tourist 
establishments: The mayor in response to $m y$ question on taxation regulation stated,

to solve the municipalities' financial problems, we need to have a legal authority to collect taxes from tourism establishments: I know this kind of fee exists in Greece and other countries, but in our case there is no such a law to implement it:

The Bodrum case study furnished an important finding of

organizational deficiency in the tourism sector nationally, and comparative chaos locally. This was a common theme in numerous interviews with managers and owners of tourist establishments, as reflected by the interviewee from the "Monastar hotel complex" (September 16, 1988), He replied to the question of the relationship between tourist establishments and the Ministry of Culture and Tourism, and/or municipality, "To tell the truth if you expect something to be done for you by the municipality or the Ministry, you better stop your business, We have to take care of everything ourselves!"

\section{Implementation}

Bodrum provides a suitable case to examine the implications and implementation of decisions that were relayed in a "top-down" fashion for development and planning; Planning becomes a meaningful activity only if it leads to implementation, Otherwise a plan becomes an end in itself instead of an instrument for achieving development objectives. If one accepts this definition one will also realize the reciprocal effects of both planning and implementation upon each other: Bodrum's case revealed that such an interaction has to be organized and conducted in such a manner that problems which manifest at 
the local level can be incorporated in the broader policy and planning system that operates at the national level,

The planning process at the local level, as in Bodrum, reflects what Stohr and Taylor (1981:1) called "development from above!" This type of development strategy tends to be urban and industrial in nature and capital intensive. It hampers the implementation of mobilization of each area's natural, human, and institutional (į̣, , local government) resources with the primary objective being the satisfaction of the basic needs of the inhabitants of that area. This contrasts with what Sears (1977) and Goulet (1978) called development "from below," which is supposed to involve local government and implement local needs: The implementation process is further impaired by the nature of the planning system as it lacks the principle of the politics of rational planning, The Bodrum Tourist Center was suffering from an absence of a planning organization with a multi-level planning character, essential to coordinate such a complex industry: Further, it lacked any skilled planner in the tourism field. The municipality of Bodrum was the representative of central government and not only lacked administrative, organizational, and financial capacity, but it also acted with what Faludi $(1986: 106)$ criticized as "merely as the loyal servants of their political masters, as the bureaucratic model stipulates:" This is not surprising since the genesis of planning--culminating in the establishement of SPO--was crippled by conflicts between interest groups so that SPO lost the autonomy to pursue rational development strategies: 
This situation was exacerbated by the decisions of various agencies which were at cross purposes with one another, The implementation process at the local level was a clear reflection of new economic strategies based on outward looking objectives that function at the national level: There was an obvious correlation between the nature of the national economic strategies, which paralleled functional regional planning and the policy decisions made for the various tourist regions (Friedman and Weaver, 1979) : An alternative to "functional" type planning (i.e., identified as development from "above") is "territorial planning," In this type of planning the implementation process is concerned with the integrated mobilization (i,e., development from "below") of the human and natural resources of specific historically defined regions, It is "endogenously" oriented; it engages the people of that region within the planning process and then becomes a political process to emphasize equity by seeking a general improvement of the quality of living for all the people in the area (Gore, 1984): Unfortunately, the implementation process in the case of Bodrum reflected a "breakdown" of responsibilities between the national level (MCT) and the local level (municipality)! In an interview with one of the officials in the ministry, it was stated with regards to the chaotic situation in Bodrum: "We cannot say much about Bodrum; We know what is wrong in Bodrum" (personal interview, summer 1988, Ankara):

\section{Local Government and Administration}

Local government is examined for various reasons, namely for its role in Bodrum's tourism, because it was and still remains the sole 
representative of central government and as such is responsible for tourism planning and implementation. Second, it is important to explore the deficiencies of this particular local government in terms of its administrative capacity, financial ability, as well as its degree of authority in the overall implementation and evaluation process! The role of local government in the implementation process poses a significant question where implementation is perhaps the central stage in the policy process in the Third world countries!

Bodrum is one of the 1,600 municipalities in Turkey which, under the Turkish constitution, are "public corporations established to meet the common local needs of the citizens of the provinces, municipal districts, and villages, whose decision-making organs are popularly elected" (Danielson and Keles, 1985): Regardless of the constitutional decree, the municipality of Bodrum has organized and found itself in an exceptional condition due to the influx of hundreds of thousands of visitors during the tourist season, This situation obviously requires a unique and comprehensive function concomitant with routine day-to-day local government's tasks; The Bodrum municipality can be characterized by planning inefficiency, simply meaning that the stated goals and objectives in its land use and master plan adopted in 1985 remained without the development of any strategy to achieve those goals and objectives, This condition has translated into a failure of implementation. This was exacerbated by a shortage of real and financial resources, the paucity of control and enforcement mechanisms, inadequacy of data and the like. The administrative process was further hampered by the lack of political 
and administrative measures necessary to mobilize resources: Politically, the municipality has invested in what Grindle (1987:168) called "a patronage oriented party system" reflecting the accepted general observation of the local level's "subordinate" nature to central government, The relationship between local government and central government clearly is hierarchical in nature (Kalchhem, 1980) The Bodrum municipality lacked a financial base to utilize its discretion in desperately needed areas, This tended to be compatible with the centralized system. In Kalchhem's (1980:84) terms, "The greater the ability of local government to raise finances from its own sources then the less able the central government is to control local government," Administratively, the municipality not only lacked a planning department with skilled tourism personnel, but it was angered by lack of authority to monitor tourist establishments (iạe, those enterprises in direct relation with MCT, or so-called "Belgeli" tourist establishments). Similarly, the system became anathema for promoting the popular participation of those who were essential in providing linkage to clientele for development programs and projects. Popular participation was further obscured by the dual standards that the MCT adopted toward tourism development. This translated into outright resentment between local and non-local businessmen, Administrative tutelage, control of revenue, and political patronage are the main variables which are affected by the planning process (Danielson and Keles, 1985): Bodrum's case suggests that the structural and procedural relationships between planning and administrative functions affected the outcome of planning and 
development efforts that pertained to tourism projects. Somewhat similar observations led Bryant and White (1982) to theorize that "under development and incapacity" are interwoven factors which result in the failure of a development plan, A development plan encompasses an economic and social policy: It integrates goals, measures the resources in a logical way, and is the guiding principle for all actions undertaken by local, regional, and central government bodies (Espinoza, 1985): Bodrum is a long way from this rational path, whereby government policy is an integrated socioeconomic plan and all levels of government respond to national needs and not just to those of privileged power groups.

Therefore, Bodrum's municipality can be identified as what Cleavers (1980:282-3) called "a closed system approach" to implementation, Its policies generally respond to the institutional interests of the groups that dominate the machinery: The administration of the Bodrum municipality also revealed that tourism did not become a means to eliminate or correct what Bryant and White (1982:30) named "administrative incapacity," Incapacity at the local level stems from a broader national malaise which has "external" and "internal" causes with known symptoms! Bodrum's case obviously portrays some of those very symptoms which continue to be a primary obstacle to tourism development and its positive input Nonexistent skilled personnel, highly centralized government, weak local institutions, a gap between the administrators and the public, corruption and favoritism, and the fragility of the national government that is a "soft state" are a few of the problems that require attention 
and solutions in order for an industry such as tourism to be an effective agent in uplifting the community.

"The central government completely controls the allocation of public responsibilities in Turkey" (Danielson and Keles, 1985:81). Ankara determines which functions will be performed by local governments and which will be carried out by central agencies and provincial administrations! such a centralized system has been elaborated in a historical context as "internal causes" of administrative incapacity which impinge upon local government, This condition, which is concomitant with the lack of strengthening policies from the center (i.e., technical, financial, and legal), defies the notion put forward by Padilla (1986:62) that "developing the administrative and financial capability of local governments is a precondition to achieving effectiveness in the central government's efforts to strengthen local authorities " 
CHAPTER V

CONCEPTUALIZING TOURISM'S ROLE IN DEVELOPMENT

One approach to theorizing about the way in which the international tourism industry works is to understand its economic role as a main driving force available to the world's countries! The same applies to other important activities making up world trade, and it is essential that tourism be studied by taking them into account.

Despite its economic significance, tourism has also been utilized as a highly political phenomenon (Richter, 1989). For instance, countries such as the Philippines, South Korea, the Republic of China, Turkey and Indonesia see in tourism a means of improving their international press notices! As Richter (1989:5) indicated, "The 1988 Olympics in South Korea were expected to do as much before political unrest surfaced in 1987." As she alluded to in the case of the Philippines, publicity goals which were clearly seen in the Philippines' tourism slogan under Marcos, "Where Asia Wears a Smile," a promotion specifically designed to defuse criticisms of martial law and allay the fear of potential visitors as to their security.

The Olympics' politics in South Korea were deployed in a sea of unrest--for social justice and equal distribution of wealth due to economic growth. As Amirahmadi (1989:181-2) noted, "The Olympics [had] been made religion since 1981" when Seoul was awarded the summer Games! Wrote Chira (1988a), quoting a magazine publisher in South Korea, 
"Anyone against it [was! labeled an infide]" To better appreciate the truth behind this statement, we must recall that the Olympics came into the life of the Koreans at a very sensitive period in the history of their nation, right at the point of a growing demand for a new beginning, A transition was occurring from the status quo to a wholly new domestic and international order, under this condition the Olympics served as a constraint on the government, the military and the opposition. It also allowed the ruling elite to control political activities of the opposition and defer political and socioeconomic reforms, "With Olympics 'peace zones' in force in the city, the police [were] poised to crack down on anyone who demonstrated or staged labor strikes, legal activities in normal times."

POLITICS OF TOURISM

Political objectives as a single motive to develop the tourism industry not only leads to poorly allocated funds but also results in the detriment of a productive industry because of short-lived projects with no development strategy, As Richter (1985:57) revealed, referring to the Philippines, depending on one's information, in the period of 1975-1976 between $\$ 410$ and $\$ 545$ million of government money became directly tied up in hotel financing; The relative size of this commitment can be compared from several angles. It was between oneseventh and one-fifth of the government's total proposed 1976 expenditures of $\$ 3,05$ billion. It was more than the amount borrowed in 1976 from the World Bank of $\$ 315$ million. The Development Bank of the 
Philippines (DBP) alone spent a "staggering $\$ 229.29$ million" through July 1976 on tourism projects.

From a development standpoint, the expenditure on hotel financing alone is between 30 and 40 times the amount that the government spent on public housing. Richter continues, saying that it is unfortunate that the government was not zealous for agrarian reform or low-cost housing instead of developing a showcase tourism, which was subsidized by Filipino citizens through taxation and social security payments: The same political dynamics are present in all authoritarian regimes that want to advertise a veneer of development to boost their political status; this strategy has been used since the days of Franco in the 1930s. Pi-Sunyer, in her study of Spain, documents the use of tourism in the 1930s as a way of countering hostility to fascist Spain:

For foreigners visiting Spain was offered as evidence that the dictatorship was accepted abroad.... The controlled media constantly repeated statistics on the growth of tourism and explained at great length how this apparently inexhaustible source of wealth benefited the Spanish people (1979:61).

As international tourism involves the movement of people from country to country, many governments will use it for their political objectives regardless of the cost to the environment and society. Franco's Spain in the 1930s (Pearce, 1981), Marcos's Philippines (Richter, 1989), the Shah's Iran (Graham, 1980), Duvalier's Haiti (Richter, 1989), Korea's state (Amiyahmadi, 1989) all exploited tourism for their own personal and political needs. Not to mention the United State's policy of using tourism as a political weapon to demonstrate opposition to so-called unfriendly nations by forbidding travel to those 
countries (e.g., Cuba, Lybia). While this demonstrates one dimension of tourism development for political purposes, another aspect of this development pertains to the international funding organizations and foreign borrowing as well as the influence of TNCs. Henceforth, policy decisions for the development of the tourism industry need not be the status quo, but rather different alternatives can be undertaken to prevent misuses and engender popular support. As suggested by Wood $(1980: 571)$ in his analysis of tourism in southeast Asiz,

Every government in non-socialist Southeast Asia has opted for capital-intensive, international standard hotels as the basis of its tourist industry. This is a political choice, entailing the subsidy of the hotel sector by the state, which has a number of cultural ramifications. A strong case could be made for developing a type of tourism based on modernizing and expanding the traditional accommodation systems of the region, for example, the losmen in Indonesia.... Given the extremely high import content of the luxury hotels...the net foreign exchange gains of luxury tourism are often quite small.

\section{ECONOMICS OF TOURISM}

The tourism industry, which developed mainly after the second World War, has become a model for generating foreign exchange among various developing countries. One of the main advocates of tourism development in the less developed nations is the United Nations. This is reflected in the establishment of the World Tourism organization (WTO) in the early 1970s, as a specialized UN agency. These and other supporters of the development of international tourism in developing countries not only view the phenomenon as a cornerstone in the evolution of a liberal-capitalistic system that can be promoted in the interests 
of the economic development of the Third World, but also as a vehicle to increase mutual understanding in this world (Peppelenbosch and Tempelman, 1989:24)。

However, the economic significance of the tourism industry relates to the nature of the industry, which is an "export" and "basic" industry. It is basic because a community depends on such income in order to pay for imported goods, services, and taxes (Murphy, 1985). As Verbeke and Dietvorst (1987:365) noted, tourism is being seen as the "goose that lays the golden egg،" Obviously it is an area looked to for further expansion and therefore is to be stimulated and promoted (Loukissas, 1982:524)。

Various economic factors motivate the public sector to foster tourist development, namely (1) improved balance of payment situation, (2) regional development, (3) diversification of the economy, (4) increased income levels, (5) increased state revenue (i。e., taxes), and (6) new employment opportunities (Pearce, 1981).

The economic impact of tourism can be illustrated by its magnitude; it is the largest industry in the world, and it is expected to maintain that distinction until at least the middle of the twentyfirst century (Waters, 1986:7). In 1985, as Richter (1989:3) wrote, worldwide tourist expenditures were estimated at $\$ 1,800$ billion: Over one hundred twenty-five nations consider tourism a major industry, and in nearly a third of those countries, it is a leading industry, a top earner of foreign exchange, and a critical source of employment.

Today tourism activity is an export industry that is not confined to market-oriented countries. Socialist nations have seen the possibilities in tourism development and have introduced tourism 
development programs. For example, the People's Republic of China, Cuba, and vietnam have in recent years sought a judicious blend of capitalistic profit and socialist political advantage by encouraging Western tourism (Richter, 1989; Robinson, 1976).

The Soviet Union has a similar motive in its efforts to promote tourism. On the economic side, the foreign exchange potential is obviously significant. As Young (1975:43-44) has stated,

A painstaking analysis by Soviet statisticians has revealed that the average profit, if that is the right word, from one tourist is equal to the export of nine tons of coal, fifteen tons of oil and two tons of grain. Further, if Lake Baikal were exploited as a tourist center, it would earn twice as much hard currency as the total export of oil from the USSR--without depleting its stocks of raw materials.

Moreover, with new upheaval in centrally planned countries under the Perestroika policy, tourism is likely to become a solution to the economy of shortage. For various reasons the tourism market will develop in the centrally planned economies. First, there is the example of newly emergent destinations, such as Turkey, which from a low base in tourist arrivals and receipts has, in a relatively short time, become a major destination country. Second, there is a new mood of openness in centrally planned countries. Glasnost in the USSR is an example of the increasing willingness of several Eastern European countries to welcome international intercourse. Third, the centrally planned countries have many attributes of successful tourist destinations (Buckley and witt, $1990: 13-14)$.

The economic impact of tourism in Caribbean countries is a wellknown phenomenon. It has been equated with various productive activities in Bali (Dekadt, 1979). The economic impact of tourism on 
Bermuda is staggering, The industry provides, directly or indirectly, three-quarters of all jobs (Bryden, 1973). Spain's example of tourism-induced economic development has been followed by Yugoslavia! Three five-year economic and social development plans between 1955 and 1970 specified that tourism be treated as an "activity of special importance" for the development of Yugoslavia in general (Mihovilovic, 1980:111). According to Mihovilovic, by 1980 it was expected that foreign currency earnings from tourism would amount to $\$ 1.2$ billion.

Mexico's success in its tourism industry, documented by Mathieson and wall (1982), was that Mexico was able to avoid the industrial stagnation and inflation found in much of Latin America because of the buoyancy of the tourism industry: Mathieson and wall maintain that by the 1970s tourism also emerged as a major export industry in Greece, Kenya, Tunisia and Morocco.

An example of South Asian countries was described by Pye and Lin (1983), where leakages ${ }^{1}$ of manufacturing industries have been much

${ }^{1}$ Leakage and linkage issues have remained subjects of controversies within the protagonists and the opponents of Third World tourism. However, leakage refers to the substantial share of foreign exchange earned from tourism that leaks out of the host country and flows back to the country of tourists' origins or to foreign investors and exporters in general (Roekaerts and Savat, 1989:45). And/or in Britton's terms "underdeveloped countries participating in the international tourist trade are thus obliged to accept a high degree of foreign ownership, retention of tourist receipts in earnings" (1989:98) ? Whereas, linkage (a positive economic externalities) is simply an inducement to activity on the part of one enterprise created by the actions of another (Weiss, 1988). 
higher than that of tourism! In Korea, for example, the leakage index for tourism was 19,7 percent, while in the electronics industry it was 50 percent and in the machine sector 23 percent.

In the case of microstates, ${ }^{2}$ tourism as an alternative form of economic development is almost inevitable, assuming that international tourism continues to grow and that these states need export earnings beyond minimal levels (Wilkinson, 1989).

These political units share many traits: small size and population, stagnant and archaic economic structure, under development, peripheral location, limited resource bases (including energy), lack of revenues for imports, high transport costs, lack of local markets, and lack of infrastructure and service industries.

Africa's tourism, despite many limitations including: capital, distance from the large North American and European markets, cost of travel, and its poor image abroad due to political instability, has been growing continuously. For example, in the case of Kenya tourism was one of the top three domestic exports along with coffee and tea between 1963 and 1980 (Surmary, 1987; Teye, 1986).

According to a study by the WTO 26 African countries, or 47 percent, have included tourism in their national development plans

2 The term "microstate" has been used to describe a variety of types of political units. First applied to small countries by Harrigan (1974), it usually refers to independent nations with populations under one million. It has also been used to include various other forms of government, including associated states, territories and dependencies: While such areas are not independent and therefore not completely autonomous in decision making, they are at least potentially involved to some greater or lesser degree in determining policy ( $\mathrm{e}_{\mathrm{g}} \mathrm{g}_{\mathrm{f}}$ tourism development). 
This compares with $23: 5$ percent in Americas, 25 percent in South Asia and the Middle East, and 44 percent in Europe, ls an example, Tanzania's current ten-year development plan for 1980-1990 involves a \$181.7 million expenditure on tourism expansion, including 17 new hotels and lodges: Tourism development in the countries of Southern Africa has been held back by protracted wars; however, countries such as Zambia, Angola, Mozambique and zimbabwe are now able to expand or begin development of their tourist industries (Teye, 1987:12).

The expansion of tourism has gone beyond not only traditional enclave spots, but also across even the Muslim nations which are perceived as being conservative. The factor of religion, even though a limiting one, has not been able to prevent those governments from capitalizing on the tourism sector.

It is the "economics" of tourism that occupies most of the recent empirical analysis of its impact. In other words, it is in the context of "development" strategies that preliminary consideration of tourism has been growing.

The UN Conference on International Tourism held in 1963 emphasized the influence of tourism as a tertiary industry, creating prosperity through the development of communications, transportation, accommodation, and other consumer services: The economic significance of tourism has spurred "rural tourism" development, which did not exist ten years ago (Peters, 1969; Edwards, 1989): There have been various arguments to justify rural tourism development. The situation in many rural areas is one of low levels of income per capita linked to high 
unemployment rates: The rural situation has been detailed (Gilbert, $1989: 40)$ as one where

* unequal standards of living give rise to rifts and divisions in society;

* the existing primary activities cannot support economically efficient communities;

* the continuing exodus of people and jobs from the remote to the already overcrowded urban areas could lead to further congestion in these areas;

* rural areas contain a good deal of social capital, which would be expensive to redistribute; and

* many people in these areas do not want to leave and others would return if given a chance.

There is further argument for developing tourism as an alternative in rural areas, As suggested by Gilg (1978), rural areas are based on agricultural production which is susceptible to violent fluctuation due to its reliance on the optimum conditions of nature; In both political and social aspects, tourism development in the rural areas heightens small-scale development and training which is more prone to local participation and control.

In fact, tourism development in the case of the Third world (particularly those countries with a predominant rural-agricultural sector--Turkey is a case in point) can alleviate unequal spatial distribution problems. The rural areas have potential and are in great need of nonagricultural employment at a time of mechanization revolution. Rural tourism planning can be an important aspect of 
integrated rural planning, Rural tourism can become a mechanism to divert and inject some of capital into rural areas.

Multiplier Effect

The most common method to quantify and estimate the income generated from tourism is by determining the "multiplier effect" for a destination: The conceptual definition of this method was elaborated by Murphy (1985:90) as:

Visitor expenditure represents only the first stage of the economic impact on a destination community; for like other generators of basic income, tourism's contribution can multiply as the exira income passes throughout an economy.

In fact, it is the "multiplier effect" which determines tourism's contribution to regional development and development in general in comparison to other sectors (Pearce, 1981). As Pearce (1981:60) elaborated,

It should be remembered at the outset, however, that the "tourist multiplier" is but a modification of a standard Keynesian multiplier which was first developed in a general context in the 1930s. This multiplier effect is not confined solely to tourism as some studies seem to imply. What is at question is whether the multiplier effect of tourism is any greater or lesser than that of industry, forestry or agriculture.

The size of the multiplier is an important component of the economic benefits of tourism to the community, because this reflects how many times the impact of each tourist dollar goes around the local system before disappearing entirely through the various leakage channels. Here the concepts of "leakage" and "linkage" appear to be in close relation with the size of the multiplier. Leakage or the exit of tourist dollars out of the destination area in the form of savings or 
imports, ceases to generate further increases in income, employment or government revenue. The leakage of tourist receipts will result in a smaller multiplier effect. Linkage, or the dispersion of tourist dollars into the host community will affect the size of the multiplier positively。

The size of the multiplier would vary in relation to the national economy in terms of the self-sufficiency of that particular economy. This means that if the economy is less developed and there is a great need to import services and goods for tourists, this will translate into greater leakage and a lower multiplier effect, whereas higher selfsufficiency will result in a larger size of multiplier effect (Murphy, 1985; Peters, 1969; Mathieson and Wall, 1982; Bryden, 1973).

Taking the income finally generated as $A Y$ and the initial injection of expenditure as $A E$, the multiplier is given by the expression AY/AE (Edwards and Cleverdon, 1982:147). This process continues with diminishing effect until the value added, which is generated, becomes virtually zero. For example, the tourism income multiplier for Sri Lanka is estimated at 1.59. This means that every Rupee (currency of Sri Lanka) that the tourist spends in Sri Lanka leads to an increase in national income eventually by approximately one Rupee and 59 cents (Pye and Lin, 1983). See also Table XXXVIII for tourist income multipliers for selected countries.

\section{Employment}

The impact of tourism on employment is related to the industry's nature, which is labor intensive; Salaries and wages generated by 
TABIE XXXVIII

TOURIST INCOME MUITIPIIERS FOR SELECTED COUNTRIES, CITIES, AND REGIONS

Destination Tourist Income Multiplier

\begin{tabular}{|c|c|}
\hline Turkey & 1.96 \\
\hline United Kingdom & 1.73 \\
\hline Republic of Ireland & 1.72 \\
\hline Egypt & 1.23 \\
\hline Jamaica & 1.23 \\
\hline Dominican Republic & 1.20 \\
\hline Cyprus & 1.14 \\
\hline Northern Ireland & 1.10 \\
\hline Bermuda & 1.09 \\
\hline Hong Kong & 1.02 \\
\hline Mauritius & 0.96 \\
\hline Antigua. & 0.88 \\
\hline Missouri State, USA & 0.88 \\
\hline Bahamas & 0.79 \\
\hline Walworth county, Wisconsin, USA & 0.78 \\
\hline Fiji & 0.72 \\
\hline Cayman Islands & 0.65 \\
\hline Iceland & 0.64 \\
\hline Grand County, Colorado, USA & 0.60 \\
\hline British Virgin Islands & 0.58 \\
\hline $\begin{array}{l}\text { Door County, Wisconsin, USA } \\
\text { Solomon Islands, Melanesia }\end{array}$ & $\begin{array}{l}0.55 \\
0.52\end{array}$ \\
\hline Republic of Palau, Micronesia & 0.50 \\
\hline Victoria Metropolitan Area, Canada & 0.50 \\
\hline Sullivan County, Pennsylvania, USA & 0.44 \\
\hline City of Carlisle, Cumbria, UK & 0.40 \\
\hline Western Samoa, Polynesia & 0.39 \\
\hline Gwynedd, North wales, UK & 0.37 \\
\hline East Anglia, UK & 0.34 \\
\hline City of winchester, UK & 0.19 \\
\hline
\end{tabular}

Source: Fletcher, 1989:527. 
tourist expenditure usually amount to about 50 percent of that direct expenditure (Peters, 1969:244). In countries such as Jamaica, Spain and Mexico, tourism is the largest earner of foreign exchange and the leading industry in terms of income and employment (Mathieson and Wall, 1982:33) Tourism also can offer employment to the semi-skilled and unskilled (Young, 1964:44).

Employment generated by the tourist industry can be divided into: * direct employment (resulting from the sale of goods and services to tourists, $e_{\times} g_{2}$, hotel personnel, taxi drivers, shop assistants)

* indirect employment (firms that supply goods and services to the tourist business)

* other enterprises (mostly construction of large infrastructural works like airports, roads, hotels). In the case of Tunisia, tourism's direct contribution in creating jobs has been at the rate of between 0.88 and 1.2 per hotel bed, depending upon occupancy rate, Also the same study indicates that the tourist expenditure in Tunisia generates as many as four jobs outside hotels for each job within the hotel (Dekadt, 1979). In the case of Malta, Dekadt maintains the number of jobs in the hotel and food service industry rose form 3.03 in 1960 to 5.83 in 1975 , and its share of the labor market increased from 0.6 percent to 3.5 percent. Spain's share of labor force due to tourism was indicated at 1.4 million, or 11 percent in 1971 (Murphy, 1985:33)。

One of the prime objectives of the tourist industry has been the creation of rural employment. This will result in prevention of out- 
migration of young rural residents. Tourism was seen as a means of supplementing the traditional primary sector with tertiary employment (Murphy, 1985:96). It also provides secondary employment (indirect), which includes jobs in those sectors supplying the tourism sector, or the activities benefiting from expenditures generated by it. This category includes the construction, agriculture, fishing, manufacturing, and processing sector (Edwards and Cleverdon, 1982). Gray (1974:395) concluded that "developing nations are usually characterized by a shortage of formal skills. The ability of the tourism industry to use labor very extensively is an important virtue in the industry:" Especially, the contribution of tourism to women's employment has been cited by various authors (Cater, 1987:220). In fact, new trends and innovations are stemming from the utilization of tourism or its diversification, As Dernoi (1983:155) writes:

The aims and forms of tourism tend to diversity in order to offer a steadily wider choice to the urban tourist. It is in this context that the interest in tourism in rural areas has been increasing in many countries in the last 5 to 10 years, and is forecast to grow further.

Being a labor-intensive industry, some have claimed tourism further alleviates the prevailing unemployment crisis in the less developed countries. From an input-output study undertaken in Mexico, indications were that 41 jobs were created by an investment of $\$ 80,000$ in tourism. This ratio was favorable in comparison to the same investments in the petroleum and metal industries (Culpan, 1987:549). However, there is a critical aspect of tourism employment as Peppelenbosch and Tempelmen (1989:27) noted, "...employment opportunities created by tourism may have distorting effects on existing 
employment structures.... The 'glamour' of a job in the tourist industry attracts many (mostly) young people, who leave their mainly agricultural occupations in the rural areas to flock to tourist regions." As they referred to the case of Seychelles for example, "Fishing and the cultivation of food crops declined substantially because of lack of labour which has moved to the tourist business."

\section{Foreign Exchange}

Many countries have embraced tourism as a way to increase foreign exchange (FE) earnings to produce the investment necessary to finance economic growth. As Rosensweig noted (1988:89), "Foreign tourism has a high income elasticity (we estimated an elasticity around 1.5) and is widely projected to become the world's leading source of foreign exchange earnings." see also Table XXXIX, which summarize the dramatic growth of U.S. dollar earnings from foreign tourism as well as its share of total exports of goods and services within the selected countries. Most of the LDCs are facing the problem of balance of payments. It is likely that any industry which may help this problem would receive government support. As Young $(1975: 43)$ wrote, "Most of the time this situation often occurred at the expense of other industries which have a high import content or which do not export." He maintains that many countries with a strong dependence upon international trade have been heavily influenced by balance of payments considerations in formulating official policies regarding tourism.

FE earnings of various LDCs are highly dependent upon two important aspects. The first aspect is the "leakage" and "linkage" 


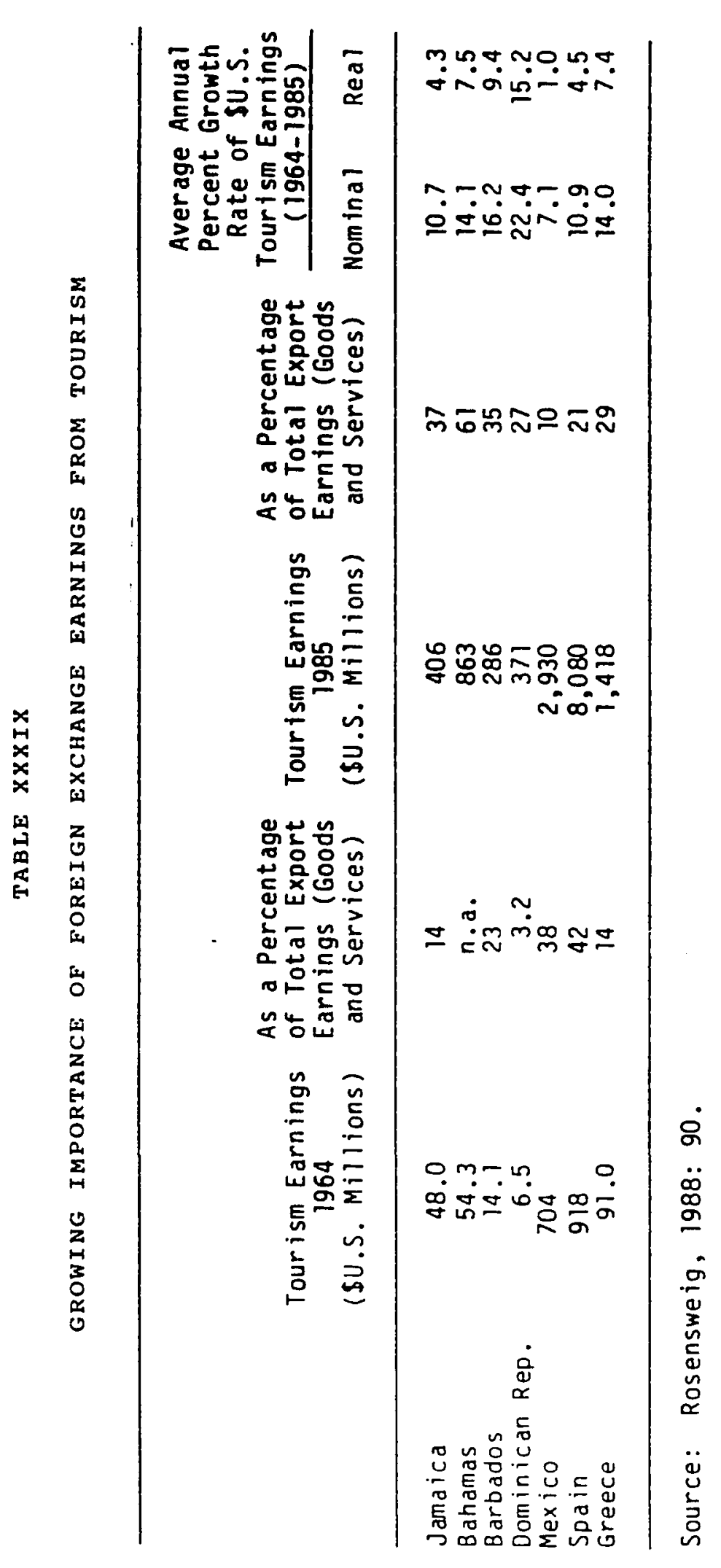


within the tourism earnings, Second is the notion of the "import content" of tourism.

Various LDCs are achieving different FE earnings depending on their capacity to be self-sufficient in terms of import product. This is called the import content of tourism earning; Edwards and Cleverdon (1982:146) addressed this issue with these classifications! The full scale of realized net earning proportion of gross tourism earnings can be summarized as follows:

108 totally import reliant (e.9!, Mauritius)

$10-508$ heavily import reliant (e,g!, less developed Caribbean and South Pacific Islands)

50-708 imports of luxuries and a few necessities le.g\%, better developed Caribbean Islands)

70-908 imports principally for luxuries le.g., advanced manufacturing sector with good resources--Kenya, Tunisia, Greece, Yugoslavia, etc $)$

The second proposal in terms of tourism earnings classified by Young $(1975: 45)$ is as follows:

1. "Least leakage" or the "highest linkage" case. This is when tourist facilities are largely constructed of local materials and local labor, operated by local workers and owned by local people. This is also the case when the inputs into the tourist industries are mostly domestically produced, In this case, linkage effects may be higher by 85 percent. 
2. The "least linkage" case. This is the case exemplified by many African countries where operating supplies such as food and beverages, construction materials, and tourism personnel (including managers) are all imported: In this case, the ratio of net FE earnings to gross tourist receipts may fall as low as 45 percent.

3. The "intermediate" case, This is the case of countries which developed rapidly and are not heavily dependent upon imports (Pye and Iin, 1983:160).

Furthermore, it has to be noted that net income from tourism may be far less than the gross receipts! studies revealed that total net income may drop to about ten percent (as in the case of Mauritius), to 40 percent (Tanzania), or may be as high as 75 percent (Tunisia). These differences are strongly related to the internal organization of the tourist industry, vis-a-vis the share of national and local interests in the tourist business. If this economic sector is dominated by foreign investments in accommodation and transport (international hotel chains, travel agencies and airlines), a major portion of the earnings will flow back to the metropolitan countries in the form of salaries to expatriates, profits, interest on loans, and so on (Ascher, 1985; Peppelenbosch and Tempelmen, 1989)

\section{SKEPTICAL VIEWS: PROS AND CONS}

Tourism has been subject to much controversial literature in terms of its socio-cultural impact (Matthews, 1978): Therefore, there is not much agreement among social scientists about the consequences of 
international tourism, Although a majority of social scientists appear to emphasize the negative consequences of tourism, there are also those who believe that tourism development in Third World countries have on the whole produced positive results and those who think that tourism by itself has probably produced no appreciable change in traditional societies (Dogan, 1989; Kousis, 1989):

In fact, the idea of "alternative tourism" as conceived by Krippendorf $(1982,1987)$ and "community based" tourism development (Murphy, 1985) have certainly awakened interest in overcoming some of the negative aspects which also alarmed many others (Richter, 1989:180). A community development perspective has become not only a metaphor but also a means to minimize some of the social cultural costs and to strengthen the local's economic base by employing a "social multiplier" technique to illustrate the desirable effects of tourism initiatives on a host community (Leathers and Misiolek, 1986; Getz, 1989).

Nonetheless, the 1970 s and 1980s have become an exa of growing disappointment and criticism of tourism's overall benefit in the Third World. The potentially serious psychological, social, and cultural effects of tourism were given prominence in the non-empirical studies of Young (1973) and Turner and Ash (1975).

Criticism became acute when tourism's economic impact was scrutinized for lack of incoxporation of social and environmental costs, which are difficult to quantify and measure through a routine costbenefit analysis: This culminated in the belief that on the social side, tourism leads to a "revolution of rising expectations" and western consumerism (Lea, 1988:51). It also was purported to be contributing to 
a push for modernization without the prior industrial phase of development experienced in the Western world.

In Bryden's (1973:92) terms, it is the interaction variable between consumer and producer when they confront each other that results in a new set of effects rather than the consequences of the mode of production, per se. These arguments generally apply to all destinations in LDCs (Cleverdon, 1979; Jafari, 1974). The socio-cultural impact of tourism has been considered in general to be negative with its expansion. It gains further attention when it heightens the political and economic disruption in the overall development strategies. For example, in the case of African tourism development, Teye (1987:13) has cautioned that

there is always the risk that benefits to African countries will be negated by disruptions in traditional lifestyles, erosion of cultural values and loss of stabilizing customs.... The youth of Africa appear to be very vulnerable to the potential social impact of the demonstration effects of tourism.

The seriousness of social impacts has been alarming to various tourist destinations. Dogan (1989:216) disclosed the following:

A majority of the scientists writing on this subject have thought that the effects of tourism on the whole have been negative. Among the major negative consequences of tourism are decline in traditions, materialism, increase in crime rates, social conflicts, crowding, environmental deterioration, and dependency on the industrial countries.

In the case of the Pacific Islands, leaders have been advised to hold back lest they are drawn into the trap of development for the benefit of developers whose sole purpose is the maximization of profits (Gunn, 1988:9). Some have also argued the social impacts of tourism in 
terms of local participation, thus raising some ethical questions about the role of public participation in the decision-making process, control of foreign influence and ownership, and the direction of management and training in the local tourist industry (Din, 1988). In his examination of four Malaysian island resorts Din alerts us that, unlike the idealtypical case as depicted in the evolutionary models in the tourism literature, the extent of local entrepreneurial involvement is usually very limited, owing to the fact that the local indigenous groups are rarely adequately preadapted to the business culture of tourism, Din suggests that if the intended objectives were to spread benefits to the local community, deliberate measures would have to be carefully introduced, to enable indigenous groups to take advantage of the opportunities brought in by tourism.

Finally, three broad and complementary aspects of tourism's influence on the community have been proposed. The first portrays the tourist-host encounter as an identifiable event with a number of positive and negative outcomes dependent on the forms of tourism development in certain destinations, second is a functional view of various elements of Third World society which may experience change as a direct result of tourism, such as moral behavior, language and health, The third perspective considers aspects of cultural change that come about through tourism's influence in restructuring traditional skills and customs (Lea, 1988:62). Most of the negative impacts of tourism, as Lea described, are the consequence of tourism when the industry becomes increasingly institutionalized (i,e., mass tourism)! 
One of the main manifestations of socio-cultural impact has been put forward within the context of the demonstration effect of tourism: Many of the most serious criticisms of unbridled tourism growth and acquiescent government policy have involved various dimensions of cultural pollution supposedly infecting insular life (McElroy and de Albuquerque, 1986)

One of the most recent critiques of tourism's impact, which also threatens the industry itself, is manifested by the arrival of the metropolitan tourists and their affluence in the LDCs. They often pursue the four S's of tourism--sea, sand, sun and sex (Lea; 1988; Pearce, 1981; Matthews, 1978)! The consequences of such interaction between "host and guest" clearly exposes the magnitude of the problem in the study of "Tourism and Aids in Thailand" This problem is becoming particularly acute in locations where sexual attractions used to be an important determinant of the tourist flow (cohen, 1988:467): Cohen believes that the tourist industry and tourism policy makers are just beginning to grapple with AIDS-related problems, which as yet remain largely unexplored or are yet ill defined;

Rapid and unplanned tourist development also heightens social problems, which is clearly visible in the Caribbean Islands (Young, 1975:48), And in Greenwood's terms, "Perhaps tourism deserves to rank beside industrialization as a perverse and contradictory agent of change" (1972:91). This is especially so when tourism reinforces the superior consumption pattern in the unbalanced development context which characterizes Third World countries (Jafari, 1974). 
A dichotomized standing began to develop toward the field of tourism development in the forms of "pros and cons" in which the economic benefits were questioned and even translated into disbenefits of tourism. This dichotomy is picture in Figure 19 which demonstrates the pros and cons of tourism development on economic, planning, social and socio-psychological, and cultural/environmental grounds.

For instance, the social aspects of "tourism" have been referred to as an element that injects the behavior of a wasteful society in the midst of a society of wants (Dekadt, 1979). And/or it is believed that the behavior of the tourists can lead to a demonstration effect that may undermine the zest for work and increase thriftlessness among the local population:

Thus, the concept of "alternative tourism" has become the main concern of various scholars to confront as a mechanism to minimize some of the immediate negative impacts as well as to suggest policies that can positively affect the industry's development in the long run, For instance, the "Topia House" in Trinidad has called for the localization of the tourism industry, which includes hotel ownership as well as complete reliance upon local goods and services (Matthews, 1977). RESURGENCE OF PARADIGMS

Up to 20 years ago, all the studies tended to assume that the extension of the tourism industry in the Third world was a proper step for development and economic growth. During the early periods (post World War II), economics played a dominant role, Thus, the beginnings of the tourism boom in the Third World was in congruence with the 
马्.

\begin{tabular}{|c|c|c|c|c|c|c|c|c|}
\hline \multicolumn{3}{|c|}{ 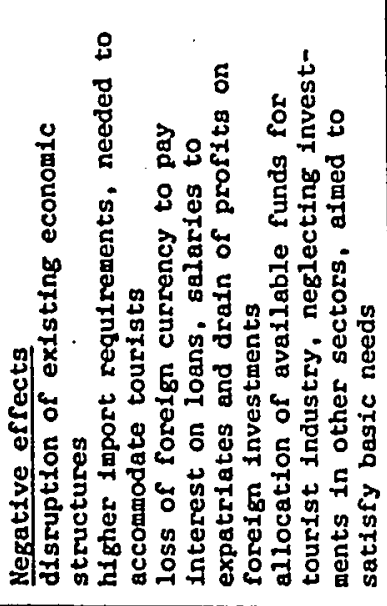 } & 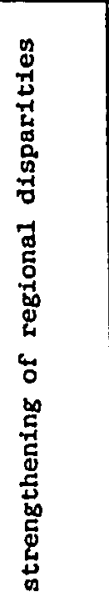 & \multicolumn{3}{|c|}{ 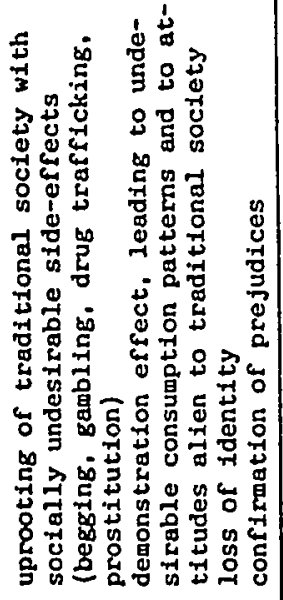 } & \multicolumn{2}{|c|}{ 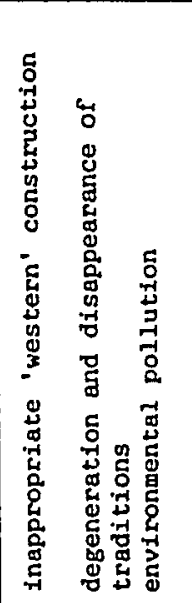 } \\
\hline 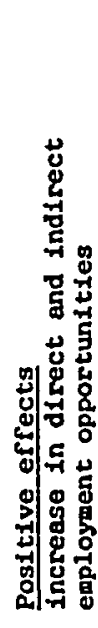 & 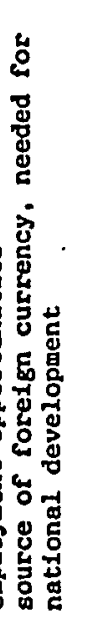 & 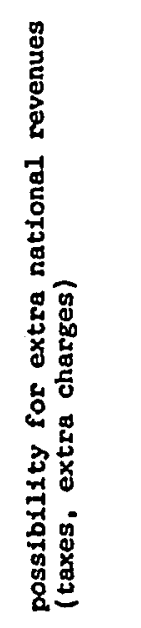 & 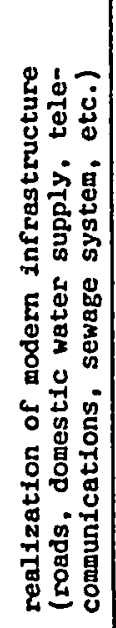 & 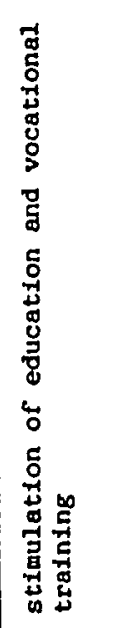 & 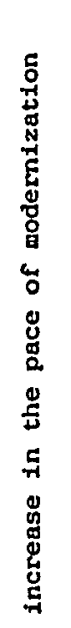 & 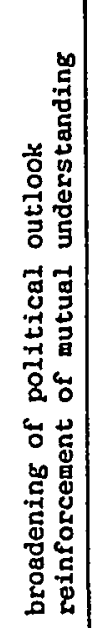 & 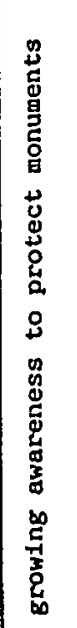 & 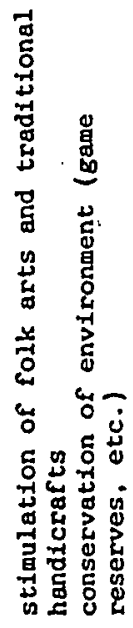 \\
\hline 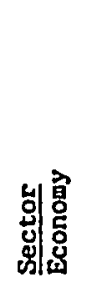 & & & 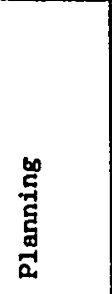 & 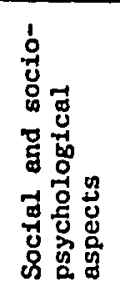 & & & 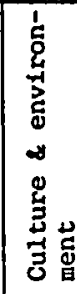 & \\
\hline
\end{tabular}

$\stackrel{9}{\ddagger}$

.

E

ठำ

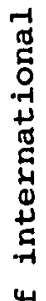

㟧。

봉

ठ̊요

त

os

용 ⿷匚

कै

离

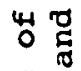

던

式是

$0 \stackrel{0}{0}$

式造

品

过

ब्नें 
overall development strategies that were advocated by international organizations.

Even though, in absolute terms, the share of developing countries within the arena of international tourism has remained small (about 108), their number has grown steadily in the last ten years and LDC participation has increased by 50 percent (Ascher, 1985) \% However, as the early economistic views of development in the Third world have begun to be challenged, it became clear that it was not tourism that led to development, but the country's general development strategy that made tourism profitable.

In the 1970s, academic observers began taking a much more negative view of development strategies in general (tourism included) (Lea, 1988). As Blomstrom and Hettne (1984:169-171) alluded to:

By the time it had become obvious for empirical reasons that the old paradigm was no longer able to provide the answers to the researcher's questions, or to serve as a basis for development strategies--facts which the United Nations "Development Decade" (the 1960s) had proved to be sadly true: A number of studies indicated "growth without development" instead.

The tourism sector as a new fuel for development in the Third World was not immune to paradigmatic analysis. Especially because of its conspicuous cultural and social impacts as well as its susceptibility to the "external factor" or domination by transnational tourism corporations (TTCS) (Ascher, 1985).

The internationalization of tourism has been given a spatial character which allows for a new emerging perspective, and this spatial dimension was elaborated by Lea $(1988: 1)$ as 
a peculiar pattern of rich, temperate, countries of origin connecting tourists to a much larger number of less affluent (i.e., LDCs) and warmer destinations comprising a "pleasure periphery" on a world scale;

And/or, in Turner's terms, "in many ways, it seems an industry tailormade for the Third world" (1976:253). It is also simultaneously the most promising, complex and understudied industry impinging on the Third World.

The formation of differing perspectives toward tourism and its role in development also began to be reflected in the UN's cautionary support of industry's development:

This has only recently become more apparent in development discussions. The U.N. affiliated World Tourism Organization reports...that by the year 2000 tourism is likely to be the most important global economic activity, Yet very few resources have thus far been directed toward addressing tourism abuses (Atix, 1986:8),

Such cautionary notions have resulted in the questioning of policies of tourism development and whether or not they are within the context of "sustainable or appropriate development strategies." This is a type of development that meets the needs of the present without compromising the ability to meet similar needs in the future (World Commission on Environment and Development--WCED, 1987). In practical terms this has also implied that tourism is not monolithic, but manifests itself in many different forms, each striving for sustainable development. It also implies furthering types or forms of tourism activity that are conducive to attaining broader environmental and societal goals. For example, the less organized and smaller scale types of tourism do not only make lower demands on the availability of the infrastructure but also offer the best chances for local participation in the command of 
accommodation facilities and supplementary services (Singh et al., 1989)。

Conventional Approach

One of the leading advocates for tourism development within this perspective has been the World Bank, In 1976, this influential institution organized a seminar on the topic in Washington, DC, leading to a main conclusion that "tourism can make a substantial contribution to the economic and social development of many countries" (Peppelenbosch and Tempelmen, 1989:24). This advocacy was manifested in three ways:

* Technical assistance, especially in the preparation of tourist development plans

* Loans for major infrastructural projects

* Loans and equity investments in privately owned tourism plant, particularly hotels,

Table XI shows the extent and distribution of tourism comitments by the world Bank Group through 1977.

This view approaches tourism development in parallel with neoclassical economists and modernizationists who are much more concerned with economic growth without development--classifying tourism in terms of its many functional parts without any political overtones: This perspective pays little attention to the historical experience of change in Third World societies and the possible contribution of the industry to present inequalities (Lea, 1988). It falls short of explaining the causal-consequential relations within and among social phenomena and the laws/tendencies that govern their quantitative and 
TABLE XI

TOURISM COMMITMENTS OF THE WORLD BANK

GROUP THROUGH 1977 BY REGION

(\$ MILIIONS)

\begin{tabular}{lcccr}
\hline Region & IBRD & IDA & IFC & Total \\
\hline \hline Africa & & & & \\
Latin America/Caribbean & 85.0 & -14.0 & 25.3 & 140.2 \\
Middle East & 36.0 & 6.0 & -- & 99.8 \\
Europe & 25.0 & 20.2 & 17.6 & 62.8 \\
Asia & 246.9 & 40.2 & 58.3 & 345.4 \\
\hline Total &
\end{tabular}

Source: Pearce, 1989:46.

Source of data: Wood, 1979.

qualitative development and decline (Amirahmadi, 1989). Nevertheless,

this conventional approach has its roots in the traditional development

theories which are typified by the fact that they blame internal factors

as causes of underdevelopment.

In Lim's words:

By constructing polar ideal-types of society called traditional and modern, they consider that development takes place as a country moves from the traditional pole to the modern pole of the continuum. The main causes of underdevelopment are inherent in the Third World countries themselves, the major triggers of development lie in the introduction of "modernization items" from advanced capitalist countries to remove the internal obstacles to development (1985:11).

The implications of this perspective on tourism have translated to an emphasis on the considerable economic importance of the industry to all participants and upon ways to improve its efficiency and minimize its adverse impacts: Further elaboration of tourism development by conventional theories has produced a functional approach which is based 
on a scenario that developing countries are faced with marketing problems in traditional exports and with secular declines in their terms of trade.

On the other hand they would argue that developing countries that wish to diversify from the traditional agricultural exports into manufacturing exports are frustrated because of the tariff policies of industrial countries and the limited domestic markets of developing countries. Therefore, tourism has great appeal as it is subject to very different demand conditions. It is a rapidly growing industry, having a high income elasticity of demand. It is more difficult for industrial countries to impose restrictions, although restrictions are not unknown (Bryden, 1973; Edwards and Cleverdon, 1982; Mathieson and Wall, 1982). A more functional approach has tried to generalize international tourism by dividing the travel process into three main elements:

1. a "dynamic" phase covering movement to and from the destination;

2. a "static" phase involving the stay itself; and

3. a "consequential" element describing the chief economic, physical and social impacts on the environment.

These elements are illustrated in Figure 20, demonstrating the "impact oriented" nature which dominates in international tourism studies: Obviously it stops short of dealing with causal relationships, and the apolitical framework reduces its value in analyzing the Third World situation (Lea, 1988).

Nonetheless, tourism has continued to be encouraged and recomended by those who are focused on the effectiveness of the market 


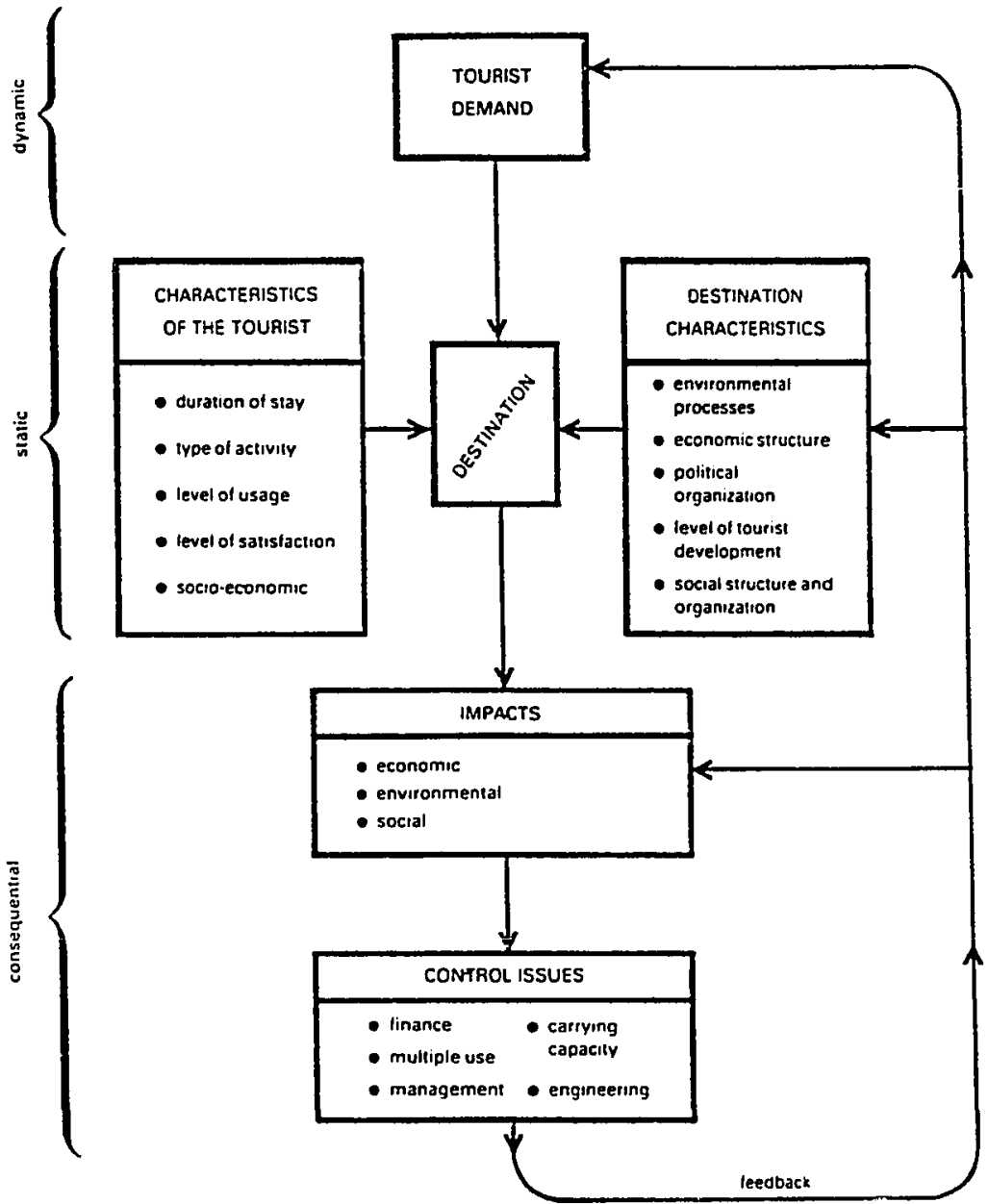

Figure 20. Tourism process according to functional perspective. Source: Lea, 1988:17: 
mechanism as a means of allocating resources, By focusing on certain socio-cultural, economic, and political factors that are indigenous to LDCs, these explanations have not succeeded in addressing the influence of the international economic and political system that interacts in LDCs tourism development process (Lim, 1985).

Consequently, the functional view pays little attention to inequalities in the industry, preferring to concentrate on describing the characteristics of the tourist, various impacts, and different kinds of destinations, The static approach is itself confusing because it neglects the dynamics of change at tourist destinations (Lea, 1988), One cannot ignore the fact that the shape of the tourist industry in the Third World changes over time; it can also be adversely affected when increasing popularity threatens things like the carrying capacity of local attractions: In addition, problems arise in how the market will approach the production life cycle problem: an evolutionary sequence of tourism development conceptualized as exploration, involvement, development, consolidation, stagnation and rejuvenation or decline (see Figure 21):

The product cycle concept defines the normative approach to tourism as it reveals the complexity of the product in relation to the unpredictable market, Butler (1980) in his model elaborated (Figure 21) a process which clearly calls for a warning regarding the real impact of tourism in various stages and the role of numerous players in its evolution. His model has two important elements to be aware of: sustainability of tourism as a locally operated activity, and the significance of "planning," As he noted: 


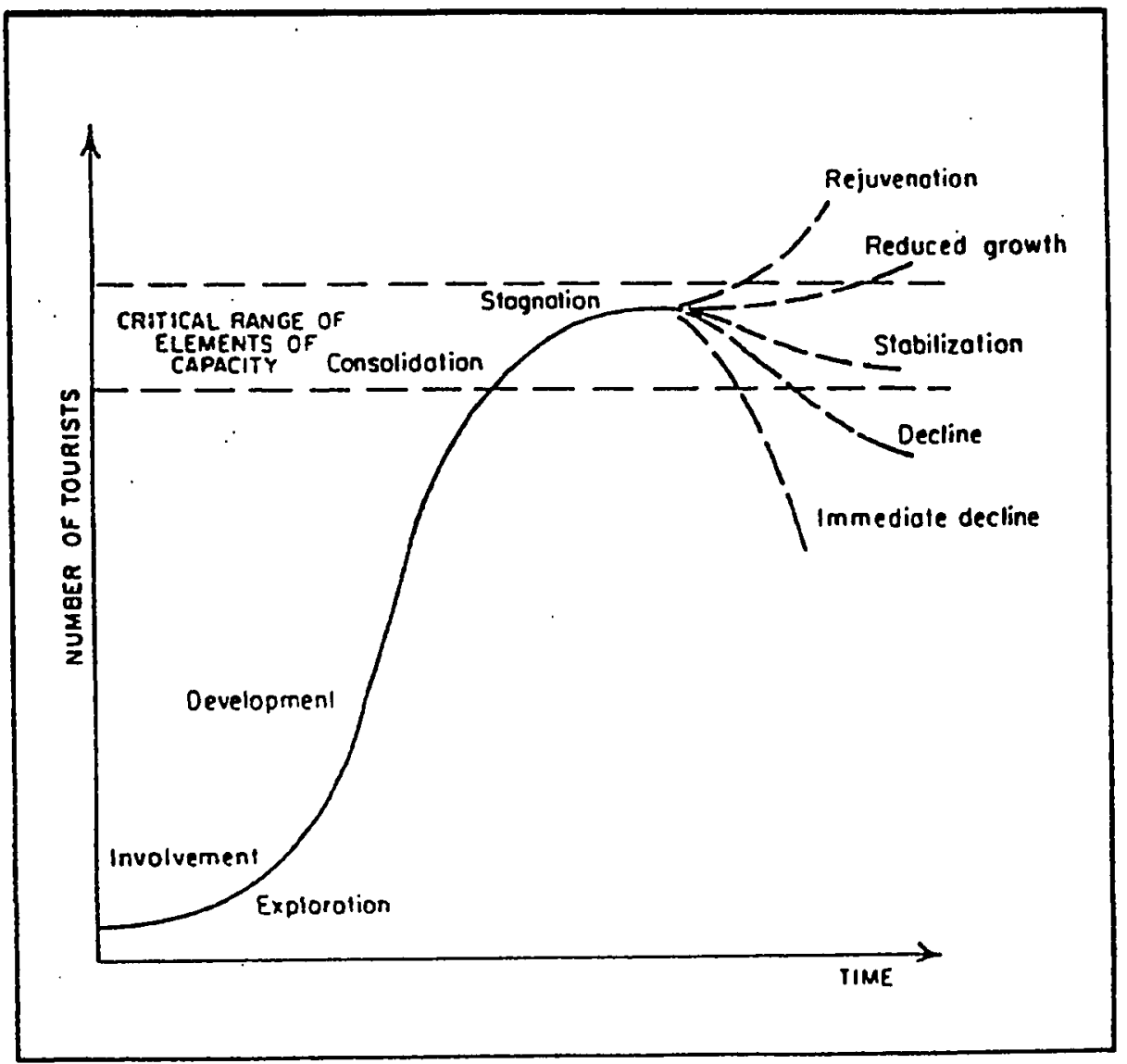

Figure 21. A hypothetical evolution of a tourist area. Source: Butler, 1980:7. 
Some locally provided facilities will have disappeared, being superseded by larger, more elaborate and more up-todate facilities provided by external organizations, particularly for visitor accommodation (1980:8) :

The functional approach is tailored to the economic objectives of the metropolitan core nations, and concomitant with the neoclassical development perspective, the special manifestation of which is the growth center concept; Thus they are based on strategies of outwardlooking urban and industrial natures, capital intensive, and dominated by high technology and the "large project" approach (Iea, 1988; Stohr and Taylor, 1981), The "large project" approach is usually a corporate activity Due to its high entry costs, individual entrepreneurs rarely engage in this scale of tourist exploitation. such enterprises are built, owned, and managed by corporations--often transnationals (Rodenberg, 1989:208) However, this perspective and its view of tourism in the Third World remained based on the modern-traditional dichotomy, which has been a central conceptual model for the analysis of social and economic change: It has encouraged a one-sided emphasis on the process of development as a penetration of the traditional system by the "elements" of "modernization" which are thought to be equated with development (McGee, 1974; Bernstein, 1971): The major limitation of this approach, apart from its acceptance of a linear theory of the tourism process (as well as social and economic change), has been its delineation of destination as static

Finally, a new trend which has led to the rise of neo-liberalism has emerged! It is a form of the revived conventional paradigm, In 
this case neo-liberalism the philosophy of modernizationists in the 1980s, translated into "global Reaganomics"--which coincided with the troubled import substitution industrialization in the Third World. Tourism became one of the means to get out of this crisis (Blomstrom and Hettne, 1984), In Roekaerts and Savat's terms, "It fitted into the pattern of open, foreign-led 'development' adapted by the non-communist states of Asia" (1989:52). And/or as Halliday (1989:1-2) paraphrased, ...a divide which in strictly economic terms has been compounded by the new methods that advanced capitalism has developed to enhance itself, never short of innovation at someone else's expense: these include the internationalization of sex-tourism, the durping of toxic waste in the Third World and the destruction, for northern use, of vast areas of the South's ecology.

Tourism itself was not immune to this newly revived economic order: Many LDCs were advised to liberalize their economies, encourage entrepreneurship, and find their comparative advantages, all in accordance with the neo-classical theories,

\section{Folitical Economy Approach}

The formation of this approach is rather new and it is just beginning to find its position as an alternative analytical as well as critical means to understand the complexity of the tourism industry and its role in the development of LDCs: The absence of this type of approach can be detected from Van Doorn (1979:6) when she addressed any effect of tourism, be it raised employment, decreased awareness of cultural identity of the contribution of health facilities must be weighed explicitly against the underlying theory of development. Most studies have only an implicit notion based on an intuitive feeling of one of the two mainstreams in development theory. The traditional and the modern theory (cf Pearce, 1989:12). 
Therefore, the conventional approach to development in general and tourism in particular, from either the early modernizationist or recent neo-liberal's standpoint, recommends pure market command of the economy (i.e., in a Rostowian schematic for development). Recently, however, an alternative paradigm has begun to appear: This paradigm, established as a "third worldist" solution to the interpretation and analysis of development and under-development, is known as "dependency" theory, Tourism as a new activity for economic rewards in the Third World--after its early domination by economistic perspectives--began to come under scrutiny by dependentistas as well, The shift in paradigmatic analysis is reflected in Dekadt's (1979) outcry, as he noted

a great deal of literature on tourism's contribution to development is devoted to either narrowly defined costbenefit analysis, imprecise comments on the socio-cultural effects of tourism or more technical issues such as tourist flow predictions, factors determining hotel location, and the regional impact of tourist expenditures..4: However, most of this research has a common deficiency. Discussion over the impact of tourism is typically divorced from the historical and political reality of processes that have led to the condition of under-development (cf Britton, 1989:93).

Then Britton continues,

Debate on the advantages and disadvantages of tourism [are] conducted without regard to those theories of political economy [which are] concerned with widespread, persistent poverty, and the causes of increasing inequality between and within nations!

The political economy approach has become an indispensable

alternative to analyze the role of tourism, zammit (1981:37) noted:

Over the last two decades, tourism has undergone a radical change from travel mainly within developed countries to mass organized tourism, often in underdeveloped countries. Parallel changes have occurred in the structure of tourism 
and a considerable part of the tourist industry is now financed, influenced and organized by transnational corporations, Tourism has become big business,

In fact, the international structure of the tourism industry is such that developing countries assume a largely passive and dependent role, Such a "role" is clearly discernible from the disposition of transnational tourism corporations (TTCs) within the world tourism industry! The international hotel industry is under the virtually complete control of the major hotel chains. The 12 largest chains together own nearly one million hotel rooms in more than 5,000 hotels and have a global annual turnover approaching $\$ 15$ billion, The predominance of TTCs is equally marked in air transport where the 20 leading companies, taken together, have a turnover of $\$ 40$ billion, In the tour operator sector, package tours account for more than 80 percent of tourists, and are becoming increasingly closely associated with TTCs in their market share (Ascher, 1985):

Thus, under such circumstances, developing countries that wish to expand tourism activities are generally obliged to negotiate with TTCs, that is, an external element in the process of development, It has been argued by dependentistas, that these "external elements" through their close association with dominant local political and commercial classes, are able to encourage political decisions, commercial practices, and labor legislation consistent with their interests (Britton, 1989).

It is not surprising that the challenge to the conventional approach in the tourism sector came from regions where the dependency paradigm was strongly patronized and even translated to development 
policies--namely in the Caribbean and in Africa (Blomstrom and Hettne, 1984):

Addressing Some Problematic Projects

Where the "development" theory was analyzed beyond a simple

"economic growth" model, several empirical studies raised some very

serious doubts about the viability of tourist development in its present

form, Pearce (1989:12) referred to Brydon's study of the Caribbean

case:

Brydon was one of the first to recognize explicitly that tourism development takes different forms and its impact is conditioned by the context in which development occurs. In particular, he notes that his general conclusions about the viability of tourism in the Caribbean results from the high degree of foreign ownership and consequent repatriation of profits, the employment of non-nationals with similar results and the real costs to the nation of government involvement in the provision of infrastructure and incentives:

The outright skepticism of the views was heightened when the use and misuse of the tourism multiplier effect was examined in various cases including the Caribbean example. This process was calculated in 1969 by a consulting firm called zinder and Associates employed by the United States Agency for International Development (USAID) under the title, "Future of Tourism iri the Eastern Caribbean" It contained a highly controversial calculation of the tourism multiplier for those islands accepted by the governments in the region: This report soon became the object of critical analysis by other economists including Levitt and Gulati (1970), and Bryden and Faber (1971)؛ Zinder and Associates claimed to have calculated a tourism income multiplier for 
the Eastern Caribbean islands of 2,3 , When the multiplier was recalculated, it resulted in a multiplier of only 1.36 (Lea, 1988; Matthews, 1977)。

Another case in the Caribbean was Jamaica: With the emergence of Manley's regime, the atmosphere for dependentistas became prone to analysis of the overall economic condition, including tourism. They criticized tourism as a practice which merely emphasized Jamaica's role as an object of exploitation and intensified its cultural dependence. This process proved to be a critical point for the dependentistas, when the tourist traffic was drastically reduced as a result of a campaign by the North American media which portrayed the island in the sun as an orgy of violence. Hotel occupancy went down to 30 percent during 1977, and the so-called dollar tourist belt in the north assumed a ghost-like character (Blomstrom and Hettne, 1984):

Even in African development debates, tourism did not escape the dependentistas' interpretation of this sector's socioeconomic role: The economic impact of tourism came under fire when the eminent Tanzanian academic Shivji lone of the most important analysts of development and underdevelopment in Tanzania) criticized the justification for tourism in terms of its being "economically good" as failing to appreciate the integrated nature of the system of underdevelopment (Lea, 1988), This brought about a new paradigm illustrating clearly that tourism and economic development needed to be examined at two different levels simultaneously. This view emphasized that ignoring either of these levels resulted in an unrealistic assessment of tourism's economic impacts. 
First it is essential that tourism's economic benefits be weighed against a wide range of perceived costs! To look only at purely economic considerations isolated tourism from its development context in the Third World:

Second, it is clear that the techniques used to measure economic impact are sophisticated and quantitative and disguise the fact that the complex interactions of tourism with other sectors of the economy are not fully understood.

Finally, the South African pleasure periphery located in the BLS countries (i,e, , Botswana, Lesotho, and Swaziland) proved the vulnerability of the tourism market when it was not diversified and remained dependent on the tourist originating country As Lea (1988:1819) reported

A steep decline in the fortunes of BLS tourism began in the late 1970 s with occupancy rate falling by a quarter in only two years, The reason for this had little to do with events inside countries like Lesotho and Swaziland where the physical capacity of the industry was still growing, It had everything to do with the South African source of the visitor flow where a big increase in petrol prices had dampened demand, and a major change in marketing strategy by the tourism transnationals had altered the shape of the industry:

It was on this ground that the political economy approach to tourism and the radical perspective have made their way into the newly conceived concepts of tourism, Therefore, the 1970 s witnessed various debates not only on tourism's economic cost but questioned its economic benefits as well: For example, a long debate on the economic benefits of tourism dominated academics, civil servants and townspeople headed by Mahigu, a political scientist at the University of Dar es Salaam in 
Tanzania, The differing views culminated in the following statement:

In assessing the economic implications of tourism we need to look at it from an overall view of our economic philosophy and not from the narrow and short term view of whether it makes profit or loss at a given period of time. This is where my disagreement with Mr. Mitchell lies. He implies in his articles that profitability of an industry should be the sole criteria in determining investment priorities and development strategies regardless of the economic and political implications, But I maintain that investments in our country ought to be geared towards transferring our economy into a self-reliant one even if such projects may not yield immediate profits in the short run (Lea, 1988:40):

Thus the economic efficacy of tourism is transformed into a perspective on the whole condition of underdevelopment

Tourism and Dependency: A Mode of Analysis

What has changed "tourism" from a pure blessing to a controversial subject in the Third world development is discernible from the complexity of "development" per se. The nature of development was defined by Golilet as follows:

Development has usually been treated as a process, a particular kind of social change, Nevertheless, development is also a state or condition. Whenever society is called developed of underdeveloped we refer to its present condition. similarly, when development is declared to be a major goal of Third World nations, the allusion is to a terminal condition, not to a process. Thus the single term "development" refers both to the destination of a journey and to the journey itself (Pearce, 1989:6):

Thus, consequential questions arise when different definitions of

development are entailed by those processes, As Seers writes:

The questions to ask about a country's development are three: what has been happening to poverty? What has been happening to unemployment? what has been happening to inequality? If all three of these have declined from high 
levels, beyond doubt there has been a period of development for the country concerned. [One can also add the element of self-reliance,] (Seers, 1977:5):

Based on preceding notions, "development of tourism," and hierarchical system of international tourism organization resulted in a concept known as the "peripheral tourism" model. Tourism development in the peripheral economic system corresponds to the policies that have been implemented on a regional basis

In recent applications of seaside development (according to Gormsen's model of spatio-temporal development), there has been a dependence on external capital and international investment, within Gormsen's (1981) terms "much of this tourism being characterized by large scale hotels and elite oriented investments" (Pearce, 1989:20) 4

The center/periphery analysis of tourism development has employed three levels of analysis: First, international linkage between metropolitan and periphery tourism sectors: second, the generalized distribution of tourist industry expenditure. Third, an enclave model of tourism in a periphery economy (Britton, 1989)?

As Britton (1989:111) elaborated this model, eight generalized propositions were summarized as follows:

1. The establishment of a tourist industry in a peripheral economy will not occur from evolutionary, organic processes within that economy:

2. While the peripheral economy provides the setting, metropolitan enterprises largely dictate the form and 
characteristics of the tourist experience, or product, offered in a new destination.

3. Since foreign companies are most important in defining what constitutes a tourist product, tourist services in a peripheral destination are likely to be owned and provided by these firms. Where local entrepreneurs collaborate in the provision of these services they will be members of a privileged commercial elite:

4. The direction of capital accumulation in the industry will be up to the three-tiered hierarchy: from petty producers, to local dominant sector enterprises, and ultimately overseas to foreign tourist corporations!

5. The hierarchical pattern of commercial power based on enterprises can be redefined in terms of a specialization of functions within the industry:

6. Following from four and five above, the structure of the tourist industry at the international and destination levels is tending towards monopolistic organization:

7. Most peripheral tourist destinations were previously integrated into the international economy to provide supplies of raw material commodities to colonial powers, 8. Finally, the historical expansion of metropolitan capital into the periphery was closely associated with the development of transport networks, The inclusion of Third World destinations into the international tourist industry 
is likely: Therefore, to be closely associated with the spatial patterns of these transport infrastructure;

Eventually Britton's dependency model on tourism in the Third world

galvanized into the "enclave model" which depicts tourism in a

dependency relation with physical, commercial, and social dimensions

(Figure 22): Figure 22 illustrates the primary return flows of tourists

from metropolitan countries to key cities and resort enclaves in the

periphery

The political economy approach further conceptualized the

organization of international tourism into a structural model which

encompasses three-tiered hierarchy (see also Figure 23): As Britton

(1982:343) elaborated,

At the apex are metropolitan market countries in which are located the headquarters of those transport, tour, hotel, and tourism supplying companies which dominate the lower levels of the industry hierarchy: At the intermediate level, in the tourist destinations of the underdeveloped countries, are the branch offices and associate commercial interests of metropolitan firms operating in conjunction with their local tourism counterparts. At the base of the pyramid lie those small scale tourism enterprises of the destination country which are marginal to, but dependent upon, the tourist companies of the intermediate level,

Finally, the dependency approach dwells on the structural inequalities in world trade and suggests that international tourism is unlikely to achieve a better balance among rich and poor participants until a corresponding shift also occurs in the whole pattern of country-tocountry relationships (Lea, 1988): A complete analysis must therefore its role in development of Third World countries: As London and Smith (1988:461) warned, 


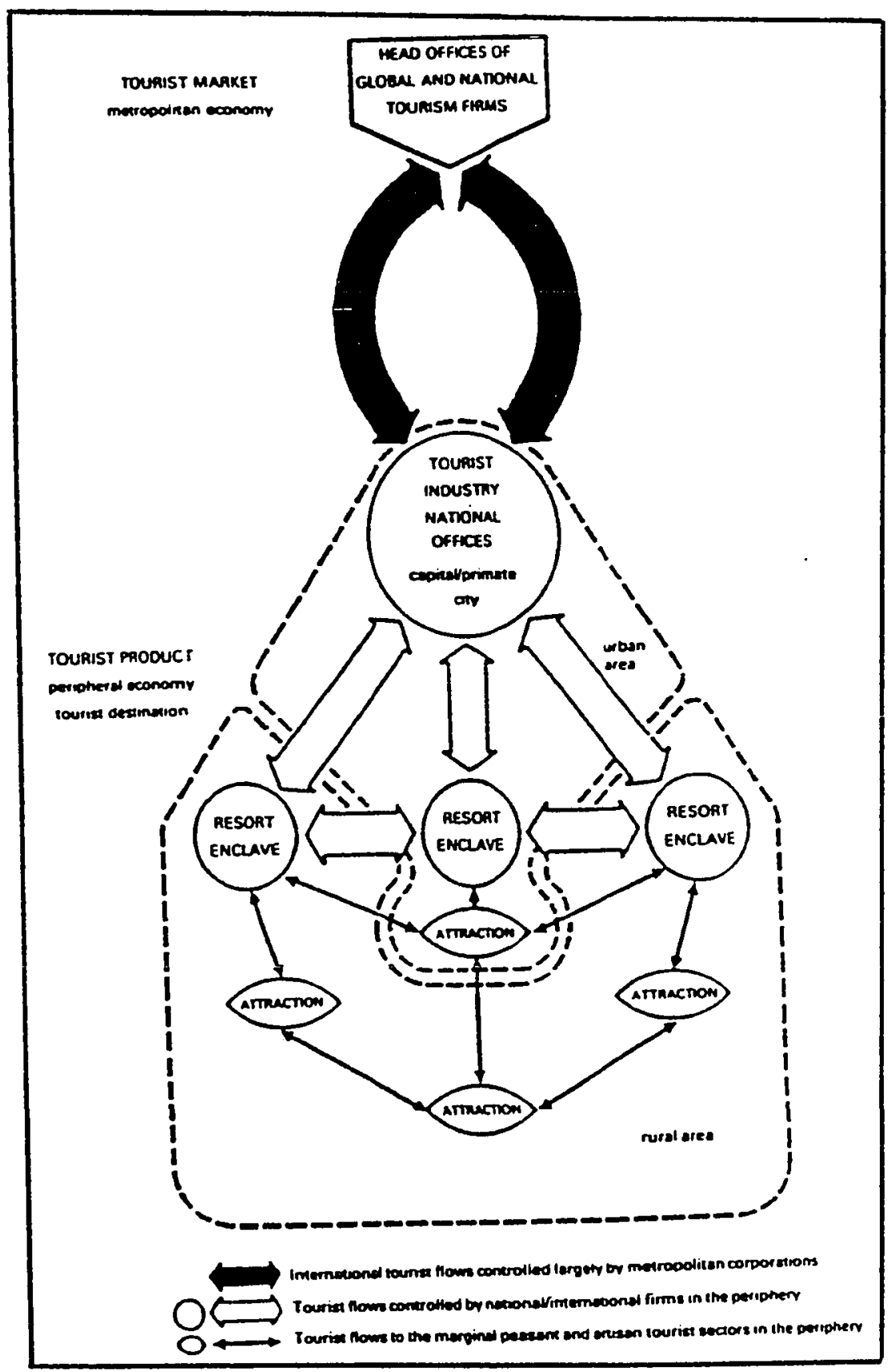

Figure 22. An enclave model of Third world tourism. Source: Britton, 1982:342. 


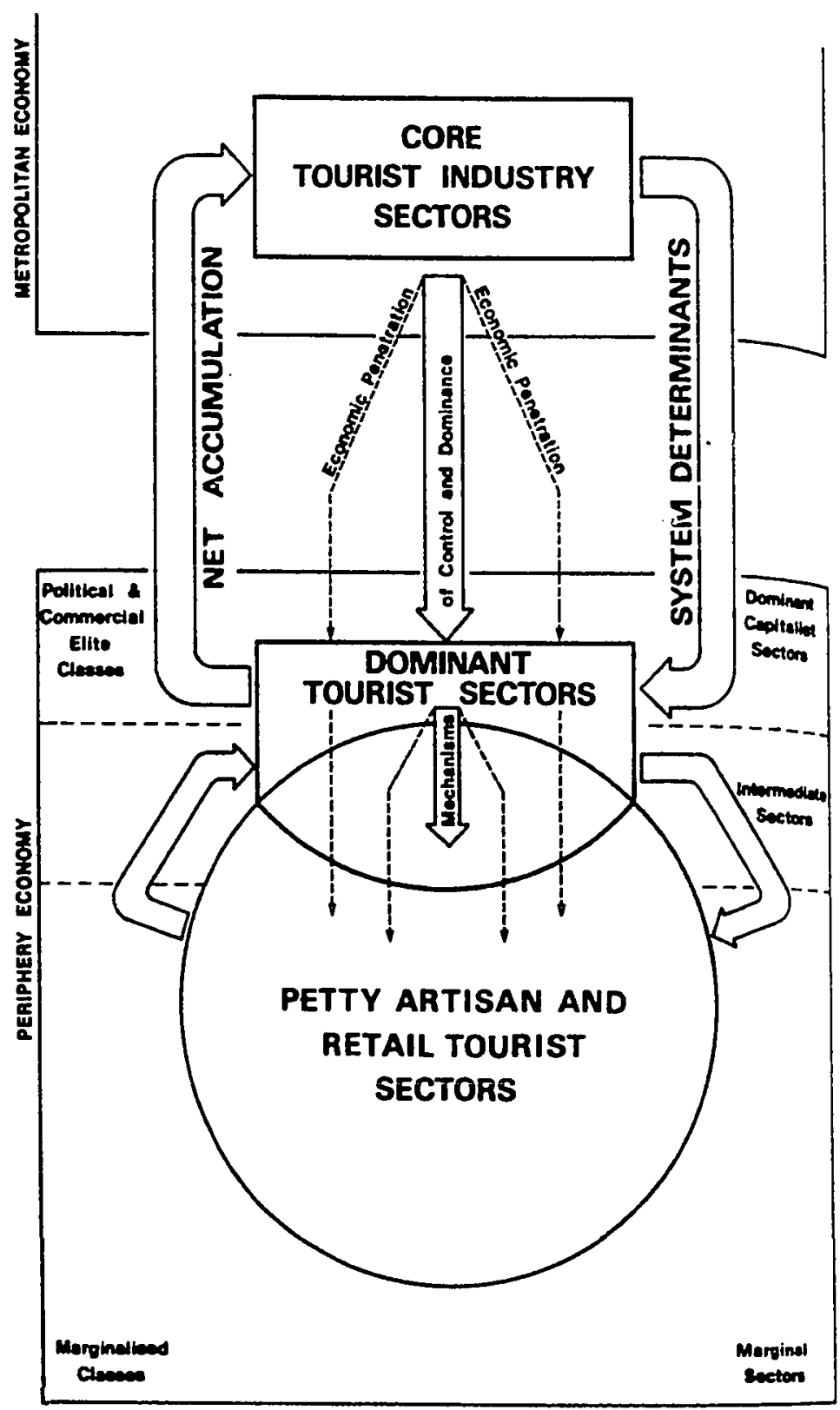

Figure 23. A structural model of Third World tourism. Source: Britton, 1983:344. 
Urbanization and development in the Third World cannot be fully understood unless analyses include both international and intra-national factors and combine the insight of dependency/world system analysis with those of human ecology and modernization theory.

The "dependency" approach as a mode of analysis should not be considered as a "static" phenomena in investigating the development process, rather it has evolved into new dynamic mode of analysis. This theoretical dynamism has its policy implications as well. For instance, Samir Amin $(1990: 62)$ in his new publication raises the issue of

"delinking" in which

Development of countries on the periphery of the world capitalist system must therefore come through an essential "rupture" with that system, a "delinking" or refusal to subject the national development strategy to the imperatives of "worldwide expansion," But the meaning we give to the concept of "delinking" is in no way synonymous with autarky: The meaning is as follows: the pursuit of a system of rational criteria for economic options founded on a level of value on a national basis with popular relevance, independent of such criteria of economic rationality as flows from the dominance of the capitalist law of value operating on a world scale.

The State's Role in Tourism Development

While the theoretical discourse of the "state" has remained unresolved--among the theories relevant to the state-society relationship--effective state intervention is now assumed to be an integral part of successful capitalist development (Rueschemeyer et al:, 1985, Amsden, 1990): In fact, a new approach to the state's role in socioeconomic transformation is attributed to the so-called late industrializers including South Korea, Taiwan, India, Brazil, Japan, Mexico, and possibly Turkey: All these newly industrialized countries 
have two features in common, first, all started to grow without indigenous technology and second, their states played an active role in their economic transformation (Amsden, 1990, 1985),

Furthermore, the capitalist development of NICs and state's role have also transformed the theoretical paradigms--either "market" oriented classicists or "dependency" oriented neo-Marxists and nonMarxists:

As $\operatorname{Lim}(1989: 481)$ noted,

The growth of the newly industrialized countries forces us to think about the possible reversal of dependency:!: Experimentation with employee stock owmership plans in capitalist nations: !challenge the usefulness of simplistic ideological divisions.

And, as Rueschemeyer and Evans (1985:44) reiterated,

In the Third World, where the capacity of the private entrepreneurial class to undertake industrialization was always viewed with a more skeptical eye, even conventional economic analysis has acknowledged the importance of the role of the state,

Where the state has played an indisputable role is in the mostly atomistic industrial sectors? Tourism requires no less and in fact far more of the state's involvement because it is a multifaceted industry: As Theuns (1989:199) noted,

A central role in determining the conditions for the development of tourism with its comprite product is played by government policies of a general nature and by policies which are tourism sector specific By exercising an influence on the conditions for tourism development government policies at the same time exert a direct or indirect influence on the impacts to be derived from the functioning of tourism as an economic activity. This influence on impact is not limited to the economic domain but extends to impacts in other domains such as culture and ecology as well. 
Despite the policy of "export oriented growth," the role of the state in Turkey towards tourism has remained an ambiguous one, That is, the absence of a national tourism policy raises the question whether or not a sustainable tourism sector can be developed based on rationally elaborated industrialization models, since the state's role, albeit outward economic policies, plays a crucial role in the outcome, As Milor (1990:1) addressed,

atthe performance of states like Korea, Brazil, Japan, France, and West Germany that have combined entrepreneurial state interventionism and market orientation is clearly superior to recent experiences in Chile, Argentina, the United States and Great Britain. In these latter countries, throughout the mid-1970s and ' 80 s, government attempts to allow the unfettered operation of the market at best produced a change in the distribution of growth between sectors-financial services gained at the expense of manufacturing--and at worst led to low rates of growth and deindustrialization,

Mechanisms for the State Involvement: The state's intervention in the tourism sector can be examined by considering several important aspects; The first, is the new perspective on "state" and its ability (i,e,, with the birth of NICs) to bypass both state-centered and society-centered explanations! The second being the need for certain policy instruments (institutions) and apparatuses which are essential in order to intervene effectively: In addition, the role of "policy elite" has also been recognized as important in making any intervention effective, if not necessarily successful, As elaborated by Grincle and Thomas (1989:220-221) in the following terms:

Among the interests of the state, for example, are the achievement and maintenance of its own hegemony vis-a-vis societal actors, the maintenance of social peace, the pursuit of national development as defined by policy elites representing particular regimes, and the particular 
interests of regime incumbents in retaining power. The state, and by extension, policy elites, strive for autonomy to make and pursue policy choices, but do not necessarily achieve it because of the variable power of societal classes or groups that constrain the state:

From the above explanation the "state interests approach"

formulated which concludes that

policy or institutional reform $\left[e_{!} g_{4}\right.$, tourism development policy] comes about because of the interaction of policy makers attempting to generate responses to public problems and the constraints placed upon them by political, economic, and social conditions and by the legacy of the past policy (Grindle and Thomas, 1989:221).

If the "state interests approach" is employed as a contextual

definition for intervention, certain elements are also needed to make

the intervention effective: These elements are the recognized

properties of the state, especially when the state is referred to as a

society shaping institution.

The state's intervention in tourism in the IDCs becomes necessary

as Jenkins (1980:27) paraphrased:

When funds are required to support investment in tourism, the government is often the only agency able to raise or guarantee the loan. At the macro level, the government has ultimate responsibility for the allocations of funds and resources for specific sources it is a government responsibility to decide on regulations and loans which can affect tourism:

Capacity and Autonomy: The state "capacity" simply refers to the pattern of strengths and weaknesses to intervene in a policy area, in this case tourism development, The capacity of the state is manifested in its bureaucratic machinery which encompasses the various policy instruments: Policy instruments are the means that the state has at its disposal to formulate policies and pursue the implementation of the 
policies: They are the keys to the state's capacity to intervene (Skocpol, 1985; Evan and Rueschemeyer, 1985).

The most direct and explicit manifestation of state capacity to intervene is usually in the national tourism administration: These policy instruments are in charge of national tourism development in the form of ministries or the constituted part of a government department In the case of Turkey they are referred to as the MCT, TB, and SPO,

State intervention depends upon the capacity of these institutions to make policy decisions, Factors affecting such policy decisions are: Technical analysis, bureaucratic motivation, political stability and support, and international leverage in the forms of access to aid, loans, and trading relations. The capacity to intervene can be undermined by the historical nature of the policy instruments and their previous tasks within the broader state institution, For instance, the bureaucratic machinery that is elevated to a policy maker position for tourism, cannot easily switch to or expand into this field of action, In addition, data about particular social and economic conditions as well as about the effects of past interventions have to be gathered and are difficult to come by: Where the market signals cannot be counted upon either for policy formulation or implementation, information gathering becomes an important and difficult task for organizational capacity (Evans et alı, 1985)。

Subsequent to organizational capacity, the state needs to overcome serious obstacles to effective intervention in shaping not only tourism but the whole national development, as well: Such obstacles include, 
the impact of dominant interests, the balance of class power, and the issue of state autonomy (Amsden, 1990):

The issue of state autonomy in inference to NICs has put forward a new paradigm in the analysis of development. In terms of the operation of the market mechanisms and the role of the state for intervention as Amsden (1990:31) argued "It is not merely an extension of advancedcountry capitalism. The failure to perceive this fact has created a crisis in Western intellectual understanding of Pacific dynamism." Nonetheless, "autonomy" and "capacity" to intervene are reinforcing properties of the state in this model. Equally important is the policy instruments (in the form of organizations and institutions) to factualize the policies. The presence and absence of specific organizations and their historical connections to the state policies are underlining factors in understanding the state capacities and incapacities (Rueschemeyer et al, 1985) " For example, Amsden stresses

the extent to which the capacity of the Guomindang regime on Taiwan to extract resources from agriculture depended on the prior existence of a state monopoly in the production and distribution of fertilizer-a monopoly established through the nationalization of Japan's industrial properties on the island after WWII (Amsden, 1985:351) :

State-Owned Enterprises: Newly industrialized countries häve created state-owned enterprises as one of the main policies for their development, Turkey's case is not an exception to this rule, particularly during the etatist era! In Rueschemeyer and Evans' words, "Inceed, for them the existence of a strategically located set of stateowned enterprises probably constitutes a prerequisite for effective intervention in the economy " 
State-owned enterprises have forwarded an institutional approach to the overall analysis of state intervention in the process of development! Therefore, not only in tourism (the concern of this study) but also in other key economic sectors, the role of the state has become the focal point in Third World development analysis: As Amsden (1990:15) described, Japan, Korea, Taiwan, Mexico, Brazil, Turkey, India as newly industrialized countries

have different growth rate not because markets have been
allowed to operate more or less freely, but because the
institutions general to late industrialization have
functioned with varying degrees of effectiveness
The varying degrees of effectiveness of the institutions (state in
particular) in the case of Turkey's tourism is what poses the most problematic aspect. Especially the "tourism" sector which unlike any conventional sector has its own characteristics (properties and tendencies) hence corresponds to a peculiar niche;

In the case of South Korea, for example, state has implemented its interventional and participatory policies and programs by superseding the market principles via strategies that included: price manipulation, conglomerate functions, strategic shop-floor focus, and labor! Equally significant, are the exclusive characteristics of the state's intervention namely: disciplining big business (in relation to capital flow); developmentalist (inducing investment and autonomy); raising productivity (even by successful repression); and participatory organization (Amsden, 1990),

State Intervention: Turkey's Case, The state's involvement in the tourism sector then usually comes about as a part of a broader 
policy of intervention. Tourism is encouraged as a means to increase the inflow of foreign currency or pursued for political purposes rather than as an end in itself (Pearce, 1989): As Pearce (1989:41) elaborated "the extent of public intervention varies from country to country and is to a large degree determined by the general philosophy and policies of the governments in question!"

In Turkey's case one can look at the decision making process pertaining to the tourism sector, policies and programs directed to lead this sector Turkey's bureaucratic machine (iı̣ı, product of state evolution from above) has lacked the necessary ingredient within the bureaucracy that impaired the capacity to formulate policy (Trimberger, 1978), Grindle and Thomas (1989) called this factor "technical analysis" which requires information, analysis, options presented by technical advisors, and experts, This impairing factor can also be inferred to the deficiency within the "policy instrument" (MCT, SPO), which within a broader spectrum of bureaucracy is needed to carry out the policy making process, Rueschemeyer and Evans (1985:61) elaborated about this deficiency in the following terms:

State managers are not omniscient, omnipotent demiurges,:
they often lack the knowledge necessary for formulating
"correct" policies aimed at the promotion of accumulation
and system maintenance, Furthermore, even if state managers
hit on an essentially "correct" policy, they will not be
able to implement it unless they have their disposal a
previously constructed bureaucratic machinery with
appropriate [tourist-sector specific knowledge] capacities
for action,
Turkey's tourism pertaining state intervention also has become subject to the role of "circumstance"--the particular conditions surrounding the emergence, consideration, and pursuit of particular reformist 
initiatives (Grindle and Thomas, 1989). This circumstantial variable can be explained clearly by the shift from ISI to XOG. This process confused the degree of the state's intervention in general and in the tourism sector in particular: The impact of such a reform upon the institutions who were involved with the tourism sector entailed a perception among the policy elites that they were either unable or unwilling to deal with the tourism sector as a serious issue. The Process of Privatization and its Implications. The establishment of state economic enterprises (SEE) in the early 1930s manifested the state's determination to intervene in the economic transformation of the nation. Although the tourism sector was not considered to be a significant area. Nevertheless the state established a few tourist accommodation facilities called "TURBAN" Tourism enterprises: The state economic entexprises (SEEs) owned 47 percent of Turkey's industry and they have monopolies of cigarettes and tobacco, spirits and petro-chemicals. They were originally set up to pioneer the development of Turkish industry during the early years of the Republic, until private capital was sufficiently powerful and developed to take over all sectors of the economy (Walstedt, 1985). By the early 1980s state involvement in tourism succumbed to a policy of crisis-ridden circumstances which hampered the essential factors for effective state intervention. This accompanied the tourist boom in Turkey which was due to a new "destination fashion" factor for the European market and "war factor" for some middle eastern countries namely Iran and Iraq. 
Many of the factors that were associated with the role of the state can be explained by the shift from ISI (closed economy) to an open economy or "liberalization" and "privatizations"

A uniquely Turkish solution to industrialization and development was initiated under the ideology of nationalism, The shift to "privatization" was defined as:

The turning over to private individuals and organizations of economically-oriented enterprises which [were] managed and owned by the public: [The] transfer of ownership [had] two purposes.... The first of which [was] to remove the concerns from the area of the state's direct control and intervention, and the second of which [was] to reduce the assortment of burdens which these organizations impose upon the national budget, furthermore the objectives of privatization may be listed as follows:

* Strengthening the free market economy

* Increasing productivity in the economy

* Improving the distribution of income

* Diversifying the base of capital ownership

* Developing the capital market

* Encouraging the greater tendency of savings toward the stocks (TUSIAD, 1987:19-20; Walstadt, 1980:70):

The policy shift of the 1980s has had two significant implications pertaining to the "state" as an intervening actor and "tourism" as a newly developing sector! In terms of the "state," the etatism was dismantled to a great degree, This was manifest in the open door policy of the invitation of foreign investment into free trade zones and curtailment of state involvement:

The first contradiction to the state intervention model was manifest in the policies of privatization, Contrary to the etatist policies of the autonomous Turkish state and its bureaucracy, the new shift forced the state enterprises to operate under market conditions without any state subsidies: The eventual reduction in the state 
participation in the areas of economic activity covered by these enterprises will dramatically alter the sectoral organization of the economy, Particularly in the manufacturing and service sector lial, tourism) (Ramazanoglu, 1985:232).

The second contradiction crystallized into a new policy of foreign investment in various sectors including tourism. The capacities of the state apparatus was further undermined by the new institutional reform which was an important variable! As Rueschemeyer and Evans (1985) noted, "The historical character of the bureaucratic apparatus in any attempt to explain its capacity, or lack of capacity to intervene," Thus, the bureaucratic responsibilities were withdrawn from the Ministries of finance, industry and commerce, and the SPO was transferred to a new foreign investment department (Ramazanoglu, 1985). consequently, the tourism sector fell into vagaries of new "privatization" policies which encouraged foreign investors by a set of new incentives, which included:

* Long-term subsidized interest rate,

* Five-year exemption from construction and property taxes,

* Provision of state land for tourism projects for 99 years at low rental,

* State provision of basic infrastructure in tourist development area (Liu, Var and Timur, 1984)؛ Measures were also taken to encourage tour operators through subsidies for charter flights with empty seats and by devaluing the Lira: 
Tourism which was only allowed to be under joint foreign ventures, due to etatist policies, became a sector in which the government made substantial changes in order to promote foreign investment; Under the new economic regime, foreign investment up to 100 percent was encouraged, and complete control of the project was left to the investor (Ramazanoglu, 1985):

The ramifications of the state's curtailment could be seen in the "policy" and "planning" areas, whereas state intervention in tourism accommodations has been realized in various forms in many other countries (i,e Zealand; social tourism in Europe), Turkey's state owned tourism establishments were privatized. Hence, not only were sector-specific policies (environmental, cultural/social) in disarray, but also the general policies (national, regional/local) remained in a vacuum, This has also been a pattern when it comes to the tourism sector. As Ersek and Duzgunoglu noted:

Significant problems in this field have been encountered during the implementation stages of the First Five-Year Plan and during the first two years of the second plan (1963-72) due to lack of policy decisions and tools to indicate the spatial distribution of resources and priority areas: The definition of priority areas and policy decisions concerning the geographical distribution of resources is of prime importance for a country like Turkey. This is especially so because of the scale and variety of Turkey's tourism resources (Pearce, 1989:254):

The state intervention which constitutes the state activity (policies and programs) can be examined by the criteria of "planning" for tourism. Recognition of the importance and value of planning for tourism is reflected in the number of tourism plans which have been 
prepared in the last two to three decades : The World Tourism organization established an inventory of over 1,600 assorted tourism plans in 1980 (WTO, 1980c), The state's intervention in the planning process is a proactive stance with regard to state policies to tourism planning, Whereas, in Turkey with the privatization policies, the diminishing of the state's capacity and autonomy to intervene, a vacuum of "planning" (as a requirement for sector-specific policies) has been created,

Consequently, Turkish tourism with the present nature of state involvement can be characterized as a crisis-ridden condition. It is certain that policy reform will continue to be an important issue facing the government in respect to the tourism sector However, this analysis one more time emphasizes the dynamics of policy and institutional changes pertaining to agenda setting, decision making, and implementation. Under the present condition, this suggests that the shift in policies have not been successful in galvanizing various alliances around a cohesive approach to tourism development. But this is not new to the process of development and planning in Turkey, as periods of non-planning strategies are not unknown to her! In fact, "tourism" as illustrated in this case, is not prone to becoming subject to a non-planning strategy, but rather has been perceived as a shortterm pragmatic solution to economic problems. In the historical clashes between "etatism" and "reformism" there have been periods of confusion which resulted in disastrous upheavals: As Hershlage (1988:12-13) elaborated, 
atdespite some success in the first part of the 1950s, the politically oriented "total outlay" policies quickly resulted in a "balancing" economic failure in the second half of the decade and in political and social upheavals.: : In the present context the period of the 1940 s and 1950 s is a deviation from planned development concepts and strategies of the two adjacent periods, 1930s and 1960s:

On the issue of "state," a myriad of lessons have revolved around the role of the state in NICs, Contrary to the ideology of Western free-marketeers, most Third World nations need more state intervention, not less (Belo and Rosenfeld, 1990:462): As Amsden (1985:99) exemplified,

In terms of scope, Taiwan is simply a particularly striking example of the positive association between state intervention and the acceleration of economic growth that is now generally accepted to prevail in cases of Third world capitalist development.

NICs undeniable economic development (Amin, 190; Blomstrom and Hettne, 1984) has proved the essential contribution of state intervention to economic development, They also demonstrate the reciprocal interaction between the structure of the state apparatus and the process of economic growth (Amin, 1990; Blomstrom and Hettne, 1984; Amsden, 1985): The state does not have to become the property of economic interest groups, especially in the areas of tourism, which requires the state to achieve a degree of independence not only from domestic economic elites but also from foreign agencies: 
CHAPTER VI

ALTERNATIVE TOURISM DEVELOPMENT POLICY

Opponents of high-volume, large scale, enclave forms of tourist development have suggested that there must be other, better ways of developing tourism in Third world countries (Pearce, 1989:101). Cohen (1989:128) elaborates,

The idea of alternative tourism has its source in two contemporary ideological preoccupations: one is the countercultural rejection of modern mass consumerism, and the other the concern for the impact of the modern industrial world on Third World societies.

Thus, the search for appropriate tourism in the Third World has been increasingly occupying not only the literature, but also has manifested through different organizations and concepts including: "The Ecumenical Coalition on Third World Tourism," "Eco-Tourism," New Age Initiated Transformational Travel," and "Towards Socially Responsible Tourism," to name a few.

Alternative tourism calls for the development of a type of tourism in which both local populations and the tourists can participate in and benefit from. Concern for tourism's impact in the Third World has grown to a crisis level. As Srisang (1990:119) noted:

...contrary to the claims of the authorities promoting it, tourism has not benefited the people of the Third World; nor has it brought peace or mutual understanding among peoples. Instead, it has tended to reinforce existing prejudices and even racial discrimination. Moreover, it has bastardized cultures, caused social degradation, ecological disruption, and abuse or power. Tourism has been called a new form of 
colonialism. It can also be seen as a new and perverted form of religion.

In addition, mass tourism has been criticized for increasing the degrees of external control and for failing to deliver on promised economic benefits. As Nash and Butler (1990:303-304) noted,

...alternative tourism as an exercise in sustainable resource management....investigations of the conditions where there is a real possibility that such tourism can succeed... for an understanding of the whole process of policy formulation and implementation, including the role of the major decision makers, without which a policy for alternative tourism development would be hard to implement.

An alternative tourism policy in the Third world in general and Turkey in particular, would first need to incorporate the primary conditions for and impacts of tourism (Theuns, 1989). Secondly, it should be dealt with by policy makers and experts at the same time. In addition, an alternative policy must formulate a type of policy that can avoid the various negative impacts of tourism, and at the same time enhance the contribution to development with respect to local content, employment, income distribution, dependency, and socio-cultural initiatives. Therefore, tourism needs to be analyzed from three angles: tourism as a leisure activity, tourism as a production activity, and tourism as a developmental factor. It is the latter aspect that has enticed numerous suggestions for new policies in the Third world tourism. This is due to its different external environment, which has a bearing on both the conditions for and the effects of tourism development. In regard to tourism development in developing nations, both the conditions for and effects of tourism are dependent on a wider environment than just the economic institution (Go, 1990). 
Thus, efforts must be made to create a policy that is a dynamic system consisting of three interrelated sets of components: values, processes, and forms:

* The values underlying alternative tourism are based on the concepts of emancipation and self-determination and the search for spontaneity, enhanced interpersonal relations, creativity, authority, solidarity, and social and ecological harmony.

* The processes involved depend on a much fairer partnership between external and local entrepreneurs and organizers at all stages of development (initial research, legal and financial organization, construction, operation, management and sharing of benefits).

* The different forms (social, spatial, ecological, architectural) that alternative tourism takes must reflect the underlying principles of self-determination and integration: use of local materials and traditional forms of architecture, use of local builders, management and employees (Pearce, 1989:101-102).

\section{DEVELOPING AN ALTERNATIVE TOURISM POLICY}

\section{National Tourism Organization (NRO)}

The first step in realization of an alternative tourism development policy is the establishment of an organization that is aware of general development policies and able to integrate tourism sector specific policies. Although the MCT functions as Turkey's NTO, the MCT needs to be converted to an organization that is knowledgeable about 
tourism. Its traditional administrative nature is rather general/governmental with little or no expertise in development of tourism.

The task of the NTO is two manifold. As demonstrated in the hypothetical model (Figure 24), it has to be armed with autonomy, capacity, and policy instruments related to the tourism sector in order to be able to implement, evaluate, and monitor continuously. NTO must have capability to articulate an orderly development process. It needs to survey the national tourism in numerous areas, it has to have a department to analyze and synthesize. For example, they would need to analyze the external tourist travel pattern, past and present tourist arrivals, and existing/potential tourist attractions. Then, based on these aspects a market analysis of tourist projections would be made: NTO (contrary to MCT) would plan and make strategic decisions before a project's implementation rather than following its implementation. NTO would represent firmly and demonstrate concertedly the public sector's role in tourist development.

In Turkey's case, the provincial administrative system could fill the vacuum of regionalization, and in coordination with NTO develop a series of cooperative agencies to coordinate development and reduce the fragmentation within the tourist industry (Montgomery and Murphy, 1983). Equally important, such a coordinated relation between NTO and provincial/local agencies would produce a form of tourism that would be conducive to Turkey's social structure. For example, farm tourism or rural tourism can be operated and encouraged as an alternative form for those regions that are away from the ocean beaches. This option being a 


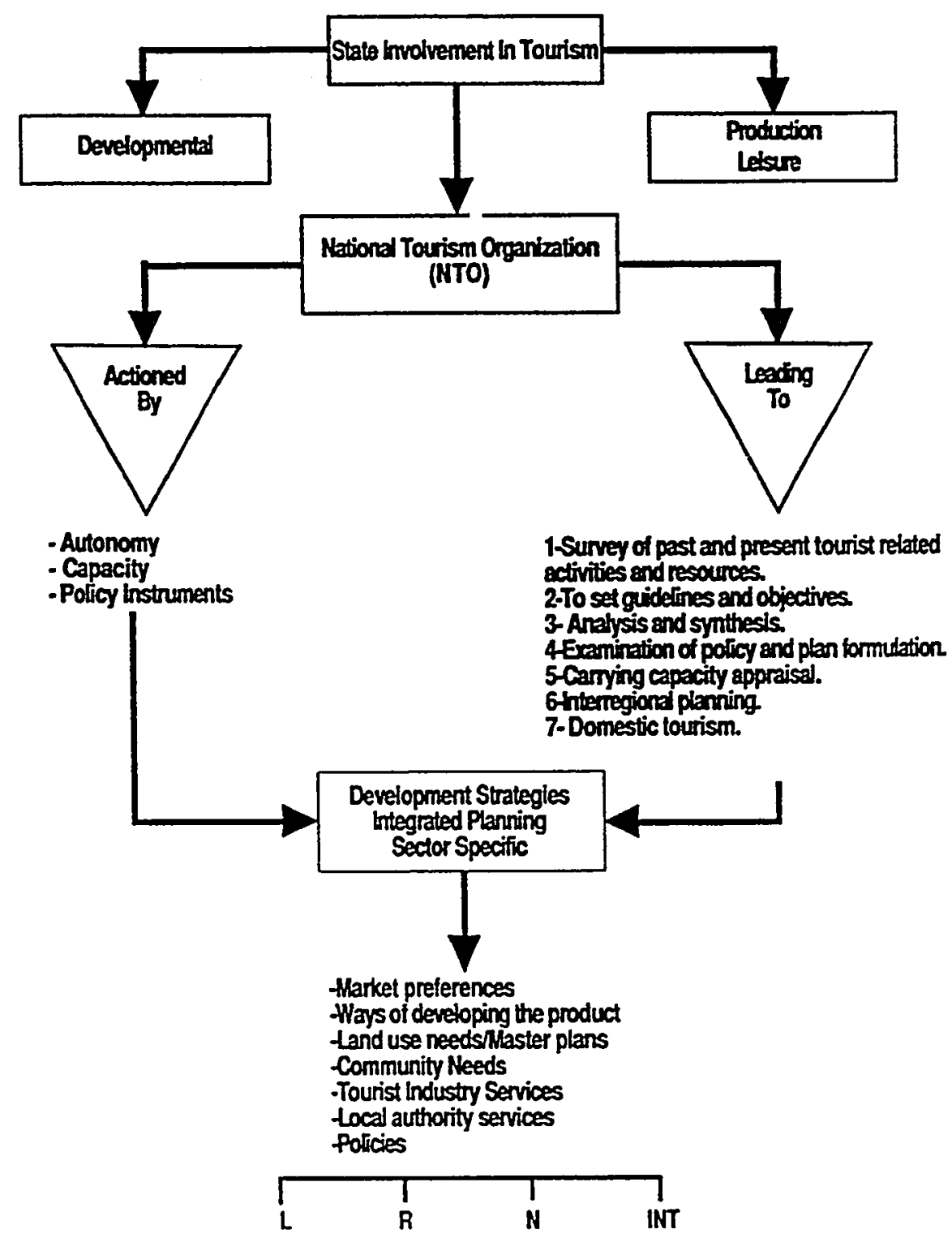

Figure 24: A hypothetical model for an alternative tourism organization. 
rather locally oriented project, would benefit local communities more than enclave developments, NTO, contrary to MCT, would need to adopt a platform as its planning guideline to achieve not only policy formulation, but also to encompass numerous tourism related aspects. This process would come about by determination of preliminary objectives.

The following are the tasks required to follow through such a process:

1. Survey: Informational knowledge gathering of existing and potential tourist and tourist attractions via provincial/local agencies from Turkey's tourism. The survey also will include the private sector's input and capacities as well as the local communities suggestion for tourism activities. The survey must contribute to: guiding government actions and the actions of those in the private and non-profit sectors: The survey must include relationships of the attractions selected to the potential tourist markets.

2. To set guidelines to determine which specific objectives and actions should be pursued to meet the needs of those in the particular destinations under consideration. This step will also help the planners to determine logical tourism development regions (Inskeep, 1988).

3. Analysis and synthesis: An important feature of this stage is the impact analysis of existing tourist activities, and with respect to the market, the country's objectives of tourism development. This stage will also guide a balanced tourism marketing planning program to meet future tourist demand; contribute economically, socially, and environmentally to the host community, while helping to alleviate 
problems in these fields; and ensure a reasonably local oriented profitable tourist trade.

The analysis also clarifies ways to integrate tourism into the overall development policy and strategy in other sectors (i.e., transportation). The analysis will take into account the demographic, economic, sociocultural, environmental, land use, and land tenure patterns as they affect and are affected by tourism.

4. Examination of policy and plan formulation: This aspect of NTO will take into consideration all the elements that have been surveyed and analyzed. Finally, alternative policies will come out of this process. The plans will be outlined, and the evaluations will be made. It will be determined how well each fulfills the tourism objectives, optimizes economic benefits, minimizes environmental and sociocultural impacts, and integrates into the overall development policy and plan.

5. Carrying capacity approval. The failure to plan for carrying capacity has had grave consequences. This has resulted in many cases (e.g., in the case of Boorum) in over capacity within the areas developed for tourism, causing the destruction or near destruction of historical landmarks and even of the natural environment. This aspect would be given more attention in the planning of tourism.

The concentration of tourism activities in the western regions of Turkey (Aegean and Marmara region) requires that carrying capacity be a planning tool.

6. Interregional planning is an important aspect in Turkey's alternative tourism policy. The main emphasis at this stage should be 
joint marketing and promotional plans with both tourist attracting countries (i.e., Greece) and tourist generating countries (i.e., Iran and Iraq). This process is especially productive where the international circuit travelers or wanderlust tourists are common. Such innovative activities have been implemented successfully in South American countries, namely, in the Andes route and Maya route (Pearce, 1989).

Support for a regional approach to the problems of tourism, regardless of intra-regional rivalries and competition, is in consonance with tourist market diversification. Especially, since the tourist market is susceptible to unpredicted fluctuations due to various factors. Turkey could capitalize on numerous interregional tourism markets, despite the political obstacles to such processes. Local enterprises can directly form communication channels to attract tourists from these markets, especially those with similar sociocultural backgrounds. Cooperation with regional rivals (i.e., Greece, Cyprus) on tourism enterprises can open up new channels that can be capitalized on. Such mechanisms have paid off handsomely in Latin American countries.

7. Domestic tourism: Domestic tourism and its significance to the industry's success and survival is a fact. As Ahluwalia (1986:54) alluded to this issue noting:

It is not universally recognized that domestic tourism is a highly important segment of the industry and one whose role is certain to increase in the coming years. In fact it constitutes the base on which all tourism rests. The absence of any type of planning procedure or policy guidelines on this issue in Turkish tourism is due to first the lack of a national 
tourism policy on the states' part, which indicates its unreadiness to assist and support the tourist industry; and second, to the obsession with international tourism for the immediate need of foreign exchange (Wahab, 1975).

Domestic tourism in Turkey's case would not only benefit the industry, but also would have positive sociocultural and economic prospects for the multi-ethnic nation. The economic impact can be seen when there is a downturn in the industry due to political reasons. Domestic tourism would support the industry and prevent its collapse in cases when international tourists are deterred. As Jafari (1987:30) warned:

The demand for international tourism depends on many external factors such as international economic prospects, international political climate, air accessibility, or seasonal vacillation, to name a few. International and even regional change in any of these factors, which could have major influence on the foreign tourists' arrivals, have limited influence on the domestic tourism.

Alternative Tourism Policy: A Viable Path

The Turkish path of tourism development should come as an "indigenous form" within the context of the overall socioeconomic development policy. This form will not only bear the economic aspect but also it can be a new instrument for world peace and understanding. Alternative tourism can be used as a stimulus for national development by forging links between it and other sectors, especially agriculture and agro-industry. Local cuisine and Turkish culture should be encouraged rather than allowing the country's culture to be 
determined by some preconceived notion of what the tourist might expect. In order to diversify the market, great emphasis should be placed on non-European markets as well. There is considerable potential for a vast tourist market in the Middle Eastern countries. Promotions and marketing schemes can be used to encourage tourists in neighboring countries in order to provide a useful complement to other visitors in the so-called "off season."

The term "alternative" tourism has been converted to "responsible and sustainable tourism" which can be defined as

relating to all forms of tourism with respect to the host natural, built, and cultural environments and the interests of all the parties concerned, i.e., hosts, guests/visitors, tourist industry; governments et al. (Wheeler, 1990:262).

Responsible and sustainable tourism grew out of the condition for and effects of tourism in the LDCs. Responsible can be defined as the form of tourism that is responsible for the social/cultural and environment while sustainable can be defined as a form that provides a condition for a sustainable and reproducible industry that is beneficial to the local population. This form of tourism is a "just" form intended to mean that both parties should benefit equally, personally and economically from the encounter (Cohen, 1989).

An appropriate tourism policy for Turkey must not be contained to an "economic" objective only. In addition it should not be confined to a certain region that benefits only certain groups. The establishment of the Ministry of Culture and Tourism was a step in the right direction. It is important that cultural interests be given priority 
but they need to be defined nationally and furnished for the integration of national development. Tourism development does not need to be influenced by foreign consultants and their normative planning criteria. Therefore, NTO needs to develop context-specific planning criteria as an indigenous policy maker.

Although Turkey has embarked upon an export oriented economy which makes her trade dependent, tourism development can still be indigenously organized, locally oriented, and shared regionally. Tourism in Turkey has great potential to become a major foreign exchange earner as a consequence of a proportionately small import leakage, The multiplier effect for Turkey's tourism is one of the highest. These criteria and Turkey's rich tourist resources call for a rather sustainable marketable tourism product. It is unfortunate that it has not yet become a focus of implemented policies.

One of the organizational shortcomes is that MCT has become an institution without national goals. It is focused on certain regions and within those on only certain types of tourism activity. In the reorganized NTO, what should come foremost in the planners' minds, is that "tourism policy should be governed by the general principle of obtaining the best possible result for the society as a whole" (Din, 1989:195). While an alternative tourism policy requires government intervention and involvement as well as support of local entrepreneurship to establish modest tourism facilities, it is not against mass tourism altogether. Mass tourism and large scale enterprises must follow certain principles that are compatible and conducive to national development goals. An important aspect of the 
former type is that it is conducive to the promotion of domestic tourism as well. Domestic tourism, as explained earlier, is a vital part of NTO policy particularly during times of problems with the international market, and also during the off-season tourism،

Finally, Turkey has entered a new path in her quest for national development and industrialization. Turkey has been compared to Korea since they have taken similar steps and have been subject to similar foreign aids (Krueger, 1987), Both countries are referred to as adopters of "dependent development"--a model that government plays a decisive role in economic activities; Ironically, until the 1960 s Turkey had done much better in respect to numerous economic indicators in comparison to Korea. It was after the 1960 s that Korea's growth surpassed Turkey by a considerable margin (Krueger, 1987). But Turkey has also shifted to an export oriented economic policy in 1980s, which is what Korea's growth has been attributed to, whether or not Turkey will be as successful as Korea has yet to be determined, but a tourism policy need not necessarily be organized and operated by the laws and players of the export oriented model. The industry's uniqueness allows its development not to be based on purely commercial considerations, If tourism achieves a marginal alleviation of regional disparities, it will be a success for long term political stability! Government intervention in tourism with an alternative tourism policy can make the industry a complementary element to creating an environment for further growth. An alternative tourism development policy in Turkey's case needs to develop based on that country's long-term development objectives (e.g., alleviation of regional disparities, unemployment, local 
participation). This path of development policy requires close cooperation between policy makers and scientists with an acknowledgement of both the conditions for and the effects of tourism development.

The alternative policy calls for government intervention to engage in a "collaborative planning" endeavor with the private sector. Equally important, the government's role needs to be an element of directing and pushing tourism development toward a more local orientation with less dependence on foreign nationals. As Din (1989:199) noted,

Effective government intervention is certainly necessary where the invisible hands of the market fails. It is only through deliberate government policies that more equitable distribution of benefits and costs among members of the host community can be ensured, and that the needs of tourists can be integrated with the needs of the host community.

Thus, tourism in Turkey's case need not be subject to dependent development. Alternative tourism can become responsible and sustainable via government devotion to tourism and the involvement of communities in its operation. However, the development of an alternative tourism development policy requires a skilled tourist organization to take the lead in implementing five areas which are key to making the "tourism" sector responsible as well as sustainable:

* Gross foreign exchange earning (i.e., the inflows of foreign currency from tourist expenditures)

* Net foreign exchange earnings (i.e., the proportion of tourist expenditures which remain in the local economy)

* Net social gain (i.e., the difference between the income earned through tourism, and that which would be earned through the next best alternative use of resources) 
* Distribution of cost and benefits

* Employment creation (English, 1986).

To note, on this base the call for small scale tourism enterprises, established with local consultation and participation has been legitimized over and over. In the case of Turkey, with its conducive potentials, farm tourism, rural tourism, study tourism cultural tourism, ethnic tourism and recreational tourism are but a few of the alternatives that can be translated to policies on provincial and local levels. This can be complemented by government intervention to prevent the Tourism Transnational Corporations (TTCs), by currently available mechanisms, from taking a larger share of mass tourism which even an alternative tourism cannot do without. As Cohen (1989:138) noted,

Such an effort at reform may not do away completely with all unsavory aspects of contemporary tourism, but would lead to a more "appropriate mass tourism, and help to ameliorate acute prevailing problems.

The small scale tourism enterprises (craft tourism) have been recommended for their less negative impacts and myriad local benefits. The further issues of "scale" and "local control" can be articulated into "integrated development" as opposed to enclave development. Where an "integrated" (alternative) tourism will have following features:

* a smaller unit scale of facilities,

* entry barriers are lower and there is more incigenous capital and management, 
* because of the lower prices, the expectations of the guests attracted will differ from those staying in international class hotels. Such tourist may be more readily assimilated into the community and less socially disruptive,

* tourist acceptance by host community may be less of a problem as such tourism emerges from rather than is imposed upon the community,

* "price enclavism" may not be a feature given the smaller scale types of development related more to the local community (Pearce, 1989:102).

Alternative tourism policy calls for small-scale local orientation, and public participation in order to overcome severe regional inequalities and uneven patterns of income distribution. An appropriate tourism policy for Turkey must not be contained to an "economic" objective only. In addition it should not be confined to a certain region that benefits only certain groups. The establishment of the Ministry of Culture and Tourism was a step in the right direction. It is important that cultural interests be given priority but they need to be defined nationally and furnished for the integration of national development.

Absence of Carrying Capacity Measurement: Alternative Planning Model

Carrying capacity, which enables host societies to make more efficient use of tourist facilities and land transportations, is defined as an idea that recognizes that both natural and manmade 
have upper limits in their capacity to absorb visitors, above which a deterioration of the resource itself takes place, Although the concept is simple, its application is complex because of problems in measuring changes that occur and discovering the causal relationships between tourist impact and the effect on the environment (Lea, 1988:61); Lindsay (1986) with respect to national parks in the united States, suggests: "Carrying capacity can be further defined by the formula:

$$
C C=f\left(Q, T, N, U_{T}, D M, A B\right)
$$

which states that carrying capacity is a function of the quantity of the park's resources, the tolerance of its resources to use, the number of visitors, the type of use, the design and management of the visitor facilities and the attitude and behavior of its visitors and managers (cf Pearce, 1989:169).

It is unfortunate that the dominant pattern (such as in the case of Turkey) has been no prior capacity analysis. Carrying capacity analysis should be seriously considered in the planning process in order to inhibit saturation of facilities (physical capacity), the degradation of environment (environmental capacity) or ciminishing visitors' enjoyment (perceptual or psychological capacity) (O'Reilly, 1986). However, there are two schools of thought concerned with the nature and interpretation of tourism carrying capacity! These concepts can produce different planning devices to measure and prevent the over capacity of tourist centers.

First, tourism capacity is envisaged as the capacity of the destination area to absorb tourists before negative impacts of tourism 
are felt by the host country. In other works, the capacity is dictated by how many tourists are wanted rather than how many tourists can be attracted. Here more attention is paid to the host country and population than to the tourist.

The second school of thought proposes that tourism capacity be considered as the levels beyond which tourist flows will decline because certain capacities, as perceived by the tourists themselves, have been exceeded, and therefore the destination area ceases to satisfy and attract them and hence they will seek alternative destinations (O'Reilly, 1986:254)。

The concept and application of carrying capacity professes to be a vital planning tool to bridge the tourism industry and environmental enhancement. As Atac-Rosch noted,

they mentally affect each other. Tourism needs environmental quality and environmental quality needs tourism: Whereas, potentially, tourism has the capacity to generate conflict within its environmental setting, conservation of the physical and human transportations base should be seen as an essential component of the tourist product. There is growing evidence of an awareness of the part of the providers and managers of tourism, including public authorities, and even of the tourists themselves, that the relationship between tourism and environment need not remain apathetic or even merely passive. Given an appropriate commitment to planning, design and management, tourism can become an active, positive agent in the process of environmental enhancement (1984:119).

Figure 25 demonstrates the mutual impact of tourism development and environmental cuality on each other.

It is not only the destination but also the tourists themselves that ought to be appraised. In addition, some idea of the complex interrelationships involved can be understood when it is realized that 


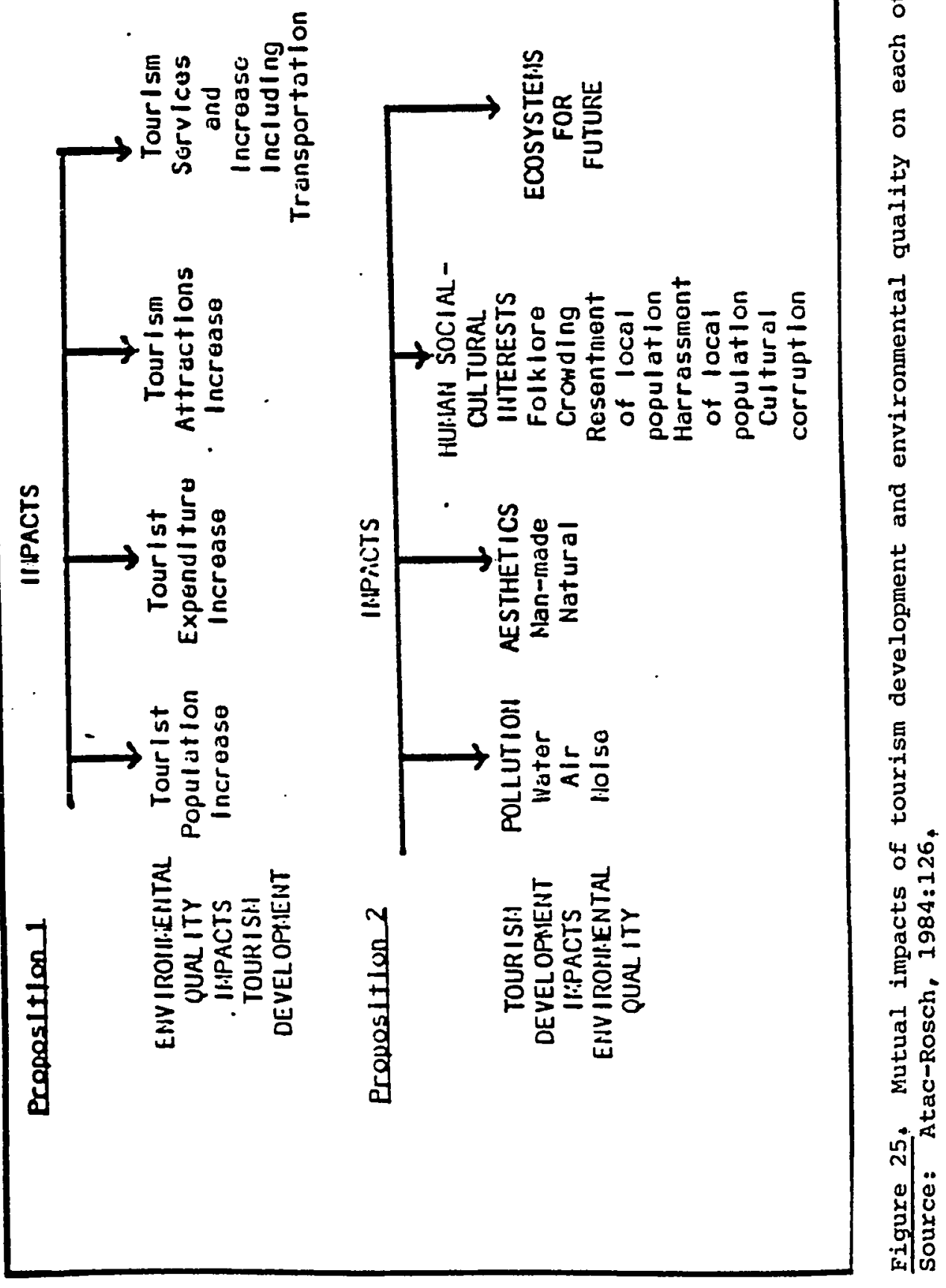


carrying capacity is affected by a range of characteristics on both sides, tourists and destinations. Iea (1988:61) categorized those characteristics for tourists as

their socio-economic profile, levels of usage, length of stay, type of activity, and levels of satisfaction; for destinations as: environmental features (topography, flora and fauna), the level of economic development, its social structure and organization, politics and the scale of tourist development. All these things together will govern the capacity of a destination to absorb the demands placed on it by tourists.

The lack of awareness of carrying capacity on the part of the IDCs will intensify the geographic concentration of pressures on usable transportations, space, local organizations, and ecological capacity. Furthermore, it can have far-reaching consequences and implications for socioeconomic development as well as the ecological and environmental balance in those countries.

One should bear in mind that carrying capacity has already been alarmingly approached in many instances due to population growth, spatial disparity and deficient technological advancement in the IDCs' as El-Shakhs and Amirahmadi (1984:38) explained:

While the natural carrying capacity of the permanently inhabited environments can and has, throughout history, been increased with developments in technology and social organizations, population pressure on such capacity increases even faster, particularly in the LDCs where such developments generally lag behind population increase.

Carrying capacity also has a social dimension; for instance, it

can relate to the level of satisfaction enjoyed by the tourists themselves. A simple random survey by Bodrum's mayor's office revealed low satisfaction with services, particularly in the food service sector during the summer of 1988. Deterioration of services in Bodrum was an 
obvious adverse result of over capacity and rather limited facilities and services.

A threatening dilemma in resort areas of LDCs is the environmental carrying capacity of the offshore features and coastal waters. Lack of knowledge to incorporate this aspect into the planning process may easily lead to health related problems due to sewage contamination of shorelines and physical pressure resulting from under water activities. This problem has already been identified by the WTO-UNEP. As they reported,

From the human health point of view, tourism planners can refer to recommended bacteriological standards to ensure adequate protection for the water. For example, the Common Market Bathing Water Directive of 1976 set bacteriological limits for traditional bathing areas: $100 \mathrm{ml}$ of sea water should not contain more than 10,000 coliform bacteria or 2000 fecal coliforms (Pearce, 1984:172).

A sociocultural capacity will relate also to the host community's perception of its interaction with the tourists, what one might term the xenophobia factor (Romeril, 1989).

Despite the difficulties in quantifying the values of carrying capacity, there have been efforts to analyze the threshold level of tourist capacity. However, as difficult as it might be, it can work well in local situations and with single type ecosystems, and it has value as an operational concept within which to undertake the tourism planning process (Wall, 1982).

The alternative approach to capacity assessment needs to be incorporated in a "model" that includes comprehensive tourism planning in a systems approach. As it has been identified in this study, the absence of a systems approach to tourism planning in Turkey has caused a 
disarray in national tourism as well as local enterprises li.e., local tourism continues to be with a locally elaborated strategy; at the national level, tourism is limited to common master plans). In fact, without a model for tourism planning it is inconceivable to have a carrying capacity assessment. Thus,

in a systems approach, capacity thresholds must be interpreted as something other than limits derived from prediction or attainment of an optional state. Threshold must be seen as part of a dynamic process aimed at overcoming barriers where possible, but one in which it is also possible to exert controls (such as limits) when necessary to satisfy objectives" (Getz, 1983:252).

Figure 26 illustrates the recommended model. This model is an alternative approach to tourism planning with the inclusion of carrying capacity assessment. It includes a systems approach and is strategic because it tends to integrate two concurrent streams of activity:

The first is general research aimed at understanding the system (usually involving models of how the system works, in order to determine causal relationships); from this emerges the identification of problems and of goals for the system. The second is the application and evaluation of controls exerted on the system (i.e., specific policies, plans, and developments) to achieve goals (Getz, 1983:253).

For instance, the application of the model to new local tourist destinations (e.g., Bodrum) has a significant implication for being concerned with process rather than final products such as master plans. The significant aspect of the model is that it represents a multi-level planning system in a fashion that is understandable to planners in different levels. Furthermore, it included various aspects of strategic planning such as continuous evaluation and review. As Getz (1983:258) noted 
THE ENVIRONMENT

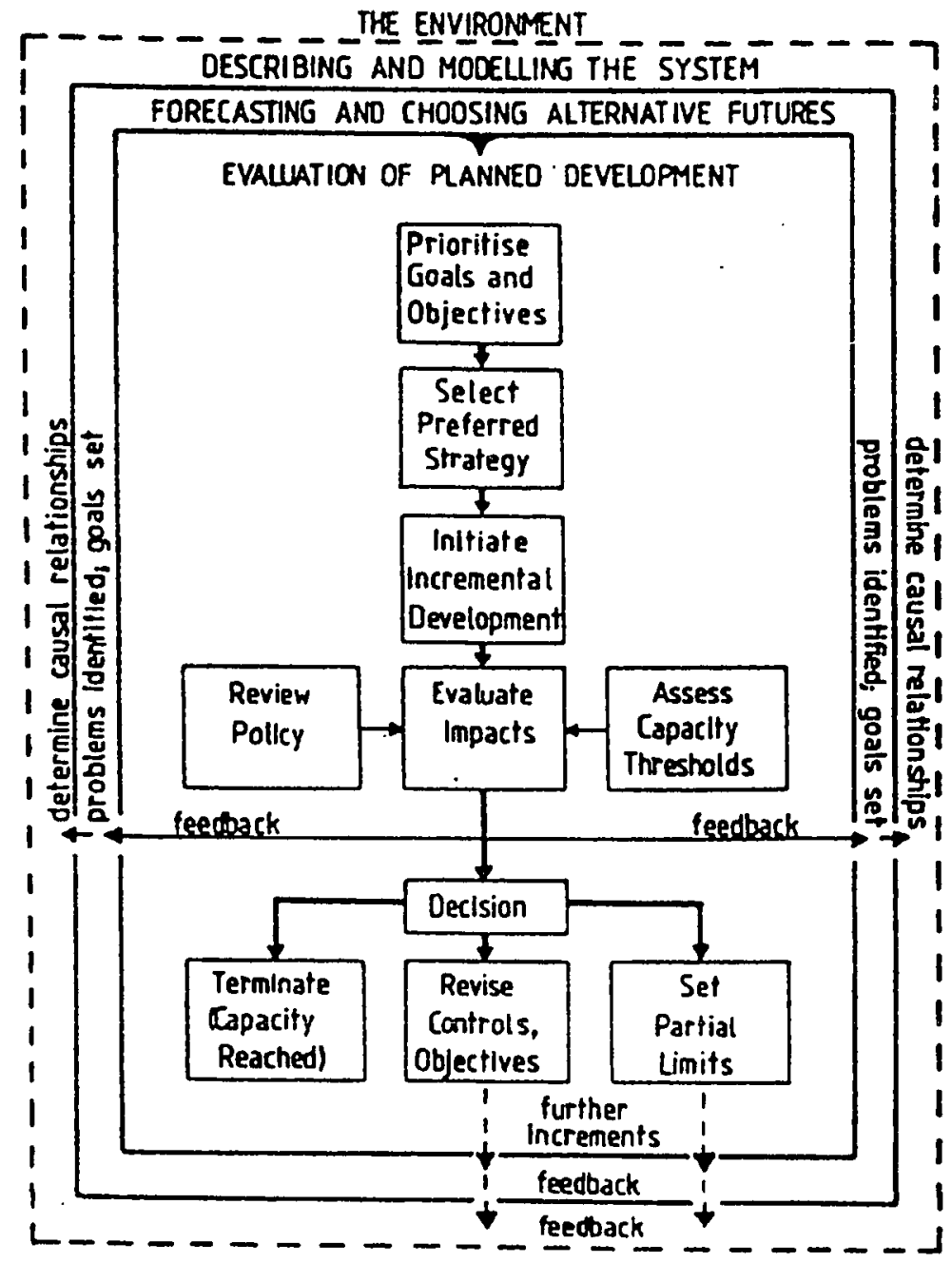

Figure 26. Assessing capacity in tourism planning, Source: Adopted from Getz, 1983:252. 
The evaluation of impacts and assessment of capacity thresholds also requires continuous attention and cannot solely be left to discrete reviews. What the model suggests is that major policy reviews should occur periodically, at which times a summary of impacts can be analyzed and the question of capacity addressed.

In particular, the model employs the feedback mechanism to reveal the hidden negative impacts that resulted from political considerations. Therefore, the feedback mechanism would be open to public scrutiny. Consequently, control will be placed in the hands of host populations, and the local attitudes and preferences would determine priorities. The model is a fundamental beginning in the case of Turkey to incorporate a "systems approach" to tourism as well as "adaptation of the planning process through increased evaluation of impacts, and through research into the nature of the system" (Getz, 1983:260),

\section{ENVIRONMENTAL ISSUE AND ALTERNATIVE TOURISM}

Tourism as a recreational phenomenon with its mass character has raised many environmental issues which are not insular to development. As Camhis and Coccossis noted, "Without a tourist policy, the fragile environment becomes seriously endangered" (1983:16). Unfortunately, the LDCs are far behind in the realization and implementation of an environmental policy. Gladwin noted the following:

As of 1986, a ball park estimate would be that 958 of all environmental laws, environmental agency personnel, environmental group memberships, and environmental protection spending around the world was concentrated in the western industrial nations $(1987: 7-8)$.

Despite the development of concepts such as "rational use of transportation," "development without destruction," and "sistainable 
development," the conflict between short-term needs for economic growth and long-term protection of the environment is still very prevalent. Tourism development is usually justified on the basis of economic benefit and challenged on the grounds of social, cultural and environmental destruction (Liu et al., 1987).

By the beginning of the 1980s, many governments realized that the development of their tourism industry in the two previous decades had not taken adequate account of the available transportation base (i,e., Turkey is a case in point) or of the environment (physical, cultural and social), nor had the demands on the country's infrastructure been properly determined. It was realized that in many cases, the industry was in danger of destroying itself if further development continued in the same way as before.... Disruptions were not a one-way process. Tourism development can and did cause disruptions to other aspects of countries' economic development and vice versa (1989:202-3).

The essence of the argument lies in the complementarity of tourism and environment with survival of the former depending on the influences on land use by the other. Despite positive compensatory outcomes, to a greater degree in the developed world and to a lesser degree in the IDCs, environmental protection from mass tourism has remained a critical area (Marsh, 1986; Lea, 1988). The induction of environmental stress by tourism was first looked into by the OECD in 1977-78. They emphasized four main groups of stress or activities: changes causing permanent restructuring of the environment, the generation of waste production, tourist activities, and population effects. These were identified according to the nature of the stresses involved and the environmental response (Lea, 1988:55). The mechanisms of tourist impact on the environment in the LDCs can be understood through its magnitude which during the last 25 years 
has become one of the world's largest industries. International tourist arrivals increased more than fivefold between 1960 and 1985, from 60 million to 340 million. Thus, as an industry, tourism has probably the most direct and indirect effects on the largest number of government ministries and departments, and therefore on the country as a whole. It has a bearing on

land use and urban development; infrastructure--airports, roads, railways, electricity generation and distribution, water and sewage; energy--oil, gas and coal; agriculture and fisheries; employment; health; education; economic and fiscal policy--including foreign investment; and foreign affairs--immigration and work permit policies (Gajraj, $1987: 5-6)$.

Gajraj continues, saying that with the very rapid development of such an all-intrusive industry it would be surprising not to find some negative repercussions, not the least of which would be some detrimental environmental effects.

In the case of Mediterranean Tourism (i.e., Turkey's tourist region), the environmental issue is alarming when by the year 2025 , it is predicted that 95 percent of the coast may be urbanized and the Mediterranean basin may have to support more than 500 million inhabitants, 200 million tourists, and 150 million cars. Many coastal areas have been spoiled already (Gajraj, 1988:8).

The interaction between tourist and the environment increases the vulnerability of both phenomena, which are extremely dependent on each other. More than perhaps any other economic activity, tourism is related to the environment and its protection (Camhis and coccossis, 1983:17). Models describing tourist systems recognize the importance of natural resources. The manner in which natural resources are utilized 
can lead to environmental degradation as sties are transformed (Gartner, $1987: 39$ )

The dominant tourist mechanism that affects the environment in the LDCs is the lack of awareness of various concepts, namely carrying capacity and institutionalized environmental programs. Many attempts have been made to relate the environmental impact to visitor number and/or activity.

Absence of Institutionalized Environmental Program

In very sensitive fragile natural environments, which in many cases are a non-renewable resource, arguments have been raised that each passing tourist contributes to the further degeneration of the attraction that has drawn them to the destination (Gartner, 1987; Hiranyakit, 1984; Wood, 1984). It has been predicted that tourism activity is on the rise and there is no sign of slowing down through the year 2000. The repercussion of such intensified leisure activity has resulted in a polarization between the environmentalists and the tourist industry. In the IDCs' case, the problem is worse and multiplied because of the lack of real political resolve to support and implement environment policies now widely accepted world-wide. While the environmental phenomenon as a vital issue remains to be recognized in the Third World, Development Projects and numerous international agreements have been formed to signify the indispensability of this issue. A sample of some recent international agreements are the following: 
* World Conservation strategy, 1980: Sustainable use of natural resources.

* Brandt Commission Report, 1980: Development must include "care of the environment."

* WTO Manila Declaration, 1980: All resources are a common heritage.

* United Nations Environment Program/WTO Accord, 1982: To promote environmentally sound tourism.

* Brundtland Report, 1987: Sustainable development with economic growth (Romeril, 1989:204).

On the national level there has been an institutionalization of the Environmental Impact Assessment (EIA) and the Environmental Quality Act (EQA), not to mention the "green" awakening, which has initiated the control of tourist flow to avoid saturation during peak seasons

(Romeril, 1989).

Failure on the part of both the government and the public in LDCs to formulate policies and institutionalize environmental programs is a caution to many groups, As Romeril (1989:205) wrote,

Even in countries such as Cyprus and Maldives, where the national tourist organizations are aware, significant negative effects are still being generated by inappropriate tourism development $+\ldots$ Bodrum Peninsula in Turkey will show that the absence of high-rise hotels is no guarantee against the despoilation of coastline.

While there has been a shift from an age of industrialization and its environmental neglect to an age of communication and enlightenment, LDCs are still lacking certain essential mechanisms to achieve such a shift (Gunn, 1988:271). This is more acute in the case of tourism 
development, which requires the formation of institutions with environmental and conservation ideologies: The significant interrelation of a sustainable development and indispensability of institutionalization of environmental programs is elaborated by Wieberdink and Ketel when they say, "it is generally accepted that in order to guarantee a sustained development process, environmental politics must form an integral part of development policies" (1988:139). They are convinced that in LDCs institutionalization of environmental programs might therefore constitute a necessary part of the realization of integrated development.

The founding of the United Nations Environment Program (UNEP) in 1982 started a new phase in the institutionalization of environmental concern (Wieberdink and Ketel, 1988): Although governments in the LDCs are aware of such issues, various factors have curtailed the formation of an effective institution to protect the fragile environment, particularly in the case of tourist destination areas, where the interaction between tourist and environment is detrimental to the overall ecology of the region, not to mention the lack of public awareness toward tourism's overall negative impact on environment, including the inadequacy of legislation and the absence of environmental education (Wieberdink and Ketel, 1988): Because of the peculiar nature of the political structure of LDCs it is rare, if not impossible, to see the establishment of an autonomous environmental agency. While tourism policy requires the cooperation of many agencies, and a continuing planning process, LDCs' tourism is dominated by bureaucrats, TNCs, and big business monopolies (Gunn, 1988), In her critical analysis of 
social and environmental impact of tourism in LDCs, hong (1985:30) stated:

While many Third World countries are pinning their hopes on the golden goose of tourism to provide the answer to their economic ills, there is the other side of the tourist coin, too. In many of these countries, with a longer history and exposure to tourism, these dreams have turned sour and many have awakened to the fact that tourism is a more subtle and dangerous form of exploitation and dominance.

In fact, such a structural form which is described in the above statement may not be the cause but surely is an indication of the absence of "participatory" and "community approach" policies towards tourist development. The non-participation of local people in the industry's development, and consequently in the tourism profit, impedes the process of institution building on the local level (Dasmann et al., 1973; Murphy, 1982; Gran, 1986). This condition, resulting in the alienation of public support and concern, prevents an integrated national policy-making process that could occur in a situation with collaborative planning and clear goals to integrate the total community's social and economic life (Gunn, 1984). Considering these points, governments in the LDCs are also deficient in the institutionalization of the responsibilities that they had originally been given. In this respect, the government can be blamed for not integrating an environmental perspective into national policy. First, in many LDCs leaders have not been interested in mobilizing widespread popular support to institutionalize an environmental program (Nelson, 1979). Second, the government lacks regulations, local and regional land use laws, and most importantly, effective development regulations to mitigate or prevent negative 
environmental impact, Such apathy on the parts of IDCs has been criticized by various voluntary organizations concerning tourism and the environment, One instance would be the cautioning report by World Wildlife Fund (WWF) (1990) of "The potentials and pitfalls of ecotourism" which has developmental as well as environmental connotations, As WWF reported (1990:2)

Many international travel agents and tour operators have yet to establish relations with local counterparts, so only a small portion of the financial gains from ecotourism stays in the areas surrounding parks. Mechanisms are not in place to evaluate the environmental impact of tourism.

There are various examples of governments hesitant to impose restrictions on land use in order to prevent environmental deterioration from occurring. Many times this hesitancy is caused by the real or perceived fear of losing revenues associated with tourist expenditures of the decline in the foreign exchange due to tourism (Carter, 19771; Stroud, 1983).

The governmental role in dealing with the environmental issue is more prominent, particularly on this issue as Atac-Rosch (1984:128) says,

at all levels of geographical decision-making jurisdictions of tourism planning, environmental concerns must play dominating roles. This can be accomplished either by establishing definite environmental intentions, like a development plan for a national park, or by attempting to control the environment impacts of a given tourism development, program or policy, or by considering the environmental implications of any model, plan, policy, program, or project related to tourism.

Despite the intensified dialogue between environmentalists and tourist professionals (i.e., bureaucrats in LDCs), there remain many in the industry who would choose to dismiss the vital interrelation between 
a sustainable development and a sound environment. There is a need to reflect on the current attitudes of organizations such as the World Bank and the WTO. These organizations, not to mention the Greenpeace movement, argue strongly for environmentally sound development. As Romeril (1989) noted, the realities of the 1990 s and beyond alternate the need for a more equitable international economic system founded in the concept of sustainable development.

In fact, a whole range of alternative tourism, nature tourism, farm tourism, kibbutz tourism, rural tourism, etc, has been offered as a vehicle for sustainable development (Travis, 1982; Gilbert, 1989; Dernoi, 1983). Some believe that ignoring such a new order of tourism development will be at the industry's peril, Romeril (1989:207) stated: An aware and completely changed industry can sustain tourism. In terms of modern thinking and eco-development, if tourism is sustained significant steps have then been taken toward maintaining environmental integrity. A healthy environmental integrity means the possibility of successful tourism which, when managed properly, becomes a resource in its own right.

Environmental impact assessment, as one of several mechanisms to contribute to the well-being of tourism as well as the whole ecosystem, is too vital to be ignored, particularly in the case of Turkey. Surveys have revealed that tourists have established opinions about various destinations which can no longer be overlooked if the industry wants to survive in the long run (Romeril, 1989). Whether in the tabloid press or up-market glossy magazines, in recent reviews nearly all the travel correspondents had a closing paragraph with a clear warning, e.g., "Turkey is the place for now: go there before it goes the way of the rest." It seems a sad epitaph that such detrimental change is seen by 
so many, particularly those who know the industry intimately, as the only inevitable outcome for an emerging tourist industry (Romeril, 1989):

The lack of awareness that manifests itself in the absence of environmental institutions can engender irreversible adverse consequences: This can be inferred from sporadic articles in the Turkish daily papers of the threatening nature of the public sector's apathy toward hazardous events to the environment and consequently to the industry; Cumhuriyet $(1988: 6)$ complained that the "present tourist structure in Turkey has become a threatening factor to the natural resources: Furthermore the lack of carrying capacity analysis is endangering the antiquities and the museums" An uproar by German "greens" initiated the involvement of a Turkish television program and the Middle Eastern Technical University to save the nesting ground of a rare sea turtle known as "caretts, carettas" that was endangered by hotel construction (Turkish Daily News, 1988:7)! The partial destruction of "Olimpos" National Park and "Gelibolu" historical park by private villa developers was permitted by the Ministry of Agriculture and Forestry (Hurryat, 1988:8),

The overall shortcomings of environmental management and planning in LDCs can be summarized as follows:

1. Inadequacies in monitoring and enforcement of existing environmental protection laws and regulations;

2. Extensive poverty that puts a premium on current incomeproducing activities (i,ę, tourism) to the detriment of long-term protection of natural systems, 
3. Difficulty in controlling the environmental effects of private sector and public sector development activities, which limits the effectiveness of public programs for environmental quality management.

4. Inadequacies in the technical, economic, and administrative expertise available for the planning and implementation of environmental management programs;

5. Minimal participation in environmental quality planning, either by the general public or by many affected governmental agencies, which reduces the effectiveness of implementation.

6. Inadequacies in environmental, economic, and social date, including difficulties in data collection and processing and lack of knowledge of past trends and baselines, which limit the quality of analysis.

7. Wide diversity of cultural values, which increases the difficulty of social evaluation of environmental quality effects (Gladwin, 1987:9-10).

To these one can add the role of TNCs and their involvement not only in tourism but in various other sectors! In reference to TNCs the United Nations made a cautionary note in the following statement:

On top of this sobering set of constraints, a number of factors relating to TNCs may further conspire to make purely national control systems either "evadable," inefficient, incomplete, unenforceable, exploitable, or negotiable (at the expense of desired environmental quality) (UN, 1982:40). Regarding Turkey's position, as of 1982 there were 162 foreign private investors (including Touristic Investments). The social and 
economic effects of these investments remains unknown. The environmental aspects of foreign private investment have been taken into consideration in the law or in the decrees (Ural, 1987),

\section{ENVIRONMENTAL PLANNING}

Alternative tourism in order to achieve the criteria for a sustainable economic activity, needs to recognize the need to conserve the environment for the protection of long-term investments in tourism infrastructure。

Alternative tourism will incorporate an environmental analysis into the overall tourism planning. This analysis must be done at both the macro-level (national/regional) and at the micro-level (local/individual) in their associated infrastructure (Inskeep, 1987), The analysis should include the Environmental Impact Assessment (EIA) as well as a carrying capacity analysis, This is necessary because in Inskeep's (1987:120-121) terms

The threat presented to the natural environment by tourist overused,pis serious in many areas, p.: This problem optomizes the importance of determining capacity for various types of tourism development.

In Turkey's case, where it is still a newly developed destination, alternative tourism can incorporate environmental planning as a basic policy into the overall tourism planning, one should bear in mind that it is the forms of tourism itself with alternative tourism development policies that facilitates an efficient environmental control. For example, a basic development policy often for environmental reasons that 
tourist facilities be contained as integrated resorts in contrast to allowing the dispersion of development throughout the region, Economically, the incorporation of environmental planning makes reasonable sense, hence it can promote measures such as the average length of stay, or tourist-days, total tourist expenditures, and net "foreign" exchange earned. From an environmental point of view, such impacts as transportation congestion, ecological disruption in nature parks, air and water pollution, and high noise levels must enter the equation (Inskeep, 1987).

Thus, alternative tourism in the forms of "quality tourism" (which implies limited, highly controlled development and selective marketing), and "special interest tourism" (which includes touristic interests in specific aspects), can be encouraged by direct government involvement Small scale tourism such as "village tourism" and "farm tourism" which are owned and operated by local people should also be encouraged, As Inskeep (1987:124) noted,

This approach brings tourism's economic benefits directly to the villagers; generates little environmental impact because it is small scale and presumably well planned, developed and operated; and appeals to a specific tourist market segment which wants to experience village life and tends to be conservation oriented.

Nonetheless, numerous methods also can be applied to achieve EIA

in tourism planning--namely, matrices, networks, quantitative, overlays, models and checklists.

In conclusion, EIA is a dynamic planning tool that it is worth incorporating into the alternative tourism path for Turkey and could 
benefit Turkey in a number of ways; First, Turkey's higher educational institutions are capable of producing educated manpower for research This would enable Turkey to capitalize on untapped resources that could bring environmental awareness to the community level where there is total absence of environmental knowledge of the dangers of tourism projects: Secondly, this would allow environmental impact monitoring to occur at all levels of government (including the evaluation of alternative plans). Thirdly, this process would allow the detection of problems for investigation and resolution and perhaps even the acknowledgement that some locations should have no tourism development because of negative environmental impacts:

COMPARATIVE NOTES: MEDITERRANEAN MODELS

\section{Background}

Greece and Spain are two traditional tourist destinations in the Mediterranean region. The magnitude of arrivals in Greece and Spain--during the 1980s--is a clear indication of their capacity and traditional background to accommodate such a mega-tourist industry Spain and Greece received over 47 million, and eight million tourists respectively in 1986, whereas Turkey had less then three million visitors in 1987 (International Tourism Reports, 1988), Spain's tourism was institutionalized during the Franco years and not only was it an economic activity, but also it served as a political instrument to reinforce the legitimization of a fascist state (Pearce, 1989; Richter, 1989) 
Spain's tourism was in full swing from 1931 to 1934 before it was interrupted by the Civil War and World War II, It regained importance in the 1950s (Tamames, 1986).

Greece's introduction to mass tourism took shape in the 1950 s after her membership in NATO, As Gianaris (1984:28) noted: US involvement

exercised control on weaponry and had great influence on important decisions through the palace and the Greek army command, not only on military, but also on political and economic macters, American military and economic aid to Greece amounted to about $\$ 100$ million per year

In addition, he noted:

Increasing number of tourists from Europe and America came to enjoy the sun-drenched haven and Homer's "wine-dark" Sea of Greece.

Notwithstanding the comparable resources/potentials, the incorporation of the tourism sector into the overall economic and political structure came much earlier for Greece and Spain than for Turkey: Greece and Spain both have a cultural affinity to the "Anglo Saxon" world as a sub-area in the Mediterranean Europe, while Turkey is still identified as a part of the Moslem world despite westernization efforts of its founders.

\section{Political Evolution: Similarities and Differences}

Historically, these countries have developed along different paths. The history of political evolution in both Greece and Spain has shaped similar economic structures in these countries which differs from Turkey; As Pridham (1984:2) noted: 
The states and societies of southern Europe present sufficient similarities in the evolution of their respective political systems, The patterns of structural societal change, and the dynamics of economic development in the nineteenth and twentieth centuries to warrant systematic as a unit.

Thus the political process in Spain and Greece is characterized with a contemporaneous argument--in terms of their transition from authoritarianism to democracy without turning back. The 1970 s began as the starting point for transition in these countries a "Mediterranean Model" of liberal democracy, Turkey's return to military rule debars her from being categorized within this model,

To comprehend the "model," the following definition is elaborated by Hague and Harrop (1982:42) as:

Liberal democracies are characterized by a high and open level of competition for power within a stable framework of institutions: The liberal-democratic system is highly inclusive, with numerous and varied channels--parties, elections, interest groups and mass media--for the articulation of popular interests and preferences! Broadly attuned to predominant mass preferences, liberal democracies have developed a moderately reformist, welfare orientation since the extension of citizenship to the lower strata.

With respect to the above definition, the process of democratization in Spain and Greece have weakened the system of clientalism and the patronage, if not dismantled them, This gave way to the formation of "party government" within their state structures (Pridham, 1984; Spourdalakis, 1988): It is also important to note that the political as well as the socioeconomic transformation of "Mediterranean Models" have their relevancy and demarcations within the Third world development process: Desire for democracy in the Third world, hence political pluralism may 
not come as a prerequisite, but it exists as a general demand on the other hand, the influence of Western Europe and their political ideologies have created a conducive environment for the successes of these democracies:

\section{Transition in Greece}

The 1960 s were a period of a crisis and began the process which shattered the clientalism and established a party system as a state structure, As Spourdalakis (1988:20) elaborated,

It can largely be summarized as a contempt for parliament as the law-making body: The complete subordination of all the party's deputies to the leader's will "..naturally not only the prewar party alignment, but also the party organization and political clientalism had to adjust to the new conditions:

The 1960's political struggle gave way to the formation of the resistance movement, which opposed the military dictatorship: The monarchists established the liberal political force and the new party "The Center Union:" CU dealt a blow to the "traditional" ways by a modern approach to the political structure, "According to its constitution the $\mathrm{CU}$ was to be organized both vertically (at the prefectural, regional and local level) and horizontally (into professional organization, women's and youth clubs) (Spourdalakis, 1988:23). This was obviously done in response to the growing popular discomfort with regard to clientalism:

The economic orientation of $\mathrm{CU}$ was industrialization via foreign investment--primarily European! By 1966, noted Spourdalakis (1988:28)

The inflow of West German and French capital had almost counterbalanced American, Most of this capital went to the 
manufacturing of export goods which became 608 of the country's overall exports.

Nonetheless, the economic boom of 1960 s--tourism included--had its impact on furthering the development of the democratic model. As Tovias (1984:159) noted,

In the 1960s and up to 1973, Spain, Portugal and Greece enjoyed higher rates of growth than the six or the nine, While in the latter GDP increased in volume on average by an annual rate of 4 to 5 percent, in the three southern European countries' annual growth rates revolved around the 6 to 8 percent mark. It is commonly agreed that the tourism boom, thad a tremendous influence on the balance of payments a. :

On the third of September, 1974 the Panhellenic Socialist Movement (PASOK) was established which was to become the first mass socialist party in modern Greek history. The PASOK represented the Greek dependentistas which was a response to: (1) Unevenness of productivity as between sectors; (2) disarticulation of the economic system; (3) domination from outside. Where in Turkey, after three decades of monoparty rule, the political process failed to mobilize and transform to what is known as a Mediterranean democracy! In Turkey, the transition of 1960s and the democratic prelude of 1970 s led to the return of military rule, The process of self-reliance that was forwarded by PASOK (as a party government) took a new president after its election by a popular vote on October 18, 1981, PASOK's agenda on socioeconomic transformation was based on

national independence, territorial integrity, popular sovereignty, social liberation, and democratic procedure, autonomous economic and social development, the revitalization of the countryside, the radical improvement of the quality of life in the city and in the village, social justice, and finally social liberation, 
On foreign policy PASOK forwarded policy of peace, realism, solidarity to the people who struggle for their national independence, or their independent economic development, and a policy based on the fact that Greece is a country which simultaneously belongs to Europe, the Balkans, and the Mediterranean, PASOK actively joined the "peace initiative of six," for its anti nuclear stand.

On the domestic front PASOK's development ideology formulated based on the belief that

the crisis of the capitalist system, on a global scaled,the intense competition, the increase at the level of accumulation and the monopolistic structure of many sectors have made the traditional means of economic policy ineffectual, thus, PASOK's choice is based on the application of democratic planning, the restructuring of the public enterprises, so that they will become better instruments in support of the private sector, the support of the "lowermiddle business" and the nationally advantageous policy for the attraction of foreign investment (Spourdalakis, 1988:202):

The new "party government" also emphasized on the need for

decentralization to transfer power to the municipal authorities and the establishment of collective bodies for the creation and the proper functioning of an "apparatus of democratic planning," Recent decentralization measures in Greece, Gianaris $(1984: 65-66)$ noted

delegate a great part of administrative authority to municipal community governments: Local governments in the rural regions and block organizations in large cities are the basic units of decision making concerning their own affairs.:4. In order to bolster the financial base of the municipalities and give them fiscal muscle, the central government transferred control of forests, mountain terrains, lakes, and all beaches (covering some 60 percent of Greece's surface area) to local authorities, Moreover, local governments can raise revenue by opening up parks and tourist resorts and collecting local property taxes and natural resource user taxes, in addition to revenue sharing and investment financing from the national budget. The Five 
Year Plan of 1983-87 provides for the gradual emancipation and financial independence of the provincial localities.

Further ideological manifestations included labor policies of independent trade unions and the abolition of anti-labor legislations, This complemented the policy of "socialization" which is a system of social control in some key sectors (of the economy) without undermining private initiative especially of the "lower-midale" ones, The success of the socialization process has been visible especially at the local level where mayoralities and communities are acquiring more economic and political power (Gianaris, 1984; Spourdalakis, 1988), Finally, the state's role in the process of capital accumulation manifested in its interventional policies which owned and controlled 95 percent of the banking system. To note, the "socialization" policy is different from nationalization in the case of Greece, This policy was formulated to pursue the formation of cooperatives and the management of enterprises by the workers and employees as well as the representatives of local or central governments (Gianaris, 1984)

\section{Implications on Local Government}

A brief comparative analysis between Greece and Turkey reveals the process and differences in terms of local government and management at the local level. Local governments play a role in the implementation of tourism activities, that is, providing services and protection of infrastructure as well as tourist/host interaction. One aspect that exists in the Greek administrative structure is the number of elected members versus appointed, something not found in Turkey second, the 
decentralized administration at the local level, which in Greece is reflected by the number of municipalities, 6,000 , Turkey, on the other hand, has only 1,600, despite the fact that the population difference between Turkey and Greece is one to five (Evangelinides, 1987; Danielson and Keles, 1985): At the same time, Turkey functions with seven regions, while Greece with much smaller area eiicumpasses 13 regions. This division of governmental structure also impacts the tourism sector and its management, For example, while Turkey remains highly centralized (regardless of new development policies), the local government in Greece has a concurrent power that lies with the municipalities and includes tourist development. This practice has yet to be realized by Turkey, and the Bodrum case study proved the lack of power in the municipalities toward tourism.

In terms of the local government's revenue, it can be argued that the political structure is permeating the distribution of revenue sharing. Since the political structures are based on different frameworks (centralized in Turkey, decentralized in Greece), it is likely that in a decentralized system the local government can maneuver for different ways of income (e.g., service charges, fees, payments, reverue from the property of municipal enterprises in case of Greece)! In Furkey, the municipality has no power to tax tourist establishments, which are licensed by the Ministry: Danielson and Keles (1985:84) noted,

Under this revenue system, Turkey's major cities were inexorably pushed to the financial brink as rapid urbanization exhausted the scope and costs of the city public services as well as the expectation of the urbanizing masses 
It is obvious that comparatively speaking, the problem in Turkey's local government is the lack of an adequately elaborated system for allocating state grants to local governments based on principles of equality, efficiency, effectiveness, which are the fundamentals needed to achieve development and promotion:

While the government systems remain to be organized in congruence with tourism development, both financially and authoritatively, the tourism industry itself in the two countries is directed under different policies. Turkey suffers from an absence of policy and a plan with no elaborated model. Greece, on the other hand, is not only managing its tourism which is three times more than Turkey's tourists arrivals (ise., 10 million in 1987 (OECD, 1988)), but it also devises policies for an alternative tourism development. These alternative policies are directed towards underdeveloped regions. The five-year plan for tourism targets will bring money and life into the more remote regions which have suffered a steady population drain. The glan also encourages the development of "agritourism cooperatives" aimed at filtering tourism money more directly into the local communities (International Tourism Reports, 1986)! While Turkey's tourism is shifting towards privatization, there is no policy to allow for the state's takeover of the establishments in case of financial trouble due to fluctuations in tourist arrivals (TB, 1988). Comparatively, Greece has predicted and devised a possible state involvement in the case of defunct businesses through state banks! With respect to investment, the Greek government is less receptive of overseas investment in their tourist industry: 
Policies of this nature indicate a "community development" perspective and an "alternative tourism" which was advocated by Murphy (1985) and Krippendorf (1987)! Respectively, "community development" is used to describe the enhancement of the host population's way of life, economy, and environment, Turkey's tourism, however, is perceived as purely commercial in nature and controlled by narrow interest groups with no guarantee of reinvestment in the local level, one other aspect of Greek tourism is their ability to attract an enormous range of visitors in terms of age, income and the type of holiday desired, This type of policy to attract various incomes and age groups is yet to be developed in Turkey! In fact one of the shortcomings of Turkish tourism is a reluctance to tap varieties of tourists from neighboring countries: According to the ITR $(1986: 47)$ this policy of tourist attracting is uniquely Greek, and has culminated in the "tourism growth in the islands and the variety of products they offer has been of great benefit to the development of the industry:"

Another advantage for Greek tourism is its membership in the EEC which will be boosted by completion of the single (internal market) by December 31, 1992 by signing the Single European Act (Lickorish, $1989: 100)$ :

While the Tuxkish government is giving up the state-owned touxist establishments (despite that successful business), the Greek government is developing a constructive cooperation with local sectors as well as promoting "social tourism" for domestic tourists! In fact the amount of government subsidy for social tourism is clearly indicated in the law! In addition to such policies which reflect the attitude of the political 
system towards the variety of market, Greece has been able to develop a market for Eastern European supply, Promotion of this market will require an educational policy to teach the public to be receptive to visitors from these countries, To summarize, the Greeks are much inclined with tourism as a "long term" prospect when it comes to tourism planning, their policies of promotion of the US market, accommodation based on supply and the visitors' income, encouraging decentralization to enhance regional development and awareness of the "saturation factor" which requires innovative policies to overcome it, overall the tourism industry as any other sector of the economy is subject to political behavior and policies of existing system. According to historical experience, know-how, marketing, and planning strategies, Turkey obviously falls behind her rivals in the Mediterranean.

Transition in Spain

Spain's position and her assessment as one of the "Mediterranean Model" of political development bears the characteristics of transforming to a "party government" after the death of Franco in November 1975; The term "party government" has been employed rightfully to elaborate the liberal democracies of 1970 s in the Mediterranean region: In such systems political parties are the vital linkages or channels of political communication between state and society, In short, they perform two crucial and complementary roles as both institutional (policy-deciding) and socio-political (mobilizing) forces (Pridham, 1984): 
One of the main ingredients of Spain's political structure has been the socialist movements including the Spanish Socialist Workers' Party (PSOE): Its inception in the late nineteenth century as well as its metamorphosis from a far-left (at one point) to a rightward orientation became an essential shift for the victory of the liberal democracy: As Gillespie (1989:300) addressed,

Certainly, the rightward move corresponded to a view broadly held among Spanish democrats that a national across-class compromise was vital in the middle and late 1970s to secure a successful regime transition.

And/or the political foundation for the 1970 s transition to a model of Mediterranean democracy guaranteed through a process which in Medhurst

(1984:33) terms,

a "democratic rupture" whereby the nature of the future political system would be left an open matter to be decided by a freely-elected constituent assembly, presided over by a provisional all party-government that did not guarantee plans to pro-regime forces:

The transition period for Spain came to close with the landslide victory of PSOE during the election of 1982. The political

transformation of Spain had a significant impact on the process of realization of the "party government" system as a means to stabilize the mobilization towards economic development and redistribution. As

Gillespie (1989:42) noted,

Judged by electoral criteria, the Socialist government of 1982-6 was largely a success story ...: Moreover, in terms of building political stability and consolidating the regime that had grown out of the political consensus of the late 1970s, the administration of Felipe Gonzalez also enjoyed considerable success.

The social achievements in the areas of education, health, social security, taxing and redistribution were complemented by national and 
regional policies towards the decentralization and autonomy of various regions: As Gilmore (1985:82) noted,

Decentralization and democracy in Spain became an undeniable reality and necessity. Previous experiments indicated that regions of Catalonia and Basque are two clear examples of unresolved Franco's centralized administration, Therefore, an alternative system was devised.

Technically, in 1983 Spain ended up with 17 autonomous communities! The constitution sets forth that autonomous communities will assume certain areas of responsibility in accordance with their statutes, A detailed policy organization and operation of these autonomous regions encompasses the following areas:

* Territorial, urban development and housing planning:

* Public works of interest to an autonomous community under construction within its territory:

* Railways and highways which begin and end within the boundaries of an autonomous community, and their respective traffic,

* Ports and airports used for recreational and other non-commercial purposes;

* Agriculture and livestock, in accordance with general economic programs:

* Forests and forestry management.

* Environmental protection activities.

* Projects concerning construction, the use of water resources, canals and irrigation systems of interest to an autonomous community; mineral and hot springs,

* Inland fisheries, shellfish farms, hunting and river fishing,

* Trade shows:

* The economic development of autonomous communities within the goals set in national economic policies. 
* Crafts (Tamames, 1986:247-48):

On the international front, the government chose to be in opposition to power blocs and declared its neutralist line, of support for Third World liberation struggles! Spain's membership in NATO became an openly and publicly debated issue, Spain became a member of the EEC in 1985. Today, Spain is Europe's star economic performer, eagerly marching toward 1992, when the Common Market nations' internal trade barriers are to fall (Oregonian, 1989:A12):

\section{Policy Implications}

Unlike France, Italy, Switzerland and Austria, Spain's tourism is a rather new spurt in the nation's socioeconomic arena. The tourism explosion placed the country in first rank in the share of tourism in Europe (ITR, 1988), In 1986 tourism contributed revenues of more than $\$ 12$ billion, Turkey's tourist revenue for the same year was less than \$1 billion (ITR, 1988:5; TUSIAD, 1988:87).

When the Spanish constitution of 1978 established a democratic period, a decentralized and autonomous local government system was realized and implemented (Roca, 1988)! Under the present constitution, the state is comprised of 19 autonomous regions, thereby giving recognition to the right to autonomy of the constituent nationalities and regions:

One of the outcomes of the transition to the "Mediterranean Model," unlike Turkey, was the structural transformation of Spain's centralized system to a semi-federal structure in which the powers of 
the state were shared with numerous newly created autonomous communities, As Donaghy and Newton (1987:98) noted,

a.each endowed with its own president, parliament, executive and high court of justice, In the modern history of Spain there is no precedent for such a major change in the structure of the state nor for such a fundamental shift of power from the center to the periphery:

The power of the local government extends to complete control over local affairs and allocates what funds they feel appropriate to tourism (ITR, 1988): Local government consists of 50 provinces and more than 8,000 municipalities. The general and specific functions of the provinces are, on the one hand, to ensure the full range of municipal services throughout the territory of the province and, on the other hand, to help coordinate local government together with the autonomous regions and states, Further contrast culminates in the regions with self-government! For example, Catalonia has been acknowledged as having a separate identity in the fields of language and culture, as well as self government institutions (Roca, 1988)! Such a decentralized system removes a heavy burden from central government on the one hand, and flourishes various initiatives based on their particular culture and attractions: As elaborated in ITR (1988:5),

Power has been devolved from central government, which means there are 19 local governments exercising varying degrees of power running the autonomous communities: The areas themselves have their own histories, languages or dialects, distinctive food and wine, and are at different stages of development,

Spain's decentralization policies which were also implemented in the tourism sector are supported by such perspectives as "decentralization and development," which in Allen's terms (1987:23), 
centralized planning, where it is apt to have a pronounced urban bias; that is to say, it usually favors large-scale industrial and infrastructural projects and these tend to be all distributed both socially and geographically within the nation:

He continues:

Territorial decentralization can alleviate all these defects, spreading investment widely, improving field conditions, making plans more sensitive to popular demands and needs and encouraging the integration of the activities of central departments in mutually supportive approaches to local problems:

In Turkey similar innovations to develop a variety of cultures and customs (e.g!, Kurds of Southeast and Black Sea area's cultures) have been ignored or totally dismissed, Such a policy in Turkey has resulted in limited tourism attractions ( $i_{i ̣, ~}$, cultural tourism) and the resentment of the nationalities themselves:

Another aspect of Spain's tourism is the strong support for domestic tourism which runs parallel with international tourism, Domestic tourism in Turkey has not been given any attention, albeit a strong market exists

One other area in which Spain differs from Turkey is in the devotion of government to promotion and marketing as well as research, While Turkey's marketing strategy suffers from traditional monolithic tactics, Spain is vigorously targeting new markets and researching for alternatives, besides sun, sea and sand, While Turkey has no promotional strategy to tap the Middle Eastern market, Spain has devised marketing strategies including: Libra--Spain's national airline; paradores--inns and shopping places; hosterias-- hotels and restaurants controlled by the state; and Amigo 2000--holiday and guide 
organizations: The state's involvement in hosterias are also directed toward the historical values of these entertaining centers with high standard accommodation facilities (ITR, 1988):

One shortcoming of Spain's government has been the negligence of planning enforcement for tourism development in some areas: As ITR(1988:11-12) reported,

Neither planning policies in general nor building regulations have always been adhered to. By the mid-1980s, it was becoming increasingly clear that the lack of control had not only led to a poor distribution of tourist income but was allowing the destruction of the attractiveness of the environment and also of existing tourist development which were threatened by overcrowding in some cases and generally poor management of the environment.

While the circumstances and tourism experience of Spain are revealing the need for tighter control, Turkey is trying to deregulate its tourism, particularly in the tourist centers of the southwest where transnationals are heavily involved.

To summarize, Turkey's tourism in comparison to Greece, Spain, and even Yugoslavia lags behind not only in terms of its share of the market, but also structurally insomuch as the tourism sector has been negatively affected by the lack of planning, and policy issues that do not promote local involvement and real economic benefit (Weber, 1989:156): As noted by clements (1989:94),

Tourism has yet to be seen in terms of long term investment planning $4:$ The country is so far behind its Mediterranean neighbors in its earnings from tourism that it is only to be expected that it feels it must move fast.

Thus one can further argue that Spain and Greece with their socioeconomic structure and much more enhanced political democracy allowed for flourishing of two vital policy mechanisms in tourism 
development, First, "decentralization" which is compatible with the political conditions in Greece and Spain and so attributable to the shift of emphasis to growth with the equity policies adopted by both countries after arrival of social-democrats to power during the 1970s (Cheema and Rondinelli, 1983): Second, while the regime in Turkey renounced authoritarianism ( $i_{\Perp} e_{\sharp}$, except for late 1960s and early 1970s) it allowed for what is known as bureaucratic retention which is responsive to the regime itself in a closed political environment (Cleaves, 1980, Grindle, 1980):

\section{Conclusion: A Synthesis}

The prospects for tourism, notwithstanding its infancy (in Turkey's case), cannot be separated from those variables that are actively affecting its process of evolution as well as its development, Turkey in comparison to Greece and Spain fails to capture the substantial market share despite its fashionability as a new destination, comparable resources and geographical positions The crux of the matter is to understand the relationship between the state's role in the development of tourism and the mechanisms of the state's policies towards a sustainable tourism development, This comparative analysis, then begins with a political question, whether or not the state has the mechanisms to direct the tourism sector, knowing that "tourism" as a sector falls within the national development policy:

In the case of Greece and Spain, notwithstanding their long history of tourism, the striking difference is the policies of the state towards development. This condition can be delineated in terms of the 
national, regional, and local policies of the governments in question, and/or through the decentralization efforts that was shown in these two cases:

Whereas, the cohesive "party governments" were developed in the cases of Spain and Greece, a policy crisis was embedded within the Turkish polity: This situation crystallized into the cumbersome task of integrating the military, civil society, and the political parties toward the common goal of development: As Heper (1990:325) succinctly elaborated:

The most recent "re-equilibrating" of democracy through the 1982 constitution was made accordingly! This constitution did not locate the state in the civil bureaucratic agencies as did the 1961 constitution. The powers of the higher tribunals and the autonomy of the universities were curbed. The president, directly and through the National security Council, and the military, indirectly, became the joint guardians of the state. However, neither was expected to exercise tutelle powers over "politics" in terms of an official ideology:

Thus, neither politically nor economicwise could Turkey achieve a clear strategy for a prospective political economy: Turkey does not qualify to be one of the Mediterranean Models of democracy, nor can she match her comparable counterpart within the NICs--Korea (Krueger, 1986; Pridham, 1984):

The implication of such an undefined political economy on tourism is yet to be felt. It is likely that the tourism sector will be a new victim of the situation as Krueger described

Turkey's economic difficulties were clearly apparent to all observers in 1957 to 1969, and by 1976. Yet in each instance, the fact that the economy was inner-oriented permitted policy makers to persist in "patch-up" efforts rather than to address their fundamental problems (1986:43): 
Thereof, tourism has yet to have a national policy, and the "patch-up" approach is still persist, Whereas in Korea's case Krueger (1986:43) noted

Policymakers' willingness to confront their problems and to recognize difficulties early, which, on one hand, led to the decision for an outer-oriented trade strategy, and on the other hand, led them to address perceived difficulties more quickly, and perhaps more importantly more fundamentally, than did Turkish policymakers:

Finally, the comparative analysis reveals the major shortcoming of the "state" in the area of decentralization and regional policies: In the case of Greece and Spain, their democratic models makes devolution rather persuasive: The Korean case presents a cohesive centralization in concomitant to the state interests approach $\left(i_{q} e_{4}\right.$, autonomy in defining the nature of public problems and developing solutions to them): Turkey's case represents a policy crisis in terms of decentralization, and the quality crisis in terms of economic interventionism, As Milor (1990:2) noted, "by term 'quality' we mean both the institutional coherence and coordination among various state organizations, and the selectivity of intervention in terms of strategic sectors and industries,"

This situation can be best described as a confusion of policymakers whether or not the issue of decentralization has been distinguished as a crisis-ridden or politics-as-usual reforms: The state of such confusion in policy production elaborated by Heper (1990:329) as he noted,

In the second part of the decade some of the powers devolved to the metropolitan municipality itself began to be taken back by central government. For example, in 1987 limitations were imposed on the borrowing powers of the 
municipalities, In the same year the government expanded the scope of the administrative tutelage of the Ministry of Publics Works and Resettlement over metropolitan municipalities,

Heper continued that the Ministry went further and took over the matters of city planning, revise and endorse plans as far as master plans. 
CHAPTER VII

ANALYSIS AND CONCLUSIONS

The main objective of this study has been an evaluation and analysis of the development process of the tourism industry in Turkey: Essentially the development of a multifaceted sector like tourism, requires a multidisciplinary approach, Tourism is an interdependently organized industry with numerous institutionalized interconnections

The basic approach of this study was a "political economy" approach, This type of approach can provide more insight in analyzing the political, social, and economical dimensions as well as enabling the achievement of an historical analysis and avoiding an ethnocentric approach, Special value can be given to the political economy approach because the role of the state (as an architect of political structure) is intertwined with international and local capital in the process of capital accumulation within the context of a certain economic strategy. The picture gets clearer as Evens (1979:72) point out,

The historical process of capitalist development occurs in a dependent country in accordance with the interaction of its internal political and economic alliances with international capitalism! This process is bound to be divergent across time and space:

Moreover, this approach is the most powerful tool to appraise and investigate a "development" process which by definition should be responsive to four fundamental demands of the Third World countries in general and Turkey in particular. Those demands are: national 
independence, social justice, democracy, and development (Amirahmadi, 1989) :

Also significant to the study has been the examination and exploration of the government's ideology and understanding in perceiving the "tourism sector," one of the natural resources of the country: The government's policy towards utilizing the tourism industry is twofold: First, how to organize and operate such a sector to maximize its profitability: This can be done by tourist business experts a second, what type of policy should be devised, and/or what form of planning is needed to utilize the tourism sector in order to make it a factor that contributes to the goals of development, The primary emphasis of this study has been on the latter factor: In order to achieve the developmental goals, the government operates and organizes various sectors (including tourism) based on policies that are conducive for capital accumulation! These strategies are also in consonance with the country's role in the international division of labor:

In other words, the government or state plays a definite role in how to formulate policies towards a sector, in this case tourism, in order to exploit the resources or the national development, A major goal of this study was to also explore the other parties who were collaborating with the state, as well as identifying the strategies that were adopted in order to reach the chosen objectives! It is after this process that one can find out if the utilization of the tourism sector is contributing to the development objectives or to those parties' particular investment goals: Whether or not those peculiar development objectives are of national interest in order to reach national 
independence, social justice, democracy, and development depends on the policies under the particular economic strategy: Therefore, the "tourism industry" is a neutral productive sector, but is subject to development strategies that various national and international interest groups have stakes in. For example, the question can be raised as to why tourism as a sector was ignored by the Turkish government until the 1980s? While the agricultural sector, on the other hand, was subject to various structural manipulations especially after the Second World War: And is tourism a proper resource for exploitation under the export-oriented model? Notwithstanding these two sectors divergent roles in the economy, the questions still remain valid, Also, in order to avoid generalization, I have paid a certain amount of attention to the nature of the tourism industry as opposed to other sectors such as the mining industry, Although, both industries can be classified as national assets of the country, their utilization can have different implications. For example, tourism requires and involves extreme environmental caution and population movement. Tourism's role in the movement of the population which is tantamount to the intensification of new businesses and activities has already contributed to the overurbanization of the western region. While overurbanization has its own bottlenecks, it is tourism which must be carefully dealt within already unequally developed regions, Turkish tourism was not realized as an economic agent for development until the 1960s, however it did not develop despite the existence of natural and spatial potentials; As Uysal (1983:15) point out, 
until recently tourism has played a minor role in the rapid expansion of Turkey's economy a. In 1971, Turkey received only about one percent of total tourists who visited the Mediterranean basin.!: By 1978 Turkey received around 1,7 million tourists,

which was minimal in comparison to Greece, Yugoslavia and Cyprus, However, Turkey's receipts from tourism as percentage of exports of merchandise remained as low as 4.5 by late 1970s, whereas this figure for the neighboring countries of Greece, Yugoslavia, and Cyprus was recorded at $24.5,14,9$ and 16.6 respectively (Diamond, 1977:542): Moreover, the tourism account showed a deficit of $\$ 64$ million in 1977 (Uysal, 1983): To note, tourism suffered from lack of a dynamic structure, and was not elevated to a ministerial position as an institutionalized economic sector until 1982,

The state's lack of commitment was also reflected in the allotment to tourism investment during the first two FYDPs (1963-1972): As Diamond reported, the impact of the investment at the aggregate level appeared meager, therefore the contribution of tourism to the national income of $\$ 1,2$ billion amounted to only $\$ 30$ million, This was 4,3 percent of total export value of $\$ 496,3$ million in 1970 , Whereas the same figure for Greece and Yugoslavia was 13 percent and 10 percent respectively (Diamond, 1977:541):

The inattention to tourism industry was also reflected in its low contribution to employment, despite the labor intensiveness of the industry: As a result tourism employed only 34,000 people during the year 1966, which registered a nonagricultural work force of 3.8 million: While some Third World countries (e.g., Kenya, Tunisia, Morocco, Thailand) have translated tourism to economic success, tourism in Turkey 
with all its potentials has remained unutilized (Diamond, 1977): Nonetheless, even though tourism showed some growth during the 1970 s (12.58 growth), it fell behind the envisaged target of 25 percent (World Bank, 1975),

\section{ETATIST ERA AND DEVELOPMENT POLICIES}

To understand the inattention to tourism development prior to the 1980s requires an examination of the etatist era under "Kamilist" ideology for economic development and industrialization: This era carried on until the development of the multiparty system of post-World War II! Etatism as an economic development strategy was armed with nationalism based on ISI in an inward-looking framework: Socioculturally, "Kamalism" favored the return to the original Turkish culture and purification of the Turkish way of life with leniency towards Western-style industrialization, However, Turkey as an Islamic nation kept secularism as a fundamental policy, this process was underway in juxtaposition to the "great war of independence" which left the country in an economic depression, and struggling to keep the remaining Ottoman Empire consolidated into one nation-state! Therefore, until the late 1930s the unstable political condition and the years of depression did not allow the flourishment of a sector for which a stable political situation was a must; In addition, etatism as a closed economic system was not conducive to investing and capitalizing on a sector such as tourism, As a result, cultural, political, and economic factors were strongly deterrent to an open-door tourism policy: 
With the shift from a monoparty to a multiparty system during the 1940 s and 1950s (ISI still intact), the political and economic environment changed: The new economic policy of liberalization allowed new class conflicts and interests to appear. In fact, post-World War II began with a new internal class structure and cleavages which initiated a unique process in Turkey's political economy: This was subject to political economists or developmentalist discourse in refuting the application of "dependencia" to Turkish case. Turkey did not abandon her policy of ISI after World war II even though the new class structure and interest groups were not necessarily adhering to etatism. With the departure from etatism and the post-war development of Europe, Turkey was placed on a new course within the international division of labor (Keydex, 1987; Ramazanoglu, 1985; Walstadt, 1980):

However, during the post-World War II era, Turkey's role remained as a bread basket for Europe with an unstable political future, Politically, class conflict and contradiction resulted in consecutive military coups. The military's role as a strong body of state was funded by Ataturk himself: These unstable political conditions were deterrents to tourism, The economic situation was manifested in crisis after crisis: Aid and loan factors not only could not alleviate the problem, but further aggravated the situation, With Turkey's cyclical economic booms and busts, devising a dynamic tourist structure became impossible, Despite the establishment of the SPO in the 1960s--to guide economic development--"planning" itself was in crisis, This situation 
was founded upon a structure of conflict within the various classes including state; As Milor (1990:4) referred,

athe establishment of planning in Turkey can be conceptualized, ,of "Bonapartism" as a basis of increasing state autonomy: This is because in the Bonapartist model, a reformist group of state officials is prepelled into a leading and relatively autonomous position in the state by stalemate within the ranks of dominant economic forces combined with the inability of subordinate classes to influence the course of events via collective action:

Finally, Turkey's strategy of ISI could never completely detach from the etatist legacy: The state as the main locomotive for development was crystallized in a military-bureaucratic complex which at the beginning of the industrialization saw itself as the only engine to drive for economic development: Second, the state's intervention in the process of industrialization did not leave any room for the private sector to engage in merger and risky ventures: This was further aggravated and blurred by crisis and conflictive class cleavages between agriculturalists and merchants: Keyder (1986b) eloquently investigated the "missing link of bourgeoisie" in the Turkish development process and revealed that until recently an industrialist class of the private sector has been missing from Turkey's environment, Until the 1980s, tourism activity was limited to state-owned operations known as TURBAN With the shift in policy from ISI to the state's new role in XOG, tourism has finally been realized for investment by the private sector: In addition, the private sector's involvement as a partner in the triple alliance is conducive to XOG strategY: 
EXPORT-ORIENTED GROWTH AND TOURISM SECTOR

With the shift to XOG strategy in the 1980 , tourism has received particular attention as a dynamic sector: The boost in tourism was caused not only by the internal policy shift, but also by a change in tourism fashion. More Europeans were drawn toward Turkish beaches, as the last stop for Mediterranean tourist flow: This has been also a trend in other NICs which have emphasized their tourism industry not only for its economics but also as a political means to exhibit the success stories of XOGs in the international context of capitalist development (Amirahmadi, 1989; Richter, 1989): The outward-looking development policies in the fairly stable political situation of the 1980 s had an inducing impact on tourism.

To note, tourism was also seen as an alternative for foreign exchange earnings which was traditionally the task of workers abroad in the form of "workers' remittances!" The second generation of Turkish workers in Europe are stabilizing themselves in Europe, and will save rather than transfer their earnings to Turkey: Therefore, tourism in an open-door economic model and in absence of continued incoming foreign currency from workers' remittances becomes lucrative in bailing out the shattered economy: Tourism is also useful to repaint a new stable political image abroad in order to attract foreign investors and multinationals to its free production zones: Tourism then was seen not only as a source of foreign exchange earnings for a desperate balance of payments, but also to serve as an advertising means for the regime to regain legitimate respect in the west, in the struggle to join the EEC. 
Not to mention the restricted industrial base and the employment problems:

With the election of November 6,1983 , following the military coup of September 1980, a radical restructuring of Turkey's traditional mixed economy was occurring (Schick and Tonak, 1987): The tourism sector was beginning to attract entrepreneurs from both domestic and foreign sources: The tourist flow to Turkey especially after 1983 increased by 75 percent in foreign arrivals and caught the government by surprise: The MCT, the major tourism institution, did not have a tourism policy guideline until October of 1988, Tourism was opened to the private sector and domestic entrepreneurs for investment under the "Free Trade Zone" policy, a legitimate ingredient of xOG not only in Turkey but in all the NICs or semiperipheries (Frank, 1981; Lim, 1985):

\section{POLICY AND PLANNING DILEMMAS IN TOURISM}

The new shift toward XOG has permitted the involvement of multinationals in tourism, however, the government has failed to come up with any guidelines to protect and manage this multifaceted industry. This occurred because of the lack of recognition and understanding of this sector which is comprised of an eclectic set of industries! In general terms, its basic components are markets; attractions; accommodations; restaurants and retail services; transportation; and information and promotion (Ankomah and Crompton, 1990): These components are interdependent and their successful operation in the context of one sector is the key to the industry's long-term development. This requires a strong institutional framework for tourism 
planning: The crisis in Turkish tourism is due to the weakness of the existing institutions that are responsible for tourism planning, They suffer from what Gunn (1988:24) elaborated as, "conventional planning (i,e , Turkey's case) has too often been oriented only to a plan, too vague and all-encompassing, reactive, sporadic, divorced from budgets and extraneous data producing," At the same time the policy makers fail to recognize the nature of this sector! Again as Gunn continued,

But organizations, governments, and all sectors involved in tourism are not recognizing how interdependent are all the separate entities and fragments that make up the whole. Tourism markets and supply are more widely scattered across the earth than for any other economic activity. It is at the interface of the many parts that many problems arise, requiring a more complex but a more broad-scale planning horizon than has been practiced in the past.

The situation has become so critical that Diamond's (1977)

disappointment with the planning, policy, and management of the sector raised harsh criticism from those who saw tourism development as an eyesore rather than a productive national resource (Cetin, 1988; Hamitogullari, 1970):

"Public policy and tourism" at the present time (i.e., with XOG policies) not only has been impaired, but rather has become more ambiguous where the market forces and privatization is cutting through some governmental control which was essential for this sector: However, policy is a complex, dynamic, ambiguous phenomenon, with inputs at a number of different levels: As Greenwood et al. (1990:54) described:

It contains issues of the relationship between economic power and political power, sat the middle-range level, organizational inputs in policy formulation are important, with a focus on negotiation and bargaining over policy 
issues; and at a micro-level, individual policy detail such as objectives receive attention, The implementation of policy involves interaction between all three levels:

One can add various individuals and agencies to those levels including local level authorities as well as conservationists! It is not unusual to see conflictive objectives between those who seek economic profit and those who struggle for conservation. In fact the policy formulation process becomes more complicated in the tourism sector because of the presence of the "tourist" element, Any policy, without considering this element will fall short of a "perfect implementation" process!

To sumnarize, the policy-making process for tourism in Turkey's case fails to distinguish between various levels and their inputs. Indeed, the analysis of and for a tourism policy has fallen short of understanding both the nature of visitor behavior which demands a policy, and the contingencies of the street-level operators of tourism and the owners/managers of tourist establishments (Lipsky, 1980): The tourism industry has been choked by a system of "top-down" perspectives of implementation. This was a legacy of a centralized system akin to other Third World regimes which were reinforced by 1950 s development theorists that were housed in the international development agencies:

What is needed is a new approach or in Elmore's (1987) terms, "backward mapping:" In this case, instead of focusing at the top level of policy formulation, backward mapping starts with the problem which demands a policy and works backwards through each implementing level, assessing the behavior and reactions of implementors and highlighting 
the importancs of discretion and bargaining in the policy process: The approach rejects a distinction between policy "formulation" and "implementation," recognizing that policy is made as it is implemented (Greenwood et al:, 1990:55) : On the "planning" side, the absence of a national tourism policy confined the industry to a planning framework characterized as "physical planning" (Atac-Rosch, 1984): This lack of policy has eliminated the applications of various "planning methods" essential to tourism development. Atac-Rosch (1984) in her investigation provided an eloquent methodology by advocating that

tourism planning should be a coordinated effort of many
different theories of planning put into practice, namely,
traditional-comprehensive planning, policy planning,
advocacy planning, transactive planning, and strategic
planning.
Not to mention recent paradigms which emphasize territorial planning or planning from below as alternative tools (Freidmann and Weaver, 1979), What is needed is tourism planning that is action orienteo, focused, explicit in mission, proactive, continuing, integrative, and values intuition and judgment. These qualities are particularly important for tourism because it is far more complicated an econoric, social and environmental activity than most (Gunn, 1988): To note, the state's role under the new economic regime has remained ambiguous in relation to the tourism industry. Where the state is finding a distinct position, as a part of triple alliance, privatization of state-owned tourist establishments have minimized the control process! This situation of leaving "tourism" to the private 
sector has already caused distortion in the outcomes of policy implementations--especially at lower levels in the policy chain?

Effective state intervention is now assumed to be an integral part of successful capitalist development (Evans et alı, 1985), However, the Turkish state is withdrawing from the tourism sector, selling TURBAN enterprises to the private sector and transforming the TB! In fact, the state's withdrawal from the tourism sector, and its takeover by the private sector and foreign investors contradicts what Rueschemeyer and Evans (1985:44) reiterated,

Insofar as economic transformation involves the institutionalization of market exchange or its extension to land and labor, even the narrowest neoclassical model has space for the state, As Durkheim argued so effectively in his polemics against utilitarianism, the market requires a strong set of normative underpinnings in order to function at all, Without effective institutionalized guarantees of these normative underpinnings, "transaction costs" will be exorbitant and the market will not allocate resources efficiently: Turkey's tourism will be likely to remain at the mercy of private sector (local capitalists) and MNCs (in the free production zones) under the XOG:

With an examination of the tourism sector and the state's role in tourism, the picture becomes clearer in terms of the evolution of the state

The state began with "etatism which was a worldwide phenomena as a strategy for industrialization where the private sector (entrepreneurial) was not allowed to play an active role in development: This coincided with the inactivity in the tourism sector: However, now that the state is withdrawing from the tourism sector (with the policy 
shift), the question remains whether the private sector will be able to develop tourism, In Turkey's case, the answer to this question cannot be an unconditional "yes!"

Not only that, but also the withdrawal of the state from the tourism sector defies the NIC's development path in which the state played a decisive role in their economic miraclest Thus, the policy crisis in tourism can be inferred from a broader and deeper disarray among policy makers, As Krueger (1987:43) noted,

The fact that the economy was inner-oriented permitted policy makers to persist in "patch-up" efforts rather than to address their fundamental problems, In one sense, the outer-orientation of the Korean trade regime must be given the fundamental credit for the more satisfactory Korean performance than the Turkish, At a deeper level, however, it might be argued that it was the Korean policymakers' willingness to confront their problems and to recognize difficulties early which, on one hand, led to the decision for an outer-oriented trade strategy, and on the other hand, led them to address perceived difficulties more quickly, and perhaps more importantly more fundamentally, than did the Turkish policymakers:

\section{CONCEPTUALIZING TURKEY'S CASE}

In conceptualizing Turkey's development process, I adhere to what

Amirahmade (1989:167) elaborated:

By development theory I mean a system of concepts that helps explain the causal-consequential relations within and among social phenomena and the laws/tendencies that govern their quantitative and qualitative development and decline. Development strategy, on the other hand, is the science of determining at each stage of development the most important tasks to be implemented, the type and amount of resources needed, and the location of development. It thus belongs to the realm of practice and involves setting priorities, making plans, and formulating policies, Development strategy, however, depends on development theory for concrete analysis of the situation to be transformed and for formulation of specific goals, objectives, and targets? 
Crisis of the one is thus crisis of the other, and this connection allows me to use them interchangeably,

With emphasis on such complexity in mind, a significant paradigmatic analysis has been involved in the Third world development process in general and Turkey in particular. Dependency theory has been employed by various Turkish scholars as the key concept in expiaining the mechanism of underdevelopment in Turkey:

However, Turkey is a unique case as compared to Latin America, and its historical process of development and underdevelopment has brought a new perspective that is critical of the "dependency" explanation for Turkey's case, The criticism of dependency has not been limited to Turkish scholars because Frank (1972), himself a founder of the theory, admits to the importance of the internal political and economic alliances in the core-periphery relationships:

What "dependencia" fails to recognize is the lack of emphasis on each country's uniqueness and the ways in which underdeveloped economies or societies have differed from each other, As Ramazanoglu (1985:16) eloquently phrased: "Theories of dependency are primarily ways of accounting for a common process of underdevelopment in which exploitation within the world system of capitalism leads to typical internal patterns of economics in the Third World:" He also criticizes the rigidity of dependencia in that development is never possible once the typical features of peripheral capitalism have developed, since further development can only be the development of underdevelopment 
Therefore, dependencia fails to explain the NICs' transition from "periphery" to "semi-periphery" which is mediating between the core and the periphery (Smith, 1989; Evans, 1979)! Moreover, where the dependencia effectively exposes the modernizationists for their lack of historical analysis of the world system and interrelationships among various players (internal and external), it is seriously flawed by a number of unwarranted assumptions, Namely, its universal application to Third World analysis and the emphasis on the system of exchange rather than interrelated systems of production, circulation, distribution and exchange: From those two assumptions one can reach the logical conclusion that contradictions of the development of capitalism lie within the international system of exchange relations rather than in the production systems of different social formations: Consequently, Ramazanoglu (1985:18) pointed out that "this view, incidentally, makes it quite impossible to understand recent Turkish history, the tremendous struggle within the Turkish bourgeoisie to gain control of the state and the 1980 coups"

To note, Turkey's case albeit her relative backwardness has a unique character: It had a similar per capita GNP as Algeria and Mexico in 1977, and it has been relatively advanced politically: Despite military interventions, it has known a two-party system in which opposing leaders have changed offices a number of times after a popular mandate, something which has never happened, for instance in Japan (Samim, 1987:172): Therefore, an alternative perspective to dependencia would most likely be able to explain Turkey's case. 
Confusion exists among various political factions from the "left" spectrum in terms of how to analyze the position of Turkey within the international division of labor: In general, the failure has been to recognize that the Ataturk's nationalism was rooted in the inherited pre-World War I Ottoman tradition. As a "Turkified" extension of the state-organized Ottoman enlightenment, Kamal's independence movement fought against British and French imperialism (Samim, 1987), In addition, Turkey's left has failed to recognize that Ataturk's nationalism implemented a combination of radical-progressive policies from above (Samim, 1987): They also failed to recognize the class character of the state which adopted immense social changes across a huge and complex land. As Samim (1987:151) reiterated:

With deep structures of both Western and Eastern origin, Turkey is reducible to neither: Ataturk represented one moment of this combination, when Turkey became a modern nation-state, albeit one without a critical element of popular participation. That paradox--which distinguishes his nationalism from almost all others--is perhaps the key to understanding Turkish developments today,

\section{DEPENDENT DEVELOPMENT: AN ALTERNATIVE PARADIGM}

Turkey's classification as a semi-periphery (NIC) qualifies her to be better understood through the "dependent development model" in the context of the world capitalist system (Weiss, 1988): The model has been applied to analyze comparatively similar processes in other NICs, namely Brazil, South Korea, and Taiwan, In these countries the elements of state and local capitalists have played a determining role in their so-called "development miracles" (Cho, 1985; Smith, 1987, 1989; Frank, 1981; Evans, 1975, 1979; Evans et al», 1985): 
By and large, the "dependent development" model stresses the method of analysis which places the concept of "dependency" in a wide range of disparate situations (Iim, 1985). As Evans (1979:27) alludes to the concept of "dependency,"

It should not refer to any fixed relations by which a country is economically dependent upon the world capitalist system. The concept of dependency means rather that the historical process of capitalist development occurs in a dependent country in accordance with the interaction of its internal political and economic alliances with international capitalism:

The "international capitalist system" should not be perceived as a monolithic formation, As Ramazanoglu (1987:29-30) noted, "When we talk of the world capitalist system we are referring to the social, political and economic activities of a multiplicity of social formations which differ from each other in a multiplicity of ways $"$

The model of dependent development and the birth of semiperipheries are examples of a range of different singular structures within the world system! There are many contradictions between, for example, OPEC and the core nations which indicate both the vulnerability of the world system and show that access to decision-making can be achieved by using economic means to achieve political ends The term semi-peripheries refers to a third category of developing nations that have achieved a certain level of development different from peripheries, A semi-peripheral state (Wallerstein, 1982:93).

appears to be a state which has a roughly even balance of core-like and peripheral-like activity:4the model of semiperipheral state is the one that exports the peripheral products to core countries and core products to peripheral areas of the world system and does both in roughly

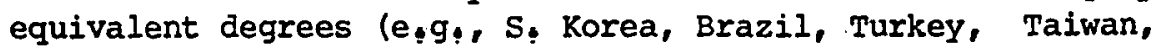
etcol: 
In this model three elements are involved to achieve capital accumulation: state, local capitalists, and MNCs, This is quite different from what dependencia pictured about "state" in the periphery. As $\operatorname{Lim}(1985: 23)$ noted:

The state acts as a central agent of capital accumulation,
The earlier dependency perspective portrayed the state as
being weak, since it reduced the state's action to economic
determinism, But in the semiperiphery, the state is strong
enough to deal with multinationals and local capitalists
alike, Usually growing out of a military coup, dhe strong
state tries to legitimize its authority by achieving rapid
industrialization, It induces the participation of both
MNCs and local capitalists in capital accumulation, It is
thus frequently caught between the opposing interests of
MNCs and local capitalists in the process of capital
accumulation.

Thus it is this model that enables an understanding to be made of Turkey's development process and the players involved. The state's role in this process has proven to be detrimental not only in creating redistributive policies, but also in determining the future of various sectors $\left(e_{!} g_{!}\right.$, tourism)

"Dependent development" is a paradigm in the continuation of a much broader process in theorizing the "development" of the Third World; It tries to explain the situation of a handful of Third World countries with their economic strategy known as XOG or outward-looking economy in contrast to early post-war ISI strategies,

To note, the crisis of Third World development has yet to come to an end even with new shifts in paradigms and the few isolated cases of economic growth. As Amirahmade (1989:173) noted,

By the 19th century all three approaches had become normal sciences, first populism, then its negation, the growth model, and then the negation of its negation, the growth with equity approach :- Consequently the cyclic return to 
and simultaneous resurgence of the old development paradigms have become inevitable since the turn of this century At present all three approaches are in a deadlock crisis!t!: Transition to a new paradigm of development seems inevitable, a paradigm that would be responsive to the four fundamental demands of the present capitalist Third world: national independence, social justice, democracy, and development:

Nevertheless, the model of "dependent development" seems to be the latest trajectory based on an outward-looking economic strategy to come to the salvation of the Third World crisis.

Dependent development of the so-called semiperipheries to some extent has shattered the rigidity of the "dependentistas" belief that development is never possible once the typical features of peripheral capitalism have developed, since further development can only be the development of underdevelopment (Ramazanoglu, 1985), In fact, such arguments have impacted on the "dependencia" paradigm to adopt a more flexible position, as the diversification of capitalist centers among the US, Germany, Japan, and other powers prevents international capital from enjoying full monopoly interests in the LDCs, Finally, this type of international environment permits a great deal of bargaining power for the states:

THE MECHANISMS OF DEPENDENT DEVELOPMENT: IMPLICATIONS FOR THE TOURISM SECTOR

Export promotion seems to be replacing import substitution as the dominant development policy in Third world manufacturing, This exportled growth policy is in line with the emerging international division of labor through which capital in the west seeks to reduce labor costs of production by shifting some industrial processes to the East and South? 
Many labor intensive industries including textile, garments, footwear, and electronics manufacturing are now in crisis. Former leading industries like automotive, steel, and petrochemical industries are being increasingly located in the Third World, with much of their production destined for export to the world market (Frank, 1981:96) ? For example, in Turkey's case, most investment permits are issued to US firms, followed by Britain, Switzerland and West Germany: Recent us investors include $E_{4} I$, du Pont de Nemour, which is developing an industrial nylon plant, and Levi Strauss, which will soon be making 500,000 pairs of jeans a year (Wenger, 1989:25):

As stated earlier the basic pillars of the "Dependent Development" model based on XOG are the triple alliance of the state, multinationals, and local capitalists: Their relationships are characterized by both cooperation and conflict, as each pursued different objectives and has different leverages: The early adopters of this "model" were South Korea, Taiwan, and the city-states of Hong Kong and Singapore in the 1960s (Frank, 1981), on the changing role of the state in Korea, Lim (1985:66) noted, 1.it was prefaced by the military coup of 1961 las it did in Turkey in 1980!, which toppled the constitutionally established civilian government of Chang, The militaryturned civilian regime later provided the setting for "dependent development" " This was also characteristic of the evolving phases of dependent development in Brazil and Taiwan:

To note, the military has played a significant role in the process of dependent development, as Lim (1985:67) elaborated, 
A military regime can be said to have many advantages in initiating development, First of all, [a] military regime is a strong position to extract resources and mobilize manpower effectively a.: Next, a military regime can put [the] command of the state apparatus,, in its own hands, for it has greater autonomy from the various dominant elites: In short, while the military is the central part of the state apparatus, it is a microcosm of the state in terms of planning, organization, and management.

However, the military's role in enticing development is not very

well founded. The military's involvement in the process of creating new strategies for development is crucial, some explanations can be applied. As Huntington (1968:192-263) inferred,

The military tends to foster either a progressive or a reactionary change depending on the particular stages of development in a Third World nation, When the middle class begins to challenge the traditional landed oligarchy, the military plays a progressive role in the quest for a new socio-political system in the form of a "breakthrough coup." But when the lower class begins to organize against the established class structure, the military plays a reactionary role in defense of the existing socio-political system in the form of a "veto coup."

At any rate, the role of the state in the recent spurt of development in the NICs has put forward new challenges to the old paradigms in determining the state's role, In Taiwan's case, wrote Amsden (1985:84):

Yet from the beginning of its reign, the Guomindang bureaucracy embarked on a set of policies that, though they appear to have been chosen for political as much as, or more than, for economic reasons, were crucial to the Island's eventual economic growth. Nowhere is this more evident than in agriculture

Furthermore, in recent years, Marxist-oriented scholars have raised the notion that state has "relative autonomy" from a social base in the dominant class. Rejecting both liberal pluralism and Marxist reductionism, they consider that the state has some degree of 
independence from the dominant class and even carries out certain reforms in favor of subordinate class ( $\mathrm{Lim}, 1985$ ):

In Turkey's case the state has never been exclusively a classical administrative bureaucracy: With the formation of the State Economic Enterprises during the 1930s, it established itself as what Amin (1976:346) called "state bourgeoisie:" Another important tier in the dependent development is characterized by local capitalists whose role in the process of dependent development has acquired a new position, However, the state's new role overshadows that of the local capitalists: Therefore, in the model of "dependent development," the local capitalists are clearly disadvantaged relative to multinationals in their maneuvering: Dependent industrialization leaves the local capitalists with no opening for economic hegemony: It is this lack of hegemonic class position or in Evans's terms (1979:39) "because of their shallow position in the domestic economy, they are supposed to survive by depending on their ability to make alliances with the state managers " In this regard the Generals' miracle in the 1980 s coup in Turkey, much like the ones that occurred in Brazil and Korea in the 1960s, has become an authoritarian model as a solution for stagnation. However, this "means" of escaping from stagnation has made exclusion worse, The new state makes repression easier, but the alliance on which it rests requires a complicated balance that leaves no room for redistributive policies (Evans, 1975:132)!

In fact the policy outcomes are not far from "contradictions," since "exclusion" is the price to be paid for removing the "stagnation," The repressive nature of newly industrialized nations, namely South 
Korea, Turkey and Taiwan, have been utilized to keep a lid on those

"contradictions" (Keyder, 1987; Amirahmadi, 1989; Frank, 1981):

The third tier in the dependent development is occupied by the

multinationals, Multinationals play a peculiar role in the process of

"dependent development 4 They are active in generating economic growth

and industrialization but are "central agents" in the process of

accumulation (Evans, 1975:126):

As Evans asserted:

Multinationals keep their headquarters in the United States, Japan or Europe, make strategic decisions at home, and send out large portions of their managers from their countries of origin, Nonetheless, these corporations depend on the combination of their operations all over the world for their profits! They have inserted themselves directly into the economics of most nations, center and periphery, and it is in this sense that they are multinationals (1975:126).

To note, in the late 1960 s MNCs accounted for some 30 percent of

the Third World countries' manufacturing exports, ranging from about ten percent in India and Pakistan to 50 percent in Singapore (Frank, 1981:99-100), MNCs involvement in the process of dependent development take place via controlled buying organizations and the provision of Free Trade zones in the host countries: The state's invitation of MNCs takes the form of using them as mediating agents of technology transfers for the purpose of reinforcing export promotion of manufactured goods! Thus MNCs participation takes the form of export-market-oriented vertical investment rather than of domestic-market-oriented horizontal investment. The difference between these two forms are that the former works on the basis of advantage assets of the dependent country, such as cheap labor and raw materials, whereas the latter is geared to import 
substitution of the basis of advantage assets of the dependent country, such as market demand (Reuber, 1973), In terms of the "productive life cycle" theory the latter is more useful in technology transfer than the former:

Another enticing factor which facilitates the MNCs involvement and flexible maneuvering, is the formation of Industrial Free Zones for the following reasons:

a) a part of an overall industrial development program of the country or of a certain region of the country;

b) a measure for solving the employment problem by the creation of new labor opportunities;

c) stimulation of development of export-oriented industries to increase export volume and foreign exchange receipts;

d) acquirement of modern industrial techniques from abroad through which the level-up of the domestic industrial standard may be achieved;

e) encouragement of new industrial investments from domestic, as well as foreign capital markets; and

f) means of a concentrated and rational development of infrastructure with the industrial free zone acting as an industrial pole (Frank, 1981:102):

The state plays a fundamental role in making the tourism sector a long-term sustainable economic activity to contribute to the overall development objectives, For the last decade the application of Free Production zones to tourism development, the involvement of MNCs, the absence of a national tourism policy, and the lack of participatory 
planning in the centralized system has not contributed to the overall national development objectives: In addition, it has turned the sector into a contributing factor of the contradictions of dependent development, The intensification of regional imbalances due to the mobilization of the population and work force to the "ready make profit" Free Production Zones ( $i_{e} e_{!}, 13$ tourist centers concentrated in Western and Southwestern Turkey) has brought overurbanization to already concentrated regions: Where MNCs are active in tourism, domestic tourism remains ignored. There is an acute need to disperse the tourist activities to potential areas (i,e., Black Sea) and Eastern Anatolya to serve the domestic market

In the absense of a national policy and effective planning an impasse has developed among the MCT (Ministry of Culture and Tourism), the local owners of tourism facilities, and the national government; As noted earlier the state plays a decisive role in most NICs! Tourism is no exception, and requires direct state control and management in cooperation with the local owners and agencies (travel agencies and hoteliers) to allocate funds for promotion and development: It is certain this process is only possible with an enforcable national tourism policy: However, the reluctance of the state to be actively involved in directing the tourism sector negates the very structure of dependent development which requires an active role by the state! Far more, government intervention is required for policy choices to be made in the midst of acute scarcity (Richter and Richter, 1985): The government needs to clarify its attitude towards the tourist industry: Although it has been recognized that tourism needs a national 
policy, no attempts have been made to coordinate policy with industry needs and developmental goals:

The current nature of the government's involvement is a passive one by definition, As a result the government role has been confined to: a) mandatory actions that are linked to legislative provision! For example, the government's investment policies which have applied to the country as a whole, have had implications on tourism, b) supportive: government does not deliberately inhibit the development of tourism; but neither does it actively encourage it. An example of this is the role of the MCT which lacks decisive government input in the policy area as well as in financing the industry as a whole (Jenkins and Henry, 1982), The lack of active government involvement and intervention in the tourism industry, as explored in this study, is due to the absense of a national tourism policy: An "active" role can lead to government commitment to the industry: This can be realized through two essential criteria. The first is the managerial and operational element. In this case, the government not only sets tourism objectives (possibly in a tourism development plan), but also introduces necessary organizational and legislative support to attain the objectives: The second criteria is the establishment of a tourism development bank, In Turkey's case this pattern has been reversed. In terms of development theory, the government should undertake an operational role in the tourism sector: In Turkey's case the government gradually withdrew from this task Contrary to the requirement for the government's active role in training, planning, and integrating the sector into the economy, the 
government privatized the few publicly owned tourism operations (Jenkins and Henry, 1982):

An alternative tourism policy would call for a new strategy based on the complexity of the tourism system and be immune to what Hershlag described as

a major flaw in the present and programmed investment
strategies, namely the concentration on the physical
infrastructure [the case in the tourism sector], and the
inadequate recognition of the priority of investment in
human resources in the process of economic and social
development (1988:67),
In fact, such "flaws" were expressed by various interviewees (officials and businessmen) in the forms of too many superstructures without adequate services or personnel: In addition, the lack of organization, policies, and tourism consciousness were also stated as problems, Nonetheless, tourism remains a vital part of the national development system and should not be sacrificed to those development theories that are conceptually growth oriented, out of an implicit belief in the "trickle-down" theory: While the fifth five-year plan's (1985-1989) declared objectives were for full employment and fighting extreme inequality, Turkey's per capita GNP of $\$ 1,000$ was far behind Portugal, Greece, and Spain (per capita GNP of $\$ 1,905, \$ 3,380$, and $\$ 4,192$ respectively for 1985$)$ : Tourism requires a genuinely integrated socioeconomic strategy! "Community oriented" tourism and small-tomedium sized tourism enterprises are feasible and compatible with the strategy known as "employment-oriented strategy" " On this account Hershlag noted, It may hold the best promise of a durable development in a country abounding in underutilized human resources, on the 
one hand, and in poverty, inequalities and overt or latent social conflicts, on the other hand:

The main emphasis of this study was an examination of the problem of tourism development ( $i_{1, e}$, in the policy and planning areas) and to propose a general conceptual framework that explains the variables within Turkey's political economy of development: The findings indicate, for the most part, that the theory of Turkey's historical development within the world capitalist system and its fundamental impact on the outcome of the tourism sector is plausible and worthy of further investigation, However, this study does not exhaust the possibilities for further research to enhance the validity of the theory:

With respect to other Mediterranean democracy models (i,e and Spain), Turkey's position remains to be seen in terms of her transition (iłe., politically) into the decentralized form as her counterparts without sacrificing an active role in tourism, Importantly enough, the transition in Spain and Greece has paved the way for their membership in the European Economic Community which Turkey is striving for! This step will, in all likelihood, boost the tourism sector and further support for an integrated, local oriented tourism planning (Loukissas, 1982)

The proposed alternative National Tourism Organization (NTO) has recommended the adoption of a policy that is not solely growth oriented, but rather is armed with planners who can embrace development strategies that are conceptualized in the context of the New International Economic Order (NIEO): The NIEO has forewarded strategies that are the basic 
needs, or employment oriented in nature. This is a more sensible strategy given the fact that, despite the resumed growth of the GNP and restrained inflation in the first half of the 1980s, "trickling down" policies have not had much effect, For instance, while the GNP implicit price deflator for 1986 was 30.6 percent, the average consumer prices went up by an estimated 34,6 percent and the average labor earnings increased by only 7.7 percent (Hershlag, 1988:160):

All told, the government has the obligation to make the tourist industry more aware of its social and cultural responsibilities to Turkey's development requirements: The government can devise a policy to coordinate various players in the industry in a fashion that can prevent the tourism sector from becoming vulnerable to unpredicted forces inherent in the tourist industry? with etatism in retreat and XOG in full course the future of the industry fundamentally remains to be seen, Thus far, the policy of "non-policy" has created distortions in the process of policy decisions as well as impediments in the process of creating a meaningful government role in tourism and in defining the kind of roles it could play, Where there is such disarray, there is also a crisis in the alternative responses to the selection of a policy that may bring the best result for Turkey's case,

Tourism should be treated as an extremely fragile national asset: It is yet to be realized that such a unique industry can have a short production life cycle if not dealt with in a carefully planned and controlled manner: However, because XOG is only a decade old and the tourism boom is still to come, the future of not just one sector, but rather the whole economic and social-political structure remains to be 
seen, However, there are certain development strategies ahead that renders optimism with caution! As noted by Hershlag (1988:159): "Turkey's economic, social and technological development is clearly on an irreversible upward trend: Even the fashionable fundamentalist trends will presumably not have a lasting effect under Kamilist Turkey s conditions!" With respect to the tourism sector, it can be planned and utilized to help achieve the two fundamental objectives that have been targeted by the present government; These can be summarized as the doubling of real per capita income and the participation of the majority of population in the overall development process. The road to obtain the second objective has already been paved through by a new openness in the political system and by the implementation (in progress) of the ambitious South-east Anatolian Project (GAP--Guneydogu Ana dolu Projesi):

As targeted, GAP will achieve the additional annual growth of 4.8 percent. It will bring 1,6 million hectares to the presently, rearly 1.5 million hectares of irrigated land. It also will produce 24 billion KWH (or over 70 percent of total power generation) by 1992, This will disperse the regional concentration of tourism, as well as reduce the regional and social inequalities in the vast southeastern area (Hershlag, 1988) : 
REFERENCES

Ahluwalia, Inder Raj 1986, "Domestic Tourism: India؛" Tourism Recreation Research. Vol, 11, No! 1, 54 :

Ahmad, Feroz 1981: "Military Intervention and the Crisis in Turkey," Merip Reports: No: 93, 5-26,

Ahmad, Feroz 1984, "The Turkish Elections of 1983," Merip Reports: Vol! 14, No, 3, 3-12,

Akoglu, Tunay 1967! "Recent Development in Turkish Tourism!" Turkish Economic Review, Vol: 8, 31-35.

Akoglu, Tunay 1970, "Tourism policy and tourism planning in Turkey," in Tourism Promotion in Turkey: Paper presented at the International Seminar held in Irmir September 2-6, 1969, Istanbul, Turkey:

Alatan, Haluk 1970, "physical Planning in Tourism in Turkey," in promotion of tourism in Turkey: International seminar on promotion of Tourism in Turkey held in Irmir September 2-6, 1969.

Allcock, B! John 1986: "Yugoslavia's tourist trade: Pot of gold or pig in a poke " Annals of Tourism Research. Vol, 13, No: 4, 565-588.

Allen, Hubert I. 1987, "Decentralization for Development: A Point of View " Planning anà Administration, Vol! 14, No, 1, 23-31.

Altintas, M! 1978! Inward-looking Industrialization Policy! Ankara: Mugla Acaderry of Economics and Commerce:

Amirahmadi, Fooshang 1987, "The Non-capitalist and way of Development!" Review of Radical Political Economics: Vol: 19, Nol 1, 22-46.

Amirahmadi, Hooshang 1989, "Development paradigms at a crossroad and the South Korean experience " Journal of Contemporary Asia! Vol 19, No, 2, 167-185:

Amin, Samir 1976, Unequal Development: New York and London: Monthly Review Press:

Amin, Samir 1990, Delinking: Towards a Polycentric World: I-ondon and New Jersey: Zed Books LTD, 
Amsden, Alice H: 1985. "The State and Taiwan's Economic Development." in Bringing the State Back In! Peter B! Evans, Dietrich Rueschemeyer and Theda Skocpol (eds!): Cambridge: Cambridge University Press:

Amsden, Alice H. 1990, "Third world Industrialization: Global Fordism or a New Model?" New Left Review: No, 182, 5-32,

Anastasopoulos, G Petros 1989, "Italy's importance in the development of tourism in the Mediterranean" Annals of Tourism Research. Vol, 16, No, 4, 570-574.

Ankomah, Paul Kwane and John L! Crompton 1990, "Unrealized Tourism Potential: The Case of Sub-Saharan Africa!" Tourism Management: Vol: 11, No: 1, 11-28,

Armstrong, Warwick and T,G, McGee 1985, Theatres of Accumulation: Studies in Asian and Latin American Urbanization: London and New York: Methuen,

Ascher, Francois 1985, Tourism: Transnational Corporations and Cultural Identities! Paris: UNESCO:

Ata, Halil 1986, "Turizm Olayi ve Turkiye'nin Durumu," Turizm Yilligi, 1985. Ankara, Turkey: T\&C . Turizm Bankasi!

Atac-Rosch, Inci 1984. Public Planning for Tourism: A general method for establidhing economic, environmental, social and administrative criteria! $P h, D$ dissertation, University of Washington:

Atac-Rosch, Inci 1988, "Turizm Planlanasi: like Capinda Alinan Politika Kararlan'nin Incelenmesi!" planlama Dergisi! No 24, 75-85.

Atix, Shelley 1986, "Building Economic Alternatives:" A Quarterly Publication of Co-op America, Washington, D.C.: Co-op America, 7, Spring:

Aydin, Zulkuf 1987. "Turkish Agrarian Debate: New Prguements or Old Scores:" New Perspective on Turkey, Vol, 1, No, 1, 81-109,

Aydin, Zulkuf 1986: Underdevelopment and Rural Structures in Southeastern Turkey: The household Economy in Gisgis and Kalhana: London: Ithaca Press:

Bach, Robert L! 1982, "On the Holism of a World System Perspective," in World System Analysis 1: Theory and Methodology: Terena K. Hopkins, Immanuel Wallerstein, $I_{4}$ Roberts Bach, Christopher ChaseDunn and Krishna Ram Mukherjee (eds.)! Beverly Hills: Sage Publications: 
Barke, Michael and Lesley France 1986. "Tourist Accommodation in Spain 1971-1981." Tourism Management. Vol, 7, No, 3, 181-196.

Bar-On, Ray 1989. Travel and Tourism Data. Phoenix, New York: Oryx Press.

Basgoz, Ilhanand and Norman Furniss 1985. "Foreign Workers in the Political Economies of Western Europe, "in Turkish Workers in Europe: Interdisciplinary Study, Ilhan Basgoz (ed.). Bloomington, IN: Indiana University Press.

Bayri, Tulay Yo and Hartley W. Furtan 1989, "The Impact of New Wheat Technology on Income Distribution: A Green Revolution Case Study, Turkey, 1960-1983،" Economic Development and Cultural Change. Vol. 38 , No.1, 113-129.

Belisle, Francois J. 1984. "Tourism and Food Imports: The Case of Jamaica،" Economic Development and Cultural Change. Vol. 32, No.4, 817-841.

Belo, Walden and Stephanie Rosenfeld 1990. "Dragons in Distress: The Crisis of the NICs." World Policy Journal. Vol. 7, No. 3, 431468.

Berberoglu, Berch 1982. Turkey in Crisis: From State Capitalism to Neo-Colonialism. London: Zed Press.

Bernstein, Henry 1971. "Modernization Theory and the Sociological Study of Development." Journal of Development Studies. Vol, 7, No. 2, 141-160.

Bernstein, Henry 1977. "Notes on Capital and Peasantry." Review of African Political Economy. Vol, 10, 60-73.

Blomstrom, Magnus and Bjorn Hettne 1984. Development Theory in Transition--The Dependency Debate and Beyond: Third World Responses, London: zed Books Itd.

Bodrum 1988. Bodrum and Environs 188: The Complete Guide, Bod-Info Tuxizm ve Ticaret, Istanbul: Turkey.

Boratav, Kurkut 1979. "Import-substitution and the IMF's Intentions." Milliyet, August 27, 11.

Braddon, C.J.H: 1982, British Issues Paper: Approaches to Tourism Planning Abroad, London: British Tourist Authority.

Brett, Edward 1983. International Money and Capitalist Crisis, London: Heinemann. 
Britton, Stephen 1989, "Tourism, Dependency and Development: A Mode of Analysis," in Towards Appropriate Tourism: The Case of Developing Countries! Tej Vie Singh, $H_{+}$Ieo Theuns, and Frank $M_{3}$ Go: New York: Peter Lang.

Britton, Stephen 1983, Tourism and Underdevelopment in Fiji: Conbeffed, Australia: The Australian National University:

Britton, Stephen 1982, "The Political Economy of Tourism in the Third World!" Annals of Tourism Research: Vol: 9, No, 3, 331-359,

Britton, Stephen 1981: "International Tourism and Multinational Coporations in the Pacific," in The Geography of Multinational Corporations: M. Taylor and $\mathrm{N}$ : Thrift (eds!)! London: CroomHelm:

Bryan, Hobson and Nicholas Taylor 1987, "Toward an Outdoor Recreation Resource Policy:" Policy Studies Review: Vol, 7, No, 2, 349-358,

Bryant, Coralie and Louise G. White 1982, Managing Development in the Third World: Boulder, CO: Westview Press:

Bryden, John M, 1973, Tourism and Development: A Case Study of the Commonwealth Caribbean? New York: Cambridge University Press:

Bryden, J: and M. Faber 1971 " "Multiplying the Tourist Multiplier:" Social and Economic Studies, Vol, 20, No, 1, 61-82,

Buckley, Peter $J_{t}$ and Stephen $F_{6}$ Witt 1990, "Tourism in the Centrallyplanned Economies of Europe:" Vol! 17, No: 1, 7-18:

Burkart, $A_{4} J_{4}$ and $S_{\text {: Medlik 1981, Tourism: Fast, Present and Future: }}$ London: Hernemann:

Butler, R:W 1980, "The Concept of Tourist Area Cycle of Evolution: Implications for Management of Resources!" Canadian Geographer: Vol 24, 5-12.

Camhis, $M_{4}$ and $H_{4}$ Coccossis 1983. "Evnironment and Tourism in Island Regions:" planning and Administration: Vol: 10, No, 1, 16-24,

Camlibel, Okyay 1970. "Implementation of the Tourism Policy in Turkey," in Fromotion of Tourism in Turkey. International Seminar on Promotion of Tourism in Turkey, held in Izmir on September 2-6, 1969,

Cardoso, Fernando Henrique 1972, "Dependency and Development in Latin America," New Left Review: No! 74, 83-95: 
Cardoso, Fernando Henrique 1973, "Associated Dependent Development, Theoratical and Practical Implications," in Authoritarian Brazil: Origins, Politics and Future! Alfred Stepan (ed!)! New Haven: Yale University Press:

Cardoso, Fy. $H_{4}$ and $E_{6}$ Falleto 1979, Dependency and Development in Lat in America! Berkeley: University of California Press:

Carter, M.R: 1971; "A Method of Analyzing Patterns of Tourist Activity in a Large Rural Area: The Highlands and Islands of Scotland:" Regional Studies: Vol: 5, No, 1, 29-37,

Cater, Erlet A: 1987, "Tourism in the Least Developed Countries:" Annals of Tourism Research: Vol! 14, No: 2, 202-226:

Celasun, Merih and Dani Rodrik 1989. "Turkish Experience with Debt: Macroeconomic Policy and Performance," in Developing Country Debt and the World Economy: Jeffery $D$ : Sachs (ed!): Chicago and London: The University of Chicago Press;

Cetin, Ihsan 1988 " "Tourism and the Turkish Economy " Working Papers: Ankara: Bilkent University:

Cetin, Ihsan and Cahit Benovenli 1978, "Turkey's Tourism Policies: An Evaluation of the 1963-1977 Period and an Approach for the Future " Journal of the Mugla School of Business Administration. Special Issue, Internaltional Tourism Congress, 129-139,

Chatterjee, Lata and Peter Nijkamp 1983: "Prospects of Policy Analysis," in Urban and Regional Policy Analysis in Developing Countries, Lddata Chatterjee and Peter Mijkamp (eds Brookfield, UK: Gower House Publishing $\mathrm{CO}_{\text {: }}$

Cheema, $R_{4} A_{4}$ and $A_{4} D_{4}$ Rondinelli (eds!) 1983, Decentralization and Development: Policy Implementation in Developing Countries: Beverly Hills: Sage Publications:

Cleaves, Peter S! 1980 "Implementation Amidest Scarcity and Apathy: political Power and Policy Design," in Politics and Policy. Implementation in the Third World: $M_{*}$ Grindle (ed $)_{4}$ Princeton, NJ: Princeton University Press:

Clements, M!A 1989 , "Selecting Tourist Traffic by Demarketing:" Tourism Management: Vol, 10, No: 2, 89-95:

Chirot, Daniel 1977, Social Change in the Twentieth Century. New York: Harcourt, Brace and Javanovich:

Cho, StK, 1985. "The Dilemmas of Export-led Industrialization: South Korea and the World Economy!" Berkeley Journal of Sociology: Vol: 30, 64-94. 
Christie Mill, Roberts and Alastair M, Morrison 1985, The Tourism System, Englewood Cliffs, NJ: Prentice-Hall, Inc!

Cohen, Erik 1971: "Arab Boys and Tourist Girls in a Mixed Jewish Arab Community:" International Journal of Comparative Sociology: Vol: 12, No, 4, 217-233,

Cohen, Erik 1972, "Toward A sociology of International Tourism:" Social Research, Vol, 39, No, 1, 164-182:

Cohen, Erik 1973, "Nomads from Affluence: Notes on the Phenomenon of Drifter-Tourism:" International Journal of Comparative Sociology: Vol. 14, No: 1-2, 89-103:

Cohen, Erik 1979, "Rethinking the Sociology of Tourism!" Annals of Tourism Research! Vol. 6 , No, 1, 18-35.

Cohen, Erik 1988, "Tourism and AIDS in Thailand!" Annals of Tourism Research! Vol! 15, No, 4, 467-487.

Cohen, Erik 1989. "Alternative Tourism--A Critique," in Towards Appropriate Tourism: The Case of Developing Countries: T:V: Singh, H! Leo Theuns, Frank M, Go (eds!)! New York: Peter Lang:

Cooper, Chris and Stephen Jackson 1989, "Destination Lifecycle: The Isle of Man Case Study:" Annals of Tourism Research: Vol! 16, No. 3, 377-398,

Coppock, Jạ! 1977! "Second Homes in Perspective," in Second Homes:

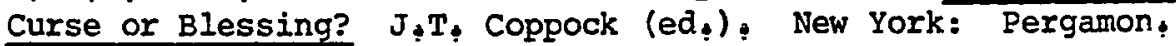

Culpan, Refik 1987: "International Tourism Model for Developing Economies:" Annals fo Tourism Research! Vol: 14, No, 4, 541-552,

Cumhuriyet 1988, "Turizm, Saray ve muzeleri Tehdid ediyor!" Cumhuriyet 18 Kasim, 6

D'Amore, Louis J: 1988, "Tourism: The World's Peace Industry," Tourism Recreation Research: Vol, 13, No, 2, 29-35,

Dalen, Erik 1989, "Research into Values and Consumer Trends in Norway:" Tourism Management. Vol: 10, No! 3,m 183-186,

Dalli, Ozuv 1970, Tourism Physical Planning in Turkey, State Planning Organization: Ankara: Turkey

Danielson, Michael, $\mathrm{N}_{\mathrm{t}}$ and Leles Rusen 1980, "Urbanization and Income Distribution in Turkey," in The Political Economy of Income Distribution in Turkey: Ergun Ozbudun and Aydin Ulusan (eds!): New York and London: Holmes and Meier Publishers, Inc; 
Danielson, Michael. $\mathrm{N}_{\text {g }}$ and Leles Rusen 1985: The Politics of Rapid Urbanization: Government and Growth in Modern Turkey: New York and Londor: Holmes and Meier

Dann, Graham, Nash Dennison and Philip Pearce 1988, "Methodology in Tourism Research:" Annals of Tourism Research: Vol, 15, No: 1, 1-29.

Dasmann, Raymond F!, John P! Milton and Peter H! Freeman 1973: Econological Principles for Economic Development: New York and London: John Wiley and Sons:

DeKadt, Emmanuel (edi) 1979 ; Tourism: Passport to Development: Oxford: Oxford University Press:

Demirgil, Demir 1987, Turkey 1986: Economic Look, Ankara: Tusiad,

Dernoi, Louis A, 1983, "Farm Tourism in Europe ${ }_{q}$ " Tourism Management: Vol! 4, 155-166!

Dervis, $K_{4}$ and S, Robertson 1978, "The Foreign Exchange Gap, Growth and Industrial Strategy in Turkey" "World Bank, No, 306: Washington, $\mathrm{D}_{\mathrm{s}} \mathrm{C}_{4}$ : World Bank,

Diamond, J. 1977. "Tourism's Role in Economic Developpment: The Case Reexamined," Economic Development and Cultural Change: Vol, 25, No, $3,539-553$

Din, Kadir H: 1982. "Tourism in Malaysia: Competing Needs in a Plural Society؛" Annals of Tourism Research, Vol: 9, No $3,453-480$,

Din, Kadir H, 1988, "Social and Cultural Impacts of Tourism," Annals of Tourism Research, Vol, 15, No, 4, 563-566,

Din, Kadir Ha 1989a, "Islam and Tourism: Patterns, Issues, and Options:" Annuals of Tourism Research: Vol! 16, No: 4, 542-563,

Din, Kadir H, 1989b, "Towards an Integrated Approach to Tourism Development: Observations from Malaysia," in Towards Appropriate Tourism: The Case of Developing Countries! $T, V_{!}$Singh, $H ! L !$ Theuns and F!M! Go (eds!)! New York: Peter Lang:

Dilsaver, Lạ, 1979, "Some Notes on the Negative Impacts of International Tourism:" Association of Pactific Coast Geographers: Year Book 41. Corvallis: Oregon State University Press:

Dogan, Yalcin 1980, Turkey in the Claws of the IMF: Ankara: Toplum Yayinevi: 
Dogan, Zafer Hasan 1989: "Forms of Adjustment: Socio Cultural Impacts of Tourism!" Annals of Tourism Research. Vol, 16, No. 2, 216$237:$

Donaghy, Peter $J$, and Michael $T_{4}$ Newton 1987: Spain: A Guide to Political and Economic Institutions, New York and Cambridge: Cambridge University Press:

Dos Santos, Theotonia 1970! "The Structure of Dependence:" The American Economic Review: Vol, 60, 231-236.

Down, Anthony 1967: Inside Bureaucracy: Boston, MA: Iittle, Brown!

Doxey, G.V! 1976. "When Enough's Enough: The Natives are Restless in Old Niagra:" Feritage Canada! Volø: 2, No, 2, 26-27!

Ebiri, Kutlay 1985. "Turkish APERTURA," in Turkey in the World Capitalist System: A STudy of Industrialization, Power and Class: Huseyin Ramazanoglu (ed $)_{!}$Brookfield: Grower!

Economic Report 1988, The Istanbul Chamber of Commerce; No 24 Istanbul, Turkey:

Economic Report 1988, Union of the Chamber of Commerce, Industry, Maritime Trade and Commodity Exchanges of Turkey: No: 67 : Instanbul, Turkey

The Economist 1988, "A Survey of Turkey: Getting Ready for Europe " June 18

Edwards, Anthony and Robert Cleverdon 1982 International Tourism to 1990. Massachusettes: ABT Books:

Edwards, Jonathan 1989, "Tourism in Rural Areas," Routism Management. Volt 10, No! $1,73-74$.

El-Shakhs, Salah and Amirahmadi Hooshang 1984. "Population Growth, Urbanization and Third World Spatial Development " Journal of Asian-Pacific and World Perspectives: Vol. 8, No. 1, 27-49,

Elephantis, Angelus 1981" "Pasok and the Elections of 1977: The Rise of the Populist Movement in Greece at the Polls," in Greece at the Polls: In the National Elections of 1974 and 1977. Howard R. Penniman (ed!) ! Washington: Puencan! Enterprise Institute for Public Policy Research.

Elmore, R_F : 1987! "Backward Mapping: Implementation Research and Policy Decisions," in Studying Implementation, Nọ: Chatham (ed.)! NJ: Chatham House?

English, Philip E! 1986, The Great Escape?: An Examination of NorthSouth Tourism! Ottawa, Canada: The North-South Institute 
Erbes, Robert 1973 International Tourism and the Eocnomy of Developing Countries: Paris: OECD!

Erdem, T: 1980! Meeting the Eighties: Ankara: Ajansturk,

Erogul, Cem 1987. "The Establishment of Multiparty rule: 1945-71," in Turkey in Transition, C.I. Schick and A.E. Tonak (eds)! New York and Oxford: Oxford University Press:

Espinoza, Romero Henry 1985, "Planning and National Development!" Planning and Administration: Vol, 12, No! 2, 28-32:

Evangelinides, Mary 1987: "The Management of Local Finance in Greece." Planning and Administration: Vol, 14, No, 2, 49-56;

Evans, Peter B. 1975, "Industrialization and Imperialism: Growth and Stagnation on the Periphery:" Berkeley Journal of Sociology: Vol: 20, 113-145:

Evans, Peter 1979: Dependent Development: The Alliance of Multinational, State and Local Capital in Brazil, Princeton: Princeton University Press:

Evans, Peter B!, Dietrich Rueschemeyer and Theda Skocpol (eds!) 1985: Bringing the State Back In, Cambridge: Cambridge University Press:

Faludi, A: 1986, Critical Rationalism and Planning: London: Point Limited.

Feifer, Maxine 1986, Tourism in History: From Imperial Rome to the Present, New York: Stein and Day Publishers:

Firat, Fuat 1989, "Tourism Marketing and Development: Structural Constraints Facing Underdeveloped Countries," in Towards Appropriate Tourism: The Case of Development Countries! T:V4

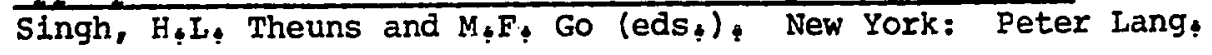

Fletcher, John E, 1989, "Input-output Analysis and Tourism Impact Studies:" Annals of Tourism Research! Vol! 16, No, 4, 514-529,

Fletcher, John and John Latham 1989: "International Tourism Training:" Tourism Management; Vol, 10, No $2,164-165$ :

Frank, Gunder A, 1969, The Development of Underdevelopment: New York: Monthly Review Press

Frank, Gunder A\& 1972, Lumpenbourgeoisie: Lumpendevelopment, Dependency, Class and Politics in Latin America! New York: Monthly Review Press: 
Frank, Gunder A: 1979. Dependent Accumulation and Underdevelopment: New York: Monthly Press Review:

Frank, Gunder A, 1981, Crisis in the Third World, New York: Holmes and Meier PUblishers, Inc:

Fraser, $R_{4}$ 1973, Tajos: The Story of a Villiage on the Costa Del Sol: New York: Pantheon:

Friedmann, $J_{4}$ and $C_{\text {. Weaver }}$ 1979, Territory and Function: The Evolution of Regional Planning, London: Edward Arnold;

Furtado, Celso 1970, Economic Development of Latin America: Cambridge: Cambridge University Press!

Gajraj, Mel 1989. "Limits to Tourism Development--Warning Signs"" Tourism Management: Vol: 10, No, 3, 202-203,

Gartner, William C! 1987, "Environmental Impacts of Recreational Home Developments:" Annals of Tourism Research! Vol, 14, No, 1, 3852 .

Getz, Donald 1989. "Special Events: Defining the Product," Tourism Management: Vol: 10, No: 2, 125-138.

Getz, Donald 1983. "Capacity to Absorb Tourism: Concepts and Implications for Strategic Planning:" Annals of Tourism Research: Vol, 10, No; 2, 239-265:

Geyikdagi, Mehmet Yasar 1984, Political Parties in Turkey. New York: Praeger:

Gianari's, Nicholas V, 1984: Greece and Yugoslavia: An Economic Comparison, New York: Praeger:

Gilbert, Alan and Josef Gugler 1982, Cities, Poverty, and Development: London and New York: Oxford University Press

Gilbert, David 1989, "Rural Tourism and Marketing: Synthesis and New Ways of Working!" Tourism Management: Vol ; 10, No, 1, 39-51"

Gilg, A.W. 1978, Countryside Planning: The First Three Decades 194576: London: Methuen,

Gillespie, Richard 1989, The Spanish Socialist Party: A History of Factionalism: Oxford: Clarendon Press

Gilmour, David 1985: The Transformation of Spain: From Franco to the constitutional Monarchy: New York: Quartet Books: 
Gladwin, Thomas N: 1987: "Environment, Development and Multinational Enterprise," in Multinational Corporations, Environment, and the Third world: Charles s! Pearson (ed!)! Durham: Duke University Press:

Go, Frank 1989: "International Hotel Industry--Capitalizing on Change:" Tourism Management: Vol: 10, No: 3, 195-201:

Go, Frank M. 1990. "Tourism in Developing Countries: Conditions for and Effects of Tourism Development in Low-income Countries: A Reseasrch and Policy Oriented Analysis at Meso-level" "Annals of Tourism Research: Vol, 17, No, 3, 486-489;

Goodman, Louis w: 1987, Small Nations, Giant Firms, New York and Londor: Holmes and Meier:

Gore, Charles 1984, Regions in Question: Space, Development Theory and Regional Policy: New York and London: Methuen.

Goulet, Denis 1978, "The Challenge of Development Economics:" Communications and Development Review: Vol, 2, No, 1, 18-23,

Graham, Robert 1980, Iran: The Illusion of Power: New York: St! Martin's Press:

Gran, Guy 1983, Development by People: Citizen Construction of a Just World. New York: Praeger.

Gray, $\mathrm{H}_{4} \mathrm{P}$ : 1970, International Travel--International Trade! Iexington, MA: Heath Lexington Books:

Gray, H.P. 1974, "Towards an Economic Analysis of Tourism Policy:" Social and Economic Studies! Vol, 23, No, 3, 386-97,

Greenwood, Davydd J: 1972, "Tourism as an Agen $t$ of Change: A Spanish Basque Case:" Ethnology: Vol, 11, 80-91,

Greenwood, Davydd J: 1976, "Tourism as an Agento of Change--A Spanish Basque Case $"$ Annals of Tourism Research! Vol, 3, No, 3, 128142 .

Greenwood, Justin, Allan M, Williams and Garetu Shaw 1990, "Policy Implementation and Tourism in the UK: Implications from recent Tourism Resarch in Cornwall:" Tourism Management: Vol, 11, No: $1,53-62$

Griffin, Keith 1979, The Political Economy of Agrarian Change: Iondon: Macmillan:

Grindle, Merilee S* (ed,) 1980, Politics and Policy Implementation in the Third World: Princeton, NJ: Princeton University Press: 
Grindle, Merilee S; and John W: Thomas 1989. "Policy Makers, Policy Choices, and Policy Outcomes: The Political Economy of Reforms in Developing Countries!" Policy Sciences: Vol, 22, No, 3-4, 213240 .

Gularlf, Haldun 1983, Development Strategies and Development Ideologies! Ankara: Yurt Yayinlari :

Gulersoy, Celik 1970, "Socio-psychologic Foundations of Tourism," in Promotion of Tourism in Turkey. International Seminar on Promotion of Tourism in Turkey held in Izmir on September 2-6, 1969.

Guneysu, Alaettin 1983: The Elan Implementation in Turkey: Ankara, Turkey: SPO

Gunn, Clare A, 1979, Tourism Planning: New York: Crane, Russaok and Company:

Gunn, Clare A. 1988 (2nd edition)! Tourism Planning: New York: Taylor and Francis,

Gunn, $C_{+}$and $J$, Jafari 1981: "World Tourism Conference: An Intergovernmental Tourism Landmard!" Annals of Tourism Research. Vol: 7, No. 3, 478-485.

Hacioglu, Needet 1988, "Turizmin Gelisme-sinde cok uluslu Turizm Isletmelerinin Rolu! " Turizm Yillig! Tạ: Turizm Bankasi, Ankara, Turkey.

Hague, $R_{4}$ and $M_{4}$ Harrop 1982 \% Comparative Government London: Macmillan.

Hale, William 1981, The Political and Economic Development of Modern Turkey, New York: St , Martin's Press:

Halliday, Fred 1989, From Rabul to Managua: Soviet-American Relations in the 1980's: New York: Pantheon Books:

Hamitogullari, Basir 1968; "Turkiyede Turizim ve Iktisadi Kalkinma"" Siyasal Bilgiler Fakultesi Dergisi: Ankara, Turkey:

Hamitogullari, Basir 1970. "Turk Turizminde Temel Sorun" Siyasal Bilgiler Fakultesi Dergisi: Ankara, Turkey:

Hardiman, Margaret 1988; "Social and Cultural Impacts of Tourism!" Annals of Tourism Research: Vol, 15, No, 4, 563-566,

Harrigan, Norwell 1974, "The Legacy of Caribbean History and Tourism," Annals of Tourism Research! Vol, 2, No, 1, 13-25: 
Hartmann, Rudi 1986, "Tourism and the Seasonality" Tourism Recreation Research: Vol: 11, No, 1, 35-39,

Held, Colbert $C+1989$, Middle East Patterns: Places, Peoples and Politics! Boulder: West View Press:

Helleiner, GoK, 1976, "Transnational Enterprises, Manufactured Exports and Employment in Less Developed Countries:" Eccnomic and Political Weekly: Combay, Annual Number, February:

Heper, Metin 1990, "The State, Political party and Society in Post-1983 Turkey " Government and Opposition: Vol! 25, No, 3, 321-333,

Hershlag, Z,Y: 1968, Turkey: The Challenge of Growth! Netherlands, Leiden: $E_{q} J+B x i l 1$

Hershlag, Z,Y, 1988, The Contemporary Turkish Economy, London and New York: Routledge:

Hiller, HaI. 1975, "The organization and Marketing of Tourism, in $A$ New Kind of Sugar: Tourism in the Pacific, $B_{4} R_{4}$ Finney and Ko, Watson (eds!): Honolulu: East-West Culture Learning Center!

Hiranyakit, Somchai 1984: "Tourism Planning and the Environment!" Industry and Environment, Vol, 14, 11-12,

Holden, Peter (ed,) 1984, "Report of the Workshop on Alternative Tourism with a Focus on Asia!" Bangkok: Ecumenical Coalition of Third World Tourism.

Hong, Evelyne 1985, "See the Third World While It Lasts: The Social Environmental Impact of Tourism with Special Reference to Malaysia," Consumers Association of Penang: Penang, Maleysia,

Horowitz, Donald L! 1989, "Is There a Third-World Policy Process!" Policy Sciences: Vol, 22, No, 3-4, 197-212,

Hughes, HoI! 1984, "Government Support for Tourism in the UK!" Tourism Management: Vol: 5, No, 1, 13-19,

Huntington, Samuel p, 1968, Political order in Changing Societies: New Haven: Yale University Press:

Hurryat 1988, "Yine Kiyi Yagmasi!" Hurryat: Kasim 1, 8,

Hyden, Goran 1983, No Short Cut to Progress: African Development Management in Perspective: Berkeley: University of California Press:

Hymer, Stefan 1974, Multinational Corporation: A Radical Approach. Cambridge: Cambridge University Press: 
Inskeep, Edward 1987, "Environmental Planning for Tourism:" Annais of Tourism Research. Vol, 14, No. 1, 118-135.

Inskeep, Edward 1988, "Tourism Planning: An Emerging Specialization," Journal of the American Planning Association: Vol, 54, No: 3 , $360-373$ :

International Herald Tribune 1988, "Tourism Bank's Hotel Interests to be Privitized" April 24, 11.

International Tourism Reports (ITR) 1986, "Greece" London: The Economist Intelligence Unit: No $3,45-61$.

International Tourism Reports (ITR) 1988, "Spain!" London: The Economist Intelligence Unit: No, 1, 5-29,

International Tourism Reports (ITR) 1989: "Turkey:" London: The Economist Intelligence Unit: No, 1, 35-55,

Istanbul Chamber of Industry 1988, Distribution of Turkey's Gross Domestic Product by Provinces, Instanbul: Avciol Matbaasi!

Jafari, Jafar 1974, "Socio-economic Costs of Tourism to Developing Countries:" Annals of Tourism Research! Vol, 1, No , 7, 227-263,

Jafari, Jafar 1981: "Limit to Tourism Development" " Journal of Travel Research: Vol: 19, No, 3, 25-26:

Jafari, Jafar 1982, "The Tourism Market Basket of Goods and Services," in Studies in Tourism, Wildlife, Parks, Conservation, $T+V$. Singh, et al: (eds!): New Delhi: Hetropolitan!

Jafari, Jafar 1983, "Understanding the Structure of Tourism," in Tourism and Culture: A Comparative Perspective, $E, C$ : Nebel (ed.)! New Orleans: University of New Orleans Press:

Jafari, Jafar 1987. "Tourism Transnational Corporations and Cultural Identities!" Annals of Tourism Research! Vol! 14, No, 2, 289292.

Jafari, Jafar 1987: "On Domestic Tourism!" Tourism Recreation Research: Vol: 12, No, 1, 29-31.

Jafari, Jafar and Dean Aaser 1988, "Tourism as a Subject of Doctoral Dissertations!" Annals of Tourism Research! Vol, 15, No, 3, 407430

Jafari, Jafar and Ritchie J!R! Brent 1981" "Toward a Framework of Tourism Education: Problems and Prostpects!" Annals of Tourism Research: Vol, 8, No, 1, 13-34: 
James, $K_{t} P_{4}$ and $C_{4} K_{0}$ Wilber (eds!) 1979, Directions in Economic Development: Notre Dame: University of Notre Dame Press:

Jenkins, C\&I, 1982, "The Effects of Scale in Tourism Projects in Developing Countries:" Annals of Tourism Research" Vol! 9, No, 2, 229-49.

Jenkins, $C_{0} L_{0}$ and $B_{\sharp} M_{8}$ Henry 1982, "Government Involvement in Tourism in Developing Countries:" Annals of Tourism Research: Vol: 9, No: 4, 499-523,

Kaiser, Ct and ItE, Helber 1978, Tourism: Planning and Development: Boston, MA: CBI Publishing,

Kalchhem, Chaim 1980. "The Limited Effectiveness of Central Government Control over Local Government:" Planning and Administration. Vol: 7, No, 1, 76-87:

Kariel, Herbert $G_{\$}$ 1989, "Tourism and Development: Perplexity or Panacea?" Journal of Travel Research Vol, 28, No, 1, 2-7,

Karpat, Kemal G, 1976, The Gecedondu: Rural Migration and Urbanization! Cambridge: Cambridge University Press!

Kaspar, Jiri 1987! "Constructing a Scientific Discipline!" Annals of Tourism Research, Vol, 14, No, 2, 274-275:

Kaul, R!N! 1985, Dynamics of Tourism: A Trilogy: Vol! 1! New Delhi: Sterling Publishers Private Limited.

Kazgan, Gulten 1989, "Internal and External Constraints of Export Oriented Growth Strategy:" New Perspectives on Turkey: Vol! 3, $59-82$

Kemal, Ahmet 1984: "Military Rule and the Future of Democracy in Turkey:" Merip Report! Vol! 14, No: 3, 12-16!

Kenna, Roger and Joe Stork 1989, "Talking Up Tuxkey!" Merip Report: Vol! 19, No, 5, 11-12:

Keyder, Caglar 1979, Imperialism, Underdevelopment and Turkey, Istanbul: Birikim.

Keyder, Caglar 1987a, "Economic Development and Crisis: 1950-80," in Turkey in Transition: New Perspectives, $C_{4} I_{0}$ Schick and $A_{9} E_{0}$ Tonak (eds:): New York and Oxford: Oxford University:

Keyder, Caglar 1987b, State and Class in Turkey: A Study in Capitalist Development: London and New York: Verso: 
Keyder, Caglar 1987c. "The Political Economy of Turkish Democracy," in Turkey in Transition: New Perspectives: $C_{4} I_{\text {s }}$ Schick and $A_{4} E_{4}$ Tonak (eds!): New York and Oxford: Oxford University Press

Klak, T, 1989, "Multidimentionality in State Policy and Programs: A Critique of Pluralist State Theory:" Government and Planning: Vol. 7 , No. $4,471-474$.

Kofas, Jon $V_{t}$ 1989, Intervention and Underdevelopment: Greece During the Cold War: University Park and Iondon: The Pennsylvania State University Press:

Kousis, Maria 1989: "Tourism and the Family in a Rural Cretan Community:" Annals of Tourism Research! Vol: 16, No, 3, 318-333,

Krippendorf, Jost 1982, "Towards New Tourism Policy: The Importance of Environmental and Socio-cultural Factors," Tourism Management: Vol: 3, No, 3, 135-148,

Krippendorf, Jost 1986, "Tourism in the System of Industrial Society:" Annals of Tourism Research. Vol 4 13, No, 4, 517-533,

Krippendorf, Jost 1987, The Holiday Makers, London: Heinman:

Krippendorf, Jost 1987: "Ecological Approach to Tourism Marketing!" Tourism Management: Vol 8 , No, 2, 174-177,

Krueger, Anne 0: 1974 Foreign Trade Regime and Economic Development: Turkey: New York: Columbia University:

Krueger, Anne 0; 1987. "The Importance of Economic Policy in Development: Contrast Between Korea and Turkey:" Working Papers: No, 2195, Cambridge: National Bureau of Economic Research, Inc:

Kultur ve Turizm Bakanligi 1985: "Kalkinma Planlari, Yilik ProgramLarve Icra Planlarinda: Turizmః" T.Cৎ Kultur ve Turizm Bakanligi: Ankara: Turkey,

Lang, Reg 1986, "Planning for Integrated Development" conference on Integrated Development beyond the City: June 14-16, Rural and Small Town Research and Studies Program, Canada, New Brunswick: Mount Allison University

Lea, John 1988, Tourism and Development in the Third World: New York: Rutledge, Chapman and Hall, Inc:

Leathers, Charles $G_{\text {: }}$ and Walter S! Misiolek 1986. "Cost-benefit Analysis in Planning for Tourism Development: The Special Problem opf Socio-cultural Costs:" Tourism Recreation Research, Vol, 11, No, $2,85-91$; 
Lee, Gabriel P. 1987, "Tourism as a Factor in Development Cooperation:" Tourism Management: Vol: 8, No, 1, 2-20,

Levitt, Kari and Ifbal Gulati 1970, "Income Effects of Tourist Spendings Mystification Multiplied: A Critical Comment on the zinder Report." Social and Economic Studies: Vol, 19, No: 3, 326343.

Lickorish, J:I: 1989, "European Tourism 1992: The Internal Market!" Tourism Management: Vol., 10, No. 2, 100-110:

Lim, Hyun-Chin 1985, Dependent Development in Korea: 1963-1979, Seoul, Korea: seoul National University Press!

Lim, G.C. 1989. "State and Society: Some Reflections on Theory and Theory-building," Government and Planning; Vol, 7, No, 4, 475482.

Lipsky, Michael 1980, Street-level Bureaucracy: Dilemmas of the Individual in Public Services: New York: Fussell Sage Foundation:

Iiu, Juanita Ct, Pauline Jạ Sheldon and Turgut Var 1987. "Resident Perception of the Environmental Impacts of Tourism," Annals of Tourism Research: Vol, 14, No, 1, 17-38:

Liu, J, T, Var and At Timur 1984, "Tourist-income Multipliers for Turkey " Tourism Management: Vol, 5, No, 4, 280-87!

London, Bruce and David A. Smith 1988, "Urban Bias, Dependence, and Economic Stagnation in Noncore Nations:" American Sociological Review! Vol 53, No: 3, 454-463.

Loukissas, Philippos J! 1982, "Tourism's Regional Development Impacts: A Comparative Analysis of the Greek Islands:" Annals of Tourism Research, Vol; 9, No, 4, 523-541:

MacCannell, Dean 1976, The Tourist: A New Theory of the Leisure Class: New York: Schocken Books:

Mader, Ueli 1989, "Towards Socially Responsible Tourism," Tourism Management: Vol:, 10, No: 1, 76-77:

Mandel, Ernest 1974, Marxist Economic Theory: London: Merlin Press:

Manisali, Erol and Yarcan Sukru 1987. "Survey of Turkish Tourism Industry: Possibilities for Joint Ventures:" Middle East Business and Banking: Ankara: Turkey:

Mansur, Fatma 1972, Bodrum: A Town in the Aegean, Leiden,

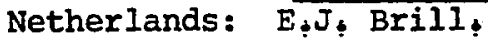


Margulies, Ronnie and Ergin Yildizoglu 1987. "Agrarian Change: 1923$70, "$ in Turkey in Transition: New Perspectives, $C_{4} I$ schick and A\&: Eonak (eds!)! New York and Oxford: Oxford University Press:

Marsh, $J_{4} S_{q}$ 1986, "National Parks, Tourism and Development: Easter Island and The Galapagos Islands," in Canadian Studies of Parks, Recreation and Tourism in Foreign Lands! J!s: Marsh (ed Ontario: Trent University:

Matthews, Harry G. 1977, "Radicals and Third World Tourism: A Caribbean Focus:" Annals of Tourism Research: Voit 5, 20-29,

Matthews, Harry, G! 1978, International Tourism, A Political and Social Analysis: Cambridge, MA: Schenkman PUblishing Co,

Mattieson, Alister and Geoffrey Wall 1982 „ Tourism: Eocnomic, Physical and Social Impacts: London: Longman Group:

McElroy, Jerome and Klaus DeAlbuquerque 1986 (Fal1): "The Tourism Demonstration Effect in the Caribbean," Journal of Travel Research: Vol, 12, No, 2, 31-34,

McGee, T,G, 1974. "In Praise of Tradition: Towards a Geography of Anti-development:" Antipodes Vol! 6, No: 3, 30-47,

McGee, T4. 1976, "The Persistence of the Proto-Proletariat: Occupational Structures and Planing of the Future of Third World Cities " Progressive Geography! Vol, 9, 3-38;

McIntosh, Robert $W_{:}$and Charles R: Goeldner 1986, Tourism: Principles, Practices, Philosophies: New York: John Wiley and Sons, Inc:

MCT 1983, "Tourism Investment in Turkey:" Ankara: Turkey:

MCT 1987, Turizm Yatirim Alanlari, Ankara, Turkey: Kultur ve Turizm Bakanligi,

MCT 1988: "Bulletin of Tourism Statistics 1987:" Ankara, Turkey,

MCT 1988. "Central Organization Scheme," Ankara: Turkey!

Medhurst, Kenneth 1984. "Spain's Evolutionary Pathway from Dictatorship to Democracy," in The New Mediterranean Democracies: Regime Transition in Spain, Greece and Portugal: Geoffrey (ed!)! UK: Frank Cass:

Met, Onder 1988, "Turizm Yatirimlarinda Finansman Sorunlari ve 'Finansal Kiralama Alternatifi!" Tourzm Yilligi 1988, Ankara, Turkey: T:C, Turism Bankasi, 
Michale, Charles-Albert T: 1976: The Multinational Companies and the New International Division of Labor: Geneva: International Labor Office:

Mihovilovic, Mạ: 1980, "Leisure and Tourism!" Internaational Social Science Journal: Vol: 32, No 1 ; 99-113,

Mill, Robert $C_{\ddagger}$ and Alsteir M. Morrison 1985 + The Tourism System: An Introductory Text, Englewood Cliffs, NJ: Prentice-Hall, Inc:

Milor, Vedat 1990, "The Genesis of planning in Turkey" " New Perspectives on Turkey, No $4,1-31$ \%

Montgomery $G_{4}$ and $P_{4} E_{\text {? }}$ Murphy 1983, "Government Involvement in Tourism Development: A Case Study of TIDSA Implementation in British Columbia," in Tourism in Canada: Selected Issues and Options! P4 Murphy (ed.), Victoria: University of victoria:

Murphy, Peter, E. 1982, "Tourism Planning in London: An Exercise in Spatial and Seasonal Management:" Tourist Review: Vol! 37, No, $1,19-23$;

Murphy, Peter, E! 1985, Tourism: A Community Approach, New York: Methuen.

Myrdal, Gunnar 1968: Asian Drama: An Inquiry into the Poverty of Nations: Vol: 1: New York: Random House:

Nash, Dennison and Richard Butler 1990, "Alternative Forms of Tourism," Annals of Tourism Research: Vol, 17, No, 2, 302-305,

Nayyar, Deepak 1975, "The Impact of Transnational Operations on Export of Manufactures from Developing Countries:" UNCTAD, Secretariat! August:

Nayyar, Deepak 1976, Transnational Corporations and Manufactured Exports from Poor Countries: Sussex: University of Sussex:

Nelson, Joan M, 1979, Access to Power: Politics and the Urban Poor in Developing Nations: Princeton, NJ: Princeton University Press:

Nguyen, Tri $2 * 1989$, Third World Development: Aspects of political Legitimacy and viability: Cranbury, NJ: Fairleigh Dickinson University Press!

OECD 1983. "Tourism Policy and International Tourism in OECD Member Countries:" Paris: Organization for Economic Cooperation and Development,

OECD 1984, "Tourism Policy and International Tourism in OECD Member Countries:" Paris: Organization for Economic Cooperation and Development: 
OECD 1985. "Tourism Policy and International Tourism in OECD Member Countries:" paris: Organization for Economic Cooperation and Development:

OECD 1987: "Tourism Policy and International Tourism in OECD Member Countries!" Paris: Organization for Economic Cooperation and Development:

OECD 1988. "Tourism Policy and International Tourism in OECD Member Countries:" Paris: organization for Economic Cooperation and Development:

OECD 1988, Report on Regional Problams and Policies in Turkey, Paris: Organization for Economic Co-operation and Development.

OECD 1989, National and International Tourism Statistics, 1974-1985, Paris: Crganization for Economic Co-operation and Development.

Olali, Hasan 1970: "Tourist Potential and Supply Capacity in the Promotion of Tourism in Turkey," in Promotion of Tourism in Turkey, International Seminar on Promotion of Tourism in Turkey held in Izmir on September 2-6, 1969,

Olali, Hasan 1986, "Turizm Yilligi 1985," Turk Turizmini Dunya Turizmine Entegras Yonu, $T_{\ddagger} C_{\$}$ Turizm Bankasi! Ankara, Turkey

The Oregonian 1989: "Spain's Prosperity Sparks Challenges!" June 25, 12A:

The Oregonian 1989, "Will Tourism Invigorate Mexican Economy," August 17, $9 A_{\text {: }}$

O'Reilly, Aọ M+1986! "Tourism Carrying Capacity: Concept and Issues:" Tourism Management: Vol, 7, No, 4, 254-258,

Ozbudun, Ergun 1981: "The Nature of the Kemalist Political Regime," in Ataturk, Founder of a Modern State: $A_{*}$ Kazancigil and $E_{i}$ Ozbundun (eds!)! Iondon: Hurst:

Padilla, Perfecto L! 1986, "Developing Administrative Capability:" Journal of Planning and Administration, Vol; 13, No. 2, 56-62.

Pamuk, Sev\}et 1981. "The Political Economy of Industrialization in Turkey:" Merip Report! No 92, 26-30,

Pamuk, Sevket 1988, "War, State Economic Policies and Resistance by Agricultural Producers in Turkey 1939-1945," New Perspectives on Turkey: Vol, 2, 19-37,

Pearce, Douglas G, 1981, Tourist Development: London and New York: Longman. 
Pearce, Douglas G. 1987. "Spatial Patterns of Package Tourism in Europe:" Annals of Tourism Research! Vol, 14, No, 2, 183-202 ?

Pearce, Douglas G! 1989, Tourism Development: 2nd edition \$ New York: Longman Scientific and Technical:

Pearse, Andrew 1980, Seeds of Plenty, Seeds of Want: A Critical Analysis of the Green Revolution: London: Oxford University Press:

Peppelenbosch, Pim and Gertjan Tempelman 1989, "The Pros and Cons of International Tourism to the Third World," in Towards Appropriate Tourism: The Case of Developing Countries: $T_{0} \mathrm{~V}_{\varphi}$ Singh, $\mathrm{L}_{4} \mathrm{H}_{4}$ Theuns and $M+F !$ Go (eds!): New York: Peter Lang:

Perez, Io, Jr, 1974, "Aspects of Underdevelopment: Tourism in the West Indies:" Science and Society: Voo, 37, 473-480,

Peters, Michael 1969, International Tourism: The Economics of the International Tourist Trade! London: Hutchinson!

Pi-Sunyer, Oriol 1979, "The Politics of Tourism in Catalonia:" Mediterranean Studies: Vol: 1, No, 2, 46-69:

Pizam 1982 (Winter)! "Tourism and Crime: Is There a Relationship?" Journal of Travel Research: Vol, 20, No, 3, 7-10,

Portes, Aljandro, Manuel Castells and Lauren A: Benton 1989, The Informal Economy: Baltimore and London: The Johns hopkins University Press:

Pridham, Geoffrey 1984, "Comparative Perspectives on the New Mediterranean Democracies: A Model of Regime Transition?" in The New Mediterranean Democracies: Regime Transition in Spain, Greece and Portugal! Geoffrey Pridham (ed!)! UK: Frank Cass!

Pye, Elwood A, and Iin Tzong-Biau (eds!) 1983, Tourism in Asia: The Economic Impact: International Development Center Research: Singapore University Press :

Rada, Jaun 1981; The Impact of Microelectronics: A Tentative Appraisal of Information Technology, Geneva: International Labor office:

Ramazanoglu, Caroline 1985, "Labor Migration in the Development of Turkish Capitalism," in Turkey in the world Capitalist System: A Study of Industriatlization, Power and Class: Huseyin Ramazanoglu (ed!)! Brookfield, England: Grower:

Ramazanoglu, Huseyin (ed,) 1985, Turkey in the World Capitalish System: A Study of Industriallization, Power and Class: Brookfield, England: Gower: 
Reuber, Grant I, 1973, Private Foreign Investment in Development: Oxford: Clarendon Press

Richter, Linda K, 1987, "The Search for Appropriate Tourism," Tourism Recreation Research: Vol! 12, No: 2, 5-7,

Richter, Linda $\mathrm{K}, 1989$. The Ppolites of Tourism in Asia, Honolulu: University of Hawaii Press:

Richter, $L_{4} K_{!}$and $W_{4} I_{4}$ Richter 1985, "Policy Choices in South Asian Tourism Development," Annals of Tourism Research, Vol ${ }_{4}$ 12, No; 2, 201-219:

Robinson, H: 1976, A Geography of Tourism; London: MacDonald and Evans:

Roca, Boschi Nuria 1988, "Local Government in Spain: Territorial Organization and Financing!" Planning and Administration. Vol. 15, No, 1, 6-18.

Rodenburg, Eric $E_{+}$1989; "The Effects of Scale in Economic Development--Tourism in Bali," in Towards Appropriate Tourism: Teh Case of Developing Countries, $T_{4} V_{4}$ Singh, $H_{4} L_{q}$ Theuns and F!M\& Go (eds!)! New York: Peter Lang,

Roekaerts, Mil and Kris Savat 1989, Mass Tourism in South and Southeast Asia--A Challenge to Christians and the Churches," in Towards Appropriate Tourism: Teh Case of Developing Countries:

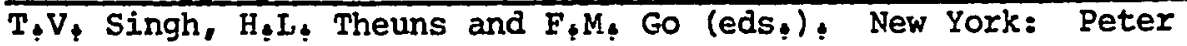
Lang:

Romeril, Michael 1989, "Tourism and the Environment--hccord or Discord?" Tourism Management. Vol, 10, No, 3, 204-209,

Rondinel1i, Dennis A, 1983, Development Projects as Policy Experiments" An Adaptive Approach to Development Administration! New York: Methuen:

Rondinelli, Dennis $A_{4}$, James $S_{4}$ McCullough and Ronald W: Johnson 1989 "Analysing Decentralization Policies in Developing Countries: A Political Economy Framework" "Development and Change: Vol, 20, No, $1,57-87$;

Rosensweig, Jeffry A, 1988, "Elasticities of Substitution in Caribbean Tourism:" Journal of Development Economics! Vol $429,89-100$ ?

Rueschemeyer, Dietrich and Peter B! Evans 1985, "States as Promoters of Economic Development and Social Redistribution," in Bringing the

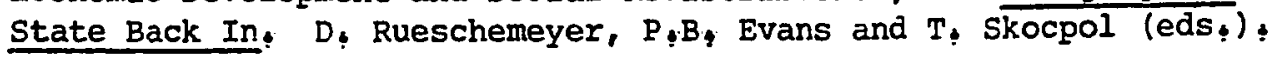
Cambridge: Cambridge University Press: 
Rueschemeyer, Dietrich and Peter B, Evans 1985: "The State and Economic Transformation: Toward an Analysis of the conditions Underlying Effective Intervention," in Bringing the State Back In: $D$; Rueschemeyer, $P_{\bullet} B_{q}$ Evans and $T_{i}$ Skocpol (eds!)! Cambridge: Cambridge University Press,

Sabalo, Yves and Raul Trajtenbert 1976, The Impact of Transnational Enterprises on Employment in the Developing Countries! Geneva: International Labor office:

Sachs, Jeffrey $D_{4}$ (ed!) 1989, Developing Country Debt and the World Economy: Chicago and London: The University of Chicago Press:

Samim, Ahmet 1987, "The Left," in Turkey in Transition: New Perspectives: $C_{t} I_{!}$Schick and $A_{!} E_{!}$Tonak (eds!), New York and Oxford: Oxford University Press:

Samuelson, A\&P, 1976: Economics: New York: McGraw-Hill Book Company:

Schick, Irvin C, and Ahmet E: Tonak 1987, "The International Dimension: Trade, Aid and Debt," in Turkey in Transition: New Perspectives: C.I. Schick and $E_{!} A_{4}$ Tonak (eds!)! New York and Oxford: Oxford University Press:

Seers, Dudley 1977: "The New Meaning of Development" International Development Review: Vol. 9, No: 3, 2-7.

Seidman, R! 1979, "Development Planning and Legal order in Black Anglophonic Africa," Studies in Comparative International Development: Vol: $14, \overline{3-27}$

Sessa, Alberto 1988, "The Science of Systems for Tourism Development" Annals of Tourism Research! Vol! 15, No, 2, 219-235:

Sigaux, G. 1966, History of Tourism, London: Leisure Art:

Sinch, Vir Tej, Leo H, Theuns and Frank M. Go (eds!) 1989, Towards Appropriate Tourism: The Case of Developing Countries! New York: Peter Lang,

Skocpol, Theda 1985, "Bringing the State Back In: Strategies of Analysis in Current Research in Bringing the State Back In ${ }^{n}$ E⿺B Evans, D, Ruschemeyer and $T$ ! Skocpol (eds!): Cambridge: Cambridge University Press:

Smith, David A! 1987: "Overurbanization Reconceptualized: A Political Economy of the World-System Approach!" Uxban Affairs: Vol, 23, No, 2, 270-294, 
Smith, David A: 1989, "Urbanization in the World System: Impleications for Planning," paper presented in the Annual Conference of the Association oof Collegiate Schools of Planning: October 1989, Portland, OR:

Smith, Stephen $L_{4} J_{q}$ 1989a! Listen to the People: ParticipationObserver Evaluation of Development Projects, New York: Oxford Oniversity Prest:

Smith, Valene I! (ed,) 1989, Hosts and Guests: The Anthropology of Tourism! 2nd edition, Philadepphia: University of Pennsylvania Press:

So, Frank $S_{4}, I_{4}$ Stollman, $F$, Beal and $S_{4} D_{4}$ Arnold (eds:) 1979, The Practice of Local Government Planning! Washington, $D_{m} C_{!}:$ International City Management Association:

Sonmez, M, 1980, Crisis in the Turkish Economy: 24 January Decrees and Their Aftermath: Istanbul: Belge;

SPO 1963. Annual First Five Year Development Plan, 1963-1967. Ankara, Turkey;

SPO 1964, First-Five Year Development Program, 1963-1967, State Planning Organization! Ankara, Turkey,

SPO 1967: State Planning Organization, Ankara, Turkey,

SPO 1968, Outline of a Proposed Program for Development of Tourism in Turkey: State Planning Organization! Ankara, Turkey:

SPO 1969, Second-Five Year Development Plan, 1968-1972, State Planning Organization: Ankara, Turkey

SPO 1972, Unbalanced Development Between Regions in Turkey: State Planning Organization, Ankara, Turkey:

SPO 1975, Third-Five Year Development Plan, 1973-1977, State Planning Organization: Ankara, Turkey:

SPO 1977. State Planning Organization, Ankara, Turkey:

SPO 1980, "1980 Yili Yatirim Programi:" Devlet Planlama Teskilat. Ankara, Turkey:

SPO 1981. Summary Report on Fourth-Five Year Development Plan, 19791983, State Planning Organization, Ankara, Turkey:

SPO 1987. Fifth-Five Year Development Plan, 1979-1983, State Planning Organization: Ankara, Turkey: 
SPO 1987. "Planning Tools Used for the Less Developed Regions!" State Planning Organization: Ankara, Turkey:

SPO 1988: Foreign Investment Regulation and Application Forms; Ankara, Turkey

Spourdalakis, Michalis 1988; The Rise of the Greek Socialist Party: Lond and New York: Routledge

Srisang, Koson 1990, "The Ecumenical Coalition on Third World Tourism:" Annals of Tourism Research! Vol, 17, No, 2, 119-121,

Stohr, Walter $B_{q}$ and Fraser $D_{4} R_{4}$ Taylor (eds ${ }_{4}$ ) $1981_{4}$ Development from Above or Below?" The Dialectics of Regional Planning in Developing Countries: New York: John Whiley and Sons!

Stroud, Hubert B, 1983, "Environmental Problems Associated with Large Recreational Subdivisions:" Professional Geographer: Vol: 35, No: 3, 303-313,

Summary, Rebecca M, 1987, "Tourism's Contribution to the Economy of Kenya:" Annals of Tourism Research: Vol, 14, No, 4, 531-540,

Sunkel, Oswaldo 1973: "Transitional Capitalism and National Disintegration in Latin America" " Social and Eocnomic Studies: Vol, 22, 132-176:

Tamames, Ramon 1986, The Spanish Economy: An Introduction, New York: St: Martin's Press.

Teye, Victor $B_{1}$ 1986, "Liberation Wars and Tourism Development in Africa: The Case of Zambia!" Annals of Tourism Research! Vol! 13 , No, 4, 589-608,

Teye, Victor B! 1987: "Developing Africa's Tourism Potential: Prospects and Issues!" Tourism Recreation Research! Vol, 12, No: 1, 9-14,

Teye, Victor B: 1988, "Coup d'etat and African Tourism: A Study of Ghana," Annals of Tourism Research: Vol! 15, No: 3, 329-356,

Theuns, Leo H, 1987! "Ignoring Priorities for Tourism Research!" Tourism Recreation Research, Vol, 12, No, 1, 33-37,

Theuns, Leo fi, 1987, "Appropriate Tourism for the Third Forld, A Bibliography on the Sociocultural Dimension: 1963-1984" Tourism Recreation Research! Vol! 12, No, 2, 55-64:

Theuns, Ieo k. 1989, Toerisme in Ontwikkeling-slanden: Netherlands: Tilburg University Press:

Time 1988, "Turkey: The Hot New Tourist Draw:" June 13, 66-67, 
Tisdel, C. 1988, "Sustainable Development: Differing Perspectives of Ecologists and Economists, and Relevance to LDCs," and "Turkey: The hot New Tourist Draw" "Time! June 13, 66-67,

TB 1987: "Southwest Turkey Touristic Investment Areas!" Tourism Bank: Ankara, Turkey:

Tourism Bank 1988, "Tourism Investment Procedures and Incentives in Turkey " $T, C_{\text {q }}$ Turizm Bankasi, Ankara, Turkey

TB 1988a! "1987 Annual Report:" $T_{\ddagger} C_{\ddagger}$ Turizm Bankasi! Ankara, Turkey

Tourism Bank 1988b! "Selected Financial Figures on Turkish Tourism!" Ankara, Turkey,

Travis, Anthony S, 1982, "Managing the Environment and Cultural Impacts of Tourism and Leisure Development:" Tourism Management: Vol: 3, No: $4,256-262$ :

Trimberger, Ellen Key 1978, Revolution from Above: Military Bureaucrats and Development in Japan, Turkey, Egypt and Peru, NJ: Translation Books:

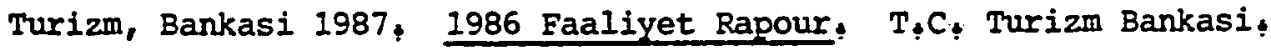
Ankara, Turkey

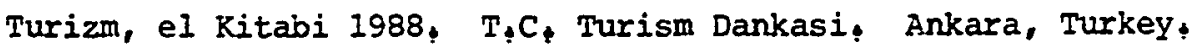

Turkey Tourism, Oportunities for Investors 1987, Ministry of Culture and Tourism, Pnkara, Turkey.

Turkish Daily News 1988, "Government Moves for the Environment!" July $7,7:$

Turkmen, Mustafa 1988, "The Turkish Plan for Tourism," paper presented in the British Travel Trade Seminar on Turkey, held in London on July 21, 1988,

Turner, $L_{4}$ and $J_{4}$ Ash 1975, Golden Words: International Tourism and the Pleasure Periphery: Iondon: Constable:

Turner, Louis 1976, "The International Division of Leisure: Approaches to a Dialogue " tourism Recreation Research: Vol, 12, No. 2, 6970.

Tusiad 1982, "The Turkish Economy 82," Turkish Industrialists and Businessmen's Association; Istanbul, Turkey:

Tusiad 1986, "The Turkish Economy, 86!" Turkish Industralists' and Businessmen's Association, Istanbul, Turkey: 
Tusiad 1988, "The Turkish Economy '88," Turkish Industrialists' and Businessmen's Association, Istanbul, Turkey

Ulusan, Aydin 1980: "Public Policy toward Agriculture and its Redistributive Implications," in The Political Economy of Income Distribution in Turkey: Ergun Ozbudun and Aydin Ulusan (edse): New York and Iondon: Holmes and Meier Publishers, Inc;

Onited Nations 1979, "Industrial Priorities in Developing Countries: The Selection Process in Brazil, India, Mexico, Republic of Dorea an Turkey: "New York: United Nations:

United Nations 1982, Transnational Corporations in International Tourism, New York: United Nations:

Ural, Engin 1987, "Environmental Protection and Foreign Private Investment in Turkey," in Multinational Corporations, Environment and the Third World! Charles $s_{4}$ Pearson (ed!)! Durham: Duke University Press:

Uysal, Muzaffer 1983, "Construction of a Model which Investigates the Impact of Selected Variables on International Tourist Flows to Turkey:" $P h_{\imath} D$, dissertation! Texas: Texas $A$ and $M$ University:

Vaitsos, Constantino $v_{\$} 1976$, Employment Problems and Transnational Enterprises in Developing Countries: Distortions and Inequality: Geneva: International Labor Office

Van Doonn, J!W!M! 1979, "The Developing Countries: are They Really Affected by Tourism? Some Critical Notes on Socio-cultural Impact Studies," paper presented at Seminar on Leisure Studies and Tourism, December 7-8, 1974. Warsaw:

Vaner, Semih 1987. "The Army," in Turkey in Transition: New

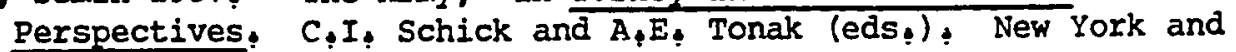
Exford: Oxford University Press!

Verbeke,-Myrveim, Jensen and Adri Dietvorst 1987, Leisure, Recreation, Tourism: A Geographic View on Integration: Vol, 14, No, 3, 361375:

Vernon, Raymond 1977, Storm Over the Multinationals: The Real Issues: Combridge: Harvard University Press:

Wahab, Salah 1975, Tourism Management, Iondon: Tourism International Press:

Wall, G, 1982, "Cycles and Capacity--Recipient Theory or Conceptual Contradiction!" Tourism Management: Vol, 3, No, 3, 188-192,

Wallerstein, Immanuel 1974, The Modern World System I! New York: Academic Press: 
Wallerstein, Immanuel 1979, The Capitalist World-Economy, Cambridge: Cambridge University Press:

Wallerstein, Immanuel 1980, the Modern World--System II, New York: Academic Press:

Walstedt, Bertil 1980, State Manufacturing Enterprise in a Mixed Economy: The Turkish Case! Baltimore and London: Johns Hopkins University Press:

Warren, Bill 1973, "Imperialism and Capitalist Industrialization" The New Left Review: Vol, 81, 3-46;

Waters, Somerst $R_{q}$ 1986: Travel Industry World Yearbook: The Big Picture: Vol, 30\% New York: Child and Waters:

Weber, Sandra 1989; "Yugoslav International Tourism!" Tourism Management: Vol: 10, No, 2, 156-164,

Weiss, John 1988, Industry in Developing Countries: Neew York: Croom Helm.

Wenger, Martha 1989, "Turkey," Merip Report: Vol! 19, No, 5, 23-26,

Wheeler, Brian 1990: "Responsible Tourism 4 " Tourism Management, Vol: 11, No, 3, 262-263,

White, J4 1967: History of Tourism London: Leisure Art:

Wieberdink, Ange and Kete van Argen 1988, "Institutionalization of an Environmental programe in a Third World Country: The Establishment of an Environmental Institute in Nicaragua," Development and Change: Vol, 19, No, 1, 139-157:

Wilkinson, Paul $\mathrm{F}_{\mathrm{b}}$ 1989; "Strategies for Tourism in Island Microstates:" Annals of Tourism Research: Vol, 16, No, 2, 153177 :

Wood, Robert $E_{\text {q }}$ 1980, "International Tourism and Cultural Change in Southeast Asia:" Economic Development and Cultural Change! Vol, 28 , No, 3, 561-581:

Wood, Robert E, 1984, "Ethnic Tourism, the State, and the Cultural Change in Southeast Asia," Annals of Tourism Research, Vol, 11, No. 3, 353-374,

World Bank 1979, Turkey: Policies and Prospects for Growth: Washington, $\mathrm{D}_{4} \mathrm{C}_{4}:$ World Bank?

World Commission on Environment and Development (WCED) 1987: our Common Future, New York and Oxford: Oxford University Press: 
World Wildife Fund 1990. "The Potentials and Pitfalls of Ecotourism:" Focus: Vol, 12, 2:

WTO 1980, "Physical Planning and Area Development for Tourism in the Six WTO Regions, 1980," Madrid: World Tourism Organization!

WTO 1985. "Methodological Supplement to World Travel and Tourism Statistics:" Madrid: World Tourism Organization.

WTO 1988, "Current Travel and Tourism Indicators!" Madrid: World Tourism Organization,

Yalpat, Altan 1984, "Turkey's Economy Under the Generals:" Merip Report: Vol: 14, No: 3, 16-25:

Ybarra, Josep Antonio 1989, "Informalization in the Valencian Economy: A Model for Underdevelopment," in The Informal Economy: A:

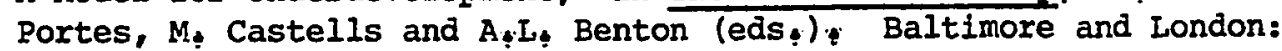
Johns Hopkins University Press.

Yerasimos, Stephane 1987. "The Monoparty Period," in Turkey in

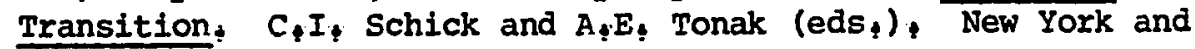
Oxford: Oxford University Press:

Yesilada, Birol 1987, "New Political Parties and the Problems of Development in Turkey:" New Perspectives on Turkey: Vol, 1, No, $1,35-63$;

Young, George 1973 : Tourism: Blessing or Blight? London: Pelican!

Young, Ruth $C_{1}$ 1977. "The Structural Context of the Caribbean Tourist Industry: A Comparative Study!" Economic Development and Cultural Change, Vol: 25, No, 4, 657-672\%

Young, George 1975: "Tourism: Blessing or Blight?" Development Digest: Vol, 13, No, 1, 43-54,

Zammit, Ann 1981: "Transnationals in Developing Country Tourism," International Tourism Quarterly Special Report: Vol, 39, No, 1 , 37-56: 